\title{
Metal-on-metal hip arthroplasty
}

Citation for published version (APA):

Jelsma, J. (2022). Metal-on-metal hip arthroplasty: physical activity monitoring, outcomes and systemic toxicity. [Doctoral Thesis, Maastricht University]. Proefschriftenprinten.nl. https://doi.org/10.26481/dis.20220121jj

Document status and date:

Published: 01/01/2022

DOI:

10.26481/dis.20220121jj

Document Version:

Publisher's PDF, also known as Version of record

\section{Please check the document version of this publication:}

- A submitted manuscript is the version of the article upon submission and before peer-review. There can be important differences between the submitted version and the official published version of record.

People interested in the research are advised to contact the author for the final version of the publication, or visit the DOI to the publisher's website.

- The final author version and the galley proof are versions of the publication after peer review.

- The final published version features the final layout of the paper including the volume, issue and page numbers.

Link to publication

\footnotetext{
General rights rights.

- You may freely distribute the URL identifying the publication in the public portal. please follow below link for the End User Agreement:

www.umlib.nl/taverne-license

Take down policy

If you believe that this document breaches copyright please contact us at:

repository@maastrichtuniversity.nl

providing details and we will investigate your claim.
}

Copyright and moral rights for the publications made accessible in the public portal are retained by the authors and/or other copyright owners and it is a condition of accessing publications that users recognise and abide by the legal requirements associated with these

- Users may download and print one copy of any publication from the public portal for the purpose of private study or research.

- You may not further distribute the material or use it for any profit-making activity or commercial gain

If the publication is distributed under the terms of Article $25 \mathrm{fa}$ of the Dutch Copyright Act, indicated by the "Taverne" license above, 


\section{Metal-on-Metal Hip Arthroplasty}

Physical Activity Monitoring, Outcomes and Systemic Toxicity 


\section{Metal-on-Metal Hip Arthroplasty}

Physical Activity Monitoring, Outcomes and Systemic Toxicity

Jetse Jelsma 
Jetse Jelsma ${ }^{\circledR}$, Maastricht, the Netherlands, 2021

For all articles published, the copyright has been transferred to the respective publisher. No part of this thesis may be reproduced in any form or by any means without written permission from the author or, when appropriate, from the publisher.

Design: Fred Freij

Layout: Fred Freij

Printed by: www.proefschriftenprinten.nl

ISBN: 978-90-831893-9-0

Financial support for the publication of this thesis was provided by: Anna Foundation|NOREF, Biomet Nederland, department of Orthopedic Surgery and Traumatology - Zuyderland Medical Centre, Bureau Wetenschappelijk Onderzoek/ Medische opleidingen - Zuyderland Medical Centre, Gulf Coast Data Concepts, Hanssen Footcare, Maastricht University, Marti-Keuning Eckhardt Stichting, Nederlandse Orthopaedische Vereniging, OIM Orthopedie, Smeets Loopcomfort, Spronken Orthopedie,

The research presented in this thesis was conducted at the department of Orthopedic Surgery and Traumatology, Zuyderland Medical Centre, Sittard-Geleen, the Netherlands. 


\title{
Metal-on-Metal Hip Arthroplasty
}

\section{Physical Activity Monitoring, Outcomes and Systemic Toxicity}

\author{
PROEFSCHRIFT
}

ter verkrijging van de graad van doctor aan de Universiteit Maastricht, op gezag van Rector Magnificus Prof. dr. Rianne M.Letschert, volgens het besluit van het College voor Decanen in het openbaar te verdedigen op vrijdag 21 januari 2022 om 12.00 uur

door

Jetse Jelsma

Geboren op 12 maart 1989 te Leeuwarden 


\section{Promotor}

Prof. dr. I.C. Heyligers

\section{Copromotores}

Dr. Ir. B.P. Grimm

Dr. M.G.M. Schotanus

\section{Beoordelingscommissie}

Prof. dr. L.W. van Rhijn (voorzitter)

Dr. R. H.M. ten Broeke

Dr. E.H. van Haaren (Zuyderland Medisch Centrum, Sittard-Geleen)

Prof. dr. M. Poeze

Prof. dr. B.W. Schreurs (Radboud Universitair Medisch Centrum, Nijmegen) 


\section{Contents}

Chapter I General Introduction

\section{Part A Physical activity monitoring}

Chapter II Metal ion concentrations after metal-on-metal

hip arthroplasty are not correlated with habitual

physical activity levels

Chapter III Quality, but not quantity of physical activity

is associated with metal ion concentrations in unilateral hip resurfacing

Chapter IV Patients with hip resurfacing arthroplasty are not physically more active than those with a stemmed total hip

Chapter V Only limited correlations between patient-reported outcomes and objectively monitored physical activity 10-years after THA

\section{Part B}

Outcomes and Systemic toxicity

Chapter VI

Outcome of Revised Metal-on-Metal Hip

Arthroplasties: a Dutch Arthroplasty Register Study

Chapter VII

Prosthetic hip-associated cobalt toxicity:

Chapter VIII

a systematic review of case series and case reports

Metal-on-Metal Hip Arthroplasty

Chapter IX

General discussion

Chapter X

Valorisation

Chapter XI

Summary

Chapter X

Samenvatting

List of publications

Dankwoord 


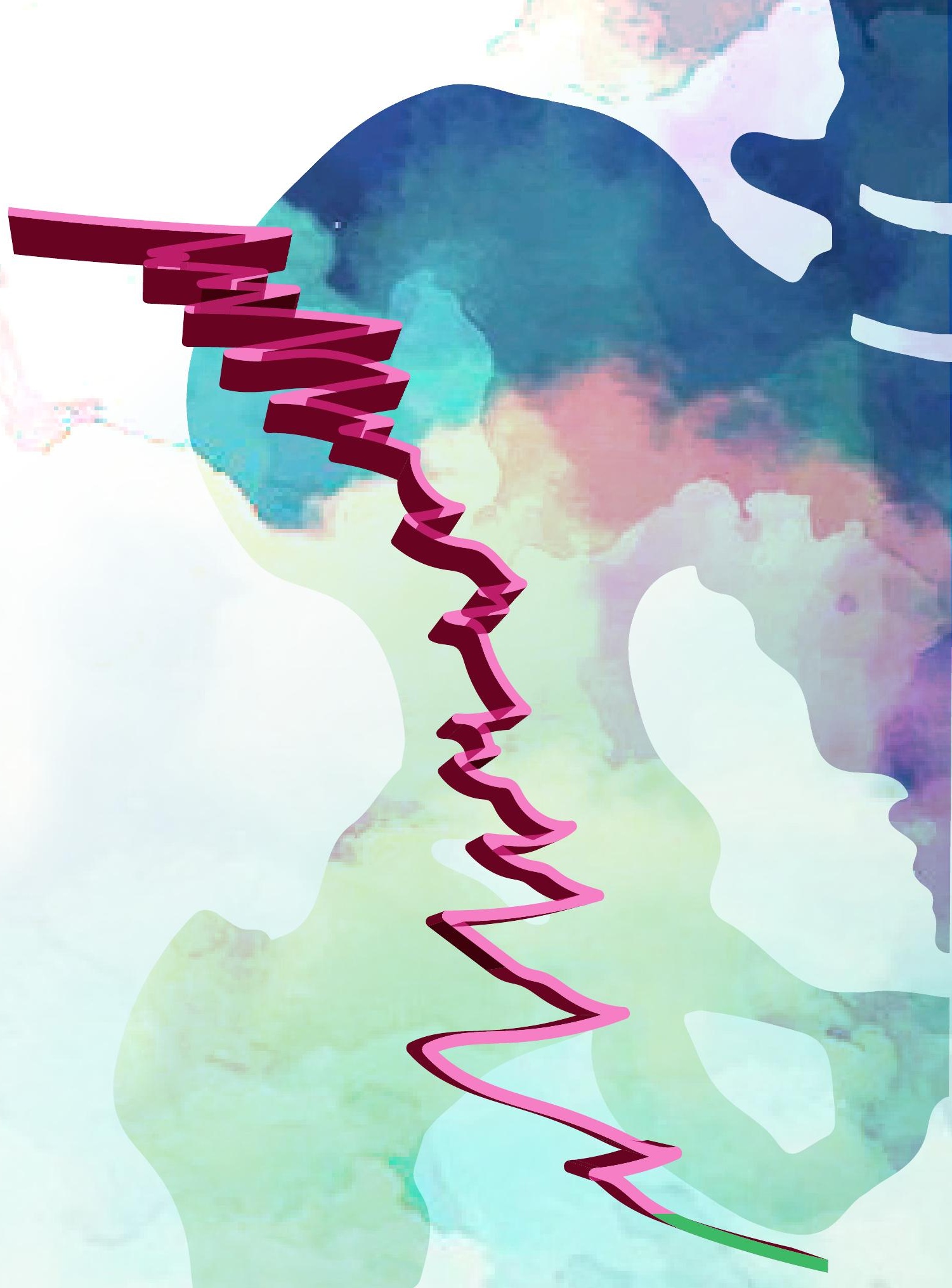




\section{Chapter I}

General Introduction

Je gaat het pas zien als je het door hebt

(Johan Cruijff) 


\section{Introduction}

Hip osteoarthritis (OA) is one of the most prevalent and disabling conditions affecting the elderly, as it often includes the loss of autonomy [1, 2]. The lifetime risk of complaints caused by OA is approximately $25 \%$ in people who live to an age of 85 years. Hip $\mathrm{OA}$ is a disease of the joint that disrupts the normal homeostatic balance between joint tissue synthesis and degradation, which means that normal biomechanical stresses become disruptive. Risk factors for OA can be divided into joint-related factors (e.g. joint morphology, muscular function, joint shape) and person-related factors (e.g. age, sex, weight, genetics, ethnicity, occupation, diet) [1]. Usually, management of hip OA begins after the onset of symptoms. At this point, there is often already significant joint damage. Non-surgical management consists of weight loss and a dietary program, exercise with physiotherapy and pharmacological management. There is no truly curative treatment [2]. In case of daily invalidating complaints, a surgical intervention might be chosen.

Total hip arthroplasty (THA) or total hip replacement (THR) is considered to be one of the most successful surgical procedures and was appointed 'the surgical procedure of the 20th century' $[3,4]$. It is considered the best treatment option for patients who are highly invalidated by (end-stage) OA, which may cause pain, joint stiffness, functional disability and limitations in their activity [5]. Other indications for THA are acute femoral fractures, osteonecrosis, late post-traumatic $O A$, rheumatoid arthritis, post-Perthes disease and tumours [6]. Each year, 1 million THA procedures are performed worldwide [7]. Based on the Dutch Arthroplasty Register (LROI), which covers $99 \%$ of all THAs in the Netherlands, 33.248 THA procedures were performed in the Netherlands in 2019. The patients' mean age was $69.1 \pm 10.4$ years, $64 \%$ were female and in $87 \%$, the indication for surgery was OA. Since the introduction of the LROI, the number of procedures has increased yearly [6]. THA is increasingly offered to younger OA patients, and it is expected that by 2030, half of all arthroplasty procedures will be performed on patients younger than 65 [8]. Patients receiving THA at any age tend to have high demands on functional outcomes, which increases the need for durability of the different prostheses.

\section{Development of total hip arthroplasty}

The history of hip arthroplasty dates back to 1821, when excision arthroplasty was performed by Antony White (1782 - 1849). With this intervention, pain was reduced and mobility maintained, but a main disadvantage was instability of the hip joint 
$[9,10]$. The procedure became popular due to the lack of other options. In the subsequent years, interpositional arthroplasty was performed using skin, fascia, muscle, pig bladder, celluloid, silver plates, rubber struts, magnesium, zinc, glass, Pyrex, decalcified bone and wax [11-13]. These interventions were all painful and subsequently failed $[9,10]$.

\subsection{Design}

The first surgeon reported to perform a THA was Themistocles Glück (1853 - 1942). In 1891, he replaced a tuberculous hip joint with an ivory ball and socket, which were fixed with nickel-plated screws. The replacements were successful in the short term, but failed due to chronic infection $[9,10]$. Marius Smith-Petersen (1886 - 1953) was the first to perform mould arthroplasty, which he explained as the principle of guiding the repair of nature for the purpose of recreating a destroyed or damaged structure. He created the first mould arthroplasty out of glass, which he implanted for the first time in 1923. It consisted of a hollow hemisphere fitting over the femoral head. The moulds were removed after 15 to 25 months, when the joint surfaces were smooth, glistening, firm and congruous. However, the glass moulds had a high risk of breaking. On the advice of his dentist, Smith-Petersen constructed a mould with vitallium, a metallic alloy consisting of cobalt, chromium and molybdenum. Smith-Petersen performed the first vitallium mould arthroplasty in 1938, followed by a total of 500 arthroplasties, with acceptable and predictable results. A revision was performed in 53 cases [14].

In 1938, Philip Wiles (1899 - 1966) was the first to perform a hip arthroplasty using a metal acetabular component and a metal head for articulation (figure 1). He used stainless steel components, and the replacement was attached to the outside of the bone with a metal plate and screws. The results were not satisfactory due to accelerated wear and thus early failures [15]. The phenomenon 'wear' is defined as a progressive loss of material (debris) due to the friction between moving surfaces [16].

In 1948, Robert Judet (1901 - 1980) and his brother Jean Judet (1905 - 1995) used a prosthesis made of polymethyl-methacrylate (PMMA)(Figure 2) [18]. This material was already used by ear-nose-throat doctors. The prosthesis was shaped like a mushroom, consisting of a rounded head and a long stem. The procedure was called 'resection-reconstruction' or 'prosthetic replacement of the femoral head'. The femoral head was thought to be the generator of pain in $\mathrm{OA}$, and thus replacement was expected to lead to a decrease in pain. In the first cases, the stem broke, and hence the stem was reinforced. The brothers reported that seven out of ten patients 


\section{Chapter 1}

had no or a negligible amount of pain in the postoperative phase. Unfortunately, the prosthesis was very susceptible to wear [16]. Unsatisfactory results were shown by the Judet brothers in 1952 [19]. In the years after, several surgeons attempted to improve the Judet prosthesis, which resulted in the Thompson prosthesis, the Jaenichen-Collison prosthesis and the Fitzgerald prosthesis, all of which were hemiarthroplasties, i.e., replacements of the femoral head only, leaving the acetabular site untouched [20-22]. George McKee (1906-1991) and John WatsonFarrar (1926-1999) reported that replacement of the femoral head only tackles half of the problem if degenerative changes are present in the acetabulum [23].

Figure 1. The first MoM THA by Philip Wiles (1938)[15].

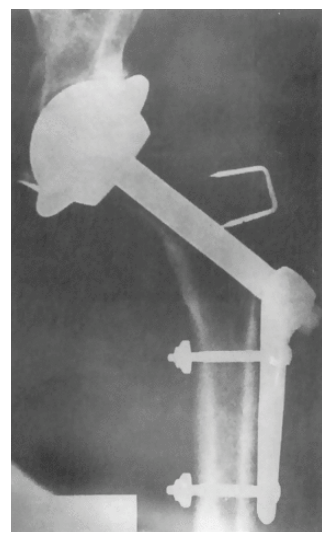

Figure 2. The standard Judet prosthesis and a modification with four X-ray wire markers [17].

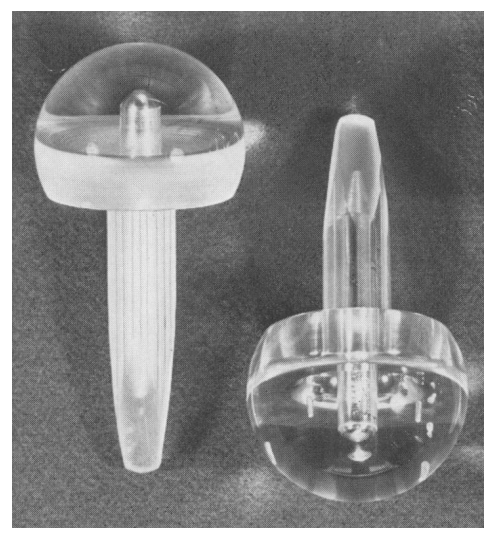

Both mould arthroplasty and the Judet prosthesis can be seen as precursors of hip resurfacing arthroplasty (HRA). This is a procedure in which a hollow, mushroomshaped cap is placed over the head of the femur and a matching cup is placed in the acetabulum. In the late 1950s, Charnley (1911-1982) used a Teflon double cup, and Townley (1916-2006) used a polyurethane to anchor a metal cup to the femoral head and resurface the acetabulum (1960). Muller (1918-2009) used a prosthesis with both components made of cobalt-chrome (1968), and Freeman (1931-2017) used a metal-on-polyethylene (MoP) combination in the early 1970s. All these approaches showed early failures, which were partly due to polyethylene debris and the ensuing development of osteolysis, which resulted in prosthetic loosening, and to a lack of surgical experience [24-26]. 
The failures of metal-on-metal (MoM) bearings were due to local effects of metal particles, which were noted during revision surgery [3]. These failures were explained by mechanical and biological facts (aseptic lymphocyte-dominated vasculitis-associated lesion (ALVAL)). When a MoM bearing is placed on a titanium stem, the cam effect generates a 'titanosis'. This is a type of metallosis that is not specific to MoM bearings [27]. A solution was found in the use of larger diameter femoral heads, which would result in a better lubrication and would increase stability and mobility. This solution also meant a return to HRA, a procedure that has various theoretical advantages over conventional stemmed THA: Iow volumetric wear, a femoral head with large physiological diameter offering stability, nearnatural joint kinematics, an increased range of motion compared to small-diameter THA, and preservation of the femoral bone, which allows an easy revision if needed [28].

\subsection{Fixation}

The modern era of THA began with the ideas of Sir John Charnley (1911 -1982). His low-friction arthroplasty consisted of three parts, which in principle were identical to the prostheses used today: a polyethylene acetabular component and a metal femoral stem, both fixated to the bone by means of acrylic bone cement. The early results of ultrahigh-molecular-weight polyethylene (UHMWPE) compared to Teflon were very impressive, and the durability improved. At this point, the focus changed to understanding fatal pulmonary embolism (2\%), high infection rates $( \pm 10 \%)$ and cement fixation failures [29]. Periprosthetic osteolysis was seen in longer followup of THA, which was an unexpected and initially unrecognized complication leading to failure. Research showed that this periprosthetic osteolysis was due to a macrophage-induced response to polyethylene wear particles. Cement was considered the cause of poor outcomes ('cement disease'), while in many cases, the main causes actually were the implant design and the cementing technique [30].

Thinking that 'cement disease' was the main cause of failure of cemented THA, surgeons were motivated to search for uncemented options. However, the smooth surfaces of the uncemented implants developed in the 1970s could not achieve a strong adherence to bone. Coating materials that allowed bone ingrowth and ongrowth became available in the 1980s and gained favour for the uncemented hip arthroplasty [30]. Osseointegration was described as "the attachment of lammelar bone to implants without intervening fibrous tissue" [31]. Initial stability and osseous contact were necessary to hold the prosthesis steady while bone could form and adhere to the porous prosthesis surface. Where micromotion was very low, bone would form, which demonstrated the importance of initial stability [32]. Prevention 
of stress shielding, i.e., the decreased loading of the proximal femoral bone due to a stiffer implant made of metal, was obtained by ensuring that the implant has a low Young's modulus, which is the measure of the rigidity of an object. Stress shielding occurs because of the difference in stiffness between implantand bone, which might result in a decreased loading of bone and therefore in increased bone resorption (Wolff's law) and finally in an increased rate of aseptic loosening [33]. However, implant survival is also determined by the elasticity modulus, because a low Young's modulus indicates less rigidity and results in more micromotion, which is negative for the bone-implant interface [34]. In the manufacturing of hip implants, a compromise is needed, since a high Young modulus is required to prevent aseptic loosening, whereas a low Young modulus is required to prevent stress shielding [35]. More stress shielding is observed in uncemented hip arthroplasty, because the need for a larger diameter results in a stiffer stem, creating more stress shielding than in cemented hip arthroplasty. Because of the optimal Young's modulus of bonecement and the reduced diameter of a cemented stem, cement fixation of the femoral implant in general induces less stress shielding than an uncemented fixation.

Currently, uncemented fixation of THA is the most frequently used fixation type in THA. In 2019, uncemented fixation was used in $68 \%$ of primary THA procedures in the Netherlands [6]. However, cementing techniques have been improved in the past few decades; the current fourth generation of cementation consists of a canal plug, serial high-pressure pulse lavage, retrograde filling of the femoral canal and proximal pressurization with later insertion of an implant into viscous cement. This is considered the gold standard in modern cemented arthroplasty [32].

\subsection{Bearing}

The normal joint loads and motions must be transmitted by the bearing surfaces of a hip prosthesis. The bearing or bearing surface is the area of contact between two objects [36]. Selecting the best material for the bearing has been an issue since the beginning of THA. Glück used an ivory ball and socket (1891), whereas Wiles used a metal acetabular component and a metal head (1938) [9, 10, 15]. Since the 1950s, MoM THA was used by George McKee and John Watson-Farrar. They used a ball and socket type replacement consisting of a chrome-cobalt alloy. A modified Thompson stem was used, in combination with a cup that was screwed in the acetabular roof. After Sir John Charnley described the use of methylmethracrylate to anchor a Thompson prosthesis within the femoral shaft, McKee-Farrar designed a new acetabular prosthesis, which was used regularly [23]. However, later research showed high revision rates. The MoM method became unpopular due to the local 
effects of metal particles which were noted during revision surgery [3]. The McKeeFarrar and Ring models were abandoned in the 1970s, in favour of Charnley's ideas [9]. Charnley used small femoral heads, based on the theory that this smaller surface area would reduce wear based on friction. He understood that low friction wear was more important than low pressure wear, so a smaller head was used (Low Friction Arthroplasty Concept) [3]. The early results of Charnley's UHMWPE were very impressive and the durability improved [29].

The implant failure of THA based on polyethylene wear known as 'polyethylene disease' led to renewed interest in hard bearings such as MoM and ceramic-onceramic ( $\mathrm{CoC})$. A CoC-bearing has a high resistance to wear due to its hardness and wettability. It was shown that wear rates were a 50 -fold lower than those of UHMWPE [37]. Nevertheless, the bearing was never widely used due to the risk of fracture, problems in achieving a durable fixation between bone and ceramic implants and the higher costs. Also, ceramic liners are sensitive to implant positioning. Squeaking is a well-known negative side effect of CoC-bearings, although it does not influence hip function, nor is loosening or osteolysis more frequent in 'squeaking' hips [37].

When Bernhard Georg Weber (1927-2002) observed that certain MoM prostheses functioned well at long-term follow-up, he hypothesized that failure was due to unsuitability of the bearing materials used, the design of the implant, or technical errors. Weber and his industrial partner manufactured the Metasul bearing [27, 38]. Since 1992, Weber has used uncemented components (Metasul bearing in a Zweymüller cup) and proved reliable and satisfactory long-term results.

Derek McMinn (1953-, United Kingdom), Michael Wagner (1957-, Germany) and Harlan Amstutz (1931-, USA) were the first to start implanting HRA with a MoM articulation [39-41]. In-vivo wear rates in these 'second generation' MoM bearings were almost 100 times lower than in MoP bearings, and the small particles were less likely to induce the macrophage-induced response observed in MoP bearings leading to osteolysis $[42,43]$. In the early 2000 s, the worldwide popularity of HRA increased because of excellent early short-term results [44]. An estimated 1 to 1.5 million patients received a MoM hip arthroplasty, either HRA or large-head MoM (LHMoM) THA $[45,46]$. The use of LHMoM THA was popularized in parallel with HRA. In 2002, Korovessis et al. reported that there "was no evidence that MoM articulation gives rise to new problems or complications" [47]. The future would prove, however, how mistaken they were. 
Figure 3. Example of HRA and LHMoM THA system (Conserve ${ }^{\oplus}$ Plus; Wright Medical Technology, Memphis, TN, USA)[48].

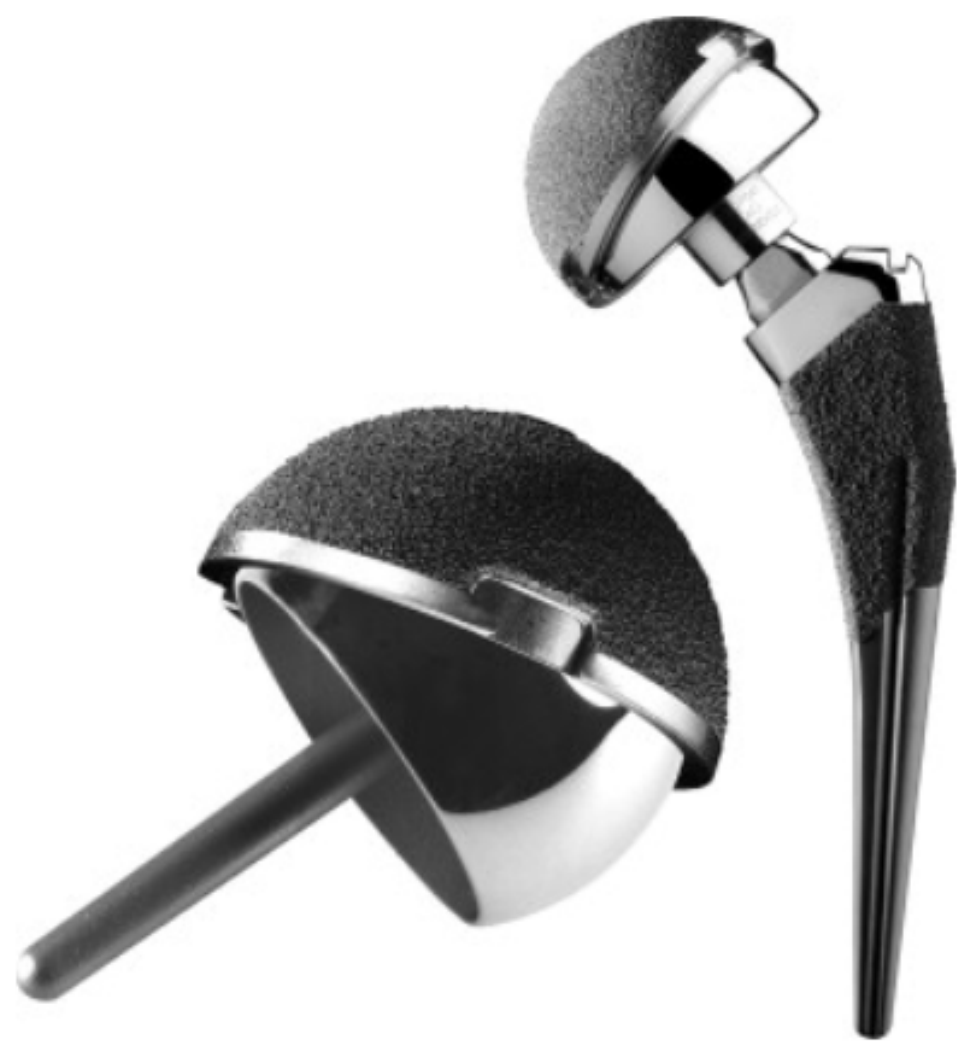

\subsection{Metal-on-metal issues}

Concerns have been voiced since the beginning of MoM arthroplasty. Local tissue reactions were already described in 1975, and in 1994, studies found dissemination of cobalt and chromium ions into the lymphatic system, liver, and spleen. In 1998, cobalt and chromium ions were shown to be toxic to monocytes in culture [45]. The first results published by McMinn in 2003 concerning the Birmingham Hip Replacement (BHR) started the trend for larger heads in hip arthroplasty [45]. Since 2004 , concerns increased. Multiple studies including national registry data showed high failure rates as neither HRA nor LHMoM THA achieved the 10-year survival rate threshold of $95 \%$ set in 2000 by the National Institute for Health and Care Excellence (NICE) $[49,50]$. In 2005, an internal memo of DePuy showed that manufacturers were aware of the potential genotoxicity, but stated that 'the ultimate test is the long term human experience'. A year after, dr.Schmalzreid, one of DePuy's prosthesis designers 
and an orthopaedic surgeon, wrote a paper to counter emerging concerns about MoM hip arthroplasty [45].

On 7 September 2010, the Medicines and Healthcare products Regulatory Agency (MHRA) recalled the Articular Surface Placement (ASR) (DePuy Orthopaedics, Warsaw, Indiana, USA) hip prosthesis. Consequently, this implant was withdrawn by the manufacturer [51]. Failure rates of $25 \%$ to almost $50 \%$ were shown for the ASR HRA and LHMOM, respectively [52]. It was shown that after implantation, all patients with a MoM hip prosthesis had raised metal ion concentrations of cobalt and chromium in body fluids (blood, serum, plasma, urine) [53]. Blood or serum metal ion concentrations are used as a surrogate marker of in-vivo wear [54]. These concentrations might be influenced by a variety of parameters, which can be divided into patient factors (female sex, age at surgery (young), time since implantation), implant factors (bilateral, small femoral HRA components, design, type of implant (HRA/LHMoM)) and surgical factors (acetabular component malposition, reduced contact patch to rim distance)[55]. There was a concern that increased cobalt and chromium ion concentrations increased the risk for cancer, but this was proven otherwise in large comparative studies [56,57]. Nevertheless, in 2012, the NetherlandsOrthopaedicAssociation (NOV) advised against the use of any MoM hip arthroplasty [58,59]. New ideas led to UHMWPE crosslinking plus melting or crosslinking with added antioxidants. These innovations resulted in metal- and ceramic-on-polyethylene as the most frequently used bearings in THA, also in the Netherlands $[3,6,29]$.

\section{Clinical results and assessment of THA}

Outcome measures are used to assess change over time as well as the response to any type of intervention. Outcome after THA can be assessed in multiple ways and based on different judgements: by the clinician, by the patient, by'a significant other' or by a combination of two or more of those concerned [60]. The main outcomes of THA studied over time were implant position determined via radiographs, common adverse events and serious adverse events (SAEs) (e.g. infection), and survival of prosthesis, whereas clinical improvement and patient experience were thought to be not really relevant at that time [61]. Clinician-administered outcome assessment became more important due to improvements in prosthesis design, operative techniques, perioperative treatments and the prevention of SAEs. These assessments consisted of measures of pain, activity and joint function (e.g. the Harris Hip Score (HHS)) [62]. 


\subsection{Subjective outcome assessment}

Clinician-administered tools have shown disagreements between patients and clinicians and were therefore widely criticised [63]. The focus shifted to improving the patients' health-related quality of life, which increased the importance of outcome experiences and of the patients' and the clinicians' expectations regarding the outcomes of an intervention. Patient-reported outcome measures (PROMs) are often questionnaires that are completed by the patients themselves and that measure functional status, health-related quality of life, symptoms and symptom burden, personal experience of care, and health-related behaviors, such as anxiety and depression. PROMS can be both generic and disease-specific [64]. Life and health changes continuously and well-being is influenced by many factors, which means that PROM results are subjective by nature and influenced by socioeconomic and psychological factors $[60,65,66]$. For many PROMs, the main determinant of outcome seems to be pain, because patients experience difficulties in differentiating between pain and functional disability $[67,68]$. These drawbacks influence the validity of PROMS, especially in the assessment of objectively measurable dimensions of outcome, such as physical function [67,69]. PROM results are highly influenced by a patient's postoperative pain relief, which results in overestimation of the actual short- and long-term changes in physical function [70-73]. While PROMs are commonly used, their outcomes can suffer from their subjective nature, recall bias, ceiling effects, low response and completion rates or transcription errors, as well as from the fact that PROMS are a time-consuming method for outcome assessment [74-77].

\subsection{Objective outcome assessment}

Rather than by subjective assessments of clinicians or patients, the outcomes of hip arthroplasty should be determined by means of objective measurements. Physical activity (PA) is an outcome measure after hip arthroplasty that can be objectively determined in various ways, for instance by using optical motion capture systems, force platforms, isometric strength testing techniques, electromyography, timed performance-based tests (six minute walk test, timed up-and-go test) or by means of wearable sensor techniques (inertial measurement units (IMU), accelerometers) [78-81]. Activity monitoring with the use of continuous activity monitors (AMs) during activities of daily life ( $A D L$; 'the free-living environment') capturing PA has become possible due to advances in measurement accuracy, monitor size and costs. AMs can measure behavioral aspects of PA (e.g. number of steps) as well as qualitative aspects (e.g. steps per minute). For several studies presented in this thesis, activity monitoring was performed using a 3-axis accelerometer, gyroscope and magnetometer. Patients were monitored for four consecutive days, since a 
patient's habitual PA patterns can be representatively characterized by measuring activity for three to four days $[82,83]$. The raw signal received with this AM was analysed using published algorithms. This approach has been previously described and validated in a semi-free setting and achieved an excellent accuracy (>97\%) in determining PA levels in healthy subjects and patients after unilateral hip or knee arthroplasty [84, 85].

\section{Aims of this thesis}

In MoM hip arthroplasty, the metal surfaces are exposed to wear, which results in the release of metal ions during articulation. An indirect measure of (volumetric) wear is the concentration of metal ions in blood, serum or urine [86-88]. Dr. Schmalzried discovered that "wear is a function of use, not time" in THA with a polyethylene bearing [89]. Little is known about the influence of PA on metal ion concentrations, while in theory the daily habitual PA of patients with a MoM hip arthroplasty should be associated with metal ion concentrations in blood.

HRA was designed for highly active patients because of the various previously mentioned theoretical advantages over conventional stemmed MoP THA [28]. It can be expected that patients who received an HRA would be more physically active after surgery because of these advantages. In current literature, the only evidence available is based on self-reported activity questionnaires [90,91]. As PROMs suffer from their subjective nature, a precise analysis of the effects of PA in patients with HRA and conventional stemmed MoP THA might benefit from objective PA monitoring. In addition, to determine the value of PROMs concerning PA, PROM results should be compared with objectively measured PA.

One of the advantages of HRA is the preservation of the femoral bone, which allows an easy revision if needed. While the outcome of revision of a MoM hip arthroplasty might depend on the reason for revision, current literature on this topic is not clear. However, it is clear that MoM articulation results in local tissue reactions and raised metal ion concentrations locally but also systemically. Systemically raised metal ion concentrations are seen in all patients, with peak concentrations being reached between 9 and 18 months postoperatively. The systemic danger of highly and chronically raised metal ion concentrations is not well known, although cobalt intoxication is described in a few patients [92]. 


\subsection{Research questions:}

1) What is the relation between objectively measured physical activity and blood metal ion concentrations in patients with a metal-on-metal hip arthroplasty?

2) Are patients with an HRA physically more active than patients with a conventional stemmed THA?

3) Is objectively measured physical activity associated with patient-reported physical activity?

4) Is the outcome of revision surgery in failed MoM hip arthroplasties worse than the outcome of revision in failed non-MoM hip arthroplasties?

5) Are chronically raised metal ion concentrations associated with systemic complaints?

\subsection{Outline of the thesis}

The PA levels of patients with a MoM hip arthroplasty were objectively measured using wearable AMs and analysed to identify possible associations with blood metal ion concentrations. The first question is answered in chapter II and III. Chapter /l presents patients with any type of unilateral or bilateral MoM hip arthroplasty (HRA and/or LHMoM THA), whereas Chapter III focuses on patients with a unilateral HRA at 10-year follow-up. To answer the second question, the unilateral HRA group presented in Chapter III was matched with a cohort of patients with a conventional stemmed THA to investigate whether PA differs between these groups (Chapter IV). Both groups of patients completed a few frequently used PROMs. The self-reported outcomes were compared with the results of objectively measured PA to answer the third research question in Chapter $V$. To answer the fourth research question, data of the Dutch Arthroplasty Register (LROI) were used in Chapter VI to compare the outcomes of revisions of failed MoM and non-MoM hip arthroplasties. The answer to the fifth research question was sought in a systematic review concerning cobalt intoxication in hip arthroplasty patients (Chapter VII) and in a study using a new patient-reported questionnaire on the influences of raised cobalt ion concentrations on general aspects of health (Chapter VIII). 


\section{References}

1. Murphy NJ, Eyles JP, Hunter DJ, Hip Osteoarthritis: Etiopathogenesis and Implications for Management. Adv Ther, 2016;33(11): p.1921-1946.

2. Gay C, Chabaud A, Guilley E, Coudeyre E, Educating patients about the benefits of physical activity and exercise for their hip and knee osteoarthritis. Systematic literature review. Ann Phys Rehabil Med, 2016;59(3): p.174-183.

3. Knight SR, Aujla R, Biswas SP, Total Hip Arthroplasty - over 100 years of operative history. Orthop Rev (Pavia), 2011;3(2): e16.

4. Learmonth ID, Young C, Rorabeck C, The operation of the century: total hip replacement. Lancet, 2007;370(9597):p.1508-19.

5. Aresti N, Kassam J, Nicholas N, Achan P. Hip osteoarthritis. BMJ, 2016;354:i3405.

6. Dutch Arthroplasty Register (LROI), Online annual report 2020, https://www.Iroi-report.nl/, 2020.

7. Pivec R, Johnson AJ, Mears SC, Mont MA. Hip arthroplasty. Lancet, 2012;380(9855):p.1768-77.

8. Kurtz SM, Lau E, Ong K, Zhao K, Kelly M, Bozic KJ, Future young patient demand for primary and revision joint replacement: national projections from 2010 to 2030. Clin Orthop Relat Res, 2009;467(10):p.2606-12.

9. Gomez PF and Morcuende JA, Early attempts at hip arthroplasty--1700s to 1950s. lowa Orthop J, 2005;25:p.25-9.

10. Hernigou P, Earliest times before hip arthroplasty: from John Rhea Barton to Themistocles Gluck. Int Orthop, 2013;37(11):p.2313-8.

11. Murphy JB, I. Arthroplasty. Ann Surg, 1913;57(5): p.593-647.

12. Burlew JM, Arthroplasty of the Hip Joint, Murphy Method, Report of Four Cases. Cal State J Med, 1918;16(5):p.237-40.

13. Baer WS, Arthroplasty with the aid of animal membrane. Amer Jour Orth Surg, 1918;16(2):p.94115

14. Smith-Petersen MN, Evolution of mould arthroplasty of the hip joint. J Bone Joint Surg Br, 1948;30B(1):p.59-75.

15. Wiles P, The surgery of the osteoarthritic hip. Br J Surg, 1958;45(193): p.488-97.

16. Zagra $L$ and Gallazzi $E$, Bearing surfaces in primary total hip arthroplasty. EFORT Open Rev, 2018;3(5):p.217-224.

17. Nissen Kl, The Judget arthroplasty of the hip via Gibson's lateral approach, Postgrad Med J. 1952 Jul; 28(321): 412-423

18. Judet $J$ and Judet $R$, The use of an artificial femoral head for arthroplasty of the hip joint. J Bone Joint Surg Br, 1950;32-B(2):p.166-73.

19. Judet $\mathrm{R}$ and Judet $\mathrm{J}, \mathrm{Technique}$ and results with the acrylic femoral head prosthesis. J Bone Joint Surg Br, 1952;34-B(2):p.173-80.

20. Thompson FR, Vitallium intramedullary hip prosthesis, preliminary report. N Y State J Med, 1952;52(24):p.3011-20.

21. Peterson LT, The use of a metallic femoral head. J Bone Joint Surg Am, 1951;33A(1):p.65-75; passim.

22. Fitzgerald FP, A method of hip arthroplasty. J Bone Joint Surg Br, 1952;34-B(1):p.120-2.

23. McKee GK and Watson-Farrar J, Replacement of arthritic hips by the McKee-Farrar prosthesis. J Bone Joint Surg Br, 1966;48(2):p.245-59.

24. Reynolds LA and Tansey EM, Early Development of Total Hip Replacement. Wellcome Witnesses to Twentieth Century Medicine, vol. 29. London: Wellcome Trust Centre for the History of Medicine at UCL.

25. Kabo JM, Gebhard JS, Loren G, Amstutz HC. In vivo wear of polyethylene acetabular components. J Bone Joint Surg Br, 1993;75(2):p.254-8.

26. Huntley JS and Christie J, Surface replacement of the hip: a late revision. Can J Surg, 2004;47(4):p.302-3.

27. Triclot P, Metal-on-metal: history, state of the art (2010). Int Orthop, 2011;35(2):p.201-6. 


\section{Chapter 1}

28. Corten K, Ganz R, Simon JP, Leunig M, Hip resurfacing arthroplasty: current status and future perspectives. Eur Cell Mater, 2011;21:p.243-58.

29. Harris $\mathrm{WH}$, The first 50 years of total hip arthroplasty: lessons learned. Clin Orthop Relat Res, 2009;467(1):p.28-31.

30. Yamada H, Yoshihara Y, Henmi O, Morita M, Shiromoto Y, Kawano T et al., Cementless total hip replacement: past, present, and future. J Orthop Sci, 2009;14(2):p.228-41.

31. Albrektsson T, Brånemark Pl, Hansson HA, Lindström J, Osseointegrated titanium implants. Requirements for ensuring a long-lasting, direct bone-to-implant anchorage in man. Acta Orthop Scand, 1981;52(2):p.155-70.

32. Maggs $\mathrm{J}$ and Wilson M, The Relative Merits of Cemented and Uncemented Prostheses in Total Hip Arthroplasty. Indian J Orthop, 2017;51(4): p.377-385.

33. Niinomi $M$ and Nakai $M$, Titanium-Based Biomaterials for Preventing Stress Shielding between Implant Devices and Bone. Int J Biomater, 2011;2011:836587.

34. Elliott B and Goswami T, Implant material properties and their role in micromotion and failure in total hip arthroplasty. Int J Mech Mater Des, 2012;8:p.1-7.

35. Apostu D, Lucaciu O, Berce C, Lucaciu D, Cosma D, Current methods of preventing aseptic loosening and improving osseointegration of titanium implants in cementless total hip arthroplasty: a review. J Int Med Res, 2018;46(6):p.2104-2119.

36. Mirza SB, Dunlop DG, Panesar SS, Naqvi SG, Gangoo S, Salih S, Basic science considerations in primary total hip replacement arthroplasty. Open Orthop J, 2010;4:p.169-80.

37. Tsikandylakis G, Overgaard S, Zagra L, Kärrholm J, Global diversity in bearings in primary THA. EFORT Open Rev, 2020;5(10):p.763-775.

38. Eswaramoorthy V, Moonot P, Kalairajah Y, Biant LC, Field RE, The Metasul metal-on-metal articulation in primary total hip replacement: clinical and radiological results at ten years. J Bone Joint Surg Br, 2008;90(10):p.1278-83.

39. McMinn D, Treacy R, Lin K, Pynsent P, Metal on metal surface replacement of the hip. Experience of the McMinn prothesis. Clin Orthop Relat Res, 1996(329 Suppl): p. S89-98.

40. Wagner $\mathrm{M}$ and Wagner $\mathrm{H}$, Preliminary results of uncemented metal on metal stemmed and resurfacing hip replacement arthroplasty. Clin Orthop Relat Res, 1996(329 Suppl): p. S78-88.

41. Amstutz HC, Sparling EA, Grigoris P, Campbell PA, Dorey FJ, Surface Replacement: The Hip Replacement of the Future? Hip Int, 1998;8(4):p.187-207.

42. Anissian HL, Stark A, Gustafson A, Good V, Clarke IC, Metal-on-metal bearing in hip prosthesis generates 100-fold less wear debris than metal-on-polyethylene. Acta Orthop Scand, 1999. 70(6): p. 578-82.

43. Bitar D and Parvizi J, Biological response to prosthetic debris. World J Orthop, 2015;6(2):p. $172-89$.

44. Amstutz HC and Le Duff MJ, Hip resurfacing: history, current status, and future. Hip Int, 2015;25(4):p.330-8.

45. Cohen D, How safe are metal-on-metal hip implants? BMJ, 2012;344: p.e1410.

46. Matharu VK and Matharu GS, Metal-on-metal hip replacements: implications for general practice. Br J Gen Pract, 2017;67(665):p.544-545.

47. Korovessis P, Petsinis G, Repanti M, Papazisis Z, Iliopoulos P, Soucacos PN, Short-term results with the Zweymueller-SL metal-on-metal total hip arthroplasty. Eur J Orthop Surg Traumatol, 2002;12(2):p. 81-9.

48. Beaulé PE, Kim P, Hamdi A, Fazekas A. A Prospective Metal Ion Study of Large-Head Metal-onMetal Bearing: A Matched-Pair Analysis of Hip Resurfacing Versus Total Hip Replacement. The Orthopedic clinics of North America. 42. 251-7, ix. 10.1016/j.ocl.2011.01.005.

49. Smith AJ, Dieppe P, Howard PW, Blom AW, National Joint Registry for England and Wales, Failure rates of metal-on-metal hip resurfacings: analysis of data from the National Joint Registry for England and Wales. Lancet, 2012;380(9855):p.1759-66.

50. Smith AJ, Dieppe P, Vernon K, Porter M, Blom AW, National Joint Registry of England and Wales Failure rates of stemmed metal-on-metal hip replacements: analysis of data from the National Joint Registry of England and Wales. Lancet, 2012. 379(9822): p. 1199-204. 
51. Randelli F, Banci L, Favilla S, Maglione D, Aliprandi A, Radiographically undetectable periprosthetic osteolysis with ASR implants: the implication of blood metal ions. J Arthroplasty, 2013. 28(8): p. 1259-64.

52. Langton DJ, Jameson SS, Joyce TJ, Gandhi JN, Sidaginamale R, Mereddy P et al., Accelerating failure rate of the ASR total hip replacement. J Bone Joint Surg Br, 2011;93(8):p.1011-6.

53. Hartmann A, Hannemann F, Lützner J, Seidler A, Drexler H, Günther KP et al., Metal ion concentrations in body fluids after implantation of hip replacements with metal-on-metal bearing--systematic review of clinical and epidemiological studies. PLoS One, 2013. 8(8): p. e70359.

54. De Smet K, De Haan R, Calistri A, Campbell PA, Ebramzadeh E, Pattyn C et al., Metal ion measurement as a diagnostic tool to identify problems with metal-on-metal hip resurfacing. J Bone Joint Surg Am, 2008;90 Suppl 4: p.202-8.

55. Matharu GS, Judge A, Eskelinen A, Murray DW, Pandit HG, What is appropriate surveillance for metal-on-metal hip arthroplasty patients? Acta Orthop, 2018;89(1):p.29-39.

56. Haddad FS, Primary metal-on-metal hip arthroplasty was not associated with increased cancer risk. J Bone Joint Surg Am, 2013;95(4):p.364.

57. Kovochich M, Finley BL, Novick R, Monnot AD, Donovan E, Unice KM et al., Understanding outcomes and toxicological aspects of second generation metal-on-metal hip implants: a state-of-the-art review. Crit Rev Toxicol, 2018;48(10): p. 853-901.

58. Verhaar JA, [The hard lesson of metal-on-metal hip implants]. Ned Tijdschr Geneeskd, 2012;156(42):p. A5564.

59. Van Steenbergen LN, Denissen GAW, Schreurs BW, Zijlstra WP, Koot HWJ, Nelissen R, Dutch advice not to use large head metal-on-metal hip arthroplasties justifiable - results from the Dutch Arthroplasty Register. Nederlands Tijdschrift voor Orthopaedie, 2020;27(1).

60. Blom AW, Artz N, Beswick AD, Burston A, Dieppe P, Elvers KT et al., Improving patients' experience and outcome of total joint replacement: the RESTORE programme. Programme Grants Appl Res 2016;4(12).

61. Wylde V and Blom AW, The failure of survivorship. J Bone Joint Surg Br, 2011;93(5):p.569-70.

62. Harris HW, Traumatic arthritis of the hip after dislocation and acetabular fractures: treatment by mold arthroplasty. An end-result study using a new method of result evaluation. J Bone Joint Surg Am, 1969;51(4):p.737-55.

63. Hewlett SA, Patients and clinicians have different perspectives on outcomes in arthritis. J Rheumatol, 2003;30(4):p.877-9.

64. Weldring T and Smith SM, Patient-Reported Outcomes (PROs) and Patient-Reported Outcome Measures (PROMs). Health Serv Insights, 2013;6:p.61-8.

65. Terwee CB, Mokkink LB, Steultjens MP, Dekker J, Performance-based methods for measuring the physical function of patients with osteoarthritis of the hip or knee: a systematic review of measurement properties. Rheumatology (Oxford), 2006;45(7):p.890-902.

66. Vissers MM, Bussmann JB, Verhaar JA, Busschbach JJ, Bierma-Zeinstra SM, Reijman M, Psychological factors affecting the outcome of total hip and knee arthroplasty: a systematic review. Semin Arthritis Rheum, 2012;41(4):p.576-88.

67. Hossain FS, Patel S, Fernandez MA, Konan S, Haddad FS, A performance based patient outcome score for active patients following total knee arthroplasty. Osteoarthritis Cartilage, 2013;21(1):p.51-9.

68. Mizner RL, Petterson SC, Clements KE, Zeni Jr JA, Irrgang JJ, Snyder-Mackler L, Measuring functional improvement after total knee arthroplasty requires both performance-based and patient-report assessments: a longitudinal analysis of outcomes. J Arthroplasty, 2011;26(5):p. 728-37.

69. Terwee CB, van der Slikke RM, van Lummel RC, Benink RJ, Meijers WG, de Vet HC, Selfreported physical functioning was more influenced by pain than performance-based physical functioning in knee-osteoarthritis patients. J Clin Epidemiol, 2006;59(7):p.724-31.

70. Luna IE, Kehlet H, Peterson B, Wede HR, Hoevsgaard SJ, Aasvang EK, Early patient-reported outcomes versus objective function after total hip and knee arthroplasty: a prospective cohort study. Bone Joint J, 2017;99-B(9):p.1167-1175. 


\section{Chapter 1}

71. Mark-Christensen $\mathrm{T}$ and Kehlet $\mathrm{H}$, Assessment of functional recovery after total hip and knee arthroplasty: An observational study of 95 patients. Musculoskeletal Care, 2019;17(4):300-312

72. Naili JE, Hedström M, Broström EW, Changes of and interrelationships between performancebased function and gait and patient-reported function 1 year after total hip arthroplasty. J Orthop Traumatol, 2019;20(1): p.14.

73. Jelsma J, Pijnenburg R, Boons HW, Eggen PJMG, Kleijn LLA, Lacroix $H$ et al., Limited benefits of the direct anterior approach in primary hip arthroplasty: A prospective single centre cohort study. J Orthop, 2017;14(1):p.53-58.

74. Pronk Y, Pilot P, Brinkman JM, van Heerwaarden RJ, van der Weegen W, Response rate and costs for automated patient-reported outcomes collection alone compared to combined automated and manual collection. J Patient Rep Outcomes, 2019;3(1):p.31.

75. Chughtai M, Khlopas A, Mistry JB, Gwam CU, Elmallah RK, Mont MA, Time Burden of Standardized Hip Questionnaires. Surg Technol Int, 2016;28:p.280-4.

76. Steinhoff AK and Bugbee WD, Knee Injury and Osteoarthritis Outcome Score has higher responsiveness and lower ceiling effect than Knee Society Function Score after total knee arthroplasty. Knee Surg Sports Traumatol Arthrosc, 2016;24(8): p.2627-33.

77. Weber BA, Yarandi H, Rowe MA, Weber JP, A comparison study: paper-based versus web-based data collection and management. Appl Nurs Res, 2005;18(3):p.182-5.

78. Dobson F, Hinman RS, Hall M, Terwee CB, Roos EM, Bennell KL, Measurement properties of performance-based measures to assess physical function in hip and knee osteoarthritis: a systematic review. Osteoarthritis Cartilage, 2012;20(12): p.1548-62.

79. Senden R, Grimm B, Meijer K, Savelberg H, Heyligers IC, The importance to including objective functional outcomes in the clinical follow up of total knee arthroplasty patients. Knee, 2011;18(5):p.306-11.

80. Greene BR, Doheny EP, O'Halloran A, Kenny RA, Frailty status can be accurately assessed using inertial sensors and the TUG test. Age Ageing, 2014;43(3):p.406-11.

81. Bolink SAAN, Naisas $H$, Senden R, Essers $H$, Heyligers IC, Meijer $K$ et al., Validity of an inertial measurement unit to assess pelvic orientation angles during gait, sit-stand transfers and step-up transfers: Comparison with an optoelectronic motion capture system. Med Eng Phys, 2016;38(3):p.225-31.

82. Mâsse LC, Fuemmeler BF, Anderson CB, Matthews CE, Trost SG, Catellier DJ et al., Accelerometer data reduction: a comparison of four reduction algorithms on select outcome variables. Med Sci Sports Exerc, 2005;37(11 Suppl): S544-54.

83. Kang $M$, Hart PD, Kim Y, Establishing a threshold for the number of missing days using $7 \mathrm{~d}$ pedometer data. Physiol Meas, 2012;33(11):p.1877-85.

84. Lipperts M, van Laarhoven S, Senden R, Heyligers I, Grimm B, Clinical validation of a bodyfixed 3D accelerometer and algorithm for activity monitoring in orthopaedic patients. J Orthop Translat, 2017;11:p.19-29.

85. Van Laarhoven SN, Lipperts M, Bolink SAAN, Senden R, Heyligers IC, Grimm B, Validation of a novel activity monitor in impaired, slow-walking, crutch-supported patients. Ann Phys Rehabil Med, 2016;59(5-6):p.308-313.

86. Daniel J, Ziaee H, Pradhan C, Pynsent PB, McMinn DJW, Blood and urine metal ion levels in young and active patients after Birmingham hip resurfacing arthroplasty: four-year results of a prospective longitudinal study. J Bone Joint Surg Br, 2007;89(2):p.169-73.

87. deSouza RM, Parsons NR, Oni T, Dalton P, Costa M, Krikler S. Metal ion levels following resurfacing arthroplasty of the hip: serial results over a ten-year period. J Bone Joint Surg Br, 2010;92(12):p.1642-7.

88. Van der Straeten C, Grammatopoulos G, Gill HS, Calistri A, Campbell P, de Smet KA, The 2012 Otto Aufranc Award: The interpretation of metal ion levels in unilateral and bilateral hip resurfacing. Clin Orthop Relat Res, 2013;471(2):p.377-85.

89. Schmalzried TP, Shepherd EF, Dorey FJ, Jackson WO, dela Rosa M, Fa'vae F, The John Charnley Award. Wear is a function of use, not time. Clin Orthop Relat Res, 2000(381):p.36-46. 
90. Zywiel MG, Marker DR, McGrath MS, Delanois RE, Mont MA, Resurfacing matched to standard total hip arthroplasty by preoperative activity levels - a comparison of postoperative outcomes. Bull NYU Hosp Jt Dis, 2009;67(2):p.116-9.

91. Mont MA, Marker DR, Smith JM, Ulrich SD, McGrath MS, Resurfacing is comparable to total hip arthroplasty at short-term follow-up. Clin Orthop Relat Res, 2009;467(1):p.66-71.

92. Rizzetti MC, Liberini P, Zarattini G, Catalani S, Pazzaglia U, Apostoli P et al., Loss of sight and sound. Could it be the hip? Lancet, 2009;373(9668):p. 1052. 

Part A

Physical Activity Monitoring 


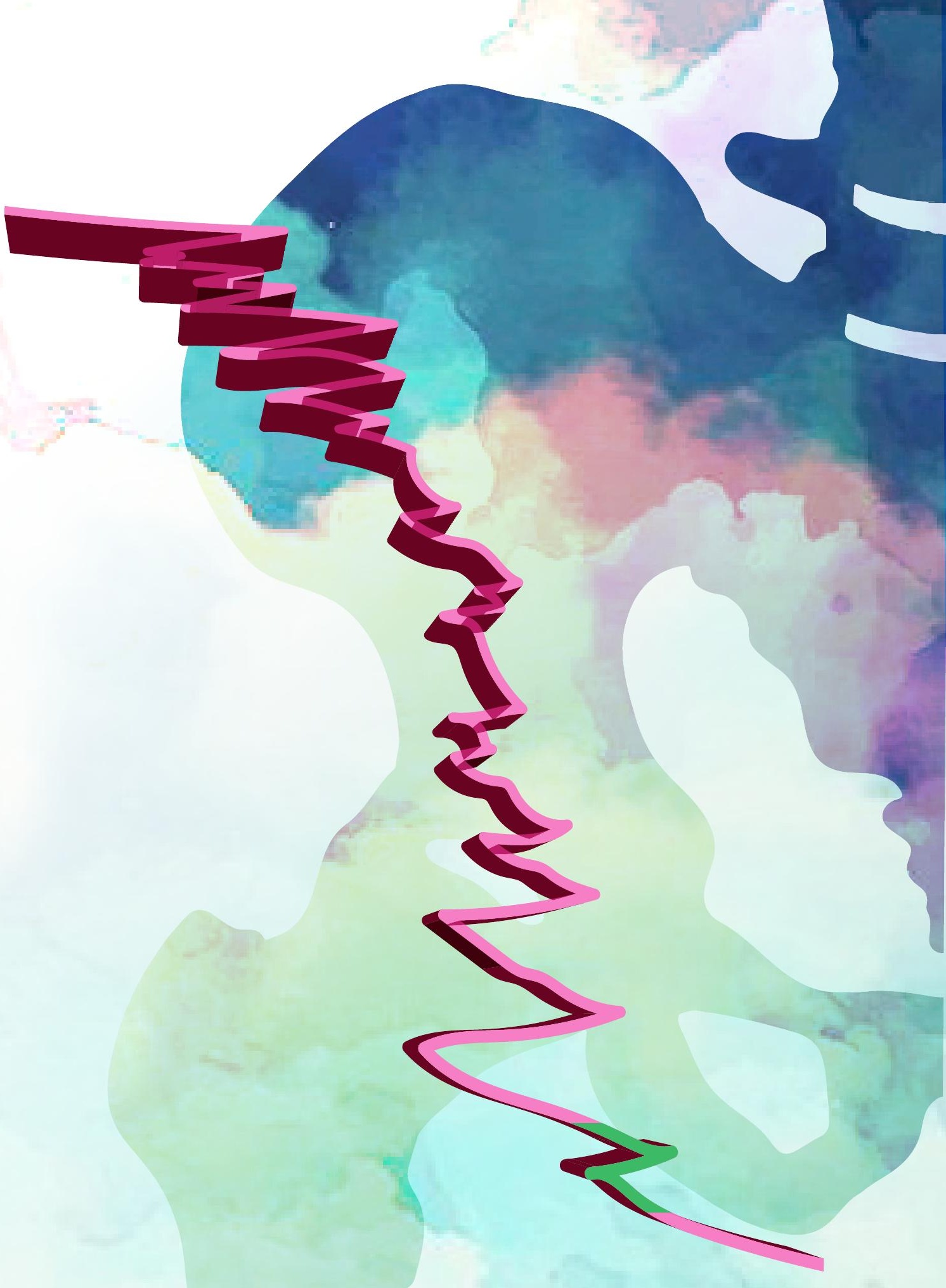




\section{Chapter II}

Metal ion concentrations after metal-on-metal hip arthroplasty are not correlated with habitual physical activity levels

Hip Int. 2019 Nov;29(6):638-646

Jelsma J, Schotanus MGM, Senden R, Heyligers IC, Grimm B

Hard work beats talent when talent fails to work hard

(Tim Notke / Kevin Durant) 


\section{Abstract}

\section{Introduction}

Metal-on-metal (MoM) hip arthroplasties have shown high clinical failure rates with many patients at risk for a revision and under surveillance for high metal ion concentrations. Implant wear releasing such ions is assumed to be a function of use, i.e. the patient's physical activity. This study aimed to assess whether habitual physical activity levels of MoM patients are correlated with metal ion concentrations and are higher in patients with high (at risk) than in patients with low (safe) metal ion concentrations.

\section{Methods}

A cohort study was conducted of patients with any type of MoM hip prosthesis. Metal ion concentrations were determined using ICP-MS. Habitual physical activity of subjects was measured in daily living using an accelerationbased activity monitor. Outcome consisted of quantitative and qualitative activity parameters.

\section{Results}

In total, 62 patients were included. Mean age at surgery was $60.8 \pm 9.3$ years and follow-up was $6.3 \pm 1.4$ years. Cobalt concentrations were highly elevated overall $(112.4 \pm 137.9 \mathrm{nmol} / \mathrm{L})$ and significantly more in bilateral $(184.8 \pm 106.5 \mathrm{nmol} / \mathrm{L})$ than in unilateral cases $(87.8 \pm 139.4 \mathrm{nmol} / \mathrm{L})$. No correlations were found between physical activity parameters and metal ion concentrations. Subgroup analysis of patients with low versus high cobalt concentration showed no significant differences in habitual physical activity.

\section{Discussion}

No correlation was found between physical activity levels and metal ion concentrations. Implant use by normal habitual activities of daily living seems not to influence metal ion concentrations. 


\section{Introduction}

Metal-on-metal (MoM) hip arthroplasty became accepted worldwide in the early 1990s. After the first generation of MoM prostheses, improved metal alloys and manufacturing techniques made this procedure very popular. Hip resurfacing arthroplasty (HRA) was designed in particular for young and active patients [1,2]. This design was thought to produce less volumetric wear due to dynamic fluid film lubrication and the improved roundness of the two metal surfaces, which were made of an alloy of cobalt, chromium and molybdenum [2-4]. Another potential advantage was the increased stability and range of motion due to the use of larger heads [2].

Despite these improvements, concerns were raised. High clinical failure rates were observed, with adverse reactions to metal debris (ARMD) and increasing revision rates in decreasing cupsizes [5-10]. Recent studies showed that $40 \%-50 \%$ of patients with a MoM hip prosthesis develop a pseudotumor, with similar prevalence in wellfunctioning hips or painful hips. Women are affected significantly more than men [11-13].

The metal surfaces are exposed to wear, which results in the release of metal ions. Hence, the measurement of metal ions is considered an indirect measure of such volumetric wear, although the true volumetric wear can only be measured on an explanted device. Cobalt and chromium ion concentrations rise significantly after MoM implantation, with peak concentrations at 9 to 18 months postoperatively. Then an equilibrium is reached between metal ion release from the implant and metal ion release from the body (e.g. via urine) [14-16]. Rising and patient-specific metal ion concentrations after this period are thought to be due to multifactorial causes: design, acetabular component malpositioning, contact patch to rim (CPR) distance and a smaller joint size seem to play a role [9,17-21].

Physical activity (PA) and the large effect of habitual physical activity levels on general health are increasingly being recognized. PA is shown to largely reduce the risk for many chronic degenerative diseases [22,23]. Measuring habitual physical activity in the free living environment using wearable activity monitors is becoming more popular in the recent years, including in orthopaedics [24]. This technique does not have the disadvantages of the ceiling effect and the highly subjective nature of self-reported questionnaires [25]. Furthermore, an accelerometer-based activity monitor is able to differentiate between the different activity types in daily live [24]. 
Implant wear is also a function of use and thus of patient activity levels. In previous studies, wear of polyethylene acetabular bearings was positively related with patients' activity [26]. Studies in patients with a MoM arthroplasty also showed that intense exercise events can temporarily raise the metal ion concentrations [27-30]. Therefore it is hypothesised that daily habitual physical activity levels of patients with a MoM hip prosthesis are positively correlated with cobalt and chromium ion concentrations. This is the first study in literature studying the relation between metal ion concentrations and different types of physical activity (qualitative and quantitative parameters) and in patients with metal-on-metal hip arthroplasty using activity monitors.

\section{Methods}

A cohort study was conducted of patients with any type of MoM bearing hip prosthesis; resurfacing, Large Head MoM (LHMoM) modular total hip replacements, both unilateral and bilateral, implanted in our hospital between August 2001 and October 2012. The majority of subjects were operated and recruited in the years 2006 to 2009, when the popularity of the procedure was highest. Exclusion criteria were dementia, inactivity due to paralysis or paresis, and surgery in the past year that influenced physical activity levels.

In 220 patients, a total of 256 MoM hips were implanted, 182 resurfacing and 74LHMoM. At follow-up time, ten patients had passed away due to causes that were unrelated to the procedure or unknown (Table I). Revision surgery had already been performed in 22 patients and was planned in two patients (Table II). A total of 63 patients gave informed consent for the study. One measurement failed. Finally, data of 62 patients with 71 MoM hip arthroplasties were used for analysis (Figure 1).

Table I. Causes of Death $(n=10)$

\begin{tabular}{ll}
\hline Causes & Number \\
\hline Unknown & $5(50 \%)$ \\
Pneumonia & $3(30 \%)$ \\
Malignancy & $1(10 \%)$ \\
Bleeding & $1(10 \%)$ \\
\hline
\end{tabular}


Table II. Reasons for Revision $(n=26)$

\begin{tabular}{ll}
\hline Causes & Number \\
\hline Fracture & $7(25.9 \%)$ \\
Symptomatic MoM & $5(18.5 \%)$ \\
Impingement & $4(14.8 \%)$ \\
Unknown & $4(14.8 \%)$ \\
Cup Loosening & $3(11.1 \%)$ \\
Femoral Loosening & $1(3.7 \%)$ \\
Dislocation & $1(3.7 \%)$ \\
ALVAL & $1(3.7 \%)$ \\
High metal ion concentrations & $1(3.7 \%)$ \\
\hline
\end{tabular}

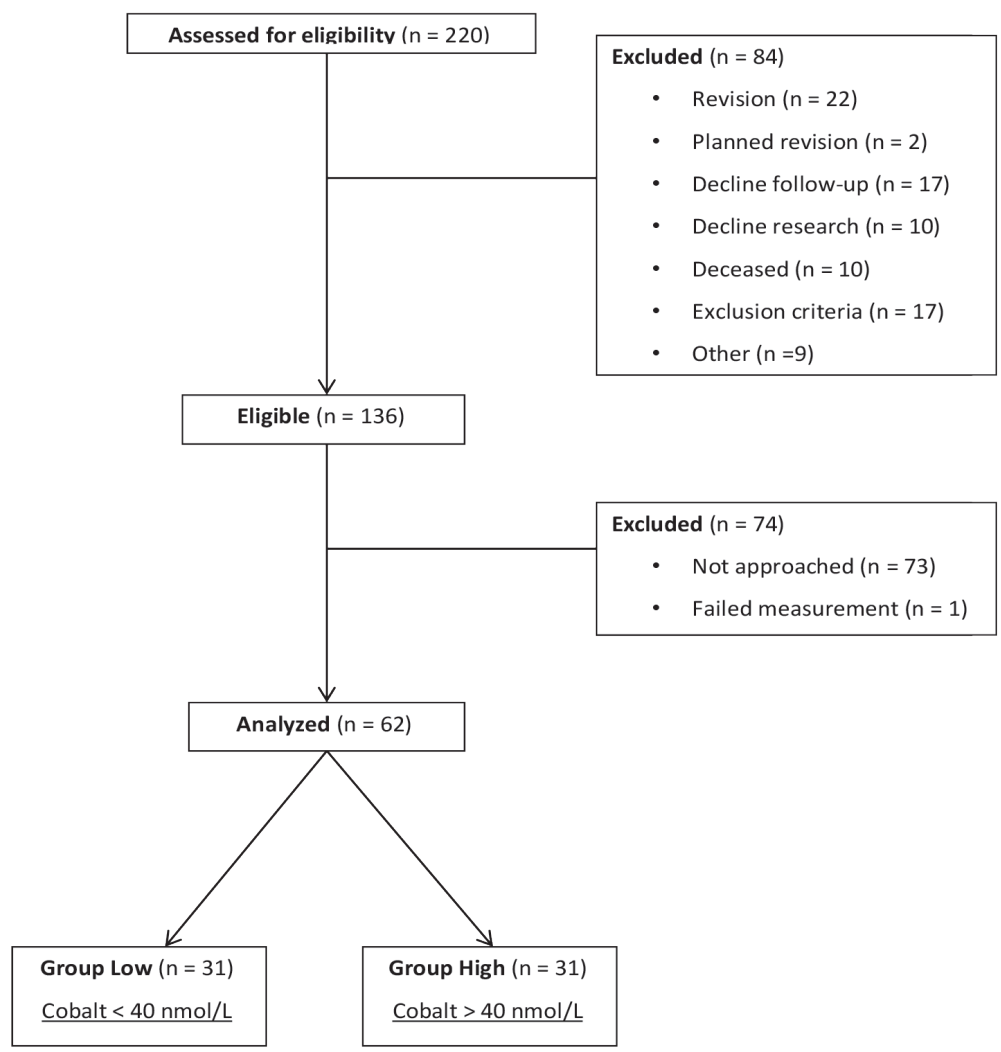

Figure 1. Diagram of the number of patients enrolled and analyzed in this study. There were two patients with a revision on one side and a reason for exclusion. Also there was one patient with a revision on one side, who did match the inclusion criteria contralaterally. 
Patients' physical activity levels were assessed between October 2012 and December 2016 using anaccelerometer-based activity monitor. The implants consisted of both resurfacings and LHMoM modular total hip replacements from the manufacturers Zimmer (Durom, Warsaw, Indiana, USA) $(n=25)$, Biomet (Recap and Mallory Head, Warsaw, Indiana, USA) $(\mathrm{n}=20)$ and Corin (Cormet, Cirencester, United Kingdom) $(n=26)$. The whole patient population measured a mean age of $60.8 \pm 9.3$ years at surgery and a follow-up of $6.4 \pm 1.4$ years. Baseline characteristics for the whole group and for the subgroups are presented in Table III.

This study was performed in compliance with the 1975 Declaration of Helsinki, as revised in 2000, was studied and approved by the IRB (METC Zuyd, Heerlen, the Netherlands, IRB Nr. 10N72) and conducted in accordance with the guidelines for Good Clinical Practice (GCP).

Table III. Baseline characteristics. Numbers [proportions] and Mean [range]

\begin{tabular}{|c|c|c|c|c|}
\hline \multirow{2}{*}{ Total Group } & & \multicolumn{3}{|c|}{ Subgroup Analysis } \\
\hline & & Cobalt $<40 \mathrm{nmol} / \mathrm{L}$ & Cobalt $>40 \mathrm{nmol} / \mathrm{L}$ & p-value \\
\hline $\begin{array}{l}\text { Number } \\
\text { of subjects }\end{array}$ & 62 & 31 & 31 & $\mathrm{x}$ \\
\hline $\begin{array}{l}\text { Gender } \\
M / F\end{array}$ & $\begin{array}{c}36 / 26 \\
{[58 \% / 42 \%]}\end{array}$ & $\begin{array}{c}22 / 9 \\
{[71 \% / 29 \%]}\end{array}$ & $\begin{array}{c}14 / 17 \\
{[45 \% / 55 \%]}\end{array}$ & .077 \\
\hline $\begin{array}{l}\text { Prosthesis } \\
\text { resurfacing/LHMoM }\end{array}$ & $\begin{array}{c}40 / 22 \\
{[65 \% / 35 \%]}\end{array}$ & $\begin{array}{c}26 / 5 \\
{[84 \% / 16 \%]}\end{array}$ & $\begin{array}{c}14 / 17 \\
{[45 \% / 55 \%]}\end{array}$ & $<.001^{*}$ \\
\hline $\begin{array}{l}\text { Side } \\
\text { uni-/bilateral }\end{array}$ & $\begin{array}{c}53 / 9 \\
{[85 \% / 15 \%]}\end{array}$ & $\begin{array}{c}30 / 1 \\
{[97 \% / 3 \%]} \\
\end{array}$ & $\begin{array}{c}23 / 8 \\
{[74 \% / 26 \%]}\end{array}$ & .424 \\
\hline $\begin{array}{l}\text { BMI at OR } \\
\text { in } \mathrm{kg} / \mathrm{m}^{2}\end{array}$ & $\begin{array}{c}27.6 \pm 3.8 \\
{[20.2-37.9]}\end{array}$ & $\begin{array}{c}27.5 \pm 3.6 \\
{[21.4-37.9]}\end{array}$ & $\begin{array}{c}27.7 \pm 4.1 \\
{[20.2-36.9]}\end{array}$ & .803 \\
\hline $\begin{array}{l}\text { Age at OR } \\
\text { in years }\end{array}$ & $\begin{array}{c}60.8 \pm 9.3 \\
{[41.6-78.1]}\end{array}$ & $\begin{array}{c}56.2 \pm 5.9 \\
{[43.0-66.3]}\end{array}$ & $\begin{array}{c}64.6 \pm 9.8 \\
{[41.6-78.1]}\end{array}$ & $<.001^{*}$ \\
\hline $\begin{array}{l}\text { Follow-Up } \\
\text { in years }\end{array}$ & $\begin{array}{c}6.3 \pm 1.4 \\
{[3.7-9.6]}\end{array}$ & $\begin{array}{c}6.8 \pm 1.4 \\
{[4.9-9.6]}\end{array}$ & $\begin{array}{c}5.9 \pm 1.3 \\
{[3.7-9.1]}\end{array}$ & $.010^{*}$ \\
\hline $\begin{array}{l}\text { Cobalt } \\
\text { in } \mathrm{nmol} / \mathrm{L}\end{array}$ & $\begin{array}{c}112.4 \pm 137.9 \\
{[9-833]}\end{array}$ & $\begin{array}{c}25.5 \pm 8.8 \\
{[9-38]}\end{array}$ & $\begin{array}{c}183.8 \pm 152.8 \\
{[41-833]}\end{array}$ & $<.001^{*}$ \\
\hline $\begin{array}{l}\text { Chromium } \\
\text { in nmol/L }\end{array}$ & $\begin{array}{c}107.8 \pm 139.9 \\
{[6-592]}\end{array}$ & $\begin{array}{c}36.9 \pm 19,9 \\
{[6-88]}\end{array}$ & $\begin{array}{c}165.6 \pm 167.5 \\
{[15-592]}\end{array}$ & $<.001^{*}$ \\
\hline $\begin{array}{l}\text { Cup Size } \\
\text { in } \mathrm{mm}\end{array}$ & $\begin{array}{c}54.5 \pm 3.6 \\
{[48-62]} \\
\end{array}$ & $\begin{array}{c}55.3 \pm 3.3 \\
{[48-62]}\end{array}$ & $\begin{array}{c}53.9 \pm 3.7 \\
{[48-62]}\end{array}$ & .116 \\
\hline $\begin{array}{l}\text { Inclination } \\
\text { in degree }\end{array}$ & $\begin{array}{l}51.1 \pm 7.7 \\
{[29-68]}\end{array}$ & $\begin{array}{c}50.4 \pm 7.8 \\
{[38-64]}\end{array}$ & $\begin{array}{c}51.7 \pm 7.7 \\
{[29-68]}\end{array}$ & .493 \\
\hline
\end{tabular}

* Significance $\leq 0.05$ 
The most recent radiographs (Standing Pelvic Anterior-Posterior (AP)) were used to determine the inclination angle of the acetabular cup. The cup inclination angle was defined as the angle between the line connecting the ischial tuberosity and the line connecting the vertices of the metal cup [31]. Cup anteversion angles were not determined for this study.

Metal concentrations were measured according to Dutch guidelines for MoM hip arthroplasty as follows: vena punction was performed by disposing the first $5 \mathrm{~mL}$ and thereafter the blood was collected a special trace elements serum tube (BD Vacutainer $368380^{\circledR}$ Trace Element, Franklin Lakes, New Jersey, United States). The collected material was stored in a refrigerator at a temperature of $2^{\circ}$ to $8^{\circ} \mathrm{C}$ and shipped to a specialized laboratory within a week at room temperature. Cobalt and chromium concentrations were determined by inductively coupled plasma mass spectrometry (ICP-MS) using the NexION ${ }^{\circledR} 300 \mathrm{X}$ ICP-MS (PerkingElmer, Waltham, Massachusetts, United States). According to the Dutch Orthopaedic Society (NOV) guidelines for MoM prostheses, a cobalt ion concentration of $<40 \mathrm{nmol} / \mathrm{L}$ is considered normal and $>40 \mathrm{nmol} / \mathrm{L}$ is considered increased, and patients were grouped accordingly for comparison [32].

Physical activity of subjects was measured during waking hours for four consecutive days in daily living using an acceleration-based activity monitor, which was attached to the non-affected upper leg, or least affected upperleg in case of bilateral hip arthroplasty, using a sticker. The four day measurement period was chosen based on evidence that an individual's habitual physical activity pattern can be representatively characterized by measuring activity for three to four days $[33,34]$. The activity monitor used (USB Accelerometer, ModelX8M-3, Gulf Coast Data Concepts LLC, Waveland, Mississippi, United States) comprises a 3-axis (14-bit, $\pm 8 \mathrm{~g}, 50 \mathrm{~Hz}$ ) accelerometer and a 3-axis magnetometer. Data collected by means of the activity monitor was analysed in MATLAB (MATLAB R2010a, The Mathworks Inc., Natick, Massachusetts, United States) using previously validated algorithms [35]. Physical activity data per day were averaged over the four measurement days. Outcome consisted of quantitative parameters (time spent walking and cycling in seconds, the number of steps and sit-stand transfers) and qualitative parameters (cadence in steps per minute and high-intensity peak counts in numbers). This technique was clinically validated by Lipperts et al. and Van Laarhoven et al. in healthy subjects and subjects who had undergone unilateral total joint arthroplasty, using video observation as the gold standard. The studies showed an excellent accuracy $(>97 \%)$ in determining activity levels with this technique in a semi-free setting $[35,36]$. Schotanus et al. used the same method to show, that patients 
who followed an enhanced recovery pathway or an outpatient surgery pathway after total knee arthroplasty recovered equally well as patients who followed a conventional discharge protocol [37-40].

\section{Statistical Analysis}

The hypothesized relationship between blood ion levels and physical activity was investigated using Pearson's R correlations. In addition, we compared subgroups with low cobalt ion concentrations $(<40 \mathrm{nmol} / \mathrm{L})$ and high cobalt ion concentrations ( $>40 \mathrm{nmol} / \mathrm{L}$ ) as well as subgroups with unilateral and bilateral prostheses using the independent samples T-test. For all analyses, a $\mathrm{p}$-value was considered statistically significant at $\mathrm{p} \leq 0.05$. Results are presented as mean $\pm \mathrm{SD}$ and/or range. Proportions (\%) are shown if necessary. Sample size was prospectively calculated for testing a weak to moderate correlation (Pearson's $R \geq 0.40$ ) and common $\alpha=0.05$ and $\beta=$ 0.20 values requiring an inclusion of $n=47$ subjects. Multivariable linear regression analysis was performed to adjust for significant differences at baseline. Data were analysed using IBM SPSS Statistics 22 (International Business Machines Corporation, Armonk, New York, United States).

\section{Results}

None of the physical activity parameters showed any correlation with cobalt ion concentrations (Table IV). Pearson's correlation showed a weak, but significant, correlation between cobalt ion concentration and age at surgery $(R=0.284$, $p=0.017$ ). As expected, there was a high correlation between cobalt and chromium ion concentrations $(R=0.833)$. In addition, we calculated a Pearson's $R$ correlation in patients with $>10.000$ steps $(n=10)$. Pearson's $R$ was $0.202(p=.575)$ for the correlation between steps and cobalt ion concentration.

Subjects with bilateral prostheses showed significantly $(p=.009)$ higher metal ion concentrations (185 \pm 107 for cobalt) than subjects with a unilateral prosthesis ( $88 \pm$ 139) (Table V). The mean BMI was $27.6 \pm 3.8 \mathrm{~kg} / \mathrm{m}^{2}$, mean cup size was $54.5 \pm 3.6 \mathrm{~mm}$ and mean inclination was $51.1 \pm 7.7^{\circ}$. These parameters did not differ significantly between subgroups with low and high cobalt concentration. Subjects walked for a mean $5404 \pm 2472$ seconds per day, which corresponds to $90.1 \pm 41.2$ minutes. Daily walking time did not differ significantly between subgroups with low and high cobalt ion concentrations ( $5229 \pm 1956$ vs $5547 \pm 2840$ ). A mean of $6694 \pm 3011$ daily steps were taken; the subgroup with low cobalt ion concentrations took $6909 \pm 2989$ steps and the subgroup with high cobalt ion concentrations took $6518 \pm 3057$ steps. 
The low cobalt ion group scored higher on the average daily cycling time (314 \pm 553 sec vs $256 \pm 518 \mathrm{sec}$ ), but this difference was not statistically significant. Also,the low cobalt ion group's daily average values for cadence ( $98.5 \pm 6.6$ vs $95.1 \pm 11.9$ steps/ min) and number of high intensity peaks ( $88.1 \pm 268.3$ vs $69.9 \pm 103.6)$ were higher, but these differenes were not significant either (Table VI).

Table IV. Pearson's R correlation for cobalt concentrations

\begin{tabular}{lcc}
\hline & Pearson's R & p-value \\
\hline Gender & .170 & .155 \\
BMI at OR & -.044 & .782 \\
Age at OR & .284 & $.017^{*}$ \\
Follow-Up & -.205 & .086 \\
Chromium & .833 & $.000^{*}$ \\
Cup size & -.039 & .747 \\
Inclination & .001 & .990 \\
Time Walk & .092 & .447 \\
Time Cycling & .227 & .057 \\
Cadence & -.202 & .091 \\
Steps & -.035 & .774 \\
Sit-Stand Transfers & -.212 & .075 \\
High Intensity & .022 & .856 \\
\hline
\end{tabular}

* Significance $\leq 0.05$

Table V. Metal ion concentrations. Mean \pm SD [range]

\begin{tabular}{lccc}
\hline & Unilateral & Bilateral & p-value \\
\hline $\begin{array}{l}\text { Number } \\
\text { of subjects }\end{array}$ & 53 & 9 & \\
\hline Cobalt & $87.8 \pm 139.4$ & $184.8 \pm 106.5$ & $.009^{*}$ \\
in nmol/L & {$[9-833]$} & {$[38-322]$} & $.018^{*}$ \\
\hline Chromium & $78.6 \pm 114.0$ & $190.5 \pm 174.1$ & \\
in nmol/L & {$[6-592]$} & {$[52-557]$} & .04 \\
\hline
\end{tabular}

* Significance $\leq 0.05$

\section{Discussion}

This study aimed to determine the relationship between habitual physical activity and metal ion concentrations in patients with a MoM hip arthroplasty, supposing that patient activity might be a factor contributing to increased metal ion concentrations. The main finding of the study was that higher activity levels 
in daily live were not directly associated with increased metal ion concentrations. In this study no correlations were found between cobalt ion concentrations and the habitual level of time spent walking, time spent cycling, the number of steps and the number of sit-stand transfers in daily live. Also, no significant differences in physical activity were found between subgroups with low and high cobalt ion concentrations. The daily step count of $6694 \pm 3011$ steps found in this study is comparable to that of healthy people of the same age, showing that this population with an MoM prosthesis is normally active [41]. Thus, the data suggest that MoM hip arthroplasty does not limit patients with regard to habitual walking activities.

Table VI. Activity Monitoring adjusted for age at surgery, follow-up time and type of prosthesis. Mean \pm SD [range].

\begin{tabular}{|c|c|c|c|c|}
\hline \multirow{2}{*}{ Total Group } & & \multicolumn{3}{|c|}{ Subgroup Analysis } \\
\hline & & Cobalt $<40 \mathrm{nmol} / \mathrm{L}$ & Cobalt $>40 \mathrm{nmol} / \mathrm{L}$ & p-value \\
\hline $\begin{array}{l}\text { Time Walking } \\
\text { in seconds }\end{array}$ & $\begin{array}{c}5403 \pm 2472 \\
{[1646-17126]}\end{array}$ & $\begin{array}{c}5229 \pm 1965 \\
{[1646-9288]}\end{array}$ & $\begin{array}{c}5547 \pm 2840 \\
{[2262-17126]}\end{array}$ & .209 \\
\hline $\begin{array}{l}\text { Time Cycling } \\
\text { in seconds }\end{array}$ & $\begin{array}{l}282 \pm 531 \\
{[0-2040]}\end{array}$ & $\begin{array}{l}314 \pm 553 \\
{[0-1940]}\end{array}$ & $\begin{array}{l}256 \pm 518 \\
{[0-2040]}\end{array}$ & .846 \\
\hline $\begin{array}{l}\text { Cadence } \\
\text { in steps/min }\end{array}$ & $\begin{array}{l}96.7 \pm 9.9 \\
{[66-115]}\end{array}$ & $\begin{array}{l}98.5 \pm 6.6 \\
{[81-112]}\end{array}$ & $\begin{array}{l}95.1 \pm 11.9 \\
{[66-115]}\end{array}$ & .472 \\
\hline $\begin{array}{l}\text { Steps } \\
\text { number }\end{array}$ & $\begin{array}{c}6694 \pm 3011 \\
{[1712-15443]}\end{array}$ & $\begin{array}{c}6909 \pm 2989 \\
{[1712-14637]}\end{array}$ & $\begin{array}{c}6518 \pm 3057 \\
{[2404-15443]}\end{array}$ & .568 \\
\hline $\begin{array}{l}\text { Sit-Stand } \\
\text { number }\end{array}$ & $\begin{array}{c}37.6 \pm 13.5 \\
{[10-68]}\end{array}$ & $\begin{array}{c}37.3 \pm 11.7 \\
{[20-61]}\end{array}$ & $\begin{array}{c}37.8 \pm 14.9 \\
{[10-68]}\end{array}$ & .129 \\
\hline $\begin{array}{l}\text { High Intensity } \\
\text { Number }>5.0 \mathrm{~g}\end{array}$ & $\begin{array}{c}78.4 \pm 197.5 \\
{[0-1406]}\end{array}$ & $\begin{array}{c}88.1 \pm 268.3 \\
{[0-1406]}\end{array}$ & $\begin{array}{c}69.9 \pm 103.6 \\
{[0-408]}\end{array}$ & .981 \\
\hline
\end{tabular}

* Significance $\leq 0.05$

Our finding that metal ion concentrations were not correlated with activity levels seem to contradict previous studies that showed that intense exercise can temporarily raise the metal ion concentrations. Gleizes et al. found increased cobalt concentrations directly after a one-hour treadmill test in a two-patientstudy [27]. Heisel et al. studied the relationship between exercise and metal ion concentrations in 7 patients at an average follow-up of 17.3 months postoperatively. They found that a mean increase in activity of $28 \% \pm 6 \%$ during a high-intensity activity week was associated with a mean decrease of $2.7 \% \pm 4.7 \%$ in serum cobalt and a mean increase in chromium concentrations of $2.0 \% \pm 3.0$. A mean increase of $1621 \% \pm 265 \%$ in activity on a treadmill test (acute activity) was associated with a mean increase of $3.0 \% \pm 3.6 \%$ in serum cobalt and a mean increase in chromium 
concentrations of $0.8 \% \pm 1.7 \%$. However, the authors noted that the values were within the variability for the measurement accuracy of these tests, so none of the differences found were significant [30]. Khan et al. did show that exercise causes a significant and immediate but temporary rise in metal ion concentrations: $13 \%$ in serum cobalt and $11 \%$ in serum chromium after one hour of exercise in 15 subjects [28]. Another study by Khan et al. showed that physical exercise raises the mean cobalt ion levels by $4.5 \mathrm{nmol} / \mathrm{L}(8 \%)$ within one hour of completing one hour of exercise. A longer postoperative period did not decrease the baseline cobalt ion concentration, and patients with a longer follow-up had a smaller rise in cobalt levels in response to exercise [29].

Our findings that metal concentrations are not correlated with physical activity appear to be confirmed by a case study of DeHaan et al., who reported on a triathlete with a resurfacing prosthesis and found no significant differences in cobalt blood concentrations before and after an 11-hour triathlon [42]. However, in this case study, blood samples were collected the day after the exercise, which means that it is possible that the metal concentrations had returned to their pre-exercise levels.

The above mentioned studies all included a small number of subjects ( $1-21)$ and showed a temporary increase in metal ion concentrations after a short-termed exercise with a cobalt ion concentration measurement immediately after the exercise. In contrast, we studied habitual physical activity levels in daily live for four consecutive days in 62 patients and found no correlations between metal ion concentrations and parameters of physical activity.This is in contrast to a recent study by Hjorth et al., which found a significant correlation between a physical activity measure and chromium ion concentrations, but not with cobalt ion concentrations [43]. Hjorth et al. used the same approach as the present study, but defined their own proprietary parameter, which may therefore be not comparable to the one used in this and other studies $[35,36]$. In the study by Hjorth et al., all activity was pooled into one parameter, which was defined as the sum of walking, cycling and high intensity activity measurements and expressed as a percentage of the total wearing time of the activity monitor instead of absolute numbers, as we did in this study. The surprising result of Hjorth et al. was that only chromium ion, but not cobalt ion concentrations are correlated with physical activity levels, which could be an indicator for a rather small effect size of physical activity levels on metal ion levels. Another explanation why Hjorth et al. identified a correlation between physical activity and chromium ion levels may be the fact that they assessed a significant part of a rather heterogenous patient population (e.g. 0.5 to 21 years of follow-up) during the "running-in" phase with highly transient metal ion 
levels, which is a strong confounder that we deliberately excluded from analysis in our study.

Our findings show no correlation between cadence and cobalt ion concentration, which is in contrast with a study by Senden et al., who showed that a higher cadence was associated with higher polyethylene wear in patients after hip arthroplasty with a metal-on-polyethylene surface [44]. One would expect that a higher habitual walking cadence in MoM would also result in a higher wear rate, expressed by higher metal ion concentrations in the blood. However, in our study, the subgroup with low cobalt ion concentrations showed a (non-significant) trend towards higher cadence compared with the subgroup with high cobalt ion concentrations. These different findings may be due to the differences in the wear regimes of MoM bearings (dynamic fluid film lubrication) and metal-on-polyethylene surfaces (mixed mode).

The present study also found no significant correlations between cobalt ion concentrations and gender, although mean cobalt ion concentration seemed higher in women. In addition, we found no correlations between cobalt ion concentrations and BMI, follow-up, cupsize or acetabular inclination angle. As stated by Maurer-Ertl et al. and Langton et al., larger resurfacing implants seem to be more resistant to suboptimal cup position $[2,9]$. This is thought to be due to a thicker fluid film and a greater arc of coverage. However, the study by Maurer-Ertl et al. did not prove this higher resistance, possibly due to the small number of patients included in the study. Also, the design of the implant and the size of the component are factors that influence edge-loading, which disrupts the fluid film lubrication and thus increases wear.

Our finding that cobalt ion concentrations were not correlated with inclination angle are not in line with a study of DeHaan et al., who compared groups with different inclination angles ( $<55$ or $>55$ degree) and showed that steep components had significantly higher metal ion concentrations ( $p=0.003$ for $\mathrm{Co}, \mathrm{p}=0.002$ for $\mathrm{Cr}$ ) [17]. Additionally, Van der Straeten et al. showed that patients with an acetabular component $\geq 50 \mathrm{~mm}$ had $64 \%$ chance of being in a well-functioning group, compared to $38 \%$ for a $\leq 50 \mathrm{~mm}$ component [18]. Our cohort consisted of subjects with a mean cupsize of $54.5 \pm 3.6$ [48 - 62] and only five patients with a 48mm cup, which is slightly below the size threshold previously investigated by van der Straten et al. The mean inclination angle was $51.1 \pm 7.7$ [29-68]. Based on the findings of Grammatopoulos et al., 22 of our subjects were not in their established inclination safezone (45 \pm 10 degree) [45]. Only 1 subject in our cohort had a cup size $<50 \mathrm{~mm}$ and an inclination outside the safezone. In the current study, the risk of increased 
cobalt ion concentrations due to acetabular cup malalignment or a small cup size is therefore limited.

This study does have a number of limitations. Although the calculated sample size of 47 was exceeded, as a first limitation, a weak correlation not tested for may still exist and form part of a highly multifactorial phenomenon. However, in this study, which included patients with a wide range of metal ion concentrations and physical activity levels, even the extremes did not show the hypothesized effect, so that a clinical effect or a trigger to adjust patient behavior regarding physical activity seems unlikely.

A second limitation is that activity monitoring was not performed in close and constant temporal proximity to the ion level measurement. Preferably, both assessments should have been made at the same moment of time. In our study there was a mean interval of $1.4 \pm 0.8$ years between physical activity monitoring and the determination of metal ion concentrations. However, as we intentionally studied habitual physical activity levels and not single peak activity events or exercise regiments, this time difference is expected not to matter, as it is accepted that a 4-day measurement is representative for an individual's general behavior over such a long period of time $[33,34,46]$. In addition, multiple studies show that metal ion concentrations become stable or decline in most hip arthroplasty patients after an initial running-in period of $+/-18$ months [14-16]. In the follow-up of our study we measured these steady-state levels of metal ion concentrations as intended.

A third limitation of the present study is that renal functions were not measured, which may have been relevant because cobalt and chromium ions are excreted by the kidneys $[47,48]$. Well functioning kidneys excrete 80 to $90 \%$ of cobalt ions within days, eliminating $>50 \%$ within 48 hours, and $60 \%$ of chromium ions are eliminated within 8 hours $[49,50]$. Measurements of metal ion concentrations were performed at variable time points during patient follow-up and the time interval to physical activity assessment was not consistent, so that physical activity in the $24 \mathrm{~h}$ prior to blood sampling is not known. Although a highly intense activity may result in temporary peaks of metal ion concentrations, Lainiala et al. did not find any association between metal ion concentrations and mild or moderate renal insufficiency [51].

Another limitation is that this was a cohort study in a rather heterogeneous population, including patients with HRA and LHMoM, both uni- and bilateral, made by multiple manufacturers and thus with different prosthesis designs. Ion release 


\section{Chapter 2}

of these implants may not react in the same intensity to different activity levels, as this may be influenced by e.g. component clearance or by the variable arc of coverage. However, these differences may influence the slope of a relationship, but not its direction. Thus this limitation can be neglected when studying the presence of a correlation between the metal ion concentrations and physical activity levels without aiming to establish a dose-response value.

Finally, a selection bias is possible, because very active patients or more concerned patients may have been more eager to participate in this monitoring study. Further research should focus on a less heterogeneous population and thereby minimizing potentially bias.

\section{Conclusion}

Metal ion concentrations in patients with a MoM hip arthroplasty do not seem to be correlated with physical activity levels as measured in terms of walking and cycling time, walking cadence and number of steps, sit-stand transfers or intensity counts. Thus it seems that every day implant use in normal habitual activities of daily living does not increase metal ion levels and their potentially harmful effects. Apparently, wear of metal implants is too multifactorial and dominated by other factors than activity levels, or else the daily activity types measured are of a low wearing nature. In clinical practice, this study may serve to reassure metal-on-metal patients that it is safe for them to engage in daily activities like walking or cycling for general health benefit without triggering critical wear or ion release. The study also indicates that there is no need to screen highly active patients more frequently. 


\section{References}

1. Hug KT, Watters TS, Vail TP, Bolognesi MP. The withdrawn ASR THA and hip resurfacing systems: how have our patients fared over 1 to 6 years? Clin Orthop Relat Res, 2013. 471(2): p. 430-8.

2. Maurer-ErtI W, Friesenbichler J, Sadoghi P, Pechmann M, Trennheuser M, Leithner A. Metal ion levels in large-diameter total hip and resurfacing hip arthroplasty--preliminary results of a prospective five year study after two years of follow-up. BMC Musculoskelet Disord, 2012. 13: p. 56.

3. Zywiel MG, Sayeed SA, Johnson AJ, Schmalzried TP, Mont MA. State of the art in hard-on-hard bearings: how did we get here and what have we achieved? Expert Rev Med Devices, 2011. 8(2): p. 187-207.

4. Chan FW, Bobyn JD, Medley JB, Krygier JJ, Tanzer M. The Otto Aufranc Award. Wear and lubrication of metal-on-metal hip implants. Clin Orthop Relat Res, 1999(369): p. 10-24.

5. Wilkinson JM. Metal-on-metal hip prostheses: where are we now? BMJ, 2012. 345: p. e7792.

6. Berend KR, Morris MJ, Adams JB, Lombardi AV Jr. Metal-on-metal hip arthroplasty: going, going, gone... - affirms. J Bone Joint Surg Br, 2012. 94(11 Suppl A): p. 75-7.

7. Levy YD, Ezzet KA. Poor short term outcome with a metal-on-metal total hip arthroplasty. J Arthroplasty, 2013. 28(7): p. 1212-7.

8. Smith AJ, Dieppe P, Howard PW, Blom AW; National Joint Registry for England and Wales. Failure rates of metal-on-metal hip resurfacings: analysis of data from the National Joint Registry for England and Wales. Lancet, 2012. 380(9855): p. 1759-66.

9. Langton DJ, Jameson SS, Joyce TJ, Hallab NJ, Natu S, Nargol AV. Early failure of metal-on-metal bearings in hip resurfacing and large-diameter total hip replacement: A consequence of excess wear. J Bone Joint Surg Br, 2010. 92(1): p. 38-46.

10. Langton DJ, Joyce TJ, Jameson SS et al. Adverse reaction to metal debris following hip resurfacing: the influence of component type, orientation and volumetric wear. J Bone Joint Surg Br, 2011. 93(2): p. 164-71.

11. Hart AJ, Satchithananda K, Liddle AD et al. Pseudotumors in association with well-functioning metal-on-metal hip prostheses: a case-control study using three-dimensional computed tomography and magnetic resonance imaging. J Bone Joint Surg Am, 2012. 94(4): p. 317-25.

12. Glyn-Jones S, Pandit H, Kwon YM, Doll H, Gill HS, Murray DW. Risk factors for inflammatory pseudotumour formation following hip resurfacing. J Bone Joint Surg Br, 2009. 91(12): p. 1566-74.

13. Bosker BH, Ettema HB, Boomsma MF, Kollen BJ, Maas M, Verheyen CC. High incidence of pseudotumour formation after large-diameter metal-on-metal total hip replacement: a prospective cohort study. J Bone Joint Surg Br, 2012. 94(6): p. 755-61.

14. Daniel J, Ziaee H, Pradhan C, Pynsent PB, McMinn DJ. Blood and urine metal ion levels in young and active patients after Birmingham hip resurfacing arthroplasty: four-year results of a prospective longitudinal study. J Bone Joint Surg Br, 2007. 89(2): p. 169-73.

15. deSouza RM, Parsons NR, Oni T, Dalton P, Costa M, Krikler S. Metal ion levels following resurfacing arthroplasty of the hip: serial results over a ten-year period. J Bone Joint Surg Br, 2010. 92(12): p. 1642-7.

16. Van Der Straeten C, Van Quickenborne D, De Roest B, Calistri A, Victor J, De Smet K. Metal ion levels from well-functioning Birmingham Hip Resurfacings decline significantly at ten years. Bone Joint J, 2013. 95-B(10): p. 1332-8.

17. DeHaan R, Pattyn C, Gill HS, Murray DW, Campbell PA, De Smet K. Correlation between inclination of the acetabular component and metal ion levels in metal-on-metal hip resurfacing replacement. J Bone Joint Surg Br, 2008. 90(10): p. 1291-7.

18. Van Der Straeten C, Grammatopoulos G, Gill HS, Calistri A, Campbell P, De Smet KA. The 2012 Otto Aufranc Award: The interpretation of metal ion levels in unilateral and bilateral hip resurfacing. Clin Orthop Relat Res, 2013. 471(2): p. 377-85.

19. Nassif NA, Nawabi DH, Stoner K, Elpers M, Wright T, Padgett DE. Taper design affects failure of large-head metal-on-metal total hip replacements. Clin Orthop Relat Res, 2014. 472(2): p. 564-71.

20. Silverman EJ, Ashley B, Sheth NP. Metal-on-metal total hip arthroplasty: is there still a role in 2016? Curr Rev Musculoskelet Med, 2016. 9(1): p. 93-6. 
21. Amstutz HC, Le Duff MJ, Bhaurla SK. Risk factors for wear-related failures after hip resurfacing in patients with a low contact patch to rim distance. Bone Joint J, 2017. 99-B(7): p. 865-871.

22. Westerterp KR. Reliable assessment of physical activity in disease: an update on activity monitors. Curr Opin Clin Nutr Metab Care, 2014. 17(5): p. 401-6.

23. Lindemann U, Zijlstra W, Aminian $\mathrm{K}$ et al. Recommendations for standardizing validation procedures assessing physical activity of older persons by monitoring body postures and movements. Sensors (Basel), 2014. 14(1): p. 1267-77.

24. Verlaan L, Bolink SA, Van Laarhoven SN et al. Accelerometer-based Physical Activity Monitoring in Patients with Knee Osteoarthritis: Objective and Ambulatory Assessment of Actual Physical Activity During Daily Life Circumstances. Open Biomed Eng J, 2015. 9: p. 157-63.

25. Terwee CB, Bouwmeester W, van Elsland SL, de Vet HC, Dekker J. Instruments to assess physical activity in patients with osteoarthritis of the hip or knee: a systematic review of measurement properties. Osteoarthritis Cartilage, 2011. 19(6): p. 620-33.

26. Schmalzried TP, Shepherd EF, Dorey FJ et al. The John Charnley Award. Wear is a function of use, not time. Clin Orthop Relat Res, 2000(381): p. 36-46.

27. Gleizes V, Poupon J, Lazennec JY, Chamberlin B, Saillant G. [Value and limits of determining serum cobalt levels in patients with metal on metal articulating prostheses]. Rev Chir Orthop Reparatrice Appar Mot, 1999. 85(3): p. 217-25.

28. Khan M, Takahashi T, Kuiper JH, Sieniawska CE, Takagi K, Richardson JB. Current in vivo wear of metal-on-metal bearings assessed by exercise-related rise in plasma cobalt level. J Orthop Res, 2006. 24(11): p. 2029-35.

29. Khan M, Kuiper JH, Richardson JB. The exercise-related rise in plasma cobalt levels after metalon-metal hip resurfacing arthroplasty. J Bone Joint Surg Br, 2008. 90(9): p. 1152-7.

30. Heisel C, Silva M, Skipor AK, Jacobs JJ, Schmalzried TP. The relationship between activity and ions in patients with metal-on-metal bearing hip prostheses. J Bone Joint Surg Am, 2005. 87(4): p. 781-7.

31. Kalteis T, Handel M, Herold T, Perlick L, Paetzel C, Grifka J. Position of the acetabular cup -accuracy of radiographic calculation compared to CT-based measurement. Eur J Radiol, 2006. 58(2): p. 294-300.

32. Verhaar JA. [The hard lesson of metal-on-metal hip implants]. Ned Tijdschr Geneeskd, 2012. 156(42): p. A5564.

33. Mâsse LC, Fuemmeler BF, Anderson CB et al. Accelerometer data reduction: a comparison of four reduction algorithms on select outcome variables. Med Sci Sports Exerc, 2005. 37(11 Suppl): p. S544-54.

34. Kang $M$, Hart PD, Kim Y. Establishing a threshold for the number of missing days using $7 \mathrm{~d}$ pedometer data. Physiol Meas, 2012. 33(11): p. 1877-85.

35. Lipperts M, van Laarhoven S, Senden R, Heyligers I, Grimm B. Clinical validation of a body-fixed $3 \mathrm{D}$ accelerometer and algorithm for activity monitoring in orthopaedic patients, Journal of Orthopaedic Translation, 2017, 11: p19-29

36. van Laarhoven SN, Lipperts M, Bolink SA, Senden R, Heyligers IC, Grimm B. Validation of a novel activity monitor in impaired, slow-walking, crutch-supported patients. Ann Phys Rehabil Med, 2016. 59(5-6): p. 308-313.

37. Schotanus MGM, Bemelmans YFL, Grimm B, Heyligers IC, Kort NP. Physical activity after outpatient surgery and enhanced recovery for total knee arthroplasty. Knee Surg Sports Traumatol Arthrosc, 2017. 25(11): p. 3366-3371.

38. van Rooij WM, Senden R, Heyligers IC, Cuppen PM, van Hemert WL, Grimm B. Physical functioning of low back pain patients: perceived physical functioning and functional capacity, but not physical activity is affected. Disabil Rehabil. 2015;37(24):2257-63.

39. Daugaard R, Tjur M, Sliepen M, Lipperts M, Grimm B, Mechlenburg I. Are patients with knee osteoarthritis and patients with knee joint replacement as physically active as healthy persons? J OrthopTranslat. 2018 Apr 3;14:8-15

40. Sliepen M, Mauricio E, Lipperts M, Grimm B, Rosenbaum D. Objective assessment of physical activity and sedentary behaviour in knee osteoarthritis patients - beyond daily steps and total sedentary time. BMC MusculoskeletDisord. 2018 Feb 23;19(1):64. 
41. Tudor-Locke C, Craig CL, Aoyagi Y et al. How many steps/day are enough? For older adults and special populations. Int J Behav Nutr Phys Act, 2011. 8: p. 80

42. De Haan R, Campbell P, Reid S, Skipor AK, De Smet K. Metal ion levels in a triathlete with a metal-on-metal resurfacing arthroplasty of the hip. J Bone Joint Surg Br, 2007. 89(4): p. 538-41.

43. Hjorth MH, Mechlenburg I, Soballe K, Jakobsen SS, Roemer L, Stilling M.Physical Activity Is Associated With the Level of Chromium but Not With Changes in Pseudotumor Size in Patients With Metal-on-Metal Hip Arthroplasty. J Arthroplasty. 2018 Apr 30. pii: S0883-5403(18)304212. doi: 10.1016/j.arth.2018.04.039

44. Senden R, Lipperts M, Grimm B. Patient Activity and in-vivo Polyethylene Wear in Total Hip Arthroplasty [abstract], in ORS Annual Meeting. 2013: San Antonio, Texas, United States of America. 26-29 January 2013.

45. Grammatopoulos G, Pandit H, Glyn-Jones S et al. Optimal acetabular orientation for hip resurfacing. J Bone Joint Surg Br, 2010. 92(8): p. 1072-8.

46. Vissers MM, de Groot IB, Reijman M, Bussmann JB, Stam HJ, Verhaar JA. Functional capacity and actual daily activity do not contribute to patient satisfaction after total knee arthroplasty. BMC Musculoskelet Disord, 2010. 11: p. 121.

47. Afolaranmi GA, Tettey J, Meek RMD, Grant MH. Release of chromium from orthopaedic arthroplasties. Open Orthopaedics J. 2008; 2: 10-18

48. Barceloux DG. Chromium. Clin Toxicol Toxicol.1999; 37(2): 173-194

49. Keegan GM, Learmonth ID, Case CP. A systematic comparison of the actual, potential, and theoretical health effects of cobalt and chromium exposures from industry and surgical implants. Crit Rev Toxicol. 2008; 38: 645-674

50. Newton AW, Ranganath L, Armstrong C, Peter V, Roberts NB. Differential distribution of cobalt, chromium, and nickel between whole blood, plasma and urine in patients after metal-onmetal (MoM) hip arthroplasty. J Orthop Res. 2012; 30: 1640-1646

51. Lainiala $O$, Reito A, Jämsä $P$, Eskelinen A. Mild or moderate renal insufficiency does not increase circulating levels of cobalt and chromium in patients with metal-on-metal hip arthroplasty. Bone Joint J. 2017 Sep;99-B(9):1147-1152 


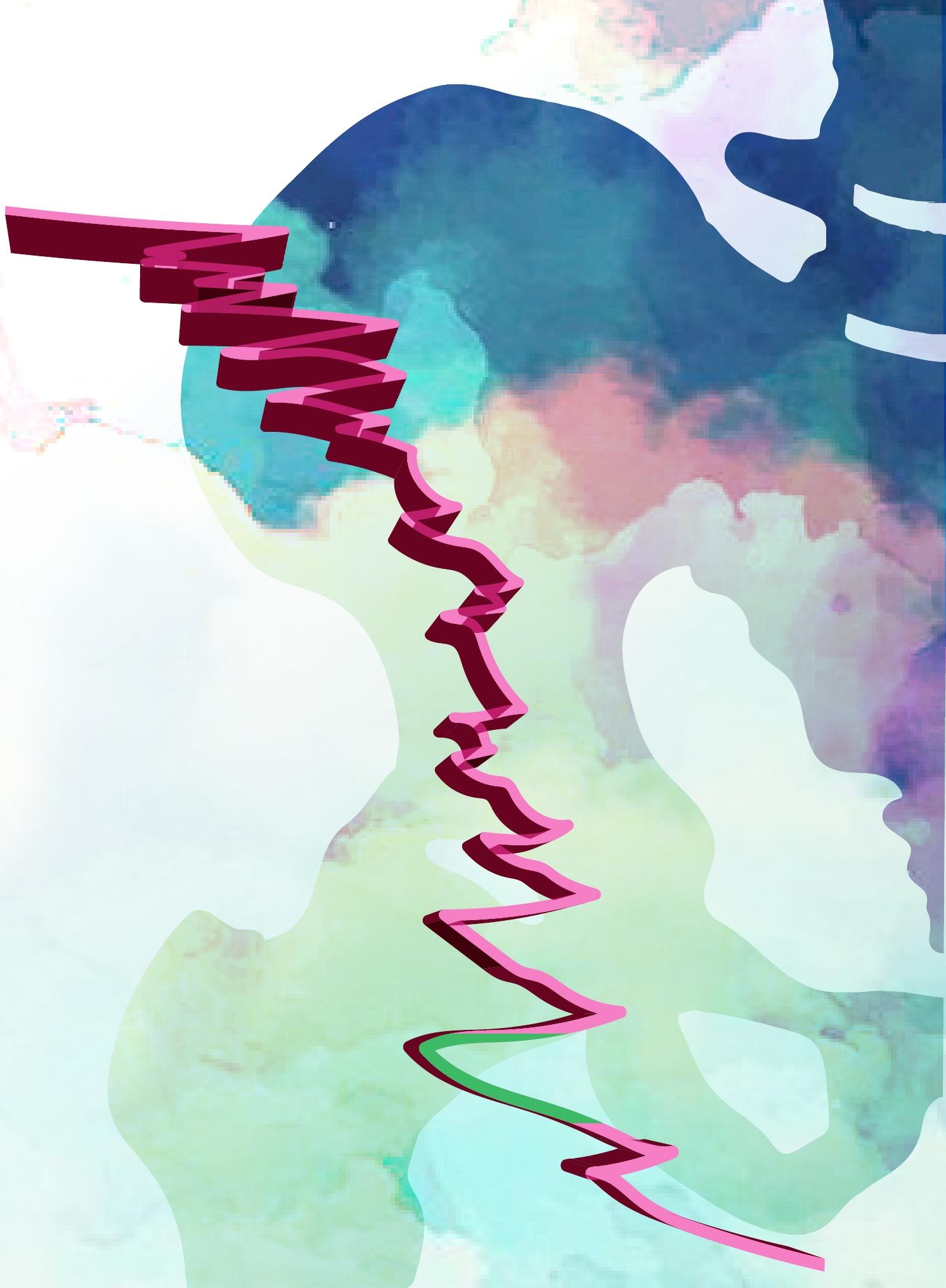




\section{Chapter III}

Quality, but not quantity of physical activity is associated with metal ion concentrations in unilateral hip resurfacing

J Orthop Res. 2020 Oct;38(10):2206-2212

Jelsma J, Schotanus MGM, van Kuijk SMJ, Buil ITAF, Heyligers IC, Grimm B

You miss $100 \%$ of the shots you don't take (Wayne Gretzky) 


\section{Abstract}

\section{Introduction}

Little is known about the influence of physical activity (PA) on metal ion concentrations in subjects with metal-on-metal hip arthroplasty. Implant wear is thought to be a function of use and thus of patient activity levels. It is hypothesized that daily habitual PA of patients with hip resurfacing arthroplasty (HRA) is associated with metal ion concentrations.

\section{Methods}

Therefore a study was conducted in patients with a unilateral HRA at 10-years follow-up. Blood metal ion concentrations were determined. An acceleration-based activity monitor was used to measure PA in daily life

\section{Results}

The cohort consisted of 12 males (75\%) and 4 females (25\%) with a median age at surgery of $55.5 \pm 9.7$ years [43.0-67.9] and a median follow-up of $9.9 \pm 1.0$ years [9.110.9]. The median cobalt and chromium ion concentrations were $25 \pm 13$ and $38 \pm$ $28 \mathrm{nmol} / \mathrm{L}$. A significant association between sit-stand transfers and highintensity peaks with cobalt ion concentrations were found.

\section{Discussion}

Regarding PA and metal ion concentrations as a proxy of wear in HRA, specific activities like transfers or qualitative aspects of activity behavior like intensity, seem to matter more than the quantity of low-intensity activities like walking or cycling. This suggests that patients may safely engage in such activities to achieve important general health benefits and quality of life. 


\section{Introduction}

Metal on metal (MoM) hip resurfacing arthroplasty (HRA) became a popular procedure in the 90s for young and active patients with hip osteoarthritis. The preliminary results of HRA were satisfactory and early investigators concluded a major wear reduction to safe levels [1]. Around one million procedures were performed worldwide in total [2]. Concerns about MoM implants have been raised since 2004 when metal ions were found in blood and urine of patients with MoM implants [3]. Hereafter, multiple studies and national registry data showed high failure rates and the 10-year survival rate threshold of $95 \%$ set by The National Institute for Health and Care Excellence (NICE) was not achieved [4].

During articulation, the metal surfaces are exposed to wear resulting in the release of metal ions. Indirect measure of (volumetric) wear is performed by measuring metal ion concentrations in blood, serum or urine, as direct measurment is only possible on explanted devices. After HRA a significant rise is seen in the cobalt and chromium ion concentration, with peak concentrations being reached between 9 to 18 months postoperative. After this period an equilibrium is reached between metal ion release from the implant and metal ion excretion from the body (e.g. via urine) [5-7]. Design of the prosthesis (alloy, surface), acetabular component malpositioning, contact-patch-to-rim distance (CPR) and a small joint size (e.g. in females) all seem to play a role in increased metal ion concentrations after this period [4, 8-10].

Little is known about the influence of physical activity (PA) on metal ion concentrations. Implant wear is thought to be a function of use and thus of patient PA levels [11]. Intense exercise events in patients with a MoM implants showed a temporary raise of metal ion concentrations [12-15]. With the use of wearable activity monitors (AM) it is possible to measure the habitual PA of patients in the free living environment. AMs are also able to differentiate between different PA types in daily life (e.g. stand, walk, sit). In the recent years this technique has become more popular [16].

The goal of the present study was to investigate the correlation between PA and metal ion concentrations under tight controlled conditions to minimize limitations. Therefore, we selected a homogenous group with a long follow-up assessed during a narrow time window and with close proximity of metal ion measurement and PA monitoring. The current study aims to give further evidence whether PA in general or specific behavior may be an important contributor in the explanation of increased 
metal ion concentrations. It is hypothesized that daily habitual PA of patients with a unilateral HRA, measured with an AM is associated with metal ion concentrations in blood at 10-years follow-up.

\section{Patients and Methods}

A part retrospective, part prospective cohort study (Level of Evidence III) was conducted from August until November 2017. Only patients with a primary unilateral HRA with a follow-up of $10 \pm 1$ years per $1^{\text {st }}$ of August 2017 were included. Two different approaches, posterolateral and straight lateral, and three different HRA implants were used (Table 1). Exclusion criteria were revision surgery, any type of hip arthroplasty on the contralateral side, dementia, inactivity due to paralysis or paresis and major surgery in the past year influencing PA.

Table 1. Characteristics of Resurfacing systems

\begin{tabular}{lccc}
\hline & Biomet ReCap & Zimmer Durom & Corin Cormet \\
\hline Radial clearance $(\mu \mathrm{m})$ & 120.93 & 68.23 & 97.67 \\
\hline Wall thickness at rim $(\mathrm{mm})$ & 3.4 & 4.6 & 5.6 \\
\hline Surface roughness $(\mu \mathrm{m})$ & 0.031 & 0.034 & 0.030 \\
\hline Mean deviation of roundness $(\mu \mathrm{m})$ & 3.2 & 6.1 & 7.3 \\
Head & 1.9 & 2.5 & 3.8 \\
Cup & $162^{\circ *}$ & $165^{\circ}$ & $160-166^{\circ}$ \\
\hline Coverage angle (angle in $\left.{ }^{\circ}\right)$ & & &
\end{tabular}

* In case of a femoral head size of $44 \mathrm{~mm}$.

This study was performed in compliance with the Declaration of Helsinki and was studied and approved by the IRB (METC Zuyd, Heerlen, The Netherlands, IRB nr: 10N72) and conducted in accordance with the guidelines for Good Clinical Practice (GCP). Eligible patients visited the outpatient clinic for a regular check according to the Dutch Orthopaedic Society guidelines. For this study the inclination angle of the acetabular cup was determined on standardized x-ray's, standing pelvic anterior-posterior (AP) and defined as the angle between a line connecting the ischial tuberosity and a line connecting the vertices of the metal cup. The acetabular cup anteversion angle can not be reliable measured on $\mathrm{x}$-ray and was therefore not determined [17].

Blood from vena punction was collected in a tube (BD Vacutainer $368380^{\circledR}$ Trace Element, Franklin Lakes, New Jersey, United States), after the first $5 \mathrm{~mL}$ were disposed. 
The collected material was shipped within a week at room temperature and stored in a refrigerator at a temperature of $2^{\circ}-8^{\circ} \mathrm{C}$ in the meantime. Inductively coupled plasma mass spectrometry (ICP-MS) (NexION ${ }^{\circledR} 300 \mathrm{X}$ ICP-MS, PerkingElmer, Waltham, Massachusetts, United States) was used to determine cobalt and chromium ion concentrations in $\mathrm{nmol} / \mathrm{L}[18]$.

An acceleration-based AM, attached to the affected leg using a skin-friendly sticker, was used to measure PA in daily life during the wake hours of four consecutive days, a common minimum period to derive a reliable estimate of habitual PA behavior $[19,20]$. A 3-axis accelerometer, gyroscope and magnetometer (HAM-IMU+alt, Gulf Coast Data Concepts LLC, Waveland Mississippi, United Status of America) was used to collect the raw signal which was analyzed for activity event classification in MATLAB (MATLAB R2018b, The Mathworks Inc., Natick,Massachusetts, United States) using previously validated algorithms [21].

Activity data were analyzed for the daily average values of days with at least 8 hours of AM-measuring time. Both quantitative (e.g. time spent performing different activities like walking and cycling in seconds, the number of steps and sit-stand transfers) and qualitative parameters of PA (e.g. walking cadence in steps/ minute and high intensity peak counts in numbers) were collected. Acceleration vector magnitude was calculated to count and classify intensity peaks.For this study intensity peak counts were accounted for events $<2 \mathrm{~g}, \geq 2 \mathrm{~g}, \geq 3 \mathrm{~g}$ and $\geq 8 \mathrm{~g}$. This classification was chosen as events $\geq 2 \mathrm{~g}$ do not usually appear during normal activities like walking but are common with impacts from e.g. sports or stumbles. The AM method used was found to work reliably in identifying activities in a semifree setting compared to human observers, with a classification accuracy of $>97 \%$ $[21,22]$. In addition, activity monitoring following this or similar protocols has shown its value for research and outcome assessment in current literature [23,24]. In addition, patient self-reported outcome measures (PROMs) were obtained. Patients were asked to fill in the Hip disability and Osteoarthritis Outcome Score - Physical Function Short Form (HOOS-PS) and the 12-item Forgotten Joint Score (FJS-12). The Harris Hip Score (HHS) was determined at the outward clinic by one of the authors (J). All three questionnaires included ' 100 ' as the best possible score.

\section{Statistical Analysis}

IBM SPSS Statistics 22 (International Business Machines Corporation, Armonk, New York, United States) was used for statistical analysis. Baseline characteristics of participants at the time of surgery (e.g. gender, age, surgical characteristics) and at the AM measurement moment (e.g. BMI, cobalt, chromium, interval LAB-AM, cup 


\section{Chapter 3}

inclination) are presented as median \pm interquartile range (IQR) [range] or count and percentage.

To study the influence of baseline characteristics on cobalt ion concentrations, a linear regression analysis was performed. Also, linear regression analysis was performed to analyze the influence of PA on cobalt ion concentrations, the analysis was adjusted for age at surgery, BMI, cup size and cup inclination to obtain an estimation corrected for potential confounding factors $[7,8,25]$. For all analyses, a $p$-value was considered to be statistically significant at $p \leq 0.05$

The cobalt ion concentrations in this cohort were significantly different from a normal distribution $(p<.001$, Kolmogorov-Smirnov test). For this reason, a linear regression analysis was performed on the cohort after excluding one subject with a very high cobalt ion concentration $(428 \mathrm{nmol} / \mathrm{L})$ as a sensitivity analysis.

\section{Results}

Between September 2003 and April 2011 a total of 182 HRA's were performed. Forty patients had a follow-up of $10 \pm 1$ year and were thus potentially eligble for this study. Revision surgery ( $n=9)$, bilateral hip arthroplasty $(n=7)$ and decline to followup or research $(n=5)$ were the most common reasons for exclusion. No contact could be obtained with two patients. In one subject the measurement failed, due to incorrect use of the AM. Finally, 16 patients were eligible and were included for analysis.

The cohort consisted of 12 males (75\%) and 4 females (25\%) with a median age at surgery of $55.5 \pm 9.7$ years and a range of $43.0-67.9$ years. The median follow-up was $9.9 \pm 1.0$ years [9.1 - 10.9]. Three different prosthesis had been used, all with an uncemented acetabular component and cemented femoral component, with a variety of cement types $(n=5)$. The straight lateral approach was used in 9 cases (56\%) and the posterolateral approach in 7 cases (44\%). The median cup size was 56 $\pm 4 \mathrm{~mm}$ [48 - 62] with an inclination angle of $52 \pm 7$ degrees [40 - 60]. The median cobalt and chromium ion concentration were $25 \pm 10 \mathrm{nmol} / \mathrm{L}[13-428]$ and $38 \pm 22$ $\mathrm{nmol} / \mathrm{L}[17$ - 457], respectively. The interval between laboratory tests and measuring PA with the AM was $1.0 \pm 1.0$ days [0 - 34] (Table 2). 
Table 2. Baseline Characteristics. Median \pm Interquartile Range [Range] or numbers (proportions)

\begin{tabular}{lc}
\hline $\mathrm{N}$ & 16 \\
of subjects & $12 / 4$ \\
\hline Gender & $(75 \% / 25 \%)$ \\
(M/F) & $55.5 \pm 9.7$ \\
\hline Age at OR & {$[43.0-67.9]$} \\
in years & $9.9 \pm 1.0$ \\
\hline Follow-up & {$[9.1-10.9]$} \\
in years from OR & $26.1 \pm 3.8$ \\
\hline Body Mass Index (BMI) & {$[21.7-36.9]$} \\
in kg/m2 & \\
\hline Manufacturer & $10(62.5 \%)$ \\
\hline \multicolumn{1}{c}{ CorinCormet } & $2(12.5 \%)$ \\
$\quad$ Zimmer Durom & $4(25.0 \%)$ \\
\hline Biomet Recap & $1.0 \pm 1.0$ \\
\hline Interval lab-AM & {$[0.0-34.0]$} \\
in days & $25 \pm 10$ \\
\hline Cobalt & {$[13-428]$} \\
in nmol/L & $38 \pm 22$ \\
\hline Chromium & {$[17-457]$} \\
in nmol/L & $56 \pm 4$ \\
\hline Cup Size & {$[48-62]$} \\
in mm & $52 \pm 7$ \\
\hline Cup Inclination & {$[40-60]$} \\
in degree ${ }^{\circ}$ & \\
\hline Approach & $7(44 \%)$ \\
\hline \multicolumn{1}{c}{ Posterolateral } & $9(56 \%)$ \\
\hline Straight Lateral & \\
\hline Cemented & $0(0 \%)$ \\
\hline \multicolumn{1}{c}{ Acetabular } & $16(100 \%)$ \\
\hline Femoral & \\
\hline
\end{tabular}

The AM was worn for a median of $4.0 \pm 0$ days [2.0 - 4.0] with $12.4 \pm 2.3$ hours [10.7 - 16.2] per day. Subjects walked for $1.3 \pm 0.6$ hours [0.5 - 2.0] per day. A median number of $5546 \pm 3286$ steps [2274 - 9966] were taken per day. The cadence, defined as the amount of steps per minute, was $102 \pm 13$ [81 - 112] steps/minute. Sit-stand transfers were performed $39 \pm 17$ [21 - 74] times each day. Intensity peaks were divided in subgroups. Peaks $<2.0 \mathrm{~g}$ were detected in all patients and were counted $14669 \pm 27903$ [2442 - 48435] times. In six subjects the activity monitor was able to measure peaks $\geq 2.0 \mathrm{~g}$ and were counted $184 \pm 692$ [29 - 1819] times. Further differentiated in peaks $\geq 3.0 \mathrm{~g}(28 \pm 185[9-651])$ and peaks $\geq 8.0 \mathrm{~g}(2 \pm 12$ [1 - 40] (Table 3). 
Table 3. Physical Activity Parameters as daily means. Median \pm Interquartile Range [range]

\begin{tabular}{lc}
\hline AM-Measurement & $4.0 \pm 0$ \\
in days & {$[2.0-4.0]$} \\
\hline Total Time & $12.4 \pm 2.3$ \\
in hours & {$[10.7-16.2]$} \\
\hline Percentage Active & $10.8 \pm 7.0$ \\
in \% & {$[4.1-18.3]$} \\
\hline Time Walked & $1.3 \pm 0.6$ \\
in hours & {$[0.5-2.0]$} \\
\hline Steps & $5546 \pm 3286$ \\
number of & {$[2274-9966]$} \\
\hline Sit-Stand Transfers & $39 \pm 17$ \\
number of & {$[21-74]$} \\
\hline Cadence & $102 \pm 13$ \\
in steps $/$ minute & {$[81-112]$} \\
\hline Intensity Peaks $<2.0 \mathrm{~g}$ & $14669 \pm 27903$ \\
number of & {$[2442-4843]$} \\
\hline Intensity Peaks $>2.0 \mathrm{~g}$ & $184 \pm 692$ \\
number of & {$[29-1819]$} \\
\hline Intensity Peaks $>3.0 \mathrm{~g}$ & $28 \pm 185$ \\
number of & {$[9-651]$} \\
\hline Intensity Peaks $>8.0$ & $2 \pm 12$ \\
number of & {$[1-40]$} \\
\hline
\end{tabular}

Regarding the association between cobalt ion concentrations and parameters of behavioral PA, a statistically significant relationship was found with cobalt ion concentrations and number of sit-stand transfers $(\beta 5.786,95 \% \mathrm{Cl} .531-11.041$, $p=.034$ ) and also with intensity peaks $\geq 2.0 \mathrm{~g}, \geq 3.0 \mathrm{~g}$ and $\geq 8.0 \mathrm{~g}$. This means that for any single additional sit-stand transfers a raise of almost $6 \mathrm{nmol} / \mathrm{L}$ cobalt is expected and for any single intensity peak $\geq 8.0 \mathrm{~g}$ a raise of more than $10 \mathrm{nmol} / \mathrm{L}$ (Table 4 ).

When excluding the subject with the highest cobalt ion concentrations the linear regression analysis showed that the significant correlation between cobalt ion concentrations and number of sit-stand transfers disappeared $(\beta .068,95 \% \mathrm{Cl}-.758$ - .894, $\mathrm{P}=.853$ ). In contrast, the relationship between the cadence in steps/minute and cobalt ion concentrations showed a trend towards significance $(\beta .753,95 \% \mathrm{Cl}$ $.028-1.533, \mathrm{P}=.057)$. The significant association with intensity peaks $\geq 2.0 \mathrm{~g}, \geq 3.0 \mathrm{~g}$ and $\geq 8.0 \mathrm{~g}$ were lost.

Patient self-reported outcome scores were high as commonly reported for successful total hip arthroplasty. The median scores of the HOOS-PS was $87.3 \pm$ 27.7 [49.2 - 100.0] and $62.5 \pm 39.5$ [2.1 - 100.0] for the FJS-12. The Harris Hip Score showed a median score of $98.0 \pm 11.0$ [59.0 - 100.0]. 
Table 4. Results of the multiple linear regressions model describing the relationship between baseline characteristics and blood cobalt concentrations. Physical activity parameters were adjusted for age at OR, BMI, cup size and cup inclination.

\begin{tabular}{lccc}
\hline Predictor & $\begin{array}{c}\text { Regression } \\
\text { Coefficient }\end{array}$ & $\mathbf{9 5 \% ~ C l}$ & p-value \\
\hline $\begin{array}{l}\text { Percentage Active } \\
\text { in \% }\end{array}$ & 1.4 & $-18.8-21.6$ & .877 \\
\hline $\begin{array}{l}\text { Time Walk } \\
\text { in hours }\end{array}$ & -45.2 & $-256.4-165.9$ & .639 \\
\hline $\begin{array}{l}\text { Steps } \\
\text { number of }\end{array}$ & -.007 & $-.041-.028$ & .675 \\
\hline $\begin{array}{l}\text { Cadence } \\
\text { in steps/minute }\end{array}$ & -1.455 & $-11.9-8.9$ & .760 \\
\hline $\begin{array}{l}\text { Sit-Stand Transfers } \\
\text { number of }\end{array}$ & 5.786 & $.531-11.041$ & $.034^{*}$ \\
\hline $\begin{array}{l}\text { Intensity peaks }<2.0 \\
\text { number of }\end{array}$ & .002 & $-.003-.007$ & .337 \\
\hline $\begin{array}{l}\text { Intensity Peaks }>2.0 g^{* *} \\
\text { number of }\end{array}$ & .233 & $.164-.303$ & $.001^{*}$ \\
\hline $\begin{array}{l}\text { Intensity Peaks }>3.0 g^{* *} \\
\text { number of }\end{array}$ & .643 & $.583-.702$ & $<.001^{*}$ \\
\hline $\begin{array}{l}\text { Intensity Peaks }>8.0^{* *} \\
\text { number of }\end{array}$ & 10.450 & $9.369-11.711$ & $<.001^{*}$ \\
\hline
\end{tabular}

* Significance at $p=.005$

** univariable analysis, not enough data for multivariable, adjusted analysis

\section{Discussion}

The aim of this study was to investigate the association between habitual PA during daily live and metal ion concentrations in patients with a unilateral HRA at $10 \pm 1$ year follow-up. The reason for increased metal ion concentrations after HRA seems multifactorial and PA might be one of the factors contributing. The current study aims to uncover an important contributor previously unknown and found a significant and clinically meaningful correlation between cobalt ion concentrations and distinct parameters of habitual PA (number of sit-stand transfers and high intensity peaks). After removal of one patient with relative abnormally high ion concentrations, also walking cadence, a proxy of walking speed, was found to have a trend towards significant correlation with cobalt ion concentrations. No significant association with cobalt ion concentrations were found for the habitual level of time spent walking, the total amount of steps and percentage of time being active. 
The present study shows that qualitative parameters of PA seem more important than conventional quantitative parameters of PA. The results suggest that patients with a MoM arthroplasty can walk as long or as many steps as much as possible, without a relation with higher ion concentrations. However, if these patients walk too fast or too hard (high impacts) or have more sit-stand transfers, they are more prone to higher metal ion concentrations. Wear regimes in MoM bearings (dynamic fluid film lubrication) seem to play an essential role in these findings. After a period of sitting, the bearing surfaces might squeeze out any fluid and get into "dry" contact so that the immediate steps made after a sit-stand transfer are without fluid film lubrication, dry or mixed-mixed mode, possibly resulting in an increase in wear of the MoM articulation and subsequently higher wear and metal ion release. More sit-stand-transfers result in more steps in such a high wear mode which may explain the higher metal ion concentrations correlated with it. These results are supported by a study of Schmalzried et al. who discovered that 'wear is a function of use, not time' in total hip arthroplasty with a polyethylene bearing, but this early study could not study cadence as a proxy of walking speed or intensity [11]. Recently, it was shown that a higher walking cadence was associated with higher polyethylene wear [26]. The current study showed that wear seems not a function of any type of use, but specific types and qualitative characteristics of use. In long-term clinical follow-up, there is no evidence in current literature that high activity levels in patients with HRA result in higher revision rates. This may be due to the fact that PA is not recorded or if so, only in PROMs which have the disadvantage of being highly subjective suffering from recall bias or having a ceiling effect for activity type, duration or intensity. These limitations do not apply to wearable sensor based PA monitoring in the free living environment [27].

The current study found a high and significant correlation between cobalt ion concentrations and the number of high intensity peaks $(\geq 2.0 \mathrm{~g}, \geq 3.0 \mathrm{~g}$ and $\geq 8.0 \mathrm{~g}$ ). Intensities are divided in low and high intensities, whereas walking and walking stairs are activities with intensity peaks $<2.0 \mathrm{~g}$, but e.g. running, jumping or other events like stumbling cause intensity peaks $\geq 2.0 \mathrm{~g}$. Previous studies in subjects with MoM implants showed that an acute PA, for example an hour running on a treadmill, resulted in an acute, but temporary raise in metal ion concentrations [12-15]. One hour of intense exercise is likely to result in a high number of high intensity peaks and thus an increase in metal ion release. The present findings are in accordance with these 'acute-activity' studies, but show that high intensity peaks also in daily habitual live are related to raised cobalt ion concentrations. 
The influence of PA on metal wear and ion release seems insufficiently explored in current literature. The current study is in line with two studies by Hjorth et al. who also found a significant correlation between higher ion concentrations and higher PA. Hjorth et al. established this relationship for chromium but not for cobalt in their first study [28]. Considering the high correlation between both due to the metal alloy composition, this seems more an effect of statistical power (small effect size). In contrast to the current study, Hjorth et al. defined a single parameter for all activity as the sum of walking, cycling and high intensity activity measurements as a percentage of the total wearing time of the AM. Thus no differentiation by activity type, frequency, intensity and duration (time), the "FITT" components of PA as defined by the World Health Organization (WHO), was possible, a concept which was applied in the current study. A significant part of the heterogeneous patient population (e.g. 0.5 to 21-years of follow-up) was assessed during the "runningin" phase with highly transient metal ion levels. In contrast, the current study was performed with a median follow-up of $9.9 \pm 1.01$ years [9.09-10.88], far beyond the running-in phase. Another study by Hjorth et al. showed an association between PA and chromium concentrations but also with cobalt ion concentrations [29]. This study by Hjorth et al. distinguishes between activities like the current study. Walking and standing time were significantly positively correlated with cobalt and chromium concentrations, whereas sitting and lying were significantly negatively correlated. Again, a single parameter for total activity was significantly positively correlated with cobalt and chromium concentrations (Pearson's R - $0.35, p=0.004$ and Pearson's R 0.44, $\mathrm{p}=0.0002$ ). In contrast, a correlation between high impact activities and metal ion concentrations was not found. Hjorth et al. measured activity independent of sleeping hours and wear time. We prefered the absolute definition of PA parameters as most commonly reported. Long and/or short sleeping time would create large variations in Hjorth's definition of PA levels and the observed effects may be due to more sleeping hours rather than increased PA.

The present results appear in contrast to our previous study, where no correlation between habitual PA and metal ion concentrations was found in a cohort study of 62 patients [30]. Also, no significant differences in PA were found between groups with a low (<40 nmol/L) and a high ( $>40 \mathrm{nmol} / \mathrm{L})$ cobalt ion concentration. This study was performed with a heterogeneous cohort including subjects with HRA, large head MoM total hip arthroplasties, both uni- and bilateral which may have confounded the correlations. In a similar fashion, the large mean interval of $1.4 \pm 0.8$ years between determining PA with the AM and determining metal ion concentrations may have reduced the statistical power for detecting a correlation. In contrast, the current study was performed in a cohort with subjects at the same 
time of follow-up with a unilateral HRA. The median interval between determining metal ion concentrations and PA monitoring was minimized and equal ( $1.0 \pm 0$ days [0 - 34]). Based on the PROMs one may assume that a representative group was selected and analysed.

The current study does have its limitations. First, although we reduced the heterogeneity compared with our previous study, this cohort consists of subjects operated with one out of three different implants, placed by two different approaches. Different implants are likely to be designed differently, including different composition. This was thought to be the reason for increased metal ion concentrations [31]. These implants may not react in the same intensity to different PA levels and thus influence the level of metal ion release. Stratifying analyses by implant type would not be feasible due to the limited sample size. It is known that a low surface roughness and high sphericity improve the wear behavior because this allows for a better fluid film lubrication. The implants used in the current study were not completely comparable according to design. However, the activity driven wear mechanisms would be similar but just different in effect (Table 1) [32]. The slope of relationship between PA and metal ion concentrations might be influenced hereby, but this is unrelated to direction.

Compliance in wearing of the AM seems good considering the $80 \%$ of subjects carrying the AM for 4 days with a median wear time of $12.4 \pm 2.3$ hours per day. The AM was worn for less than four days in a minority of subjects (20\%) and one measurement failed. Further improvements should focus on increasing the compliance and optimize results by an easy to use AM with a long battery time ( $>4$ days).

Thirdly, the cohort became rather small because of the strict inclusion criteria and only in six subjects the AM was able to detect intensity peaks $>2.0 \mathrm{~g}$. The linear regression analysis for the association between these intensity peaks and cobalt ion concentrations was performed univariable because of the limited available data. Also, the metal ion concentrations were not normally distributed. One subject showed abnormal high cobalt ion concentrations of $428 \mathrm{nmol} / \mathrm{L}$. The correlations between PA and cobalt ion concentrations were affected after excluding this subject. The same patient also showed a high number of sit-stand transfers and the most high intensity peaks, up to 10-20 times more than other subjects. The patient did not stand out with respect to other parameters. For instance, the implanted cup size was $52 \mathrm{~mm}$, and the degree of inclination was 49. This patient was eligible for inclusion, and therefore included in the primary analysis. The reason that we performed additional analyses excluding this patient only served as a sensitivity 
analysis because of this abnormal value. This way, the intended reader can judge the effect of this single extreme observation on the conclusions of the manuscript. This finding itself was the reason to perform this study and highlights the question again. Further research should focus on patients with high metal ion concentrations and the correlation with PA, high intensity peaks in particular.

The present study showed that a higher number of sit-stand transfers and a higher number of high intensity peaks are significantly associated with higher metal ion concentrations. At the same time, the daily time spent walking and the number of steps as common quantitative measures of PA behavior did not show an association with metal ion levels. It seems that general habitual PA like normal walking and stepping does not or only slightly influences metal ion concentrations. Only behavior (many STT) and qualitative aspects of PA (high intensity, fast walking) matter. For patients it seems safe to engage in activities with low intensity peaks like walking or cycling without triggering critical wear or metal ion being able to achieve important general health benefits and quality of life. 


\section{References}

1. Schmalzried TP, Fowble VA, Ure KJ, Amstutz HC. Metal on metal surface replacement of the hip. Technique, fixation, and early results. Clin Orthop Relat Res, 1996 (329 Suppl): p. S106-14.

2. Bozic KJ, Kurtz SM, Lau E, Ong K, Vail TP, Berry DJ. The epidemiology of revision total hip arthroplasty in the United States. J Bone Joint Surg Am, 2009. 91(1): p. 128-33.

3. MacDonald SJ. Metal-on-metal total hip arthroplasty: the concerns. Clin Orthop Relat Res, 2004(429): p. 86-93.

4. Smith AJ, Dieppe P, Howard PW, Blom AW; National Joint Registry for England and Wales. Failure rates of metal-on-metal hip resurfacings: analysis of data from the National Joint Registry for England and Wales. Lancet, 2012. 380(9855): p. 1759-66.

5. Daniel J, Ziaee H, Pradhan C, Pynsent PB, McMinn DJW. Blood and urine metal ion levels in young and active patients after Birmingham hip resurfacing arthroplasty: four-year results of a prospective longitudinal study. J Bone Joint Surg Br, 2007. 89(2): p. 169-73.

6. deSouza RM, Parsons NR, Oni T, Dalton P, Costa M, Krikler S. Metal ion levels following resurfacing arthroplasty of the hip: serial results over a ten-year period. J Bone Joint Surg $\mathrm{Br}$, 2010. 92(12): p. 1642-7.

7. Van Der Straeten C, Grammatopoulos G, Gill HS, Calistri A, Campbell P, De Smet KA. The 2012 Otto Aufranc Award: The interpretation of metal ion levels in unilateral and bilateral hip resurfacing. Clin Orthop Relat Res, 2013. 471(2): p. 377-85.

8. De Haan R, Pattyn C, Gill HS, Murray DW, Campbell PA, De Smet K. Correlation between inclination of the acetabular component and metal ion levels in metal-on-metal hip resurfacing replacement. J Bone Joint Surg Br, 2008. 90(10): p. 1291-7.

9. Van Der Straeten C, Van Quickenborne D, De Roest B, Calistri A, Victor J, de Smet K. Metal ion levels from well-functioning Birmingham Hip Resurfacings decline significantly at ten years. Bone Joint J, 2013. 95-B(10): p. 1332-8.

10. Amstutz HC, Le Duff MJ, Bhaurla SK. Risk factors for wear-related failures after hip resurfacing in patients with a low contact patch to rim distance. Bone Joint J, 2017. 99-B(7): p. 865-871.

11. Schmalzried TP, Shepherd EF, Dorey FJ, Jackson WO, dela Rosa M, Fa'vae F et al., The John Charnley Award. Wear is a function of use, not time. Clin Orthop Relat Res, 2000(381): p. 36-46.

12. Gleizes V, Poupon J, Lazennec JY, Chamberlin B, Saillant G. [Value and limits of determining serum cobalt levels in patients with metal on metal articulating prostheses]. Rev Chir Orthop Reparatrice Appar Mot, 1999. 85(3): p. 217-25.

13. Heisel C, Silva M, Skipor AK, Jacobs JJ, Schmalzried TP. The relationship between activity and ions in patients with metal-on-metal bearing hip prostheses. J Bone Joint Surg Am, 2005. 87(4): p. 781-7.

14. Khan M, Takahashi T, Kuiper JH, Sieniawska CE, Takagi K, Richardson JB. Current in vivo wear of metal-on-metal bearings assessed by exercise-related rise in plasma cobalt level. J Orthop Res, 2006. 24(11): p. 2029-35.

15. Khan M, Kuiper JH, Richardson JB. The exercise-related rise in plasma cobalt levels after metalon-metal hip resurfacing arthroplasty. J Bone Joint Surg Br, 2008. 90(9): p. 1152-7.

16. Verlaan L, Bolink SA, Van Laarhoven SN, Lipperts M, Heyligers IC, Grimm B et al. Accelerometerbased Physical Activity Monitoring in Patients with Knee Osteoarthritis: Objective and Ambulatory Assessment of Actual Physical Activity During Daily Life Circumstances. Open Biomed Eng J, 2015. 9: p. 157-63.

17. Kalteis T, Handel M, Herold T, Perlick L, Paetzel C, Grifka J. Position of the acetabular cup -accuracy of radiographic calculation compared to CT-based measurement. Eur J Radiol, 2006. 58(2): p. 294-300.

18. De Pasquale D, Stea S, Squarzoni S, Bordini B, Amabile M, Catalani S et al., Metal-on-metal hip prostheses: correlation between debris in the synovial fluid and levels of cobalt and chromium ions in the bloodstream. Int Orthop. 2014 Mar;38(3):469-7

19. Mâsse LC, Fuemmeler BF, Anderson CB, Matthews CE, Trost SG, Catellier DJ et al., Accelerometer data reduction: a comparison of four reduction algorithms on select outcome variables. Med Sci Sports Exerc, 2005. 37(11 Suppl): p. S544-54. 
20. Kang $M$, Hart PD, Kim Y. Establishing a threshold for the number of missing days using $7 \mathrm{~d}$ pedometer data. Physiol Meas, 2012. 33(11): p. 1877-85..

21. Lipperts M, van Laarhoven S, Senden R, Heyligers I, Grimm B. Clinical validation of a bodyfixed $3 \mathrm{D}$ accelerometer and algorithm for activity monitoring in orthopaedic patients. J Orthop Translat. 2017 Feb 27;11:19-29

22. van Laarhoven SN, Lipperts M, Bolink SAAN, Senden R, Heyligers IC, Grimm B. Validation of a novel activity monitor in impaired, slow-walking, crutch-supported patients. Ann Phys Rehabil Med, 2016. 59(5-6): p. 308-313.

23. Schotanus MGM, Bemelmans YFL, Grimm B, Heyligers IC, Kort NP. Physical activity after outpatient surgery and enhanced recovery for total knee arthroplasty. Knee Surg Sports Traumatol Arthrosc, 2017. 25(11): p. 3366-3371.

24. Daugaard R, Tjur M, Sliepen M, Lipperts M, Grimm B, Mechlenburg I. Are patients with knee osteoarthritis and patients with knee joint replacement as physically active as healthy persons? J Orthop Translat, 2018. 14: p. 8-15.

25. Langton DJ, Joyce TJ, Jameson SS, Lord J, Van Orsouw M, Holland JP et al., Adverse reaction to metal debris following hip resurfacing: the influence of component type, orientation and volumetric wear. J Bone Joint Surg Br, 2011. 93(2): p. 164-71.

26. Senden R, Lipperts M,Grimm B. Patient Activity and in-vivo Polyethylene Wear in Total Hip Arthroplasty., in ORS Annual Meeting. 2013: San Antonio, Texas, United States of America. 2629 January 2013.

27. Terwee $\mathrm{CB}$, Bouwmeester W, van Elsland SL, de Vet HCW, Dekker J. Instruments to assess physical activity in patients with osteoarthritis of the hip or knee: a systematic review of measurement properties. Osteoarthritis Cartilage, 2011. 19(6): p. 620-33.

28. Hjorth $\mathrm{MH}$, Mechlenburg I, Soballe K, Jakobsen SS, Roemer L, Stilling M. Physical Activity Is Associated With the Level of Chromium but Not With Changes in Pseudotumor Size in Patients With Metal-on-Metal Hip Arthroplasty. J Arthroplasty, 2018a. 33(9): p. 2932-2939..

29. Hjorth MH, Mechlenburg I, Soballe K, Roemer L, Stilling M. The correlation between activity level, serum-ion concentrations and pseudotumours in patients with metal-on-metal hip articulations and metal-on-polyethylene total hip articulations. Journal of Orthopaedic Translation, https://doi.org/10.1016/j.jot.2018b.11.001

30. Jelsma J, Schotanus MGM, Senden R, Heyligers IC, Grimm BI. Metal Ion Concentrations after Metal-on-Metal Hip Arthroplasty are Not Correlated with Habitual Physical Activity. Hip Int. 2018 Nov 27:1120700018814225

31. Langton DJ, Sprowson AP, Joyce TJ, Reed M, Carluke I, Partington $P$ et al. Blood metal ion concentrations after hip resurfacing arthroplasty: a comparative study of articular surface replacement and Birmingham Hip Resurfacing arthroplasties. J Bone Joint Surg Br, 2009. 91(10): p. 1287-95.

32. Heisel C, Kleinhans JA, Menge M, Kretzer JP. Ten different hip resurfacing systems: biomechanical analysis of design and material properties. Int Orthop, 2009. 33(4): p. 939-43. 


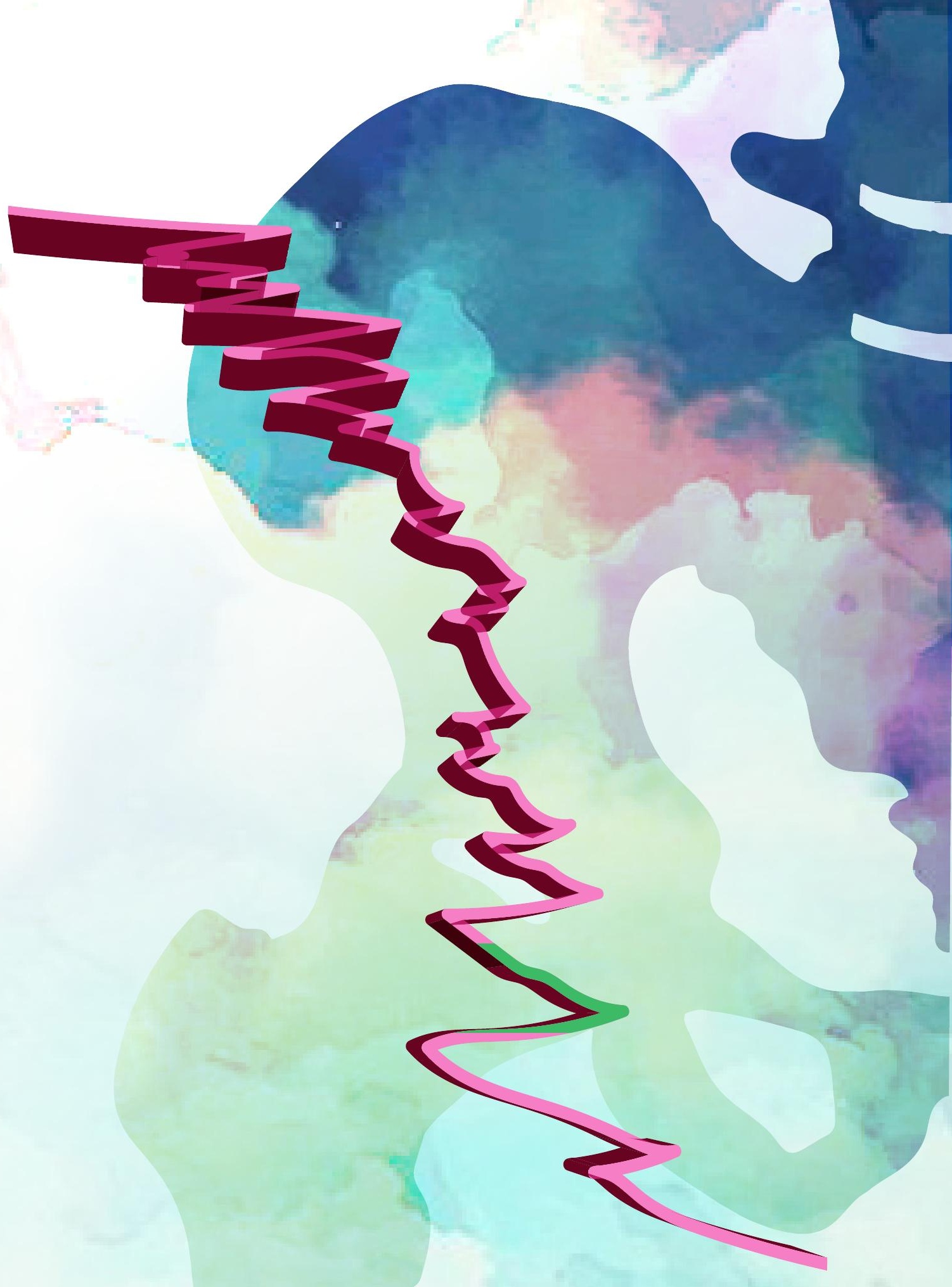




\section{Chapter IV}

Patients with hip resurfacing arthroplasty are not physically more active than those with a stemmed total hip

Acta Orthop. 2020 Oct;91(5):576-580

Jelsma J, Schotanus MGM, Buil ITAF, van Kuijk SMJ, Heyligers IC, Grimm B

Never say never because limits, like fears, are often just an illusion

(Michael Jordan) 


\section{Abstract}

\section{Introduction}

Hip resurfacing arthroplasty (HRA) was designed for the highly active patient because of the various theoretical advantages compared with stemmed total hip arthroplasty (THA), but has shown high failure rates. Physical activity (PA) after arthroplasty is frequently determined with the use of questionnaires, which are known for their subjective nature, recall bias, and ceiling effect.

These disadvantages are not applicable to physical activity monitoring (AM) using sensors. We compared objectively measured PA at long-term follow-up in a matched cohort of HRA and stemmed THA subjects

\section{Methods}

We compared 2 groups of 16 patients (12 males) in each group, one having received unilateral HRA (median age 56 years at surgery) and a matched group having received unilateral stemmed THA with a small diameter femoral head $(28 \mathrm{~mm}$ ) on conventional polyethylene (median age 60 years at surgery) with osteoarthritis as indication for surgery, 10 years after surgery. Groups were matched by sex, age at surgery, and BMI. The daily habitual PA was measured over 4 consecutive days in daily living using a 3-axis accelerometer, gyroscope, and magnetometer. Both quantitative parameters (time standing, sitting, walking, number of steps, and sitstand transfers) and qualitative parameters (walking cadence) were determined

\section{Results}

The AM was worn for a median 13 (11-16) hours per day. The median daily step count was 5,546 $(2,274-9,966)$ for the HRA group and 4,583 $(1,567-11,749)$ for the stemmed THA-group with 39 (21-74) versus 37 (24-62) daily sit-stand transfers respectively. The other PA parameters were also similar in both groups.

\section{Discussion}

We found similar median PA levels and also identical ranges. While short-term effects may exist, ageing and related behavioral adaptations or other effects seem to render the theoretical activity benefits from HRA irrelevant at longer follow-up. 


\section{Introduction}

Metal-on-Metal (MoM) hip resurfacing arthroplasty (HRA) was designed for the highly active patient because of various theoretical advantages compared to conventional stemmed MoP-THA: low volumetric wear, large physiological diameter femoral heads offering stability, near-natural joint kinematics and increased rangeof-motion compared to small-diameter THA and preservation of the femoral bone [1]. HRA was commonly advertised as 'the sporting hip' and publicity was created with subjects participating in triathlons after HRA [2]. Gait analysis studies showed that HRA subjects returned to a more normative gait pattern with a higher walking speed when compared with THA $[3,4]$. HRA showed initially promising results, however since 2004 concerns raised, because of high failure rates. In The Netherlands the use of HRA is forbidden by the Dutch Orthopaedic Society (NOV) and Government since January 2012 [5].

It can be expected that patients who received a HRA would be more physically active after surgery when compared to patients who received a stemmed THA with a small-diameter MoP or ceramic-on-polyethylene (CoP) bearing for multiple reasons: the theoretically better implant design features of HRA listed above claiming to support a more active lifestyle, the selection of patients for this particular implant (young and active) and the related patient expectations (high pre-operative demands on post-operative activity). A few studies have investigated return to sports after HRA and showed that patients were able to return to high activity levels and sporting activities postoperatively, at least at short time follow-up [6, 7]. Some studies comparing a HRA with a stemmed MoP- or CoP-THA showed higher postoperative activity levels after HRA 3-4 years follow-up. However, activity levels were determined using a (weighted) self-reported activity questionnaire [8,9]. The highly subjective nature, strong recall bias and possible ceiling effect are known disadvantages of such questionnaires especially for quantifying activity levels, which is in contrast to activity monitoring (AM) using sensors [10]. Wearable AMs measures a patient's habitual physical activity (PA) objectively and continuously in the free living environment and different physical activities can be differentiated $[11,12]$

We investigated objectively measured PA at long-term follow-up in an age and sex matched cohort of HRA and stemmed THA subjects. The hypothesis was that subjects with a unilateral HRA are physically more active in habitual daily live, measured by AM. 


\section{Patients and methods}

We conducted a cohort study at the Zuyderland Medical Centre, Sittard-Geleen, The Netherlands between August and November 2017 (recruitment of HRAgroup) and from February to June 2018 (recruitment of stemmed THA-group). We compared 2 groups, one having received unilateral HRA and a matched group having received unilateral stemmed THA with a small diameter metal or ceramic femoral head $(28 \mathrm{~mm})$ on conventional polyethyelene with osteoarthritis as indication for surgery. The HRA-group with a median follow-up of 10 [9-11] years was initially conducted for another study, the methods of which are described in detaill elsewhere [13]. The stemmed THA-group was matched by sex, age at surgery, follow-up since surgery and BMI. Patients with an uncemented, unilateral stemmed THA with a MoP- or CoP-bearing were included. The follow-up was set on 8 - 12 years to optimize the chances of a matched cohort. Finally, 16 patients consented to the study and were included as a matched cohort (Figure 1). There were no statistically significant differences between group characteristics at baseline (Table 1). The use of the AM has been described in detail elsewhere [11]. The daily habitual PA was measured during waking hours for 4 consecutive days in daily living. The AM used to collect the raw signal was a 3-axis accelerometer, gyroscope and magnetometer (HAM-IMU+alt, Gulf Coast Data Concepts LLC, Waveland Missipi, United Status of America). The data received with this $A M$ was analyzed with MATLAB (MATLAB R2017a, The Mathworks Inc., Natick, Massachusetts, United States) with the use of previously validated algorithms with an excellent accuracy (>97\%) in determining PA levels in a semi-free setting [11]. With the AM various quantitative parameters of PA can be obtained and in this study we assessed the following metrics: the time in hours standing, sitting, walking and cycling and the amount of steps and sit-stand-transfers taken. Walking cadence, defined as the number of steps per minute and a proxy of walking speed, was calculated as a qualitative paramater.

We also assessed outcome by 3 commonly used patient-reported-outcomemeasures (PROMs): the 12-item Forgotten Joint Score (FJS-12) and the Hip disability and Osteoarthritis Outcome Score Physical Function Short Form (HOOSPS), both with ' 100 ' as the best possible score and the Short Questionnaire to Assess Health-enhancing physical activity (SQUASH) to determine a total activity score [14-16]. 


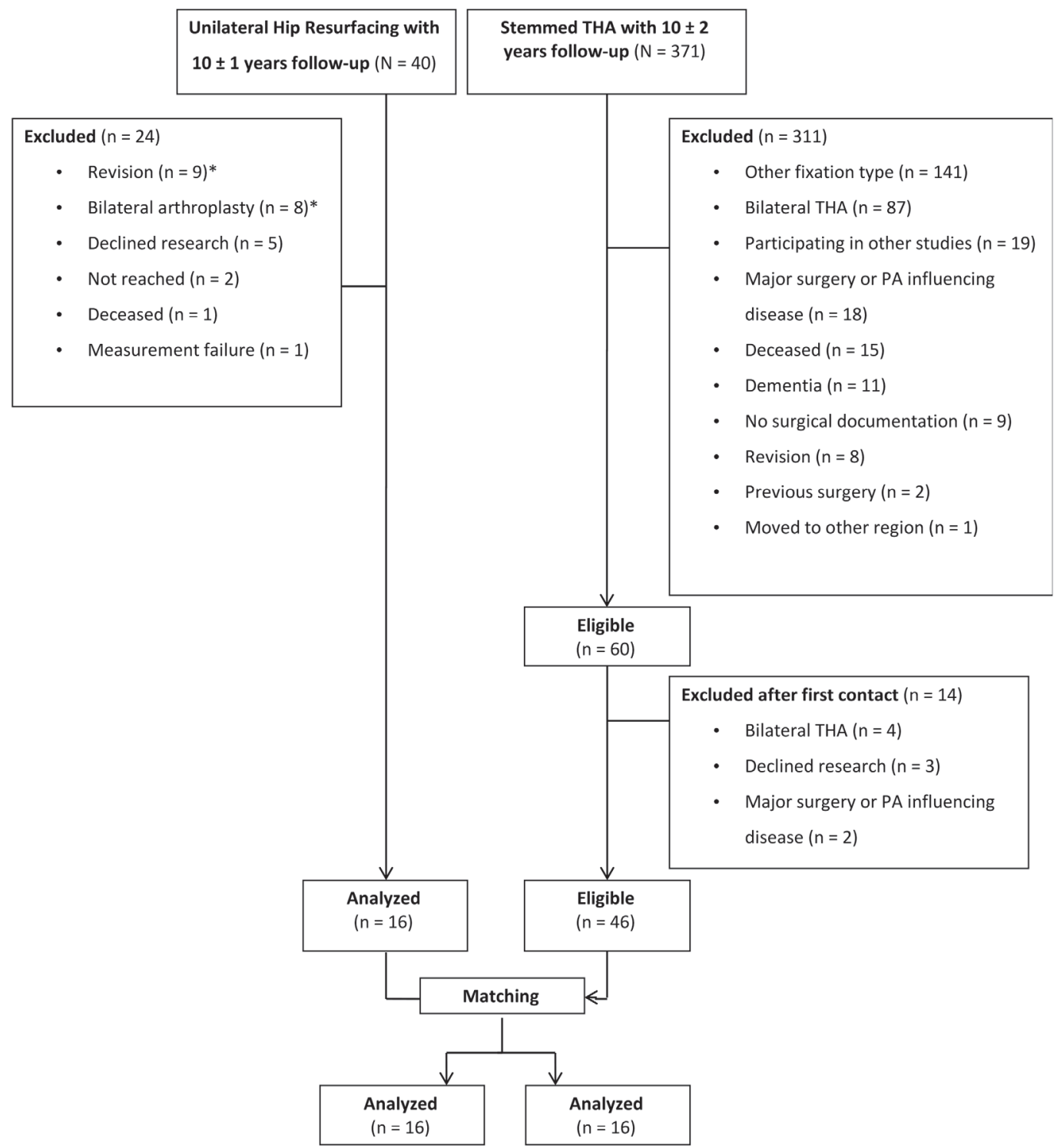

* One patient underwent revision surgery, but died a half year after due to a non-surgical reason. One patient underwent revision surgery and a primary arthroplasty contralateral a few years after.

Figure 1. Diagram of the number of patients enrolled and analyzed in this study. 


\section{Chapter 4}

This study was performed in compliance with the 1975 Declaration of Helsinki, as revised in 2013 and was studied and approved by the IRB (METC Zuyd, Heerlen, The Netherlands, IRB nr: 10N72 + amendment) and conducted in accordance with the guidelines for Good Clinical Practice (GCP). All patients signed informed consent. The authors declare they do not have any kind of conflict of interest.

\section{Statistics}

Group comparison (e.g. patient characteristics) and parameters of PA between the groups were performed using the Mann-Whitney $U$ test, because of the small groups, Pearson's chi-square test and, in case of expected cell-counts, Fisher's exact test were used to test for differences between groups present at baseline. For all analyses, a $p$-value was considered to be statistically significant at $P \leq 0.05$. Results are presented as median [range]. IBM SPSS Statistics 22 (Armonk, New York, United States) was used for statistical analysis.

\section{Results}

Groups had similar baseline characteristics (Table 1) and showed similar PA monitor parameters (Table 2) and PROMs (Table 3).

Table 1. Baseline Characteristics. Median [range]

\begin{tabular}{lcccc}
\hline & & HRA-Group & Stemmed THA-Group & P-value \\
\hline Sex $(\mathrm{M})$ & 12 & 12 & 1.0 \\
\hline Age at Surgery $(\mathrm{yr})$ & $56[43-67]$ & $60[53-68]$ & 0.1 \\
\hline Follow-up $(\mathrm{yr})$ & & $10[9-11]$ & $10[8-12]$ & 0.4 \\
\hline BMI $\left(\mathrm{kg} / \mathrm{m}^{2}\right)$ & & $26.1[22-37]$ & $29.0[20-40]$ & 0.1 \\
\hline Approach & Posterolateral & 7 & 7 & 1.0 \\
& Straight Lateral & 9 & 9 & - \\
\hline Bearing & MoM & $16(100 \%)$ & - & - \\
& MoP & - & $12(75 \%)$ & - \\
\hline
\end{tabular}

MoM = metal-on-metal, MoP = metal-on-polyethylene, $\mathrm{CoP}=$ ceramic-on-polyethylene 
Table 2. Parameters of Physical Activity Monitoring. Median [range]

\begin{tabular}{lccc}
\hline & HRA-Group & Stemmed THA-Group & P-value \\
\hline Total AM-wearing time (hr) & $12.4[10.7-16.2]$ & $14.3[10.5-16.0]$ & 0.1 \\
\hline Time Sitting (hr) & $7.6[4.6-12.0]$ & $9.6[3.8-12.7]$ & 0.1 \\
\hline Time Standing (hr) & $3.0[1.8-5.7]$ & $3.0[1.6-6.2]$ & 0.9 \\
Time Walked (hr) & $1.3[0.5-1.9]$ & $1.1[0.4-1.8]$ & 0.6 \\
Time Cycled (hr) & $0.05[0.0-0.48]$ & $0.01[0.0-1.2]$ & 0.5 \\
\hline Steps taken (number) & $5546[2274-9966]$ & $4583[1567-11749]$ & 0.6 \\
Sit-Stand-Transfers (number) & $39[21-74]$ & $37[24-65]$ & 0.7 \\
Cadence (steps/minute) & $102[81-112]$ & $98[80-110]$ & 0.3 \\
\hline
\end{tabular}

Table 3. Patient Reported Outcome Measures

\begin{tabular}{lccc}
\hline & HRA-Group & Stemmed THA-Group & P-value \\
\hline HOOS-PS & $87[49-100]$ & $67[49-100]$ & 0.3 \\
\hline FJS-12 & $63[2-100]$ & $56[4-100]$ & 0.5 \\
\hline SQUASH & $6150[1110-18480]$ & $4560[1050-9300]$ & 0.2 \\
\hline
\end{tabular}

\section{Discussion}

This observational matched-cohort study showed that patients with a unilateral HRA are not physically more active when compared to subjects with a unilateral stemmed MoP- or CoP-THA at 10-years follow-up. This is counterintuitive to expectations, as HRA patients received the theoretical advantages of the implant design (large, near physiological head diameter), surgical procedure (anatomical preservation) and represent a selection bias towards subjects presenting, being perceived by the surgeon or themselves expecting to be more physically active and demanding than patients in the stemmed conventional MoP/CoP small-diameter head THA-group. In addition, in this matched-cohort study, the median age and BMI was higher, but not significant, in the stemmed THA-group both established to be related with a less active lifestyle. Patients with both types of implants did not only have comparable mean PA levels but also showed identical ranges. Thus it seems that both implant types enable the same level of PA and that activity levels rather depend on individual lifestyle than on implant type, at least at 10-years follow-up.

PA is considered a major risk factor for a number of adverse health outcomes. Reaching a daily step count $>8000$ has been associated with a lower risk of all-cause mortality [17]. In our study 13 subjects (5 HRA, 8 stemmed THA) made $<5000$ steps/ 
day, 5 subject $\geq 8.000$ steps/day ( 2 HRA, 3 stemmed THA) and only 1 subject $>10.000$ steps/day (HRA). This suggests that almost half of the patients in this study would be considered living sedentary lifestyles with the associated risks of developing noncommunicable diseases [18]. Sedentary time as a parameter is related to but largely independent of PA levels and was numerically higher in THA than HRA $(p=.05)$, but this absolute time difference corresponds almost completely with the difference in total wear time between both groups, indicating more a difference in instructions or compliance to it for wear time (waking hours) than activity behavior.

The groups showed no statistically significant differences in the HOOS-PS and FJS-12, suggesting that the groups are comparable according to the assessed domains such as pain, patient satisfaction or perceived function. A 20-point mean difference was seen in the HOOS-PS in favor of HRA. This is in accordance with a recent publication of Oxblom et al. [19]. They studied 726 subjects 7-years after primary HRA or conventional THA showing a significant difference in HOOS subscales of function of daily living and function in sport and recreation, although HOOS subscales of symptoms, pain and quality of life, EQ-5D index and visual analog scores for pain and satisfaction did not differ.

It has been shown that patients 1 year after receiving stemmed THA only show little changes in objectively measured free-living PA compared with preoperative levels $[20,21]$. While the reason not to use a pain-free hip and improved functional capacity towards higher PA levels is multifactorial, one possible explanation is that, as PA levels are known to be related to wear of MoP bearings, long-term participation in high impact activities is usually not recommended [22]. However, there is only little prospective evidence reporting a poor clinical outcome with higher levels of activity [23]. In Danish and American guidelines and a Dutch survey most lowimpact activities were only allowed, though not necessarily promoted post-THA [24]. This is in contrast with the advice given by orthopaedic surgeons to HRA patients and the publicity of HRA manufacturers calling it a 'sporting hip'. Multiple studies have shown a high return to sport, including high intensity activities such as long-distance triathlon, after HRA $[2,25]$. For subjects with a conventional THA this has not been advised but may be possible.

The studies in current literature comparing PA or sports participation in HRA and stemmed THA have all been performed using (weighted) PA questionnaires $[8,9]$. Our study is one of the first in its kind to evaluate habitual PA in the free living environment by a wearable AM. Questionnaires are limited by the highly subjective nature and ceiling effect, which is in contrast to the objectively 
results by AM [10]. Zywiel et al. performed a study comparing PA, measured by a weighted questionnaire (comparable with the SQUASH), in HRA and matched cohort of patients with a stemmed THA [8]. At final follow-up (3-4 years) the HRAgroup had a higher mean weighted activity score than the stemmed THA-group $(p<0.01)$, while activities preoperative were similar. It was not described if there were differences regarding the instructions for postoperatively approved (high intense) PA. Other comparison studies by Pollard et al., Vail et al. and Mont et al. used UCLA activity scores and weighted activity scores and found a higher degree of PA in HRA, although these studies have numerous limitations mainly related to the uncontrolled bias of HRA towards very high pre-operative PA levels $[9,26,27]$. Our study has limitations. The number of subjects was rather low. The main cause for this was the initially strict inclusion criteria for the initial HRA study [13]. Another limitation was that no objective information, e.g. PA monitoring data, was available of the preoperative setting of the subjects. This might have influenced our results, because the physically more active patients could have been indicated for hip resurfacing at the time of surgery, and thus, selection bias may have occurred. However, such a possible selection bias would further support the finding of this study.

\section{Conclusion}

This is the first study comparing postoperative PA levels between HRA and stemmed THA using wearable sensors for objective PA measures. HRA theoretically supports high PA levels, by design and surgery, which should result in a difference at 10-years, although this study found no differences in PA and even ranges are comparable. Even well-reasoned theoretical advantages about functional advantages of any implant design require clinical validation and should not be assumed for indication (especially at risk of a disadvantage). While short-term effects may exist, ageing and related behavioral adaptations or other effects seem to render the theoretical activity benefits from HRA irrelevant at longer follow-up. PA levels at long followup seem to depend less on implant type but on other factors warranting further research to ensure the related health benefits in THA patients. 


\section{References}

1. Corten K, Ganz R, Simon JP, Leunig M. Hip resurfacing arthroplasty: current status and future perspectives. Eur Cell Mater. 2011 Mar 15;21:243-58.

2. Girard J, Lons A, Pommepuy T, Isida R, Benad K, Putman S. High-impact sport after hip resurfacing: The Ironman triathlon. Orthop Traumatol Surg Res. 2017 Sep;103(5):675-678

3. Nantel J, Termoz N, Vendittoli PA, Lavigne M, Prince F. Gait patterns after total hip arthroplasty and surface replacement arthroplasty. Arch Phys Med Rehabil. 2009 Mar;90(3):463-9

4. Gerhardt DMJM, Mors TGT, Hannink G, Van Susante JLC. Resurfacing hip arthroplasty better preserves a normal gait pattern at increasing walking speeds compared to total hip arthroplasty. Acta Orthop. 2019 Jun;90(3):231-23

5. Verhaar JA. [The hard lesson of metal-on-metal hip implants]. Ned Tijdschr Geneeskd, 2012. 156(42): p. A5564.

6. Narvani AA, Tsiridis E, Nwaboku HC, Bajekal RA. Sporting activity following Birmingham hip resurfacing. Int J Sports Med. 2006 Jun;27(6):505-7.

7. Naal FD, Maffiuletti NA, Munzinger U, Hersche O. Sports after hip resurfacing arthroplasty. Am J Sports Med. 2007 May;35(5):705-11

8. Zywiel MG, Marker DR, McGrath MS, Delanois RE, Mont MA. Resurfacing matched to standard total hip arthroplasty by preoperative activity levels - a comparison of postoperative outcomes. Bull NYU Hosp Jt Dis. 2009;67(2):116-9.

9. Mont MA, Marker DR, Smith JM, Ulrich SD, McGrath MS. Resurfacing is comparable to total hip arthroplasty at short-term follow-up. Clin Orthop Relat Res. 2009 Jan;467(1):66-71.

10. Terwee CB, Bouwmeester W, van Elsland SL, de Vet HC, Dekker J. Instruments to assess physical activity in patients with osteoarthritis of the hip or knee: a systematic review of measurement properties. Osteoarthritis Cartilage. 2011 Jun;19(6):620-33

11. Lipperts M, van Laarhoven S, Senden R, Heyligers I, Grimm B. Clinical validation of a bodyfixed 3D accelerometer and algorithm for activity monitoring in orthopaedic patients. J Orthop Translat. 2017 Feb 27;11:19-29

12. Jelsma J, Schotanus MG, Senden R, Heyligers IC, Grimm B. Metal Ion Concentrations after Metal-on-Metal Hip Arthroplasty are Not Correlated with Habitual Physical Activity. Hip Int. 2019 Nov;29(6):638-646.

13. Jelsma J, Schotanus MGM, van Kuijk SMJ, Buil ITAF, Heyligers IC, Grimm B. Quality, but not quantity of physical activity is associated with metal ion concentrations in unilateral hip resurfacing. J Orthop Res. 2020 Feb 22. doi: 10.1002/jor.24637.

14. Davis AM, Perruccio AV, Canizares M, Tennant A, Hawker GA, Conaghan PG et al. The development of a short measure of physical function for hip OA HOOS-Physical Function Shortform (HOOSPS): an OARSI/OMERACT initiative. Osteoarthritis Cartilage. 2008 May;16(5):551-9

15. Behrend $\mathrm{H}$, Giesinger K, Giesinger JM, Kuster MS. The "forgotten joint" as the ultimate goal in joint arthroplasty: validation of a new patient-reported outcome measure. J Arthroplasty. 2012 Mar;27(3):430-436

16. Wendel-Vos GC, Schuit AJ, Saris WH, Kromhout D. Reproducibility and relative validity of the short questionnaire to assess health-enhancing physical activity. J Clin Epidemiol. 2003 Dec;56(12):1163-9.

17. Saint-Maurice PF, Troiano RP, Bassett DR Jr, Graubard BI, Carlson SA, Shiroma EJ et al. Association of Daily Step Count and Step Intensity With Mortality Among US Adults. JAMA. 2020 Mar 24;323(12):1151-1160

18. Tudor-Locke C, Craig CL, Aoyagi Y, Bell RC, Croteau KA, De Bourdeaudhuij I et al. How many steps/day are enough? For older adults and special populations. Int J Behav Nutr Phys Act. 2011 Jul 28;8:80

19. Oxblom A, Hedlund H, Nemes S, Brismar H, Felländer-Tsai L, Rolfson O. Patient-reported outcomes in hip resurfacing versus conventional total hip arthroplasty: a register-based matched cohort study of 726 patients. Acta Orthop. 2019 Aug;90(4):318-323.

20. Jeldi AJ, Deakin AH, Allen DJ, Granat MH, Grant M, Stansfield BW. Total Hip Arthroplasty Improves Pain and Function but Not Physical Activity. J Arthroplasty. 2017 Jul;32(7):2191-219 
21. Thewlis D, Bahl JS, Fraysse F, Curness K, Arnold JB, Taylor M et al. Objectively measured 24-hour activity profiles before and after total hip arthroplasty. Bone Joint J. 2019 Apr;101-B(4):415-425

22. Schmalzried TP, Shepherd EF, Dorey FJ, Jackson WO, dela Rosa M, Fa'vae F et al. The John Charnley Award. Wear is a function of use, not time. Clin Orthop Relat Res. 2000 Dec;(381):3646

23. Meira EP, Zeni J Jr. Sports participation following total hip arthroplasty. Int J Sports Phys Ther. 2014 Nov;9(6):839-50.

24. Meester SB, Wagenmakers R, van den Akker-Scheek I, Stevens M. Sport advice given by Dutch orthopaedic surgeons to patients after a total hip arthroplasty or total knee arthroplasty. PLoS One. 2018 Aug 30;13(8):e0202494

25. Fouilleron N, Wavreille G, Endjah N, Girard J. Running activity after hip resurfacing arthroplasty: a prospective study. Am J Sports Med. 2012 Apr;40(4):889-94

26. Pollard TC, Baker RP, Eastaugh-Waring SJ, Bannister GC. Treatment of the young active patient with osteoarthritis of the hip. A five- to seven-year comparison of hybrid total hip arthroplasty and metal-on-metal resurfacing. J Bone Joint Surg Br. 2006 May;88(5):592-600.

27. Vail TP, Mina CA, Yergler JD, Pietrobon R. Metal-on-metal hip resurfacing compares favorably with THA at 2 years followup. Clin Orthop Relat Res. 2006 Dec;453:123-31. 


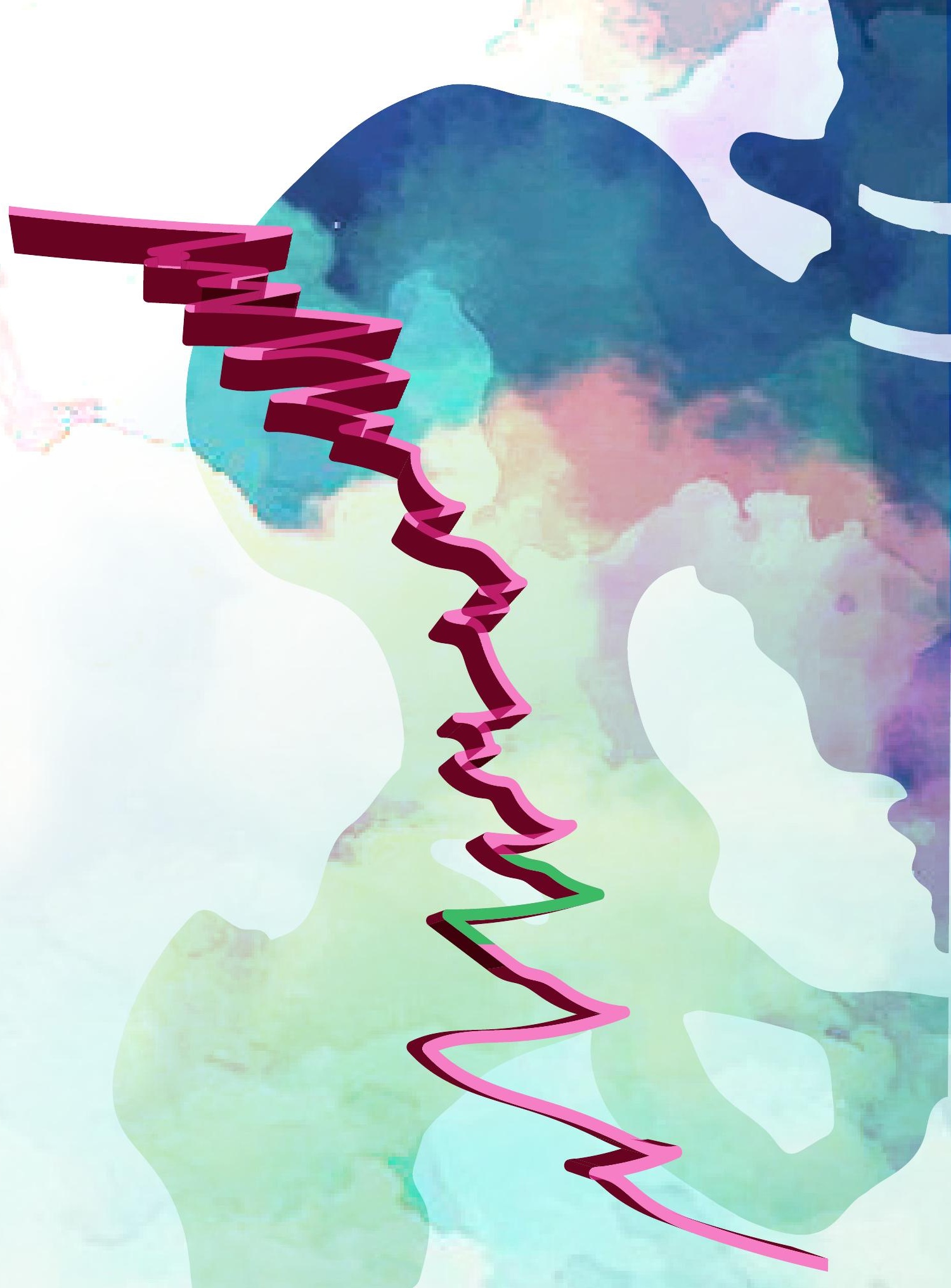




\section{Chapter V}

Only limited correlations between patient-reported outcomes and objectively monitored physical activity 10-years after THA

Accepted in: Acta Orthop Belg on 06.06.2021

Jelsma J, van Kuik S, Buil I, Heyligers I, Grimm B, Schotanus M

It's not whether you get knocked down, it's whether you get up

(Vince Lombardi) 


\section{Abstract}

\section{Introduction}

In orthopaedics, patient reported outcomes (PROMs) are designed to quantify changes in pain and to assess physical function, most often after joint arthroplasty. However, PROMs have some disadvantages; most important is their subjective nature. The aim was to investigate how patient-self-reported-outcomes of general health, disease-specific outcome and physical function, joint-awareness and selfperceived activity levels are correlated with objectively-measured physical-activity (PA) parameters derived from wearable activity-monitors (AM) in subjects with a hip-arthroplasty.

\section{Methods}

A prospective cohort study was conducted in a group of 32 patients, with a mean follow-up of 10 years after total hip arthroplasty. To assess different domains, the SF36 (general health), HOOS-PS (pain/functional outcome), FJS-12 (joint awareness) and SQUASH (physical activity) were chosen. Activity-monitoring was performed using a 3-axis accelerometer, gyroscope and magnetometer.

\section{Results}

No significant correlations between PA-parameters and the FJS-12 and SQUASH were found. The HOOS-PS was significant correlated with BMI, the daily time walking and total-time active and the amount of daily steps. The physical functioning-subscale of the SF-36 was significant negative correlated with BMI and time sitting, but significant positive correlated with time walking, total-time active and the amount of daily steps.

\section{Discussion}

Considering the value of PA for maintaining general health, the value of using sensorbased AMs to assess efficacy of treatments in this health related dimension or use it as a tool for patient education, awareness and communication, seems very high. 


\section{Introduction}

Physical activity (PA) is recognised as an important factor for health benefits. The World Health Organization (WHO) has developed public health-oriented PA guidelines because physical inactivity is a risk factor for chronic diseases and premature mortality [1]. To quantify PA, multiple techniques are used that can be divided into direct methods (e.g. accerelometers) and indirect methods including questionnaires retrospectively collecting patient perceptions of an outcome dimension [2]. Patient Reported Outcome Measures (PROMs) are used to quantify a disease state or interventional outcome as perceived by the patient, potentially improving care [3]. PROMs are available to measure pain, satisfaction, psychological dimensions such as kinesophobia or awareness and also PA. In orthopaedics, PROMs are designed to quantify changes in pain and to assess physical function (PF), most often after joint arthroplasty [4,5]. The International Society of Arthroplasty Registries (ISAR) stated that PROMs are the best objective tool currently available to evaluate patient-centered outcomes [6]. While commonly used, PROMs can suffer from their subjective nature, recall bias, ceiling effects, time consuming methodology, low response and completion rate or transcription errors [7-10].

Objective function can be assessed by performance tests such as the 'Timed-Up and Go-test (TUG)' or gait analysis in a biomechanic laboratory, but also by activity monitoring in daily life capturing PA behavior (e.g. number of steps) and qualitative aspects of PA (e.g. steps per minute). Self-reported PF and objectively measured function after total hip (THA) or knee arthroplasty (TKA) are increasingly reported in the literature before and at various time points after surgery, but also shows the limitations of PROMs [11]. Within the first 3-weeks after THA or TKA patients report improved PF (HOOS \& KOOS), but this was not correlated with objectively assessed PF (paced-walk, chair-stand,stair-climb tests)[12]. Also, at 4-months follow-up selfreported PF (HOOS \& KOOS) improved significantly whereas performance-based function (30-second chair stand-test) improved only slightly [13]. HOOS scores one year after THA were not in line with objectively measured improvements in performance-based function and gait [14].

Wearable activity-monitors (AMs) are able to differentiate between different PA types in the free living environment (e.g. stand, walk, and sit). The major purpose and patient expectation of THA is the reduction in pain and restoration of function. It is unknown if and how PROMs after THA reflect levels or qualitative aspects of PA in daily life as captured with wearable AMs. The aim of this study was to investigate how PROMs of various dimensions, general health, disease specific outcome and in 
particular PF, joint awareness and self-perceived activity levels are correlated with objectively measured PA parameters derived from wearable AMs in subjects with a hip arthroplasty.

\section{Material and Methods}

A prospective cohort study was conducted between August 2017 and June 2018. First, patients with a primary unilateral hip resurfacing arthroplasty (HRA) at $10 \pm$ 1 year were included. A total of 40 patients were eligible, but 24 were excluded, among them 9 revisions and 8 declines in follow-up/research. The other group of patients received a unilateral stemmed THA with a small diameter femoral head $(28 \mathrm{~mm})$ on conventional polyethyelene with osteoarthritis as indication for surgery. This group was matched with the HRA-group for sex, age at surgery, follow-up since surgery (8-12 years) and BMI. The groups were initially included for another study, the methods of which are described in detail elsewhere [15]. For the current study all data were merged. This study was conducted in accordance with the Good Clinical Practice (GCP)-guidelines and performed in compliance with the 1975 Declaration of Helsinki, as revised in 2013. The study was approved by the IRB (METC-Z, Heerlen, The Netherlands, IRB: 10N72 + amendment). All included patients signed informed consent.

Activity monitoring was performed and PROMs were collected at one moment in follow-up, close to 10-years follow-up (8-12 years). A 3-axis accelerometer, gyroscope and magnetometer (HAM-IMU+alt, Gulf Coast Data Concepts LLC, Waveland Missipi, United States) was used. The AM was applied on the lateral side of the affected upper-leg using skin-friendly tape. Patient's habitual PA patterns can be representatively characterized by measuring activity for 3-4 days $[16,17]$. PA was measured during waking hours for four consecutive days in daily living with a minimum of $8 \mathrm{~h}$ per day. The raw signal received with this $A M$ was analysed using published algorithms in MATLAB (MATLAB R2017a, The Mathworks Inc., Natick, Massachusetts, United States). This approach has been previously described and validated in a semi-free setting and achieved an excellent accuracy (>97\%) in determining PA levels in healthy subjects and subjects after unilateral total joint arthroplasty $[18,19]$.

The PROMs used in the current study were chosen to assess different domains and thus to study their respective correlation with objective levels and qualitative aspects of PA: general health (SF-36), pain and functional outcome (HOOS-PS), 
joint awareness and satisfaction (FJS-12) and physical activity (SQUASH). The 36item short-form (SF-36) was constructed to survey health status and designed to use in clinical practice and research. It includes eight health concepts: physical functioning, role physical, bodily pain, general health, vitality, social functioning, role emotional and mental health. For all subscales 100 is the best score and 0 the least. Only the subscale physical functioning (PF) was used [20]. The disability and Osteoarthritis Outcome Score - Physical Function Short Form (HOOS-PS) is a validated measure of physical function. The score ranges from extreme difficulties (0) to no difficulties (100) in physical function [21,22]. The 12-item Forgotten Joint Score (FJS-12) was designed to evaluate the patients' ability to forget about a joint as a result of a successful treatment. It consists of 12 questions about awareness of an artificial joint with five answer possibilities ranging from never to mostly. The FJS12 is validated and was shown to have a high internal consistency and a low ceiling effect [23]. The score ranges from 0 (worst) to 100 (best). The Short Questionnaire to Assess Health-enhancing physical activity (SQUASH) is a questionnaire to measure PA. The domain scores were calculated by multiplying the number of minutes per week with an intensity score (range 1-9) which is based on the reported intensity combined with the classification according to Ainsworth's Compendium of Physical Activities [24,25]. The sum of the scores per domain is the total activity score, which was used for this study. In order to reach sufficient content validity, van Poppel et al. recommended that at least duration and frequency should be determined by a questionnaire assessing total PA and should also cover PA in all settings during daily life [26]. This is in accordance with the FITT components established by the WHO (frequency, intensity, type and time). In light of this recommendation, the SQUASH was the only questionnaire in the current study to specifically assess PA and able to determine if patients meet recommendations for PA [27]. No funding was obtained.

\section{Statistical analysis}

Parameters of PA and results of the PROMs were averaged for the whole cohort and reported as mean \pm standard deviation (SD) [range] or with numbers and proportions (\%). Pearson's correlation coefficient ( $r$ ) was computed to quantify the correlation between parameters of PA and results of PROMs. Correlations of 0.20 0.39 were considered 'weak', 0.40-0.59 'moderate' and 0.60-0.79 'strong' [28]. No multivariate analyses were performed because the goal was to show the degree of linear relationship between two continuous measures (e.g. PROMs and PA). For all analyses, a $\mathrm{p}$-value was considered to be statistically significant at $\mathrm{P} \leq 0.05$. IBM SPSS Statistics 22 (International Business Machines Corporation, Armonk, New York, United States) was used for statistical analysis. 


\section{Chapter 5}

\section{Results}

A total of 32 subjects with 32 hip arthroplasties were included. Baseline characteristics (e.g. BMI, age) and follow-up time are summarized in Table 1.

The results of the PROMs and parameters of PA monitoring, all showing large value ranges, are shown in Table 2 and 3. Correlation coefficients were computed for PROMs with baseline characteristics and PA parameters. No significant correlations were found for the FJS-12. The HOOS-PS was statistically significant correlated with $\mathrm{BMI}$ (negative correlation), the daily time walking, the daily total time active and the amount of daily steps. The SQUASH was only statistically significant negative correlated with the age at surgery, but not with any of the objectively measured PA parameters. The PF-subscale of the SF-36 was statistically significant negative correlated with BMI and the time sitting, but statistically significant positive correlated with the time walking, the total time active and the amount of daily steps (Table 4).

Table 1. Baseline Characteristics

\begin{tabular}{lc}
\hline Sex & $24 \mathrm{M}(75 \%)-8 \mathrm{~F}(25 \%)$ \\
Age at Surgery (years) & $57.8 \pm 5.7[43.0-68.0]$ \\
Follow-Up (years) & $9.9 \pm 0.9[8.5-11.8]$ \\
$\mathrm{BMI}\left(\mathrm{Kg} / \mathrm{M}^{2}\right)$ & $28.2 \pm 4.9[20.4-39.8]$ \\
\hline
\end{tabular}

Table 2. Results of PROMs

\begin{tabular}{lc}
\hline SF-36 PF $(n=32)$ & $70 \pm 22[25-100]$ \\
HOOS-PS $(n=25)$ & $77 \pm 19[49-100]$ \\
FJS-12 $(n=31)$ & $56 \pm 31[2-100]$ \\
SQUASH $(n=29)$ & $5744 \pm 4103[1050-18480]$ \\
\hline
\end{tabular}


Table 3. Parameters of Physical Activity Monitoring

\begin{tabular}{lc}
\hline AM wearing days & $3.6 \pm 0.7[2-4]$ \\
Total measured time (hours) & $13.1 \pm 1.8[10.5-16.2]$ \\
Time sitting (hours) & $8.4 \pm 2.2[3.8-12.7]$ \\
Time standing (hours) & $3.3 \pm 1.3[1.6-6.2]$ \\
Time walking (hours) & $1.2 \pm 0.5[0.4-2.2]$ \\
Time cycling (hours) & $0.2 \pm 0.3[0.0-1.2]$ \\
Total time active (\%) & $10.4 \pm 4.4[3.4-20.0]$ \\
Sit-Stand Transfers (number) & $40 \pm 13[21-74]$ \\
Steps (number) & $5434 \pm 2566[1567-11749]$ \\
Cadence (steps/min) & $98 \pm 10[80-112]$ \\
Intensity Peaks $<2.0 \mathrm{~g}$ (number) & $27135 \pm 20741[2442-85974]$ \\
Intensity Peaks $>2.0 \mathrm{~g}$ (number) & $886 \pm 1670[0-8097]$ \\
\hline
\end{tabular}

*Daily values except AM wearing days and cadence

Table 4. Pearson's R correlation

\begin{tabular}{lcccc}
\hline & HOOS-PS & SQUASH & FJS-12 & SF-36 PF \\
\hline Age at surgery & -.031 & $-.592 * *$ & .226 & -.310 \\
BMI & $-.590^{* *}$ & -.041 & -.358 & $-.537^{* *}$ \\
Time sitting & -.395 & -.208 & -.034 & $-.407^{*}$ \\
Time standing & .267 & .211 & .021 & .327 \\
Time walking & $.498^{*}$ & .273 & .260 &. $\mathbf{5 0 0 * *}$ \\
Time cycling & -.042 & -.006 & .030 & .144 \\
Total time active &. $\mathbf{4 4 7 *}$ & .247 & .229 & $\mathbf{. 5 2 4 * *}$ \\
Sit-Stand Transfers & -.065 & -.333 & .063 & -.081 \\
Steps &. $\mathbf{4 0 8 *}$ & .199 & .209 & $\mathbf{. 4 4 5 *}$ \\
Cadence & .172 & .198 & .134 & .345 \\
Intensity Peaks $<2.0 \mathrm{~g}$ & .149 & -.050 & .228 & .165 \\
Intensity Peaks $>2.0 \mathrm{~g}$ & .142 & -.031 & .265 & .118
\end{tabular}

* Correlation is significant at the 0.05 level (2-tailed)

** Correlation is significant at the 0.01 level (2-tailed) 


\section{Discussion}

The aim of this study was to investigate the correlation between PROMs of different outcome dimensions and objectively measured PA in daily life with the use of a wearable AM in subjects 10-years after unilateral hip arthroplasty. The main finding of this study was that objectively measured PA levels (time walking, total time active, amount of steps) does not show a correlation with the FJS-12 and SQUASH, but does show a significant correlation with the HOOS-PS and PF-subscale of the SF-36 for which also sedentary time was correlated, though negatively as can be expected. The correlations found however were of moderate strength.

The SQUASH is a patient self-report of PA levels and thus is supposed to directly and most closely capture the dimensions assessed by the sensor-based PA. However, even for the same construct, the current study could not identify a correlation. Previous studies in orthopaedic populations investigating a correlation between the SQASH and objective PA measures from accelerometry could find some, mostly weak correlations. Patients after THA with unknown follow-up wore the ActiGraph accelerometer on a belt on the waist during a two-week period. Outcome, expressed in counts (the sum of accelerations measured during a time interval), was statistically significant correlated $\left(r_{\text {spearman }} 0.67, p=0.01\right)$ with the total activity score of the SQUASH [29]. This was higher than found in the study by Wendel-Vos et al. who reported a Spearman correlation coefficient of 0.45 in healthy adults with the use of the Computer Science and Applications (CSA) Activity Monitor [24]. The ActiGraph generation used in these studies was a uniaxial accelerometer which is relative insensitive to PA that requires little vertical movements like cycling. In these studies, PA was not classified in activities but summarized in an intensity count related overall metric. The AM used in the current study does not have this limitation. Terwee et al. stated that a questionnaire assessing PA should be correlated to an accelerometer by at least 0.50 [30]. Unexpected, no correlations were found between the SQUASH and the time walked and total time active, not achieving the 0.50 limit stated by Terwee et al.

Analysis of AM parameters showed that the total time active, time walked and number of steps were all statistically significant positive correlated with the HOOSPS. The HOOS-PS reports for PA during daily life, though not reporting for duration and frequency of PA as recommended by van Poppel et al., but by registering the prevalence and level of difficulties experienced during specific activities of daily life [26]. Apparently such difficulties experienced during descending stairs, getting in/ out bath or shower, sitting, running and twisting/pivoting on a loaded leg are more 
closely related with the ability of being active in daily life as represented by the total time active, time walked and number of steps performed. Nevertheless, the correlation is only moderate, which means that general and health related PA levels such as walking, daily steps taken and non-sedentary time are and can be achieved in THA patients with or without such self-reported difficulties. The investigation of such discrepancies may reveal valuable insights into THA patient outcomes and potential interventions beyond orthopaedics.

This study is the first in current literature correlating the FJS-12 with objectively measured PA. No correlations were found. The FJS-12 was designed to evaluate the patients' ability to forget about their operated joint in everyday life as a result of a successful arthroplasty. Subjects are asked for the awareness of an artificial joint during twelve different activities including physically demanding activities such as walking for more than 15 minutes, climbing stairs and when doing their favourite sport. In theory a high score and thus often forgotten joint during various activities shall facilitate and lead to higher and more intense PA in daily live. Subanalysis on the different questions was not performed, because the goal was to correlate the complete questionnaire with the objectively measured PA. The mean FJS-12 in the current study was low. Rosinsky et al. stated a threshold for success after THA with FJS-12 scores of 73.96 and 69.79 at 1- and 2-years follow-up respectively [31]. The current study reported the FJS-12 at almost 10-years follow-up and was highly influenced by three subjects with scores $<5$. In addition, a recent longitudinal study in TKA with a mean follow-up of 8.1 years (range 7.3 - 9.4) showed that PROMs and objective outcome measures drop over time [32]. Correlation testing also showed no statistically significant correlation between the FJS-12 and the SQUASH $\left(r_{\text {pearson }} .099, p=.616\right)$. It seems that daily life PA is not influenced by the degree of forgetting to have a hip replacement, both in self-report and objectively measured, but is influenced by other factors.

The present study does have limitations. At first, the SQUASH (91\%) and FJS-12 $(97 \%)$ were completed by a sufficient amount of subjects. However the analysis of the HOOS-PS was limited by a lower response and completion rate of 25 (78\%) subjects submitting fully completed questionnaires, which seems more a limitation of the PROM itself. The 'running-difficulties' question was the main question not completed. Presumably because these subjects never tried to run and thus were not able to answer how much difficulty they experienced during running. Although one may think that 'extreme difficulties' is the appropriate answer for these subjects, the HOOS-PS requires five answers to calculate a total score. In comparison, in the current study the AM was worn for the appropriate 3 or 4 days by $88 \%$ of the subjects for a 


\section{Chapter 5}

mean $13.1 \pm 1.8$ hours per day and all data were available for analysis. PROMs remain inherently subjective, prone to an individual's interpretation and perception of joint functioning. Patients can have difficulties in keeping other negative conditions or illnesses out of consideration that might have impaired mobility, general condition or quality of life. The used PROMs don't take in to account for negative conditions or illnesses [33]. The fact that subjectively reported PA levels and objectively measured PA levels do not correlate may hint at the fact, that it is inherently difficult to recall in detail PA durations and frequencies without bias questioning this approach for individual or group outcome studies but limiting it maybe to large population based research where sensor-based assessment is not yet possible. A combination of PROMs and AM displays a patient's perception on physical functioning and the practitioner/researchers view on objectively determined PA of THA patients.

\section{Conclusions}

In conclusion, this study shows that PROMs are hardly affected by or do hardly capture levels and differences in objectively measured PA, a supposedly patient centred outcome and a goal of THA. Considering the value of PA for maintaining general health, and the restoration of PA via surgery such as THA, the value of using sensor based AMs to assess efficacy of treatments in this health related dimension or use it as a tool for patient education, awareness and communication, seems very high. Future studies should focus on the changes in health status as measured by PROMs and the correlation with objectively measured PA, for example pre and post total joint arthroplasty. 


\section{References}

1. Kahlmeier S, Wijnhoven TM, Alpiger $\mathrm{P}$ et al. National physical activity recommendations: systematic overview and analysis of the situation in European countries. BMC Public Health, 2015. 15: p. 133.

2. Lamonte MJ, Ainsworth BE. Quantifying energy expenditure and physical activity in the context of dose response. Med Sci Sports Exerc, 2001. 33(6 Suppl): p. S370-8; discussion S419-20.

3. Snyder CF, Aaronson NK, Choucair AK et al. Implementing patient-reported outcomes assessment in clinical practice: a review of the options and considerations. Qual Life Res, 2012. 21(8): p. 1305-14.

4. Fidai MS, Saltzman BM, Meta F etal. Patient-Reported Outcomes Measurement Information System and Legacy Patient-Reported Outcome Measures in the Field of Orthopaedics: A Systematic Review. Arthroscopy, 2018. 34(2): p. 605-614.

5. Siljander MP, McQuivey KS, Fahs AM et al. Current Trends in Patient-Reported Outcome Measures in Total Joint Arthroplasty: A Study of 4 Major Orthopaedic Journals. J Arthroplasty, 2018. 33(11): p. 3416-3421.

6. Rolfson O, Bohm E, Franklin P et al. Patient-Reported Outcome Measures Working Group of the International Society of Arthroplasty Registries. Patient-reported outcome measures in arthroplasty registries Report of the Patient-Reported Outcome Measures Working Group of the International Society of Arthroplasty Registries Part II. Recommendations for selection, administration, and analysis. Acta Orthop, 2016. 87 Suppl 1: p. 9-23.

7. Pronk Y, Pilot P, Brinkman JM, van Heerwaarden RJ, van der Weegen W. Response rate and costs for automated patient-reported outcomes collection alone compared to combined automated and manual collection. J Patient Rep Outcomes, 2019. 3(1): p. 31.

8. Chughtai M, Khlopas A, Mistry JB et al. Time Burden of Standardized Hip Questionnaires. Surg Technol Int, 2016. 28: p. 280-4.

9. Steinhoff AK, Bugbee WD. Knee Injury and Osteoarthritis Outcome Score has higher responsiveness and lower ceiling effect than Knee Society Function Score after total knee arthroplasty. Knee Surg Sports Traumatol Arthrosc, 2016. 24(8): p. 2627-33.

10. Weber BA, Yarandi H, Rowe MA, Weber JP. A comparison study: paper-based versus web-based data collection and management. Appl Nurs Res, 2005. 18(3): p. 182-5.

11. Bolink SA, Lenguerrand E, Brunton LR et al. Assessment of physical function following total hip arthroplasty: Inertial sensor based gait analysis is supplementary to patient-reported outcome measures. Clin Biomech (Bristol, Avon), 2016. 32: p. 171-9.

12. Luna IE, Kehlet $\mathrm{H}$, Peterson $B$ et al. Early patient-reported outcomes versus objective function after total hip and knee arthroplasty: a prospective cohort study. Bone Joint J, 2017. 99-B(9): p. 1167-1175.

13. Mark-Christensen $\mathrm{T}$, Kehlet $\mathrm{H}$. Assessment of functional recovery after total hip and knee arthroplasty: An observational study of 95 patients. Musculoskeletal Care, 2019.

14. Naili JE, Hedström M, Broström EW. Changes of and interrelationships between performancebased function and gait and patient-reported function 1 year after total hip arthroplasty. J Orthop Traumatol, 2019. 20(1): p. 14.

15. Jelsma J, Schotanus M, Buil I et al. Patients with hip resurfacing arthroplasty are not physically more active than those with a stemmed total hip. Accepted by Acta Orthopedica 2020

16. Mâsse LC, Fuemmeler BF, Anderson CB et al. Accelerometer data reduction: a comparison of four reduction algorithms on select outcome variables. Med Sci Sports Exerc, 2005. 37(11 Suppl): p. S544-54.

17. Kang $M$, Hart PD, Kim Y. Establishing a threshold for the number of missing days using $7 \mathrm{~d}$ pedometer data. Physiol Meas, 2012. 33(11): p. 1877-85.

18. Lipperts M, van Laarhoven S, Senden R, Heyligers I, Grimm B. Clinical validation of a bodyfixed 3D accelerometer and algorithm for activity monitoring in orthopaedic patients. J Orthop Translat. 2017 Feb 27;11:19-29.

19. van Laarhoven SN, Lipperts M, Bolink SA et al. Validation of a novel activity monitor in impaired, slow-walking, crutch-supported patients. Ann Phys Rehabil Med, 2016. 59(5-6): p. 308-313. 


\section{Chapter 5}

20. Laucis NC, Hays RD, Bhattacharyya T. Scoring the SF-36 in Orthopaedics: A Brief Guide. J Bone Joint Surg Am, 2015. 97(19): p. 1628-34.

21. Davis AM, Perruccio AV, Canizares $M$ et al. The development of a short measure of physical function for hip OA HOOS-Physical Function Shortform (HOOS-PS): an OARSI/OMERACT initiative. Osteoarthritis Cartilage, 2008. 16(5): p. 551-9.

22. Davis AM, Perruccio AV, Canizares $M$ et al. Comparative, validity and responsiveness of the HOOS-PS and KOOS-PS to the WOMAC physical function subscale in total joint replacement for osteoarthritis. Osteoarthritis Cartilage, 2009. 17(7): p. 843-7.

23. Adriani M, Malahias MA, Gu A et al. Determining the Validity, Reliability, and Utility of the Forgotten Joint Score: A Systematic Review. J Arthroplasty, 2019.

24. Wendel-Vos GC, Schuit AJ, Saris WH, Kromhout D. Reproducibility and relative validity of the short questionnaire to assess health-enhancing physical activity. J Clin Epidemiol, 2003. 56(12): p. 1163-9.

25. Ainsworth BE, Haskell WL, Herrmann SD et al. 2011 Compendium of Physical Activities: a second update of codes and MET values. Med Sci Sports Exerc, 2011. 43(8): p. 1575-81.

26. van Poppel MN, Chinapaw MJ, Mokkink LB, van Mechelen W, Terwee CB. Physical activity questionnaires for adults: a systematic review of measurement properties. Sports Med, 2010. 40(7): p. 565-600.

27. Terwee CB, Bouwmeester W, van Elsland SL, de Vet HC, Dekker J. Instruments to assess physical activity in patients with osteoarthritis of the hip or knee: a systematic review of measurement properties. Osteoarthritis Cartilage, 2011. 19(6): p. 620-33.

28. Evans, JD. Straightforward Statistics for the Behavioral Sciences. Brooks/Cole Publishing; Pacific Grove, Calif.: 1996

29.. Wagenmakers R, van den Akker-Scheek I, Groothoff JW et al. Reliability and validity of the short questionnaire to assess health-enhancing physical activity (SQUASH) in patients after total hip arthroplasty. BMC Musculoskelet Disord, 2008. 9: p. 141.

30. Terwee CB, Mokkink LB, van Poppel MN et al. Qualitative attributes and measurement properties of physical activity questionnaires: a checklist. Sports Med, 2010. 40(7): p. 525-37.

31. Rosinsky PJ, Chen JW, Lall AC et al. Can We Help Patients Forget Their Joint? Determining a Threshold for Successful Outcome for the Forgotten Joint Score. J Arthroplasty. 2020 Jan;35(1):153-159

32. Hamilton DF, Burnett R, Patton JT et al. Reduction in patient outcomes but implant-derived preservation of function following total knee arthroplasty: longitudinal follow-up of a randomized controlled trial. Bone Joint J . 2020 Apr;102-B(4):434-441

33. Rolfson $\mathrm{O}$, Malchau $\mathrm{H}$. The use of patient-reported outcomes after routine arthroplasty: beyond the whys and ifs. Bone Joint J, 2015. 97-B(5): p. 578-81. 
PROMs \& physical activity 



\section{Part B}

Outcomes and Systemic Toxicity 


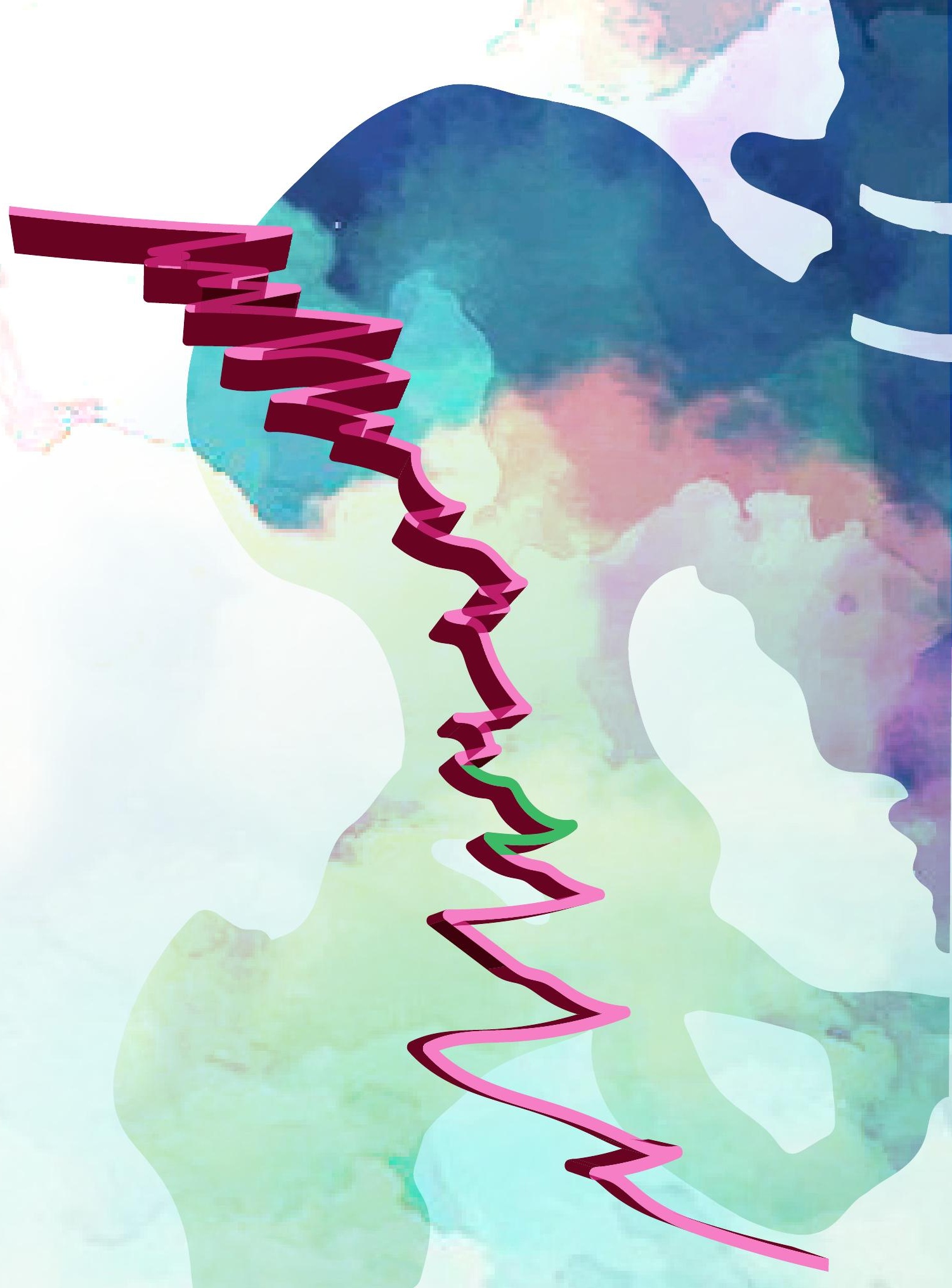




\section{Chapter VI}

\section{Outcome of Revised Metal-}

on-Metal Hip Arthroplasties: a Dutch Arthroplasty Register Study

Arch Orthop Trauma Surg, https://doi.org/10.1007/s00402-021-04257-5 (epub before print)

Jelsma J, van Kuijk S, Spekenbrink-Spooren A, Grimm B, Heyligers I, Schotanus M

Je kunt beter ten onder gaan met je eigen visie dan met de visie van een ander 


\section{Abstract}

\section{Background}

Preliminary results of metal-on-metal (MoM) hip arthroplasty were satisfactory, but since 2004 data showed high failure rates. National joint replacement registries are multi-centre databases comprised of thousands of subjects and implants which allow for identifying variables predictive of implant failure. The aim of the current study was to estimate re-revision rates after revision of a primary MoM hip arthroplasty in the Dutch Arthroplasty Register (LROI) and to assess potential predictor variables of re-revision of these MoM hip arthroplasties.

\section{Methods}

Eligible procedures were those with a revision for any reason except infection, after an initial primary surgery with a hip resurfacing (HRA) or large-head MoM (LH-MoM) total hip arthroplasty (THA). The probability of re-revision for both types of MoM hip arthroplasty over time was estimated using the cumulative incidence function taking mortality as a competing risk into account. A proportional sub distribution hazards regression model was used to assess potential predictor variables of rerevision of these MoM hip arthroplasties.

\section{Results}

A total of 3476 records of revised implants were included, of which 873 (25.2\%) were MoM-implants. Over the course of follow-up, 101 (11.5\%) MoM implants were rerevised. During follow-up 36 (4.3\%) patients who received a MoM-implant at primary arthroplasty and a revision afterwards had died. The regression model showed that for primary MoM-implants a MoM articulation after revision (HR 2.48; $95 \% \mathrm{Cl} 1.53$ - 4.03, $\mathrm{p}<0.001)$, femoral-only revisions (HR 3.20; 95\% Cl 2.06- 4.99, $\mathrm{p}<0.001)$ and periprosthetic fractures (HR 1.98; 95\% Cl $1.03-3.82, p=0.042$ ) as reason for the first revision were statistically significant risk-factors for re-revision.

\section{Conclusion}

Both types of large head MoM hip arthroplasties have shown high revision and rerevision rates, risk factors were identified. The outcome of this study can be helpful in managing expectations of patients and orthopaedic surgeons. 


\section{Introduction}

Metal-on-metal (MoM) hip arthroplasty became a popular procedure during the 1990s for patients invalidated by osteoarthritis who demanded higher activity levels. Until then, a metal-on-polyethylene (MoP) hip arthroplasty was used with so-called conventional (not highly crosslinked) polyethylene, which wore out quickly and thus needed to be replaced or revised frequently [1]. Large head MoM (LH-MoM) total hip arthroplasty (THA) and hip resurfacing arthroplasty (HRA) have the advantage of low volumetric wear and high stability [2]. Preliminary results have been satisfactory and around 1.5 million procedures have been performed worldwide [3,4]. Since 2004, multiple cohorts and national registry data showed high failure rates and the 10-year survival rate threshold of $95 \%$ set by The National Institute for Health and Care Excellence (NICE) was not achieved [5, 6]. The Dutch orthopaedic association (NOV) advised against the use of MoM-implants in 2012 $[7,8]$. Revision procedures are commonly performed in patients with failed hip arthroplasties and in general are technically challenging and expensive procedures. Although these revisions provide clinical benefit and patient satisfaction, they tend to have a worse outcome when compared to primary THA procedures $[9,10]$. Studies investigating the outcome of revision procedures are frequently limited by the small number of subjects included in these (single-centre) studies, hampering the detection of characteristics that could be a risk factor for revision [11-13]. National joint replacement registries are multi-centre databases comprised of thousands of subjects and implants which allow for identifying such variables of implant failure. The aim of the current study was to perform an exploratory approach to answer the research questions: 1 ) What is the re-revision rate after a first revision of a primary MoM hip arthroplasty, both HRA and LH-MoM THA? and 2) What are the risk factors fora re-revision after a primary MoM hip arthroplasty. To improve current practice, it is important to know the association between reason for first revision and the risk of re-revision. This should preferably lead to a better understanding of outcome in revision surgery.

\section{Methods}

\section{Data sources}

Data for the current study were provided by the Dutch Arthroplasty Register (LROI). This database is a nationwide population-based registry covering all hospitals in the Netherlands and was established by the NOV in 2007. At the time of the primary surgery both patient characteristics and surgical variables were recorded. 
If applicable, the date of death according to the national insurance database on healthcare was linked to the data from the LROI via a trusted third party (ZorgTTP) to obtain mortality of registered patients [14]. All data in the LROI is collected in the context of improving quality of care. Therefore, the current study is not required to have an institutional review board approval. The study was conducted in accordance with the Good Clinical Practice-guidelines and performed in compliance with the 1975 Declaration of Helsinki, as revised in 2013.

\section{Data selection}

Revision procedures in patients with a history of primary LH-MoM THA (head diameter $\geq 36 \mathrm{~mm}$ ) or HRA until the end of the follow-up period on December $31 \mathrm{st}$, 2018 were included. The primary surgeryshould have been performedbetween the start of the registry (2007) and January 1st 2012, when the ban by the NOV went into effect. In addition, we also selected data of all patients that received a first revision after an initial primary surgery with a non-MoM articulation in the same time period. All records with infection as a reason for the first revision were excluded $(n=313,8.9 \%)$.

The available patient characteristics were: sex, age at surgery (primary and revision), American Society of Anaesthesiologists (ASA) classification (primary and revision), indication for surgery (primary, revision and re-revision), previous surgery to the affected joint before the primary surgery, Body Mass Index (BMl; primary and revision) and smoking status (primary and revision; available from 2014). The available primary surgery characteristics were: type of surgery, year of surgery, surgical side and approach, type of implant, fixation, articulation and femoral head size. For revision and re-revision procedures the type and the reason for revision were studied, including the type of articulation after the first revision.

The dataset consisted of 2885 HRAs, 2670 LH-MoM THAs and 260874 non-MoM THAs. For the current study only the revised implant records were used. A total of 3476 revised implants records were included, of which 873 (25.1\%) were MoM implants (in 839 patients) further subdivided into 545 (62.4\%) LH-MoM THAs and 328 (37.6\%) HRAs. The most common indication at primary surgery was osteoarthritis $(89.1 \%)$. Baseline characteristics at first revision, of patients stratified to MoM and non-MoM implant, are shown in Table 1. More than one reason for revision could be registered; a total of 4253 reasons for 3476 procedures were found. 


\section{Statistics}

Baseline characteristics and surgical variables of the cohort were stratified by type of bearing (non-MoM versus MoM) and described as absolute numbers (percentage) or as mean \pm standard deviation (SD) [range]. Follow-up time was described as median and interquartile range (IQR). Differences in baseline characteristics between groups were tested using the independent-samples t-test and Pearson's chi-square test.

The probability of re-revision of MoM hip arthroplasty (HRA and LH-MoM THA) over time was estimated using the cumulative incidence function (CIF) taking mortality as a competing risk into account as both outcomes may not be completely uncorrelated. The CIF was chosen based on the current study goal 'to improve current practice, leading to better outcome in revision surgery'. The likely number of failures in practice are best represented by crude failure; composed by both failure of implants and mortality [15]. Cumulative incidence over time was visualised in a plot. The association between characteristics at the time of the first revision and the probability of re-revision was estimated using the proportional sub distribution hazards regression model and expressed as hazard ratio (HR) including the $95 \%$ confidence interval (Cl), adjusted for age and sex [16]. BMI and Charnley classification were not recorded during the first years of the registry $(<2014)$.

For this reason, it was chosen not to use these data but to use available cases for these associations as the percentage of missingness was high. Therefore, results for $\mathrm{BMI}$ and Charnley classification were considered preliminary. As the percentage of patients with bilateral implants was low (4.0\%), no additional multilevel modelling to account for clustering of observations were performed. P-values $\leq 0.05$ were considered statistically significant. All analyses were performed using IBM SPSS Statistics 22 (International Business Machines Corporation, Armonk, New York, United States) and R version 3.6.1 (The R Foundation for Statistical Computing, Vienna University of Economics and Business, Vienna, Austria). 


\section{Chapter 6}

Table 1. Baseline characteristics of both patient groups at the time of the first revision procedure. P-values are given for differences between the groups.

\begin{tabular}{|c|c|c|c|}
\hline & $\begin{array}{c}\text { MoM } \\
\text { implants }\end{array}$ & $\begin{array}{l}\text { non-MoM } \\
\text { implants }\end{array}$ & p-value \\
\hline Number of subjects (\%) & $873(25.1)$ & $2603(74.9)$ & \\
\hline $\begin{array}{l}\text { Age at surgery in years } \\
\text { Mean } \pm S D \text { [range] }\end{array}$ & $\begin{array}{c}62.1 \pm 10.5 \\
{[20-89]}\end{array}$ & $\begin{array}{c}70.1 \pm 11.0 \\
{[18-96]}\end{array}$ & $<0.001^{*}$ \\
\hline $\begin{array}{l}\text { FU' after primary surgery in years } \\
\text { Median (IQR) }\end{array}$ & $\begin{array}{c}3.8 \\
(2.1-5.8)\end{array}$ & $\begin{array}{c}2.2 \\
(0.5-5.3)\end{array}$ & $<0.001^{*}$ \\
\hline ASA-classification ${ }^{2}(\%)$ & & & $<0.001^{*}$ \\
\hline ASA I & $271(31.0)$ & $400(15.4)$ & \\
\hline ASA II & $462(52.9)$ & $1481(56.9)$ & \\
\hline ASA III-IV & $90(10.3)$ & $563(21.6)$ & \\
\hline Missing & $50(5.7)$ & $159(6.1)$ & \\
\hline Smoking (\%) & & & $0.036^{*}$ \\
\hline Yes & $53(6.1)$ & $103(4.0)$ & \\
\hline No & $275(31.5)$ & $800(30.7)$ & \\
\hline Missing & $545(62.4)$ & $1700(65.3)$ & \\
\hline \multicolumn{4}{|l|}{$\mathrm{BMI}^{3}(\%)$} \\
\hline Underweight (BMI <18.5) & $3(0.3)$ & $16(0.6)$ & \\
\hline Normal (BMI 18.5 - 25) & $117(13.4)$ & $344(13.2)$ & \\
\hline Overweight (BMI 25 - 30) & $144(16.6)$ & $384(14.8)$ & \\
\hline Obesity (BMI 30-40) & $71(8.1)$ & $183(7.0)$ & \\
\hline Morbid obesity (BMI >40) & $2(0.2)$ & $13(0.5)$ & \\
\hline Missing & $10(1.1)$ & $27(1.0)$ & \\
\hline Not registrered before 2014 & $526(60.3)$ & $1636(62.9)$ & \\
\hline
\end{tabular}

${ }^{1}$ Follow-up; ${ }^{2} \mathrm{ASA}$ : American Society of Anaesthesiologists; ${ }^{3} \mathrm{BMI}$ : Body mass index $\left(\mathrm{kg} / \mathrm{m}^{2}\right)$; ${ }^{*} \mathrm{P} \leq 0.05$ significant. MoM: metal-on-metal. SD: standard deviation. IQR: interquartile range.

\section{Results}

The median follow-up time until the first revision for MoM implants was 3.8 years (IQR: 2.1 - 5.8 years), and for non-MoM implants 2.2 years (IQR: 0.5 - 5.3 years). The most common reason for revision in the MoM group was a 'symptomatic MoMbearing' (43.1\%), while for the non-MoM group these were 'dislocation or instability' (26.2\%) and 'loosening of the femoral component' (21.5\%) (Table 2). A total revision was performed far more often in the MoM-implant group: $45.8 \%$ vs $11.9 \%$ for the non-MoM implant group. Partial revisions after HRA were not common, in contrast to a cup revision (57.4\% of revisions) for LH-MoM implants (Table 3). After the first 
revision a polyethylene bearing was mostly used, either with a ceramic $(40.8 \%$ and $29.5 \%$ ), metal (24.6\% and $50.6 \%$ ) or zirconium (4.6\% and $4.4 \%$ ) femoral head, for the MoM and non-MoM group respectively. A MoM articulation was used in $12.9 \%$ of the revision cases of the primary MoM-implant group and only in $1.0 \%$ of the revision cases of the primary non-MoM implant group.

Over the course of follow-up, 101 (11.5\%) MoM implants were re-revised. The median follow-up was 5.2 years (IQR: 2.2 - 7.3) after the first revision. During follow-up, 36 (4.3\%) patients who received a MoM-implant at primary arthroplasty and a first revision surgery afterwards had died. In the non-MoM implant cohort, $367(14.1 \%)$ re-revised implants were recorded at a median of 5.1 years follow-up (IQR:2.0 - 7.6). During follow-up 344 (13.3\%) of 2589 patients had died after the first revision.

Figure 1 shows the cumulative incidence for the probability of re-revision over 10-years follow up with $95 \%$ confidence band, taking death as competing risk into account for MoM and non-MoM implants respectively. Beneath the figure the number of patients at risk at the start of each two-year interval is shown.

Table 2. Possible indications for first revision as documented in the Dutch Arthroplasty Register. Please note: more than one reason for revision could be registered.

\begin{tabular}{lcc}
\hline & $\begin{array}{c}\text { MoM implants } \\
\text { (n=1145 indications) }\end{array}$ & $\begin{array}{c}\text { non-MoM implants } \\
\text { (n=3106 indications) }\end{array}$ \\
\hline Indication & Frequency (\%) & Frequency (\%) \\
\hline Dislocation & $31(2.7)$ & $811(26.2)$ \\
Girdlestone/spacer & $6(0.5)$ & $52(1.7)$ \\
Acetabular loosening & $120(10.5)$ & $464(15.0)$ \\
Femoral loosening & $90(7.8)$ & $665(21.5)$ \\
Periarticular ossification & $8(0.7)$ & $58(1.9)$ \\
Periprosthetic fracture & $44(3.9)$ & $419(13.5)$ \\
Insert wear & $20(1.7)$ & $127(4.1)$ \\
Symptomatic MoM bearing & $494(43.1)$ & $10(0.3)$ \\
Other & $332(28.9)$ & $503(16.2)$ \\
\hline
\end{tabular}

MoM: metal-on-metal. 


\section{Chapter 6}

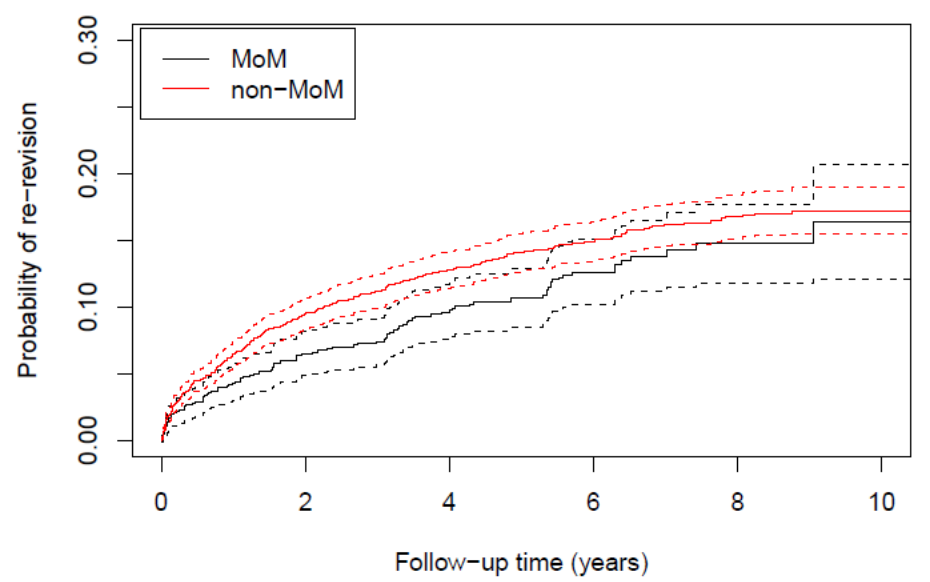

Number at risk

$\begin{array}{ccccccc}\text { MoM } & 873 & 731 & 573 & 364 & 101 & 17 \\ \text { non-MoM } & 2600 & 1945 & 1514 & 1101 & 510 & 108\end{array}$

Figure 1. Competing risk analysis; cumulative incidencefor the probability of re-revision over 10-years follow up with $95 \%$ confidence band, taking death as competing risk into account for both groups of patients. Beneath the figure the number of patients at risk at the start of each two-year interval is shown.

Table 3. Type of first revision shown for each group of patients. Please note: more than one type could be registered.

\begin{tabular}{lcccc}
\hline & $\begin{array}{c}\text { MoM implants } \\
(\mathbf{n = 8 7 3 )}\end{array}$ & $\begin{array}{c}\text { HRA } \\
(\mathbf{n = 3 2 8})\end{array}$ & $\begin{array}{c}\text { LH-MoM } \\
(\mathbf{n = 5 4 5 )}\end{array}$ & $\begin{array}{c}\text { non-MoM implants } \\
(\mathbf{n = 2 6 0 3 )}\end{array}$ \\
\hline Revision Type & Frequency (\%) & Frequency (\%) & Frequency (\%) & Frequency (\%) \\
\hline Girdlestone & $4(0.5)$ & $0(0.0)$ & $4(0.7)$ & $10(0.4)$ \\
Partial: femoral head & $423(48.5)$ & $36(11.0)$ & $387(71)$ & $2071(79.6)$ \\
Partial: insert & $281(32.2)$ & $8(2.4)$ & $273(50.1)$ & $989(38)$ \\
Partial: cup & $326(37.3)$ & $13(4)$ & $313(57.4)$ & $940(36.1)$ \\
Partial: femur & $75(8.6)$ & $29(8.8)$ & $46(8.4)$ & $858(33)$ \\
Total revision & $401(45.8)$ & $274(83.5)$ & $127(23.3)$ & $312(11.9)$ \\
Other & $3(0.3)$ & $0(0.0)$ & $3(0.6)$ & $15(0.6)$ \\
Unknown & $16(1.8)$ & $9(2.7)$ & $7(1.3)$ & $41(1.6)$ \\
\hline
\end{tabular}

MoM: metal-on metal, HRA: hip resurfacing arthroplasty, LHMoM: large head MoM total hip arthroplasty

The proportional sub-distribution hazards regression model showed that revision to a MoM articulation after the first revision of a MoM-implant was a statistically significant risk-factor for re-revision (HR 2.48; 95\% Cl $1.53-4.03, \mathrm{p}<0.001$ ), 
especially after revision of a LH-MoM THA (HR 3.45; 95\% Cl $1.89-6.30, p<0.001$ ). Also, a periprosthetic fracture of a MoM-implant as reason for first revision was a statistically significant risk-factor for re-revision (HR 1.98; $95 \% \mathrm{Cl} 1.03-3.82$, $\mathrm{p}=0.042$ ). Most partial revisions of a MoM hip arthroplasty were statistically significant risk-factors for re-revision, especially femoral only revisions (HR 3.20, $95 \% \mathrm{Cl} 2.06-4.99, \mathrm{p}<0.001)$. A symptomatic MoM bearing on the other hand was found as a statistically significant decreasing factor for the probability of re-revision (HR 0.53; 95\% Cl $0.35-0.82, \mathrm{p}=0.004$ ). The type of MoM-implant (resurfacing or LH-MoM THA) was not a statistically significant risk-factor for re-revision (HR 1.26; $95 \% \mathrm{Cl} 0.80-1.98, \mathrm{p}=0.317)$. As comparison, associations computed on non-MoM implants are presented next to MoM-implants (Table 5).

Table 4. Type of articulation after the first revision shown for both groups of patients

\begin{tabular}{lcc}
\hline & $\begin{array}{c}\text { MoM implants } \\
\text { (n=873) }\end{array}$ & $\begin{array}{c}\text { Non-MoM implants } \\
\text { (n=2603) }\end{array}$ \\
\hline Articulation after First revision & Frequency (\%) & Frequency (\%) \\
\hline CoC & $49(5.6)$ & $149(5.7)$ \\
CoM & $16(1.8)$ & $2(0.1)$ \\
CoP & $356(40.7)$ & $767(29.5)$ \\
MoC & $0(0.0)$ & $3(0.1)$ \\
MoM & $111(12.7)$ & $27(1.0)$ \\
MoP & $215(24.6)$ & $1316(50.6)$ \\
ZoP & $40(4.6)$ & $115(4.4)$ \\
Unknown & $2(0.2)$ & $3(0.1)$ \\
Missing components & $84(9.6)$ & $221(8.5)$ \\
(femoral head and/or inlay, and/or acetabulum) & &
\end{tabular}

*CoC ceramic-on-ceramic; CoM: ceramic-on metal; CoP: ceramic-on-polyethyelene; MoC: metal-onceramic; MoM: metal-on-metal; MoP: metal-on-polyethyelene; ZoP: zirconium-on-polyethyelene.

\section{Discussion}

The current study assessed the re-revision rate of MoM-implants (both HRA and LH-MoM THA) and possible risk factors forthese re-revision. The re-revision rate was shown to be $11.5 \%$ at a median follow-up of 5.2 years after the first revision. In comparison, the re-revision rate of non-MoM THA was shown to be $14.1 \%$ at 5.1 years follow-up. A MoM-articulation post-first-revision, a periprosthetic fracture as reason for first revision and femoral-only revisions were found as statistically significant risk factors for re-revision in MoM-implants. 


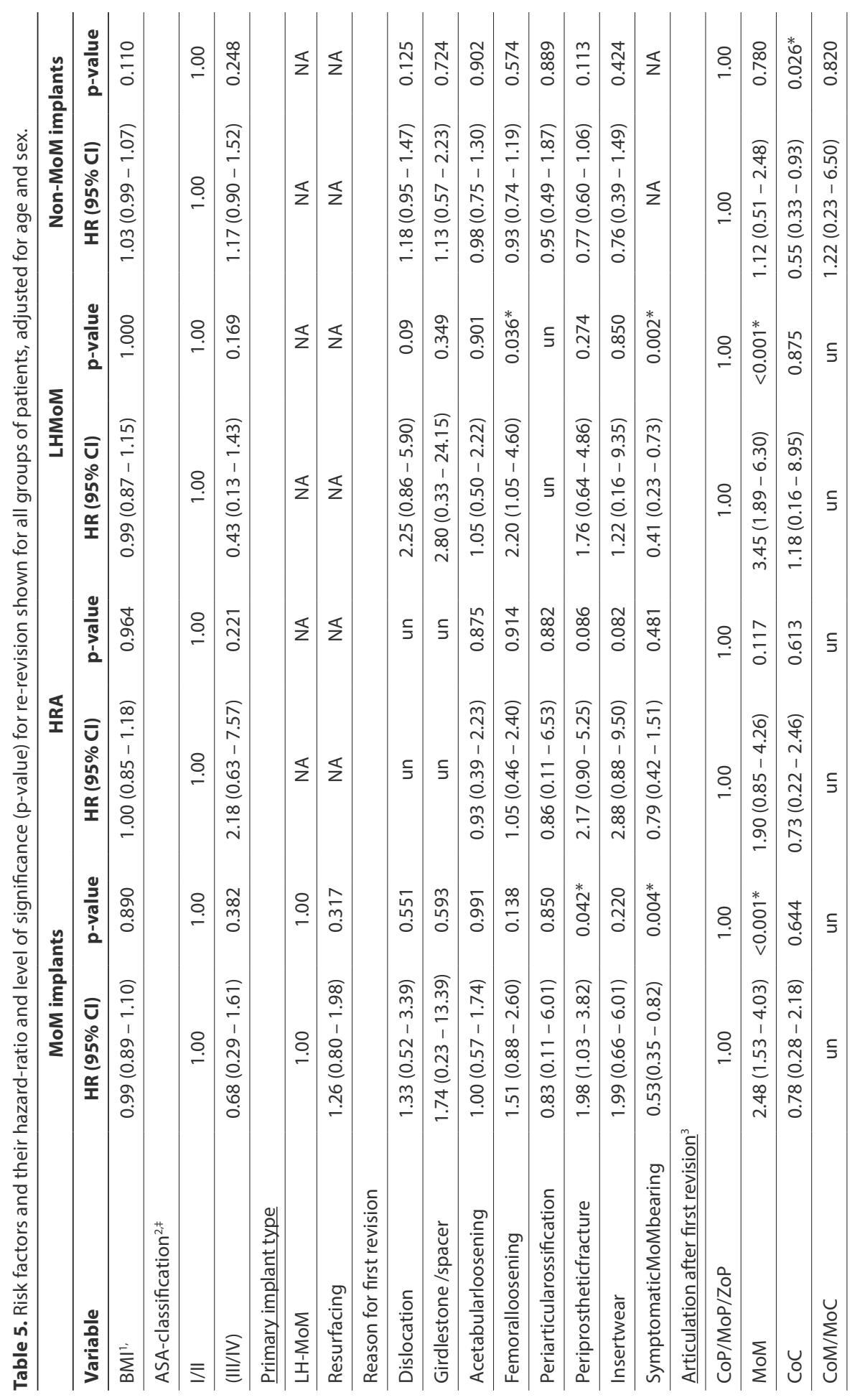




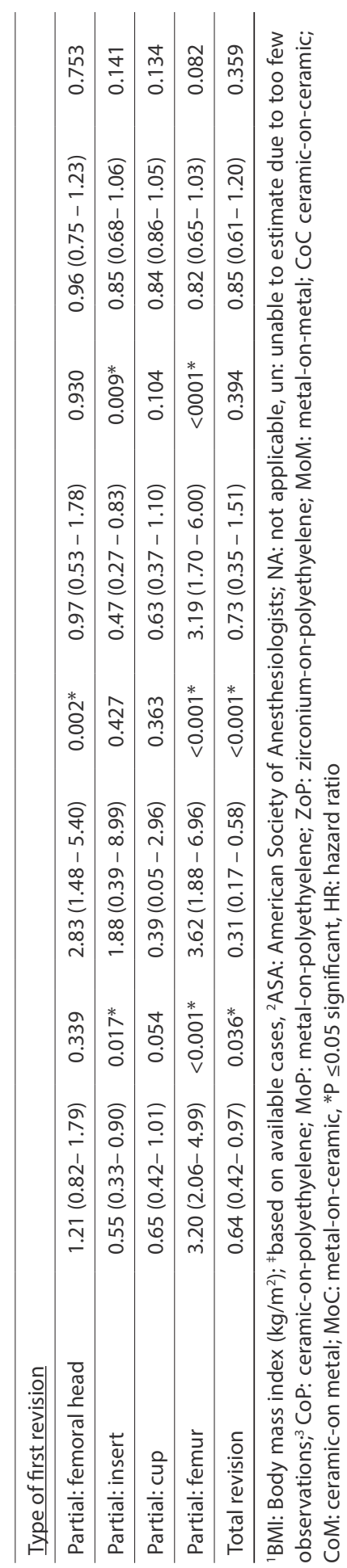


Wong et al. used the Australian registry and showed that 884 (5.8\%) out of 15360 HRA subjects underwent revision for another reason than infection. Another 102 (11.5\%) subjects underwent re-revision, which resulted in a cumulative percent re-revision of $26 \%$ at 10 -years $(95 \% \mathrm{Cl} 19.6-33.5)$. No differences in survivorship were found for the type of revision or bearing surface used during revision surgery. Other variables such as patient characteristics (e.g. BMI) and surgical techniques (e.g. surgical approach, type of implant) were not investigated [17]. In contrast, the current study combined both types of MoM hip arthroplasties (HRA \&LH-MoM THA). Type of MoM implant was not a risk factor for re-revision in the current study. In earlier studies, BMI, cobalt-chromium-containing bearing surfaces after first revision, soft tissue damage and pseudotumor/adverse reactions to metal debris (ARMD) as the reason for the first revision were shown to be variables prognostic for a poor outcome after the revision of a LH-MoM THA $[13,18]$. The current study added new proof to chromiumcontaining bearing surfaces (MoM) after first revision as risk-factor for re-revision.

A symptomatic MoM bearing as the reason for the first revision was found not to be a risk factor for re-revision. Matharu et al. showed that re-revision was performed in 192 (7.6\%) of 2535 subjects after a first revision for ARMD in subjects with a HRA or LH-MoM THA. This is lower than the re-revision rate for any reason found in the current study. They found a high BMl at first revision, modular component-only revisions (head and insert with or without taper adapter), ceramic-on-ceramic revision bearings and acetabular bone grafting as predictors of re-revision [19]. Bonner et al. reported that complications after the first revision (dislocation, ARMD, fracture, loosening and infection) were riskfactors for re-revision and also the use of a metal femoral head placed at the time of first revision compared to a ceramic femoral head, both with a polyethylene liner. In contrast to Matharu et al., BMI was not found to be a statistically significant risk factor [12]. In accordance, Lainiala et al. reported re-revision rates of $7.0 \%$ after a first revision because of ARMD in 528 MoM hip arthroplasties. Dislocation was the most common reason for re-revision, in both uni-, and multivariable analysis, a first revision head size of $\leq 36 \mathrm{~mm}$ was associated with an increased risk for dislocation [20].

The strengths of the current study are the high coverage (100\%) and completeness of the LROI database: $98-99 \%$ for primary THAs and $88-97 \%$ for hip revision arthroplasties between 2012 and 2019, the relatively large sample size, high diversity of hospitals, surgeons, patients and prostheses and thus a high generalizability. However, there are alsosome limitations of the current study. In the first years, starting in 2007, the completeness of LROI-data was not optimal with $88 \%$ in 2009 , but raised to $>95 \%$ in the years after $[21,22]$. Also, specification of ARMD and high metal ion concentrations as reason for revision is not available as a possible reason for revision. These are 
combined as 'symptomatic MoM bearing'. Patient surveillance was promoted in the last decade and the threshold to perform revision surgery was lowered by surgeons and worldwide regulatory authorities [23]. The destructive nature of ARMD makes hip stability and poor bone stock essential in revision surgery [24]. In addition, the current study found periprosthetic fractures in MoM-implants as risk factor for rerevision. We selected LROI-data of patients who underwent a first revision of their hip arthroplasty due to any reason, except infections. Patients who were treated with a plate osteosynthesis, without a revision of one or more implant components (cup, insert or stem) in case of a periprosthetic fracture, are not registered. HRA and LHMoM THA were frequently used during the first years of the register. Despite the high revision and re-revision percentage of MoM hip arthroplasties, the absolute number of re-revisions was low. Therefore, a Type II error may be present. Patient selection for (un)cemented THA (MoM and non-MoM) and HRA is influenced by age and sex, as was observed, but also by general health and functional demands potentially influencing the outcome. Implant survival or -failure can be estimated with the present data, but functional outcome including non-surgical complications and non-revised surgeries (e.g. debridement because of early infection) are unknown. Large numbers of implant records can give rise to small $p$-values and narrow confidence intervals, but the statistically significant findings may not always be of clinical relevance. National arthroplasty registry studies are limited by compliance of health institutions (at least $80 \%$ ), completeness (at least $\geq 90 \%$ ) and revision surgery as the only outcome criteria [26]. The LROI meets these requirements with a coverage of $100 \%$ and a completeness $>95 \%[21,22]$.

In conclusion, the current study aimed to answer what the re-revision rate after a first revision of a primary MoM hip arthroplasty is, and what risk factors fora re-revision after a primary MoM hip arthroplasty exist. MoM hip arthroplasties, both HRA and LH-MoM THA, have shown high revision and re-revision rates. These re-revision rates are comparable and even less frequent when compared to non-MoM arthroplasty. In accordance, also the mortality rate in MoM arthroplasty was lower, possibly because MoM arthroplasty was more frequently used in young and healthy patients (ASA I). Early revision for a symptomatic MoM bearing was found as a protective factor for re-revision. This indicates a decent surgical experience in The Netherlands for this type of revisions, potentially contributed by patient characteristics such as minimal bone loss and a good bone stock, in combination with the specific aspects of patients selected for MoM bearings (young and active). Femoral-only revisions and MoM articulations post-revision should not be used during the first revision of a failed MoM hip arthroplasty. The outcomes of this study can be helpful in managing expectations of patients and orthopaedic surgeons. 


\section{References}

1. Hernigou P. Earliest times before hip arthroplasty: from John Rhea Barton to Themistocles Gluck. Int Orthop, 2013. 37(11): p. 2313-8.

2. Corten K, Ganz R, Simon JP, Leunig M. Hip resurfacing arthroplasty: current status and future perspectives. Eur Cell Mater, 2011. 21: p. 243-58.

3. Schmalzried TP, Fowble VA, Ure KJ, Amstutz HC. Metal on metal surface replacement of the hip. Technique, fixation, and early results. Clin Orthop Relat Res, 1996(329 Suppl): p. S106-14.

4. Matharu VK, Matharu GS. Metal-on-metal hip replacements: implications for general practice. Br J Gen Pract, 2017. 67(665): p. 544-545.

5. Smith AJ, Dieppe P, Howard PW, Blom AW, National Joint Registry for England and Wales. Failure rates of metal-on-metal hip resurfacings: analysis of data from the National Joint Registry for England and Wales. Lancet, 2012. 380(9855): p. 1759-66.

6. Smith AJ, Dieppe P, Vernon K, Porter M, Blom AW, National Joint Registry of England and Wales. Failure rates of stemmed metal-on-metal hip replacements: analysis of data from the National Joint Registry of England and Wales. Lancet, 2012. 379(9822): p. 1199-204.

7. Verhaar JAN. [The hard lesson of metal-on-metal hip implants]. Ned Tijdschr Geneeskd, 2012. 156(42): p. A5564.

8. van Steenbergen LZ, Denissen GAW, Schreurs BW, Zijlstra WP, Koot HWJ, Nelissen RGHH. Dutch advice not to use large head metal-on-metal hip arthroplasties justifiable - results from the Dutch Arthroplasty Register. Nederlands Tijdschrift voor Orthopaedie, 2020. 27(1).

9. Lübbeke A, Roussos C, Barea C, Köhnlein W, Hoffmeyer P. Revision total hip arthroplasty in patients 80 years or older. J Arthroplasty, 2012. 27(6): p. 1041-6.

10. Ong KL, Lau E, Suggs J, Kurtz SM, Manley MT. Risk of subsequent revision after primary and revision total joint arthroplasty. Clin Orthop Relat Res, 2010. 468(11): p. 3070-6.

11. Grammatopoulos G, Pandit G, Kwon YM, Gundle R, McLardy-Smith P, Beard DJ, Murray DW, Gill HS. Hip resurfacings revised for inflammatory pseudotumour have a poor outcome. J Bone Joint Surg Br, 2009. 91(8): p. 1019-24.

12. Bonner B, Arauz P, Klemt C, Kwon YM. Outcome of Re-Revision Surgery for Adverse Local Tissue Reaction in Metal-on-Polyethylene and Metal-on-Metal Total Hip Arthroplasty. J Arthroplasty, 2020. 35(6S): p. S284-S288.

13. Borton ZM, Mumith AS, Nicholls AJ, Pearce AR, Briant-Evans TW, Griffiths JT. The Outcome of Revision Surgery for Failed Metal-on-Metal Total Hip Arthroplasty. J Arthroplasty, 2019. 34(8): p. 1749-1754.

14. Vektis, http://www.vektis.nl. 2017.

15. Sayers A, Evans JT, Whitehouse MR, Blom AW. Are competing risks models appropriate to describe implant failure? Acta Orthop, 2018. 89(3): p. 256-258.

16. Fine JP, Gray RJ. A proportional hazards model for the subdistribution of a competing risk. JASA, 1999. 94: p. 496-509.

17. Wong JM, Liu YL, Graves S, de Steiger R. What Is the Rerevision Rate After Revising a Hip Resurfacing Arthroplasty? Analysis From the AOANJRR. Clin Orthop Relat Res, 2015. 473(11): p. 3458-64.

18. Matharu GS, Pynsent PB, Sumathi VP, Mittal S, Buckley CD, Dunlop DJ, Revell PA, Revell MP. Predictors of time to revision and clinical outcomes following revision of metal-on-metal hip replacements for adverse reaction to metal debris. Bone Joint J, 2014. 96-B(12): p. 1600-9.

19. Matharu GS, Judge A, Pandit HG, Murray DW. Which factors influence the rate of failure following metal-on-metal hip arthroplasty revision surgery performed for adverse reactions to metal debris? an analysis from the National Joint Registry for England and Wales. Bone Joint J, 2017. 99-B(8): p. 1020-1027.

20. Lainiala O, Reito A, Nieminen J, Eskelinen A. Complications and re-revisions after revisions of 528 metal-on-metal hips because of adverse reactions to metal debris. Acta Orthop, 2020. 91(4): 365-371. 
21. van Steenbergen LN, Denissen GAW, Spooren A, van Rooden SM, van Oosterhout FJ, Morrenhof JW, Nelissen RGHH. More than 95\% completeness of reported procedures in the populationbased Dutch Arthroplasty Register. Acta Orthop, 2015. 86(4): p. 498-505.

22. LROI, Completeness of registering hospitals and completeness of registered arthroplasties in the LROI baes on the hospital information system in 2018. https://www.Iroi-rapportage.nl/ data-quality-coverage-and-completeness19.

23. Matharu GS, Eskelinen A, Judge A, Pandit HG, Murray DW. Revision surgery of metal-on-metal hip arthroplasties for adverse reactions to metal debris. Acta Orthop, 2018. 89(3): p. 278-288.

24. Law JI, Crawford DA, Adams JB, Lombardi Jr AV. Metal-on-Metal Total Hip Revisions: Pearls and Pitfalls. J Arthroplasty, 2020. 35(6S): p68-72.

26. Gomes LSM, Roos MV, Takata ET, Schuroff AA, Alves SD, Júnior AC, Miranda RH. Advantages and limitations of national arthroplasty registries. The need for multicenter registries: the RemproSBQ. Rev Bras Ortop, 2017. 52(Suppl 1): p. 3-13. 


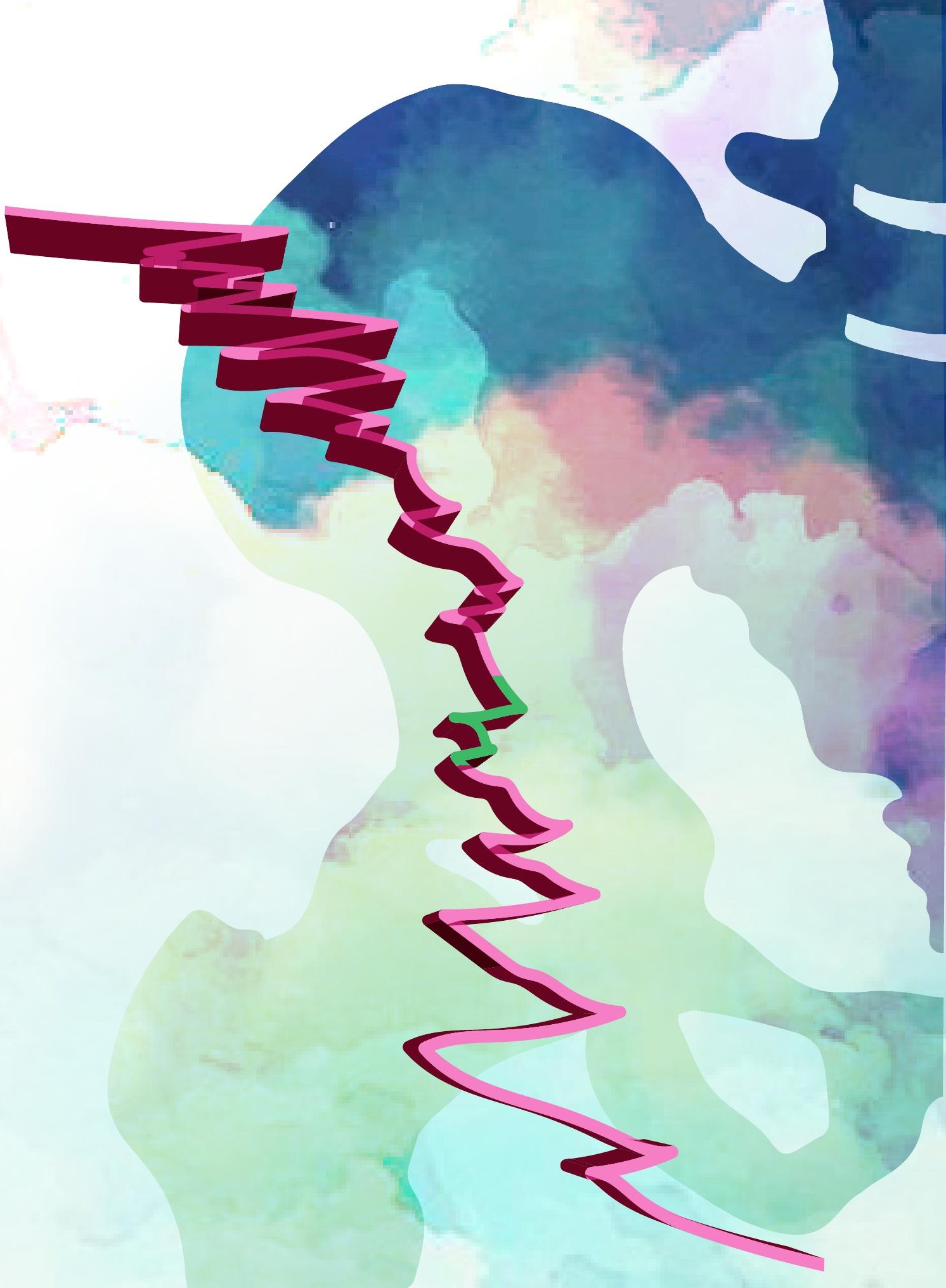




\section{Chapter VII}

\section{Prosthetic hip-associated cobalt toxicity: a systematic review of case series and}

case reports

Revision submitted: EFORT Open Reviews on 12.12.2021

Crutsen JRWA', Koper MCA ${ }^{\text {, }}$, Jelsma J, Heymans M, Heyligers IC, Grimm G, Mathijssen NMC, Schotanus MGM

A: The first two authors contributed equally to this manuscript

One man can be a crucial ingredient on a team, but one man cannot make a team

(Kareem Abdul-Jabbar) 


\section{Abstract}

\section{Introduction}

Prosthetic Hip-Associated Cobalt Toxicity (PHACT) is caused by elevated blood cobalt concentrations after hip arthroplasty. This systematic review aims to determine which symptoms are reported most frequently and in what type of bearing. We also try to determine the blood level of cobalt concentrations associated with toxicological symptoms.

\section{Methods}

A systematic review was conducted on the $10^{\text {th }}$ of July according to PRISMA guidelines. A methodological quality assessment (Risk of bias; RoB) was performed. Primary outcomes were the reported symptoms of cobalt toxicity and the level of cobalt concentrations in blood. These levels were associated with toxicological symptoms. A total of 7645 references were found of which 67 relevant reports describing 79 patients.

\section{Results}

The two most used bearings in which prosthetic hip-associated cobalt toxicity was described were metal-on-metal (MoM) bearings (38 cases) and revised (fractured) ceramic-on-ceramic $(\mathrm{CoC})$ bearings where the former ceramic head was replaced by a metal head (32 cases). Of all reported symptoms, most were seen in the neurological system, of which $24 \%$ were in the sensory system and $19.3 \%$ in central/ peripheral system, followed by the cardiovascular (22.1\%) system. The mean blood cobalt concentration on which the symptoms were presented was $572 \pm 962.2 \mathrm{ppb}$ in the entire cohort. The mean cobalt concentration for MoM-bearings was $123.7 \pm$ $96.8 \mathrm{ppb}$ and $1078.2 \pm 1267.5 \mathrm{ppb}$ for the revised fractured CoC-bearings.

\section{Discussion}

Prosthetic hip-associated cobalt toxicity might occur after primary MoM- and revised fractured $\mathrm{CoC}$-bearings. Sensory, neurological and cardiovascular symptoms were most reportedly most frequently in relation to elevated cobalt concentrations. 


\section{Introduction}

Exposure of metal ions after hip arthroplasty surgery is a widely reported phenomenon. Multiple studies have shown that increased metal ions can result in local soft tissue reactions, described as Adverse Reaction to Metal Debris (ARMD) [14]. There is, also an increasing number of case reports describing systemic reactions in relation to elevated blood cobalt concentrations, known as Prosthetic HipAssociated Cobalt Toxicity (PHACT) $[5,6]$.

Increased cobalt concentrations are often seen after implantation of metal-onmetal (MoM) hip-bearings [7]. This can be due to the release of ions from the metal (cobalt-chromium) surface either directly (corrosion) or during sliding under load, which may create wear particles (adhesion). Another source of significant metal particle release is the application of a metal component for revision of a fractured ceramic head and/or a fractured ceramic acetabular liner. In this scenario, massive three-body abrasive wear can be created, as small remaining particles of the fractured ceramic bearing lead to abrasion of the metal surface [8, 9].

The systemic effects of cobalt toxicity are historically well documented from industrial exposure, iatrogenic use of oral cobalt chloride tablets and from the beer industry as foam stabilizing agent [10-12]. The toxicity of cobalt is related to the unbound (free) form of cobalt $\left(\mathrm{Co}^{2+}\right)$ and certain patient conditions. Unice et al. stated that kidney failure, iron deficiencies, sepsis, malnutrition and use of certain medication increased the toxicity of cobalt at lower concentrations [13]. The systemic complaints in patients with PHACT may lead to a variety of symptoms: neuro-ocular toxicity (e.g. tinnitus, vertigo, deafness, blindness, convulsions, headaches and peripheral neuropathy), cardiotoxicity and thyroid toxicity [14]. Nausea, anorexia and unexplained weight loss have also been described [6, 15-17]. Initially there were concerns that high cobalt and chromium concentrations increased the risk of cancer; however this was not proven in large comparative studies [18, 19].

It is still unknown which of these systemic symptoms are mostly reported in PHACT and at what blood cobalt concentration toxicity occurs. The present study is a systematic review of the current literature reporting systemic cobalt toxicity symptoms after any type of hip arthroplasty. The aim is to define and present the most reported systemic symptoms related to PHACT and to determine blood cobalt levels associated with toxicity. 


\section{Methods}

The study protocol of this systematic review on case-reports was registered in PROSPERO, the international prospective register of systematic review, with registration number: CRD42020215827.

\section{Criteria for considering studies for this review Types of studies and participants}

Case reports concerning cobalt toxicity after hip arthroplasty were included. Patients with any type of bearing (MoM, CoC, metal-on-polyethylene (MoP), ceramicon-polyethylene (CoP)) and any type of hip arthroplasty design (hip resurfacing arthroplasty (HRA), short stem hip arthroplasty, 'conventional' stemmed total hip arthroplasty, both uncemented and cemented) were included. Articles describing allergic reactions on hip prosthesis and/or cobalt, and articles reporting only local problems around the hip such as Adverse Local Tissue Reactions (ALTR), ARMD and Aseptic Lymphocytic Vasculitis-Associated Lesion (ALVAL) were excluded.

\section{Types of interventions}

The description of an intervention was not necessary for inclusion, as patients may have died from cobalt toxicity before an intervention could be initiated. In some cases, a revision arthroplasty or chelation therapy was the intervention of choice of the attending physicians.

\section{Types of outcome measures}

Primary outcomes were the reported symptoms of cobalt toxicity and the blood cobalt concentration at which these symptoms were seen. All reported symptoms were counted and divided into nine different categories, based on the physiological system related to the occurrence of the symptoms. We followed the categories used in the study of Devlin et al., with some minor adjustments [6]. Cobalt concentrations in blood were reported in $\mathrm{nmol} / \mathrm{L}, \mu \mathrm{g} / \mathrm{L}$ and parts per billion (ppb). Cobalt concentrations in $\mathrm{nmol} / \mathrm{L}$ were converted to $\mathrm{ppb}$ whereas $1 \mathrm{nmol} / \mathrm{L}=0.059 \mathrm{ppb}$.

\section{Search methods for identification of studies}

The search was performed on July 10, 2020 in PubMed, EMBASE, Cochrane Library/ Wiley, CINAHL (EBSCO), Web of Science (Clarivate Analytics) and Trial registers (PROSPERO) by one author (MH). The following [MESH] search terms were used: "Hip Prosthesis, Arthroplasty, Replacement, Hip and Cobalt. The full search strategy and terms can be found in Appendix 3. Articles published in Dutch, English, German or Spanish were included. There were no further restrictions for publication type 
or date. Reference lists of included articles were screened for missing items. In addition, also posters presented at congresses and published abstracts were included. Duplicates were identified by one author (J) in RefWorks. All records were independently screened on title and abstract by two authors (JJ, MS), disagreement was resolved by mutual discussion. Full-text articles were assessed for eligibility by two authors (JC, MK), differences were resolved in a consensus meeting and if necessary, through discussion with another author $(\mathrm{JJ})$.

\section{Data collection and analysis}

Two authors (JC, MK) independently extracted data of the included articles and obtained the degree of bias. Differences were resolved through discussion with another author $(\mathrm{J} J)$. Data were extracted and stored in a Microsoft Excel 2019 file (Microsoft, Redmond, Washington, United States). The following data of the included studies was extracted: study ID (author, year of online publication), number of patients $(\mathrm{N})$, patient characteristics at onset of symptoms (age in years, sex), primary intervention and indication for the primary procedure, secondary intervention and indication (if applicable), follow-up (in months) since surgery, cobalt ion concentration in any type of amount (e.g. $\mathrm{nmol} / \mathrm{L}, \mu \mathrm{g} / \mathrm{L}, \mathrm{ppb}$ ) when symptoms were seen, symptoms reported, outcome after treatment, regardless of the type of treatment. All results are presented as total (percentage) or as mean (standard deviation).

\section{Quality assessment}

The risk of bias (RoB) tool of the Cochrane Handbook for Systematic Reviews of Interventions was used and the Newcastle-Ottawa Scale (NOS) was chosen to assess the quality of the articles [20-22]. This checklist is used to determine quality of nonrandomized studies, including case-controlled and cohort studies, in three areas: selection, comparability and the ascertainment of either the exposure or outcome of interest. An assessment scale is available to award stars with a maximum score of 9: one for each question in the selection and outcome scale, and two for the comparability domain (appendix 1) [21]. The follow-up as described in question 6 was determined to be at least three months in agreement with all authors. A score of less than 5 stars represents a high RoB [23].

In addition, a checklist suggested by Murad et al. was also used to obtain RoB [24]. This checklist is especially designed for case reports and exists of an eight-item tool categorized in four domains: selection, ascertainment, causality and reporting. It is a modification of the tools by Pierson, Bradford Hills and the NOS (appendix 2)[24]. The eight items of the tool were scored yes or no. Like the NOS, the adequate followup was determined to be three months. Questions 5 and 6 of the questionnaire 
were not taken into account since they were mostly relevant to cases of adverse drug events. Quality of the articles was defined 'good' when $\geq 4$ times were scored 'yes', 3-2 times 'yes' was defined 'moderate' and $\leq 1$ time 'yes' as 'poor'. All eligible case reports were included in the review irrespective of their methodological quality.

\section{Results}

Our search identified 7645 references of which 3898 were screened after removal of duplicates (appendix 3). A total of 3824 were excluded based on title or abstract, resulting in 74 eligible articles. Of these, a total of 67 were included for analysis after excluding another 7 studies, due to no original case description, retraction and no described toxicity (Figure 1). The RoB classification according to the NOS checklist resulted in a $98.5 \%(\mathrm{~N}=66)$ of low risk of bias and $1.5 \%(\mathrm{~N}=1)$ of high-risk bias of the case reports (see appendix 4). According to the checklist of Murad et al., $76.1 \%$ $(\mathrm{N}=51)$ of the studies were classified as good methodological quality. A full review of the Murad checklist is found in appendix 5.

We identified a total of 79 patients with reported PHACT. Table 1 presents the most important data of all articles and methodological quality assessment score. The full overview is shown in appendix 6 . A total of 46 (58.2\%) patients were male and 27 (34.2\%) were female. Sex was not mentioned in 6 patients. The mean age at primary surgery was $53.2 \pm 14.2$ years. The main known reason for primary surgery was osteoarthritis $(\mathrm{N}=28 ; 35.4 \%)$, however, in most reports the primary indication was unknown ( $\mathrm{N}=36 ; 45.6 \%)$. Table 2 presents the demographic data of the entire group.

\section{PHACT related to type of bearing}

The two most used bearings in the primary surgery were MoM $(\mathrm{N}=38 ; 48.0 \%)$ and $\operatorname{CoC}(\mathrm{N}=32 ; 40.5 \%)$. Also MoP $(\mathrm{N}=2 ; 2.5 \%)$ and $\operatorname{CoP}(\mathrm{N}=2 ; 2.5 \%)$ were reported, in 5 cases $(6.5 \%)$ no primary bearing was reported.

In 38 (48.0\%) patients the PHACT symptoms occurred after primary surgery of which in $34(89.5 \%)$ after a primary MoM-bearing. The mean time between the primary surgery and onset of symptoms was 2.1 (range: $0-13$ ) years. A total of 41 (52.0\%) patients developed PHACT symptoms after they had revision surgery. Especially revision of a (fractured) CoC-bearing for a MoP- $(\mathrm{N}=21)$ or MoM-bearing $(\mathrm{N}=6)$ caused the onset of cobalt toxicity symptoms. In this group the mean time of developing PHACT was 8.8 (range: 4-15) years after the primary surgery, and 2.4 (range: $0-9$ ) years after the revision surgery (table 3 ). 


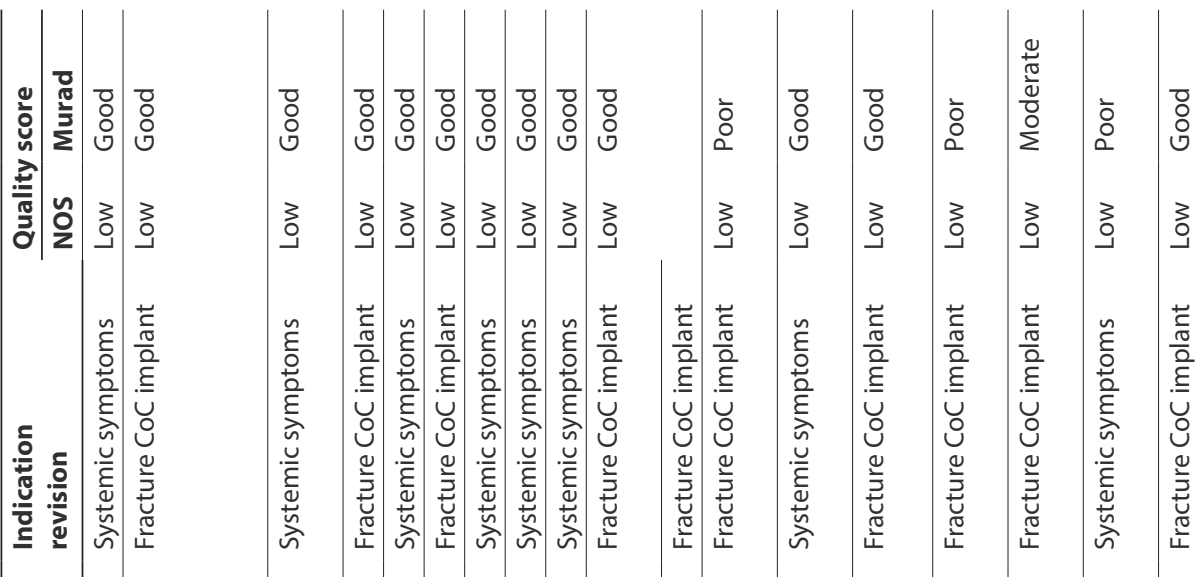

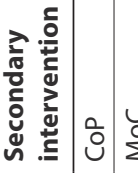

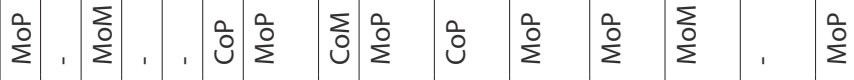

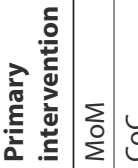

ப. .

을

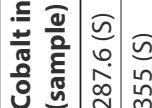

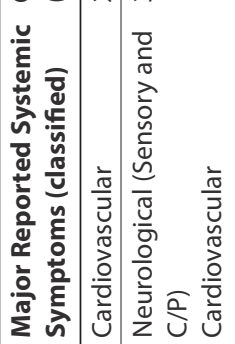

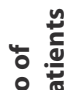

要誉

党

हั

ก

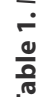

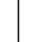

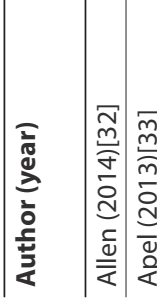

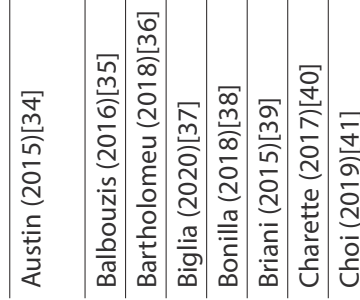

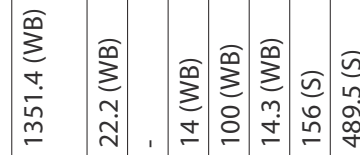

$\widehat{a}$
$a$
$\vdots$
$=$

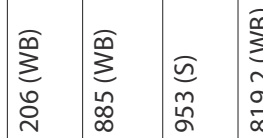

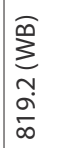

$\sqrt{5}$

弚

-

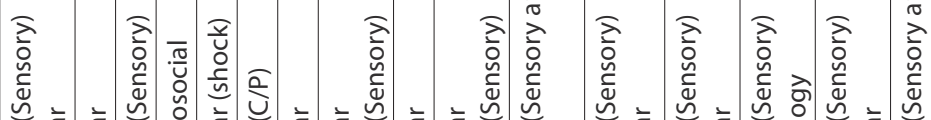

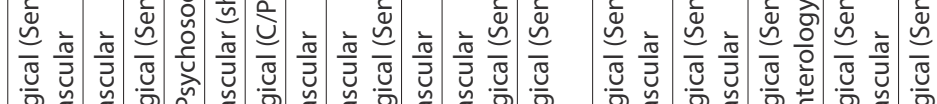

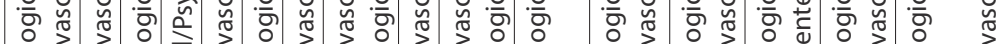

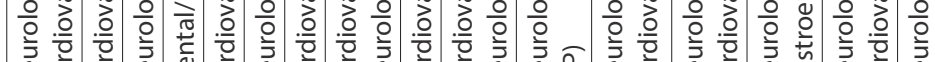

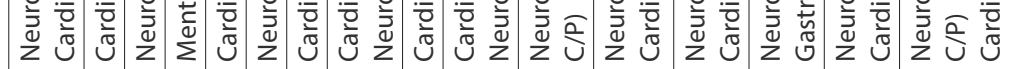




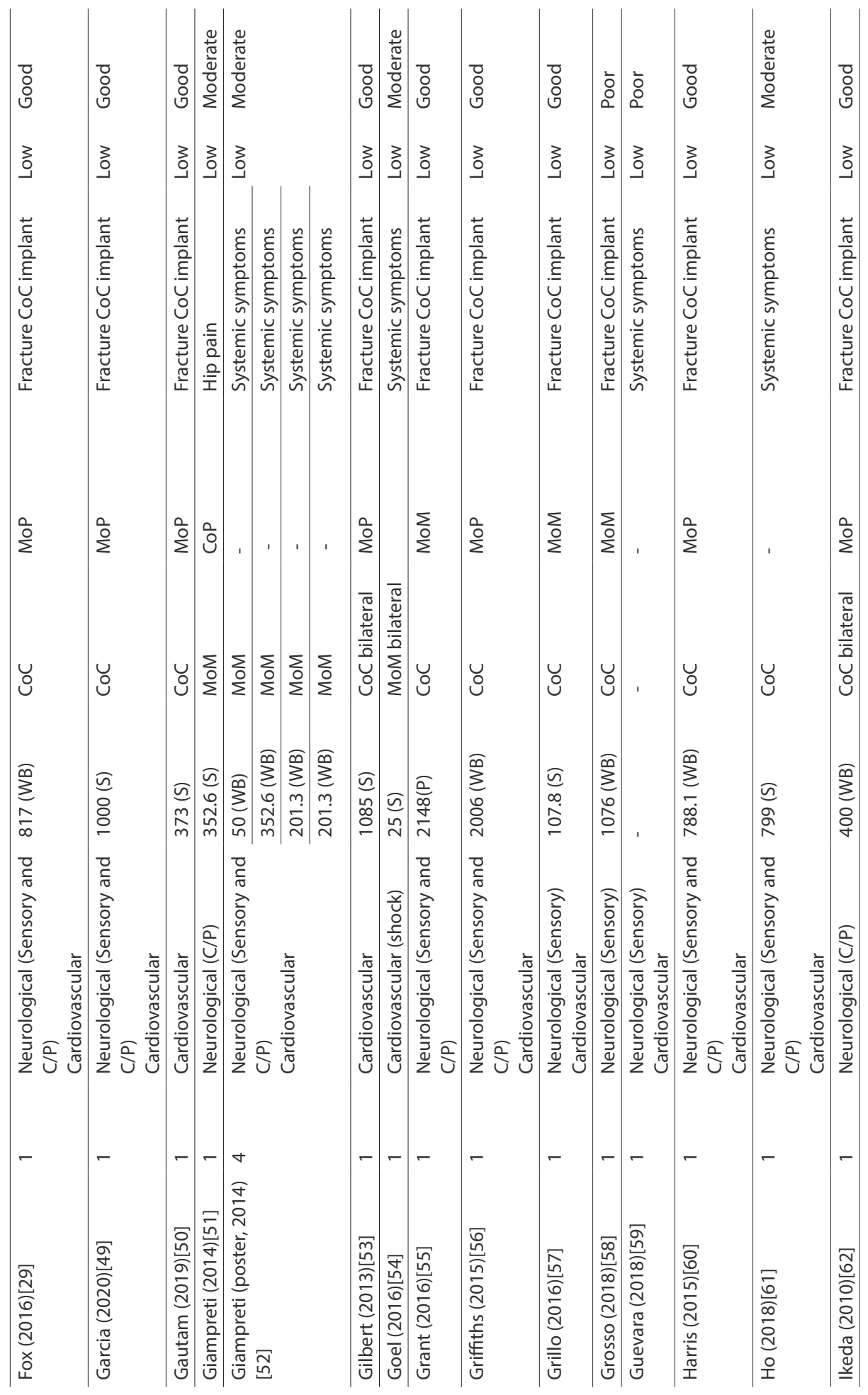




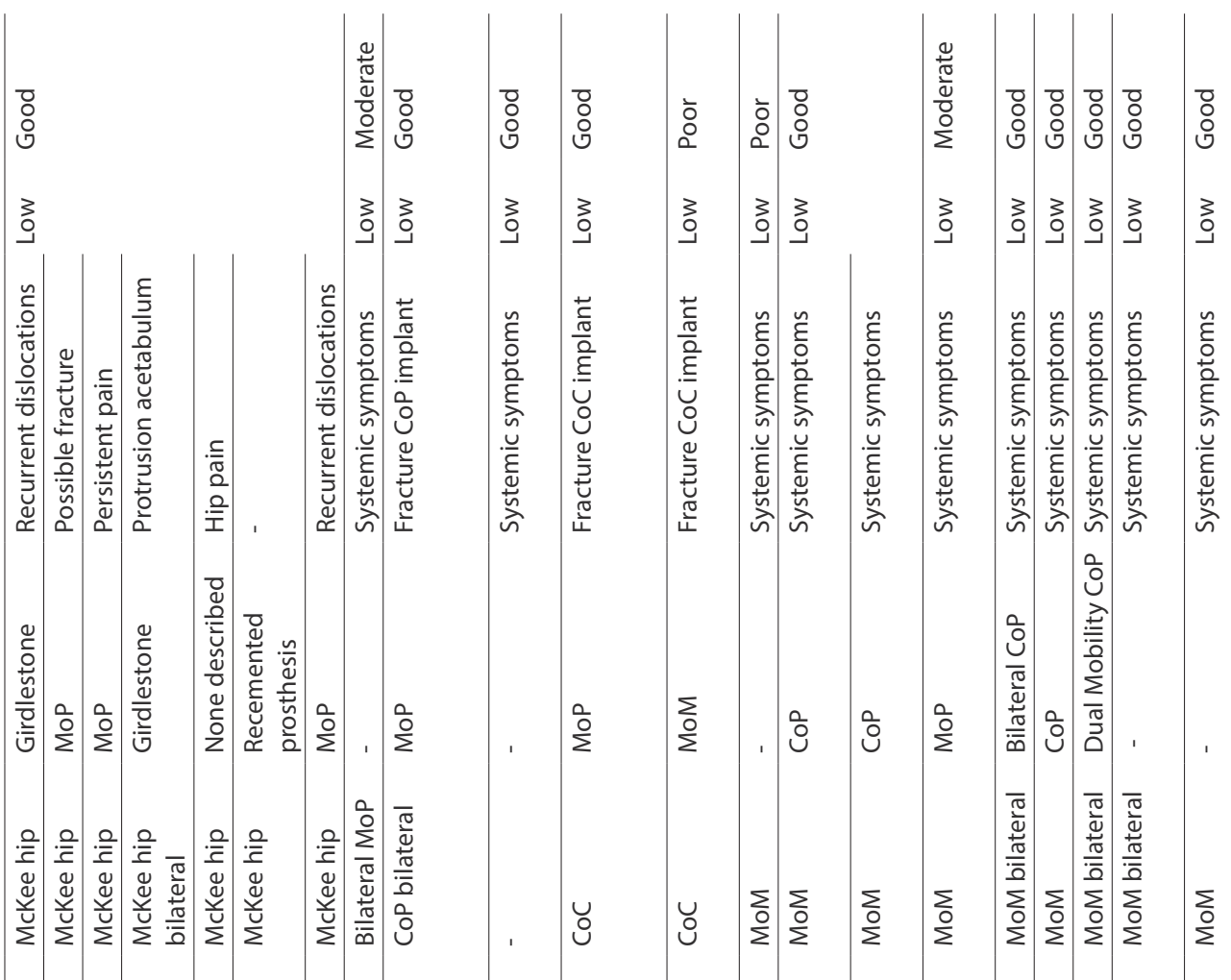

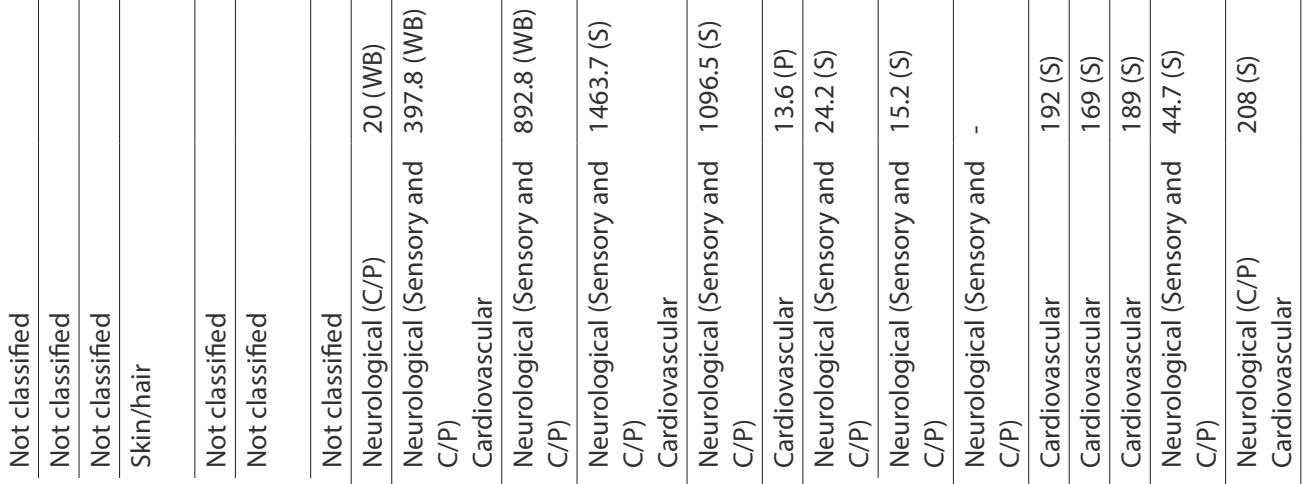

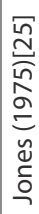

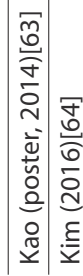

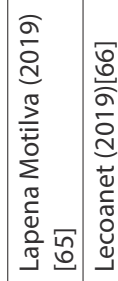

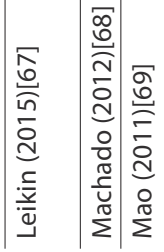

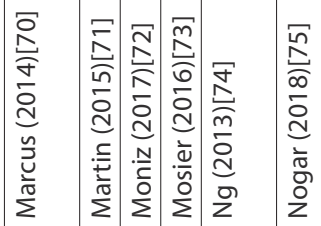




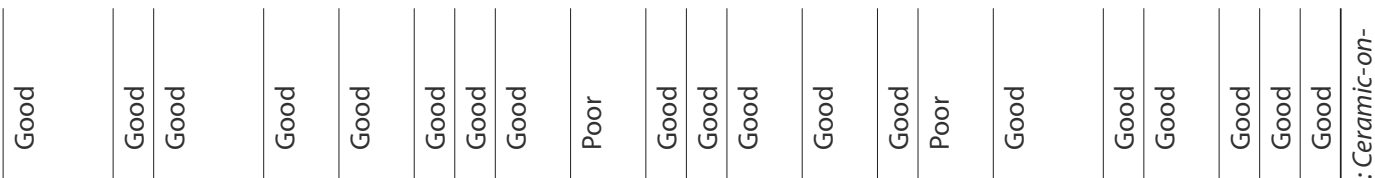

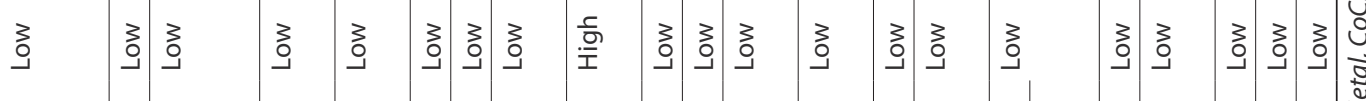

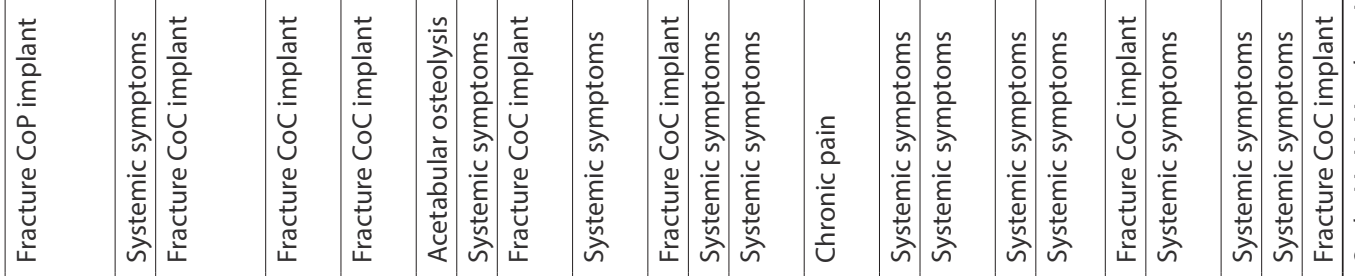

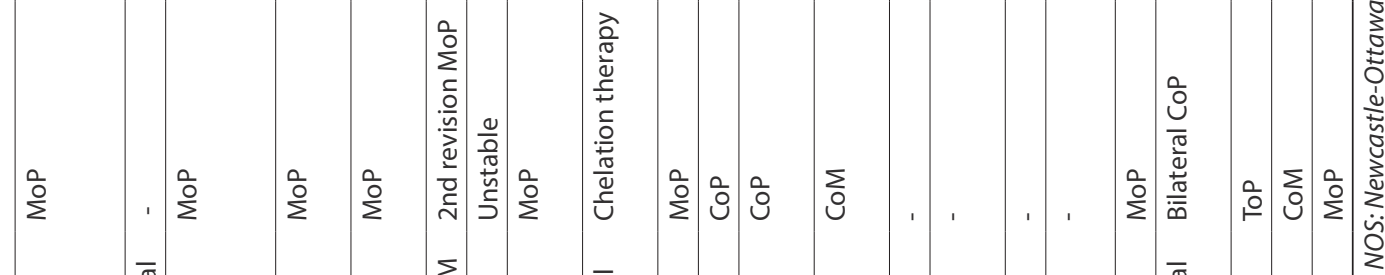

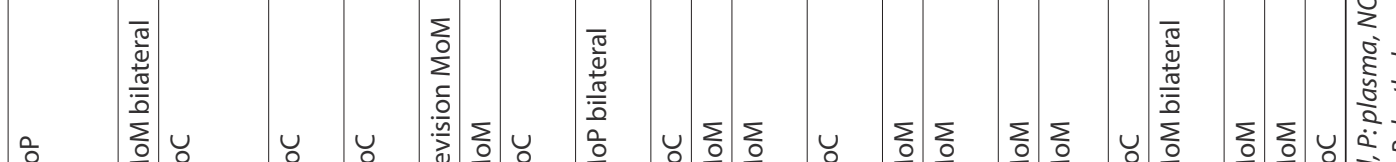

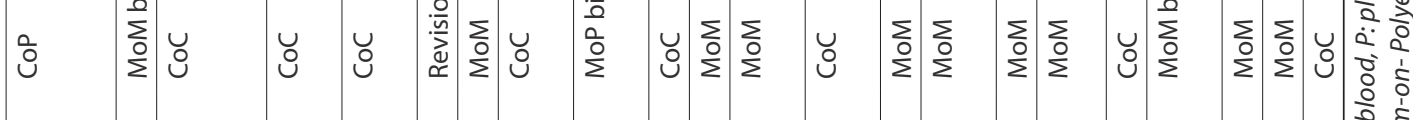

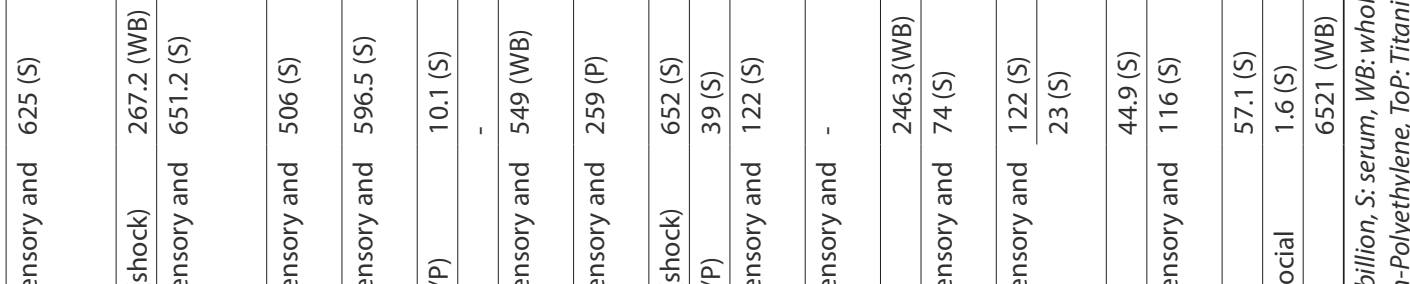

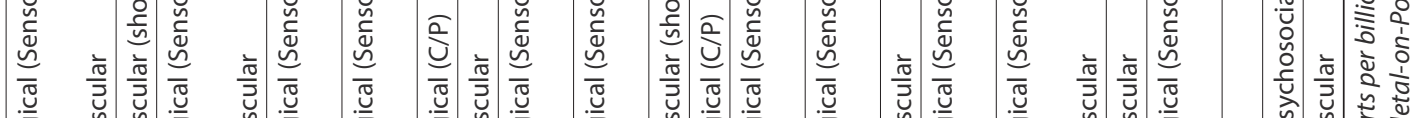

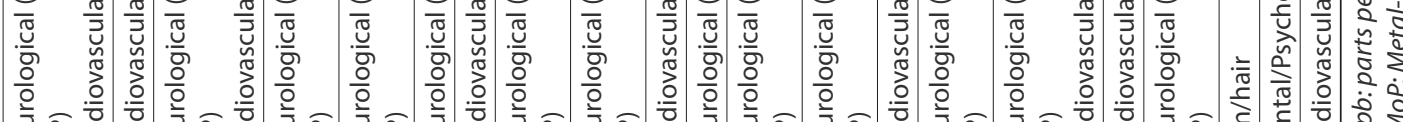

ż

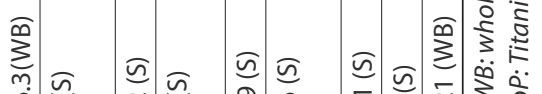



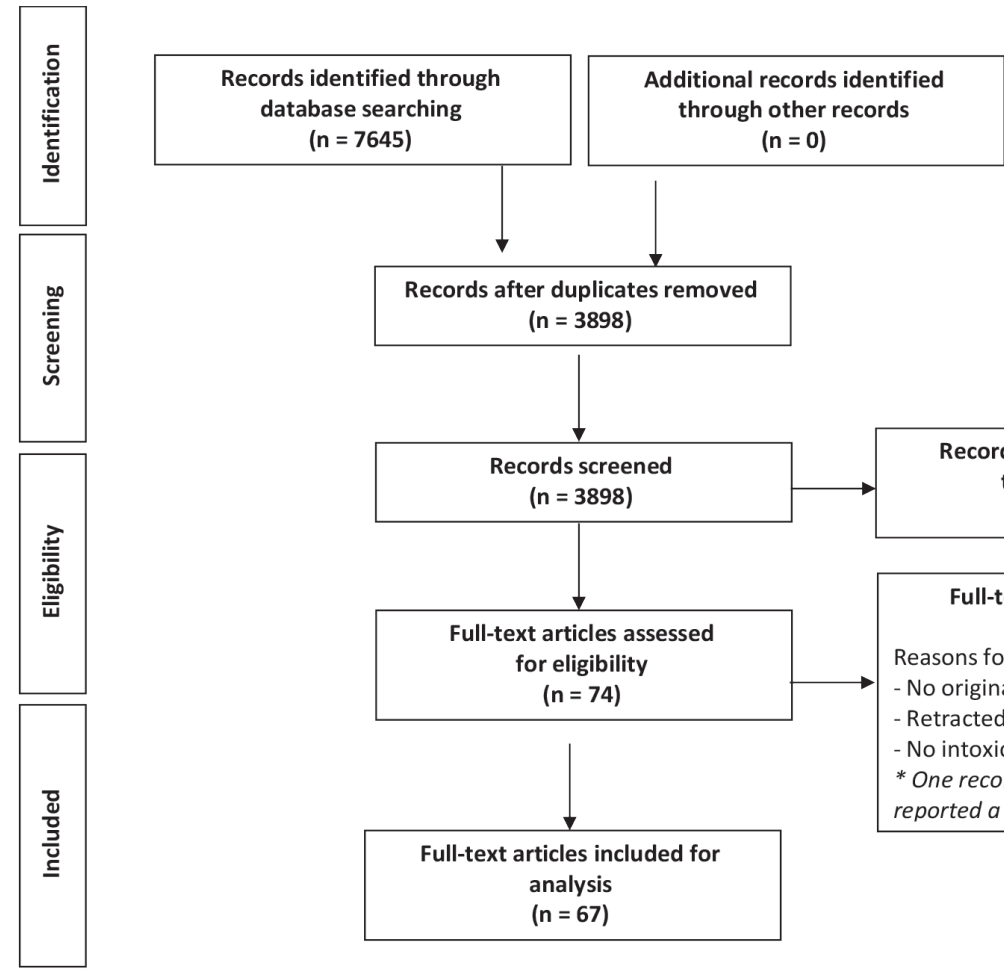

Records excluded based on title or abstract $(n=3824)$

Full-text articles excluded $(n=7)$ Reasons for exclusion*: - No original case $(n=4)$ - Retracted $(n=2)$ - No intoxication $(n=1)$

* One record was a duplicate and reported a not original case

Figure 1: Preferred Reporting Items for Systematic Reviews and Meta-Analysis (PRISMA) flowchart

\section{PHACT related systemic symptoms}

A total of 321 symptoms were scored and divided into nine different categories; neurological, cardiovascular, gastroenterology, musculoskeletal, skin/hair, thyroid, mental/psychosocial and others. The neurological symptoms were subcategorized in central/peripheral and sensory. Some patients had more than one reported symptom during the first presentation. All documented symptoms were considered and scored as possible PHACT. Table 4 shows all the different symptoms in the nine different categories.

The most identified symptoms were neurological related. Since most symptoms were especially related to the sensory system, we divided them into sensory system $(\mathrm{N}=77 ; 24.0 \%)$ and central/peripheral $(\mathrm{N}=62 ; 19.3 \%)$ related symptoms.

Hearing impairment/loss and visual impairment/retinal dysfunction were the most mentioned problems in the sensory system, with a total of 34 (44.2\%) and 25 (32.5\%) respectively. Within the 79 described patients, hearing impairment/loss encounters 


\section{Chapter 7}

for a total of $43.0 \%$ and visual impairment/retinal dysfunction for $31.6 \%$. In the central/peripheral group the most described symptoms were cognitive, memory, or concentration problems $(\mathrm{N}=16 ; 12.6 \%)$ and paraesthesia/anaesthesia $(\mathrm{N}=13 ; 16.5 \%)$.

Table 2. Demographics of all patients $(n=79)$

\begin{tabular}{|c|c|}
\hline Variable & Total \\
\hline \multicolumn{2}{|l|}{ Primary surgery } \\
\hline Mean age at primary surgery (SD) & $53.2(14.2)$ \\
\hline \multicolumn{2}{|l|}{ Indications for primary surgery (\%) } \\
\hline Primary osteoarthritis & $28(35.4)$ \\
\hline Avascular necrosis & $9(11.4)$ \\
\hline Fracture & $3(3.8)$ \\
\hline Dysplasia & $2(2.5)$ \\
\hline Hip pain & $1(1.3)$ \\
\hline Unknown & $36(45.6)$ \\
\hline Male/Female (\%) & $46 / 27(58.2 / 34.2)$ \\
\hline \multicolumn{2}{|l|}{ Primary bearing (\%) } \\
\hline MoM & $38(48)$ \\
\hline $\mathrm{CoC}$ & $32(40.5)$ \\
\hline MoP & $2(2.5)$ \\
\hline $\mathrm{CoP}$ & $2(2.5)$ \\
\hline Unknown & $5(6.5)$ \\
\hline \multicolumn{2}{|l|}{ Revision surgery } \\
\hline Mean age at revision surgery (SD) & $58.6(11.1)$ \\
\hline \multicolumn{2}{|l|}{ Indication for revision surgery (\%) } \\
\hline Systemic symptoms & $38(48.1)$ \\
\hline Fracture $\mathrm{CoC}$ & $31(39.2)$ \\
\hline (chronic) Pain & $4(5.1 \%)$ \\
\hline Recurrent dislocations & $2(2.5 \%)$ \\
\hline Protrusion acetabulum & $1(1.3 \%)$ \\
\hline Fracture & $1(1.3 \%)$ \\
\hline Osteolysis & $1(1.3 \%)$ \\
\hline Unknown & $1(1.3 \%)$ \\
\hline Male/Female (\%) & $26 / 15(63.4 / 36.6)$ \\
\hline
\end{tabular}

\begin{tabular}{ll}
\hline Cobalt toxicity & \\
\hline Mean age at onset of symptoms & $59.0(11.5)$ \\
\hline Primary PHACT complaints (\%) & $38(48)$ \\
Revision PHACT complaints (\%) & $41(52)$ \\
\hline Mean cobalt toxicity level in ppb (SD) & $572(962.1)$ \\
\hline Mean follow up time in months (SD) & $12.7(14.2)$ \\
\hline
\end{tabular}

SD: standard deviation, MoM: Metal-on-Metal, CoC: Ceramic-on-Ceramic, MoP: Metal-onPolyethylene, CoP: Ceramic-on- Polyethylene, PHACT: Prosthetic Hip Associated Cobalt Toxicity, ppb: parts per billion. 
The second most reported complaints were grouped in the cardiovascular origin. We found 71 suspected cobalt-induced cardiovascular complaints after primary and/or revision hip surgery. The described cardiovascular symptoms divers from dyspnea $(\mathrm{N}=25 ; 31.6 \%)$, cardiomyopathy $(\mathrm{N}=12 ; 15.2 \%)$, heart failure $(\mathrm{N}=10 ; 12.7 \%)$ to cardiogenic shock $(\mathrm{N}=4 ; 5.1 \%)$ (table 3$)$.

Another systemic problem, often related to cobalt toxicity, is hypothyroidism or thyroid dysfunction. We found 9 patients (11.4\%) with proven thyroid abnormalities. A total of 17 (21.5\%) patients described fatigue and nine had thyroid dysfunction. Of these 9 patients, only 3 patients had also proven thyroid dysfunction, in all other patients the cause of fatigue had not been investigated or described.

A total of 32 (40.5\%) patients were recorded with hip pain as one of the symptoms. Despite this is no systemic complaint, we felt obligated to describe this symptom as it is most likely related to (early) failure of the hip prosthesis.

In all patients who received treatment for the symptoms, by either removing the prosthesis or by medication, the symptoms reduced considerable.

\section{PHACT and blood cobalt concentrations}

The mean cobalt concentration in blood at which the systemic symptoms were related was $572.0 \pm 962.2 \mathrm{ppb}$ for the total group. However, these concentrations differ greatly between the different bearings. The mean cobalt toxicity level for specific MoM-, revised CoC-, and other bearings were respectively $123.7 \pm 96.8 \mathrm{ppb}$, $1078.2 \pm 1267.5 \mathrm{ppb}$, and $379.4 \pm 369.3 \mathrm{ppb}$. Table 5 described the mean cobalt concentration between the MoM- and revised $\mathrm{CoC}$-bearings and 3 major systemic symptoms; neurological, central/peripheral and sensory, and cardiovascular. There was no noticeable difference between the cobalt toxicity concentrations and the developed symptoms in the two bearings. After revision of the MoM-bearing or a second revision of the earlier fractured $\mathrm{CoC}$-bearing, cobalt concentrations decreased in almost all reported patients. 
Table 3. Demographics of all bearings $(n=79)$

\begin{tabular}{|c|c|c|c|}
\hline & \multicolumn{3}{|c|}{ Primary Bearing } \\
\hline & MoM $(n=38)$ & $\operatorname{CoC}(n=32)$ & $\begin{array}{c}\text { Other }(\operatorname{MoP}(n=2), \\
\operatorname{CoP}(n=2), \\
\text { unknown }(n=5)\end{array}$ \\
\hline Variable & Total & Total & Total \\
\hline \multicolumn{4}{|l|}{ Primary surgery } \\
\hline $\begin{array}{l}\text { Mean age at primary surgery in years } \\
\text { (SD) }\end{array}$ & $56.2(14.9)$ & $50.5(13.1)$ & $54.4(19.9)$ \\
\hline \multicolumn{4}{|l|}{ Indication for primary surgery (\%) } \\
\hline - Primary osteoarthritis & $16(42.1)$ & $11(34.4)$ & $3(33.3)$ \\
\hline - Avascular necrosis & $2(5.3)$ & $4(12.5)$ & $1(11.1)$ \\
\hline - Fracture & $3(7.9)$ & $1(3.1)$ & $0(0)$ \\
\hline - Dysplasia & $2(5.3)$ & $0(0)$ & $0(0)$ \\
\hline - Hip pain & $0(0)$ & $1(3.1)$ & $0(0)$ \\
\hline • Unknown & $15(39.5)$ & $15(46.9)$ & $5(55.6)$ \\
\hline Male/Female (\%) & $20 / 13(52.6 / 34.2)$ & $20 / 12(62.5 / 37.5)$ & $6 / 2(66.7 / 22.2)$ \\
\hline Primary PHACT complaints (\%) & $34(89.5)$ & $1(3.1)$ & $3(33.3)$ \\
\hline Revision PHACT complaints (\%) & $4(10.5)$ & $31(96.9)$ & $6(66.7)$ \\
\hline Cobalt toxicity level in ppb & $123.7(96.8)$ & $1,078.2(1,267.5)$ & $379.4(369.3)$ \\
\hline $\begin{array}{l}\text { Mean age at onset of symptoms in } \\
\text { years (SD) }\end{array}$ & $58.3(12.9)$ & $59.3(10.9)$ & $58.5(11.5)$ \\
\hline $\begin{array}{l}\text { Mean time in years at onset of } \\
\text { symptoms after primary surgery } \\
\text { (range) }\end{array}$ & $2.1(0-13)$ & $8.8(4-15)$ & $4.1(2-12)$ \\
\hline
\end{tabular}

\begin{tabular}{|c|c|c|c|}
\hline \multicolumn{4}{|l|}{ Revision surgery } \\
\hline $\begin{array}{l}\text { Mean age at revision surgery in years } \\
\text { (SD) }\end{array}$ & $60.7(11.2)$ & $56.9(11.4)$ & $58.5(8.8)$ \\
\hline \multicolumn{4}{|l|}{ Indication for revision surgery (\%) } \\
\hline - Systemic symptoms & $29(76.3)$ & $1(3.1)$ & $2(22.2)$ \\
\hline - Fracture CoC & $0(0)$ & $29(90.6)$ & $2(22.2)$ \\
\hline - (chronic) Pain & $3(7.9)$ & $1(3.1)$ & $0(0)$ \\
\hline - Recurrent dislocations & $2(5.3)$ & $0(0)$ & $0(0)$ \\
\hline - Protrusion acetabulum & $1(2.6)$ & $0(0)$ & $0(0)$ \\
\hline - Fracture & $1(2.6)$ & $0(0)$ & $0(0)$ \\
\hline - Osteolysis & $1(2.6)$ & $0(0)$ & $0(0)$ \\
\hline - Unknown & $1(2.6)$ & $1(3.1)$ & $5(55.6)$ \\
\hline \multicolumn{4}{|l|}{ Bearing after revision (\%) } \\
\hline - MoM & $0(0)$ & $6(18.8)$ & $0(0)$ \\
\hline - $\mathrm{CoC}$ & $0(0)$ & $0(0)$ & $0(0)$ \\
\hline - MoP & $5(13.2)$ & $21(65.6)$ & $2(22.2)$ \\
\hline - CoP & $12(31.6)$ & $0(0)$ & $0(0)$ \\
\hline • ToP & $1(2.6)$ & $0(0)$ & $0(0)$ \\
\hline - CoM / MoC & $1(2.6)$ & $3(9.4)$ & $0(0)$ \\
\hline - Girdlestone & $2(5.3)$ & $0(0)$ & $0(0)$ \\
\hline - Not suitable & $16(42.1)$ & $0(0)$ & $0(0)$ \\
\hline • Unknown & $1(2.6)$ & $2(6.25)$ & $6(66.7)$ \\
\hline Mean follow up time in months (SD) & $13(12.2)$ & $11(13.5)$ & $15(25.3)$ \\
\hline
\end{tabular}

SD: standard deviation, MoM: Metal-on-Metal, CoC: Ceramic-on-Ceramic, MoP: Metal-on-Polyethylene, CoP: Ceramic-on- Polyethylene, PHACT: Prosthetic Hip Associated Cobalt Toxicity, ppb: parts per billion, ToP: Titanium-on-Polyethylene, CoM: Ceramic-on-Metal, MoC: Metal-on-Ceramic. 
Table 4. All Systemic symptoms ( $\mathrm{n}=321 ; 100.0 \%$ ) reported in 79 patients

\begin{tabular}{ll}
\hline NEUROLOGICAL & $\begin{array}{c}\text { Total number of patients with specific complain } \\
\text { (\% of total = 79) }\end{array}$ \\
\hline Central and Peripheral (n= 62; 19.3\%) & $16(20.3)$ \\
\hline Cognitive/memory/concentration & $13(16.5)$ \\
\hline Paraesthesia/Anesthesia & $8(10.1)$ \\
\hline (Poly)Neuropathy & $7(8.9)$ \\
\hline Proprioception loss / difficulty walking & $4(5.1)$ \\
\hline Headache & $3(3.8)$ \\
\hline Hyposthenia / Asthenia & $3(3.8)$ \\
\hline Spasm / Muscle cramps & $2(2.5)$ \\
\hline Lower motor neuron syndromes & $1(1.3)$ \\
\hline Axonopathy & $1(1.3)$ \\
\hline Bulbar palsy & $1(1.3)$ \\
\hline Convulsions & $1(1.3)$ \\
\hline Neuropatic pain & $1(1.3)$ \\
\hline Parkinson & $1(1.3)$ \\
\hline Tremors & \\
\hline
\end{tabular}

Sensory (visual, auditory, gustatory, olfactory, somatosensory, and vestibular, $n=77 ; 24,0 \%$ )

\begin{tabular}{lc} 
Hearing impairment / loss & $34(43.0)$ \\
\hline Visual impairment / Retinal dysfunction & $25(31.6)$ \\
\hline Dysgeusia / Metallic taste & $5(11.4)$ \\
\hline Tinnitus & $2(2.5)$ \\
\hline Vertigo & $1(1.3)$ \\
\hline Loss of smell / Anosmia & $1(1.3)$ \\
\hline Optic nerve athrophy & Total number of patients with specific complain (\%) \\
\hline CARDIOVASCULAR (n =71; 22.1\%) & $25(31.6)$ \\
\hline Dyspnoe/Apnoe/Orthopnea & $12(15.2)$ \\
\hline Peri)cardiomyopathy & $10(12.7)$ \\
\hline Heart failure & $5(6.3)$ \\
\hline Tachycardia & $4(5.1)$ \\
\hline Cardiogenic shock & $4(5.1)$ \\
\hline Exertional chest tightness /pain & $4(5.1)$ \\
\hline Oedema & $2(2.5)$ \\
\hline Pericarditis & $2(2.5)$ \\
\hline Hypertension & $2(2.5)$ \\
\hline Syncope & $1(1.3)$ \\
\hline Pericardial effusion & 5 (2) \\
\hline
\end{tabular}




\begin{tabular}{|c|c|}
\hline GASTROENTEROLOGY ( $n=12 ; 3.7 \%)$ & Total number of patients with specific complain (\%) \\
\hline Diarrhea & $3(3.8)$ \\
\hline Nausea & $3(3.8)$ \\
\hline Vomiting & $3(3.8)$ \\
\hline Anorexia & $2(2.5)$ \\
\hline Liver failure & $1(1.3)$ \\
\hline MUSCULOSKELETAL ( $n=37 ; 11.5 \%)$ & Total number of patients with specific complain (\%) \\
\hline Arthromyalgia & $1(1.3)$ \\
\hline Decreased muscle mass & $1(1.3)$ \\
\hline Polyarthralgia & $1(1.3)$ \\
\hline Polymyalgia & $1(1.3)$ \\
\hline General stiffness & $1(1.3)$ \\
\hline SKIN/HAIR ( $=8 ; 2.5 \%)$ & Total number of patients with specific complain (\%) \\
\hline Rash/dermatitis/sarcoid-like & $6(7.6)$ \\
\hline Diaphoresis & $1(1.3)$ \\
\hline Hair loss & $1(1.3)$ \\
\hline THYROID (n = 9; 2.8\%) & Total number of patients with specific complain (\%) \\
\hline Hypothyroidism/Thyroid dysfunction & $9(11.4)$ \\
\hline MENTAL / PSYCHOSOCIAL ( $\mathbf{n}=25 ; 7.8 \%)$ & Total number of patients with specific complain (\%) \\
\hline Fatigue & $17(21.5)$ \\
\hline Depression & $4(5.1)$ \\
\hline Anxious & $2(2.5)$ \\
\hline Insomnia & $2(2.5)$ \\
\hline OTHER ( $n=20 ; 6.2 \%)$ & Total number of patients with specific complain (\%) \\
\hline Weight loss & $7(8.9)$ \\
\hline Weakness & $4(5.1)$ \\
\hline Fever & $2(2.5)$ \\
\hline Malaise & $2(2.5)$ \\
\hline Polydipsia & $2(2.5)$ \\
\hline Multi-organ failure & $1(1.3)$ \\
\hline Polycythemia & $1(1.3)$ \\
\hline Uncontrolled diabetes & $1(1.3)$ \\
\hline
\end{tabular}


Table 5. The total number of the three most presented systemic symptoms in relation with the cobalt toxicity level in the two most reported bearings (MoM and CoC).

\begin{tabular}{lcccc}
\hline Major Systemic Symptoms & \multicolumn{4}{c}{ Bearing-type and Cobalt Level (ppb) } \\
\cline { 2 - 5 } & MoM, $\mathrm{n}=$ & Mean Cobalt (SD) & CoC, $\mathrm{n}=$ & Mean Cobalt (SD) \\
\hline Neurological C/P & 17 & $127.2(110.9)$ & 16 & $889.1(574.9)$ \\
\hline Neurological Sensory & 13 & $119.4(98.7)$ & 19 & $1000.1(517.9)$ \\
\hline Cardiovascular & 16 & $169.0(100.2)$ & 19 & $778.4(504.4)$ \\
\hline
\end{tabular}

SD: standard deviation, MoM: Metal-on-Metal, CoC: Ceramic-on-Ceramic, C/P: central and peripheral, ppb: parts per billion.

\section{Discussion}

The present review shows that PHACT is mostly seen in primary MoM- and after revision of a (fractured) CoC-bearings for a MoP or MoM articulation. PHACT is a relevant and serious complication with severe systemic symptoms in the neurological, cardiovascular and thyroid system.

It was only after the recall of several MoM prostheses in 2010 that PHACT was increasingly associated to this type of bearing [6, 15]. Before that, only Jones et al. described several cases with cobalt induced systemic issues in the McKee hip ( $1^{\text {st }}$ generation MoM). In this case series (7 cases), the most frequent mentioned symptom was hip pain and showed increased concentrations of cobalt ions in urine and joint fluid [25]. Three other reports before 2010 by Oldenburg et al., Rizzetti et al. and Steens et al., showed cobalt related problems in revised ceramic bearings [26-28].

In primary MoM-implants the bearing surfaces can release metal particles through corrosion and adhesion (induced by wear). After revision of a (fractured) CoCbearing to a metal containing articulation (e.g. MoP or MoM), potentially remaining small ceramic particles in the soft tissue and joint space can cause massive abrasion on the metal surface through three-body wear. All mechanisms of particle release may contribute not only to local adverse reactions, but also to potential systemic cobalt toxicity $[8,9]$.

\section{Limitations}

There are some limitations that should be mentioned. Since there are no comparative studies, the present review consists mainly of case reports. Therefore, a publication bias is not ruled out and case reports are considered low quality research. To minimize these limitations, we have assessed the articles on quality by two different methods as guidance for a systematic review methodology publication. As 
suggested by the Cochrane Handbook we used the NOS to determine the RoB and assess the quality [22]. Since this questionnaire is not entirely consistent with the assessment of case reports we also used the checklist suggested by Murad et al.[24]. A second major limitation is the lack of controlled comparison studies, no clear reported patient histories and a wide range of blood cobalt ion concentrations. Because of that, a direct relationship between the presented symptoms and elevated cobalt concentrations can not be proven. Some of the reported symptoms can also occur independent from cobalt toxicity and might relate to common health issues or are associated with age. However, we were able to describe and present as adequate as possible the most reported symptoms associated with cobalt toxicity and high probability.

\section{PHACT related to type of bearing}

The present review showed PHACT in 38 patients with a MoM-bearing, of which 34 (89.5\%) were detected within 2.1 (range 0-13) years after the primary surgery. This is in contrast with the 32 described revised $\mathrm{CoC}$-bearings. In these bearings, only 1 (3.1\%) patient had PHACT related complications after primary surgery, whereas 31 (96.9\%) patients experienced PHACT within 2.4 (range: 0-9) years after revision surgery. In 29 (93.5\%) of these revision cases the indication was a fractured CoCbearing, plus, all the bearings used in the revision surgery contained at least one metal component (table 3 ).

\section{PHACT related systemic symptoms}

The three most affected systems in patients with cobalt toxicity are in the sensory-, neurological- and cardiovascular systems. The neurotoxic effects of cobalt have already been well established in multiple animal studies [12, 27, 30]. In addition, some case series describe the neurotoxicity in patients after the treatment with cobalt for anemia. Tinnitus and deafness, but also paresthesia and ataxia seem associated with the use of cobalt [12].

All reviewed reports presume a direct relationship with increased blood cobalt concentrations. Within the sensory system, a total of 77 symptoms were described of which the most involved were hearing $(\mathrm{N}=34 ; 44.2 \%)$ and visual impairment/loss. Most of these symptoms diminished after revision of the prosthesis and a decrease in blood cobalt concentrations was shown. The neurological problems contain mainly cognitive, memory and concentration dysfunction $(\mathrm{N}=16 ; 25.8 \%)$, as well as paresthesia/anesthesia $(\mathrm{N}=13 ; 21.0 \%)$. Patients with these symptoms also improved after explanting or revision of the hip prosthesis. 
The second most reposted complaints were grouped in the cardiovascular origin $(\mathrm{N}=71 ; 22.1 \%)$. Of these, dyspnea/apnea/orthopnea $(\mathrm{N}=25 ; 31.6 \%)$, cardiomyopathy $(\mathrm{N}=12 ; 15.2 \%)$, heart failure $(\mathrm{N}=10 ; 12.7 \%)$ and cardiogenic shock $(\mathrm{N}=4 ; 5.6 \%)$ were most described. The 4 patients with a cardiogenic shock showed cobalt concentrations from $25 \mathrm{ppb}$ to $652 \mathrm{ppb}$, however a clear dose response effect of the cobalt in these cases could not be established. Of these 4 patients, 1 died due to the cardiogenic shock, 1 needed a heart transplantation and 2 others clinically recovered after explanting the hip prosthesis.

Thyroid dysfunction in relation to cobalt toxicity is also well described in literature, and proven in 9 reported patients (11.4\%) [31]. Another symptom, often mentioned in relation with thyroid dysfunction, is fatigue. A total of 17 patients reported fatigue of which only 3 had a proven thyroid dysfunction. In all other cases there was no thyroid dysfunction described. If we combine the two different groups a total of 23 patients (29.11\%) may have cobalt related thyroid issues. This will make the thyroid dysfunction a third major affected systemic system, however we could not prove this.

\section{PHACT and blood cobalt concentrations}

Most published reports provide a toxicity level of cobalt concentration in their cases, however this concentration divers between all patients and different bearings. The cobalt levels associated with systemic toxicity were considerably higher in patients with revised $\mathrm{CoC}$-bearings when compared to patients with a primary MoM-bearing (mean of $1078.2 \mathrm{ppb}$ and $123.7 \mathrm{ppb}$ respectively - see table 5). Our assumption is that corrosion- and adhesion-related metal exposition in MoM-bearings is more gradually and slower than the massive release of cobalt containing metal wear through three-body related abrasion in fractured $\mathrm{CoC}$-bearings, which have been revised with metal-containing components. Another possible explanation is the awareness of local and systemic problems of the metal ions in MoM-bearings. As a result, clinicians are more likely to link sudden or unexplained systemic issues to the hip prosthesis.

Unfortunately, we found no controlled studies to definitively link the systemic clinical findings with the elevated blood cobalt concentrations and we were unable to determine a safe upper limit threshold for cobalt toxicity.

\section{Conclusion}

Since many MoM-bearings are still in situ, we can expect more PHACT cases. Unfortunately, the reported cobalt concentrations differ substantially between the 


\section{Chapter 7}

available case studies. Therefore, it is not possible to provide clear threshold levels for cobalt-related toxicity from this analysis. Nevertheless, clinicians should be aware that patients with a MoM- or revised CoC-bearing are at risk for developing systemic problems. Especially new onset systemic diseases related to neurological, cardiovascular and/or thyroid related symptoms could be due to elevated cobalt concentrations. We also recommend not to use a metal-based articulation in the revision of a fractured ceramic bearing and suggest keeping a close follow-up with yearly blood cobalt concentration controls in patients with MoM-bearings or a revised fractured $\mathrm{CoC}$-bearing. 


\section{References}

1. Pandit H, Glyn-Jones S, McLardy-Smith P, Gundle R, Whitwell D, Gibbons CL. Et al. Pseudotumours associated with metal-on-metal hip resurfacings. J Bone Joint Surg Br. 2008 Jul;90(7):847-51

2. Carlson BC, Bryan AJ, Carrillo-Villamizar NT, Sierra RJ. The utility of metal ion trends in predicting revision in metal-on- metal total hip arthroplasty. J Arthroplasty 2017 Sep;32(9S):S214-S219

3. Chalmers BP, Perry KI, Taunton MJ, Mabry TM, Abdel MP. Diagnosis of adverse local tissue reactions following metal-on- metal hip arthroplasty. Curr Rev Musculoskelet Med. 2016 Mar;9(1):67-74.

4. Matharu GS, Eskelinen A, Judge A, Pandit HG, Murray DW. Revision surgery of metal-on-metal hip arthroplasties for adverse reactions to metal debris: a clinical update. Acta Orthop 2018 Jun;89(3):278-288.

5. Brent J and Devlin JJ, Dilemmas about the toxicological consequences of metal-on- metal hip prostheses -- What we do and do not know, and what we should do? Clin Toxicol (Phila), 2013. 51(4): p. 195-8.

6. Devlin JJ, Pomerleau AC, Brent J, Morgan BW, Deitchman S, Schwartz M. Clinical features, testing, and management of patients with suspected prosthetic hip-associated cobalt toxicity: a systematic review of cases. J Med Toxicol, 2013. 9(4): p. 405-15.

7. Daniel J, Ziaee H, Pradhan C, Pynsent PB, McMinn DJW. Blood and urine metal ion levels in young and active patients after Birmingham hip resurfacing arthroplasty: four-year results of a prospective longitudinal study. J Bone Joint Surg Br, 2007. 89(2): p. 169-73.

8. McKellop Ha, Hart A, Park SH, Hothi H, Campbel P, Skinner JA. A lexicon for wear of metal-onmetal hip prostheses. Journal of Orthopaedic Research, 2014. 32(9): p. 1221-1233.

9. Berber R, Skinner JA, Hart AJ. Management of metal-on-metal hip implant patients: Who, when and how to revise? World journal of orthopedics, 2016. 7(5): p. 272.

10. Gross RT, Kriss JP, Spaet TH. The hematopoletic and goltrogenic effects of cobaltous chloride in patients with sickle cell anemia. Pediatrics, 1955. 15(3): p. 284- 90.

11. Curtis JR, Goode GC, Herrington J, Urdaneta LE. Possible cobalt toxicity in maintenance hemodialysis patients after treatment with cobaltous chloride: a study of blood and tissue cobalt concentrations in normal subjects and patients with terminal and renal failure. Clin Nephrol, 1976. 5(2): p. 61-5.

12. Cheung AC, Banerje S, Cherian JJ, Wong F, Butany J, Gilbert C. Systemic cobalt toxicity from total hip arthroplasties: review of a rare condition Part 1 - history, mechanism, measurements, and pathophysiology. Bone Joint J, 2016. 98-B(1): p. 6-13.

13. Unice KM, Kerger BD, Paustenbach DJ, Finley BL, Tvermoes BE. Refined biokinetic model for humans exposed to cobalt dietary supplements and other sources of systemic cobalt exposure. Chem Biol Interact, 2014. 216: p. 53-74.

14. Leyssens L, Vinck B, van Der Straeten C, Wuyts F, Maes L. Cobalt toxicity in humans-A review of the potential sources and systemic health effects. Toxicology, 2017. 387: p. 43-56.

15. Bradberry SM, Wilkinson JM, Ferner RE. Systemic toxicity related to metal hip prostheses. Clin Toxicol (Phila), 2014. 52(8): p. 837-47.

16. Leikin JB, Karydes HC, Whiteley PM, Wills BK, Cumpston KL, Jacobs JJ. Outpatient toxicology clinic experience of patients with hip implants. Clin Toxicol (Phila), 2013. 51(4): p. 230-6.

17. Ho JH, Leikin JB, Dargan PI, Archer JRH, Wood DM, Brent J. Metal-on-Metal Hip Joint Prostheses: a Retrospective Case Series Investigating the Association of Systemic Toxicity with Serum Cobalt and Chromium Concentrations. J Med Toxicol, 2017. 13(4): p. 321-328.

18. Haddad FS. Primary metal-on-metal hip arthroplasty was not associated with increased cancer risk. J Bone Joint Surg Am, 2013. 95(4): p. 364.

19. Kovochich M, Finley BL, Novick R, Monnot AD, Donovan E, Unice KM et al., Understanding outcomes and toxicological aspects of second generation metal-on-metal hip implants: a state-of-the-art review. Crit Rev Toxicol, 2018. 48(10): p. 853-901.

20. Higgins JP and Green SE. Cochrane handbook for systematic reviews of interventions. 2019: John Wiley \& Sons. 
21. Wells GA, Shea B, O'Connell D, Peterson J, Welch V, Losos M et al. The Newcastle-Ottawa Scale (NOS) for assessing the quality if nonrandomized studies in meta-analyses. Available from: http://wwwohrica/programs/clinical_epidemiology/oxfordasp., 2012

22. Higgins JPT, Altman DG, Sterne JAC. Chapter 8: Assessing risk of bias in included studies. Cochrane Handbook for Systematic Reviews of Interventions Version 5.0.1 (updated September 2008), 2008. The Cochrane Collaboration, 2008. Available from www.cochrane- handbook.org.

23. Veronese N, Cereda E, Solmi M, Fowler SA, Manzato E, Maggi S. Inverse relationship between body mass index and mortality in older nursing home residents: a meta-analysis of 19,538 elderly subjects. Obes Rev, 2015. 16(11): p. 1001-15

24. Murad MH, Sultan S, Haffar S, Bazerbachi F. Methodological quality and synthesis of case series and case reports. BMJ evidence-based medicine, 2018. 23(2): p. 60-63.'

25. Jones DA, Lucas HK, O'Driscoll M, Price CH, Wibberley B, Cobalt toxicity after McKee hip arthroplasty. The Journal of bone and joint surgery. British volume, 1975. 57(3): p. 289-296.

26. Oldenburg M, Wegner R, Baur X. Severe cobalt intoxication due to prosthesis wear in repeated total hip arthroplasty. J Arthroplasty 2009 Aug;24(5):825.e15-20.

27. Rizzetti MC, Liberini P, Zarattini G, Catalani S, Pazzaglia U, Apostoli P et al. Loss of sight and sound. Could it be the hip? Lancet 2009 Mar 21;373(9668):1052.

28. Steens W, Loehr JF, von Foerster G, Katzer A. Chronic cobalt poisoning in endoprosthetic replacement. Orthopade, 2006. 35(8): p. 860-864.

29. Fox KA, Phillips TM, Yanta JH, Abesamis MG. Fatal cobalt toxicity after total hip arthroplasty revision for fractured ceramic components. Clin Toxicol (Phila). 2016 Nov;54(9):874-877.

30. Catalani S, Rizzetti MC, Padovani A, Apostoli P. Neurotoxicity of cobalt. Hum Exp Toxicol. 2012 May;31(5):421-37.

31. Lantin A-C, Mallants A, Vermeulen J, Speybroek N, Hoet P, Lison D, Absence of adverse effect on thyroid function and red blood cells in a population of workers exposed to cobalt compounds. Toxicology letters, 2011. 201(1): p. 42-46.

32. Allen LA, Ambardekar AV, Devaraj KM, Maleszwewski JJ, Wolfel EE. Missing elements of the history. New England Journal of Medicine, 2014. 370(6): p. 559-566.

33. Apel W, Stark D, Stark A, O'Hagan S, Ling J. Cobalt-chromium toxic retinopathy case study. Documenta Ophthalmologica, 2013. 126(1): p. 69-78.

34. Austin E, Lazongas C, Thompson M. The Tragic Hip: A Case of Cobalt Poisoning. Clin Toxicol 2015; 53(7):739-739.

35. Balbouzis T, Georgiadis T, Grigoris P. Granulomatous lung disease: a novel complication following metallosis from hip arthroplasty. Hip \& pelvis, 2016. 28(4): p. 249-253.

36. Bartholomei D, Friang C, Betbeze M, Mensa C, Ohl X, Arndt C. Bilateral optic neuropathy confirmed with VEP in a case of chronic chrome/cobalt intoxication. Doc Ophthalmol, 2018. 136: p. 3-52.

37. Biglia A, Morandi V, Monti S, Delvino P, Cavagna L, Montecucco C. Cobalt hip prosthesis intoxication mimicking an autoimmune disease. Joint Bone Spine, 2020. 87(6): p. 652-654.

38. Bonilla HMG, Bhimaraj A. A case of cobalt cardiomyopathy. Journal of the American College of Cardiology, 2018. 71(11S): p. A2386-A2386.

39. Briani C, Cacciavillani M, Nicolli A, Trevisan A, Gasparotti R. Snake eyes MRI sign: possible role of cobalt toxicity. J Neurol, 2015. 262: p. 471-472.

40. Charette RS, Neuwirth AL, Nelson CL, Arthroprosthetic cobaltism associated with cardiomyopathy. Arthroplasty today, 2017. 3(4): p. 225-228.

41. Choi HI, Hong JA, Kim MS, Lee SE, Jung SH, Yoon PW et al. Severe cardiomyopathy due to arthroprosthetic cobaltism: report of two cases with different outcomes. Cardiovascular toxicology, 2019. 19(1): p. 82-89.

42. Citak M, Gehrke T, Thieme O. An Extreme Case of Systemic Metallosis After Implantation of a Hip Prosthesis. Deutsches Ärzteblatt International, 2018. 115(51-52): p. 862.

43. Czekaj J, Ehlinger M, Rahme M, Bonnomet F. Metallosis and cobalt-chrome intoxication after hip resurfacing arthroplasty. Journal of Orthopaedic Science, 2016. 21(3): p. 389-394.

44. Dahms K. Sharkova Y, Heitland P, Pankuweit S, Schaefer JR. Cobalt intoxication diagnosed with the help of Dr House. The Lancet, 2014. 383(9916): p. 574. 
45. Davies $D$ and Chareonthaitawee P. Beer-drinkers' cardiomyopathy revisited: cobalt toxicity after a non-metal-on-metal hip arthroplasty. J.Gen.Intern.Med., 2019, 34, 2, S492-S493

46. Dolliana P, Nüesch R, "Why am I Deaf and my Vision is Blurred?" Thinking of a Horse or a Zebra? Praxis, 2016. 105(5): p. 279-281.

47. Enseleit F, Frank M, Naegele M, Flammer AJ, Ruschitzka F. Hip to be square: cardiomyopathy of unknown origin. European Journal of Heart Failure, 2016. 18(S1): p. 8-521.

48. Sánchez CME and Cardona LP, Cobalt intoxication in a patient with hip prosthesis. European journal of clinical pharmacy: atención farmacéutica, 2016. 18(3): p. 189-190.

49. Garcia MD, Hur M, Chen JJ, Bhatti MT. Cobalt toxic optic neuropathy and retinopathy: Case report and review of the literature. American journal of ophthalmology case reports, 2020. 17: p. 100606.

50. Gautam D, Pande A, Malhotra R, Fatal Cobalt Cardiomyopathy Following Revision Total Hip Arthroplasty-A Brief Report with Review of Literature. Archives of Bone and Joint Surgery, 2019. 7(4): p. 379.

51. Giampreti A, Lonati D, Locatelli CA, Chelation in suspected prosthetic hip-associated cobalt toxicity. Canadian Journal of Cardiology, 2014. 30(4): p. 465. e13.

52. Giampreti A, Petrolini VM, Vecchio S, Lonati D, Ronchi A, Locatelli CA. Arthroprosthetic cobaltism: Clinical features, management and chelating therapy for a 2012-2013 case series from Pavia Poison Control Centre. Clinical Toxicology, 2014. 52(4): p. 295-443.

53. Gilbert CJ, Cheung A, Butany J, Zywiel MG, Syed K, McDonald M et al. Hip pain and heart failure: the missing link. Canadian Journal of Cardiology, 2013. 29(5): p. 639. e1-639. e2.

54. Goel S. and Hoskote S. Cobalt-induced cardiomyopathy requiring venoarterial ECMO. Critical Care Medicine, 2016. 44(12): p. 481.

55. Grant ML, Karp JK, Palladino M, Le N, Hall N, Herman JH. Does therapeutic plasma exchange have a role in the treatment of prosthetic hip-associated cobalt toxicity? A case report and literature review. Transfusion, 2016. 56(9): p. 2368-2373.

56. Griffiths J, Colvin A, Yates P, Meyerkort D, Kop A, Prosser G. Extreme Cobalt Toxicity: Bearing the Brunt of a Failed Ceramic Liner: A Case Report. JBJS case connector, 2015. 5(4): p. e92.

57. Grillo LM, Nguyen HV, Tsang SH, Hood DC, Odel JG. Cobalt-Chromium Metallosis With Normal Electroretinogram. Journal of Neuro-Ophthalmology, 2016. 36(4): p. 383-388.

58. Grosso M, Park P, Macaulay W. Multi-system manifestion of cobalt toxicity in the setting of metal-on-polyethylene total hip arthroplasty. HIP International, 2018. 28(1_suppl): p. 3-187.

59. Guevara G, Baily C, Logan P. Hip pain-An unusual cause of vision loss. Irish Journal of Medical Science, 2018. 187(2): p. 7-10.

60. Harris A, Johnson J, Mansuripur PK, Limbird R. Cobalt toxicity after revision to a metal-onpolyethylene total hip arthroplasty for fracture of ceramic acetabular component. Arthroplasty today, 2015. 1(4): p. 89-91.

61. Ho VM, Arac A, Shieh PB. Hearing and vision loss in an older man. JAMA neurology, 2018. 75(11): p. 1439-1440.

62. Ikeda T, Takahashi K, Kabata T, Sakagoshi D, Tomita K, Yamada M. Polyneuropathy caused by cobalt-chromium metallosis after total hip replacement. Muscle \& nerve, 2010. 42(1): p. 140143.

63. Kao C, Bunning RD. Toxicity from elevated cobalt and chromium blood levels after hip implant: A case report. Physcial Medicine and Rehabilitation, 2014, 6;9:S208.

64. Kim CH, Choi YH, Jeong MY, Chang JS, Yoon PW. Cobalt intoxication heart failure after revision total hip replacement for ceramic head fracture: a case report. Hip \& pelvis, 2016. 28(4): p. 259-263.

65. Lapena Motilva J, de Lara Cadinanos PM, Duran GO, Diaz Diaz J, Requejo VH, Collado JB et al. Cobalt poisoning secondary to hip prosthesis. European Journal of Neurology, 2019. 26(S1): p. 347-935.

66. Lecoanet $\mathrm{P}$, Blangis M, Garcia M, Legallois Y, Fabre T. Chromium-cobalt intoxication with intense systemic complications following total hip revision after per-operative ceramic fracture. Case reports in orthopedics, 2019. 2019. 


\section{Chapter 7}

67. Garcia MD, Hur M, Chen JJ, Bhatti MT. Cobalt toxicity from hip arthroplasty with visual/hearing/ neuropathy improvement within days post revision. Clin Toxicology, 2015. 53(7): p. 760.

68. Machado C, Appelbe A, Wood R. Arthroprosthetic cobaltism and cardiomyopathy. Heart, Lung and Circulation, 2012. 21(11): p. 759-760.

69. Mao X, Wong AA, Crawford RW. Cobalt toxicity-an emerging clinical problem in patients with metal-on-metal hip prostheses. Med J Aust, 2011. 194(12): p. 649-51.

70. Marcus S, Woodkotch D, Cobalt toxicity from hip joint replacement. Clinical Toxicology (2014), 52, 682-818)

71. Martin JR, Spencer-Gardner L, Camp CL, Stulak JM, Sierra RJ. Cardiac cobaltism: a rare complication after bilateral metal-on-metal total hip arthroplasty. Arthroplasty today, 2015. 1(4): p. 99-102.

72. Moniz S, Hodgkinson S, Yates P. Cardiac transplant due to metal toxicity associated with hip arthroplasty. Arthroplasty today, 2017. 3(3): p. 151-153.

73. Mosier BA, Maynard L, Sotereanos NG, Sewecke JJ. Progressive cardiomyopathy in a patient with elevated cobalt ion levels and bilateral metal-on-metal hip arthroplasties. Am J Orthop, 2016. 45(3): p. E132-E135.

74. Ng SK, Ebneter A, Gilhotra JS, Hip-implant related chorio-retinal cobalt toxicity. Indian journal of ophthalmology, 2013.61(1): p. 35.

75. Nogar J, Bellis M. A case of reversible cardiomyopathy associated with elevated cobalt and chromium levels. Clinical Toxicology, 2018. 56(10): p. 912-1092.

76. Payen C, Pulce C, Sapori JM, Vial T. Cobalt cardiotoxicity in a patient with bilateral

77. metal-on-metal (MoM) arthroplasty. Clinical Toxicology, 2015. 53(4): p. 233-403.

78. Pelayo-de Tomás J, Novoa-Parra C, Gómez-Barbero P, Cobalt toxicity after revision total hip replacement due to fracture of a ceramic head. Revista Española de Cirugía Ortopédica y Traumatología (English Edition), 2017. 61(3): p. 203-207.

79. Pelclova D, Sklensky M, Janicek P, Lach K. Severe cobalt intoxication following hip replacement revision: clinical features and outcome. Clinical Toxicology, 2012. 50(4): p. 262-265.

80. Peters RM, Willemse P, Rijk PC, Hoogendoorn M, Zijlstra WP. Fatal cobalt toxicity after a nonmetal-on-metal total hip arthroplasty. Case reports in orthopedics, 2017. 2017.

81. Reich MS, Javidan P, Garg VK, Copp SN. Chronic systemic metal ion toxicity from wear on a revised cobalt-chromium trunnion. Journal of orthopaedic case reports, 2019. 9(2): p. 48.

82. Reid NE, Mazer-Amirshahi M, Litovitz TL. Cobalt, Cardiomyopathy, and Chelation in a Patient with a Metal-on-Metal Hip Implant. Journal of Medical Toxicology, 2014. 10(1): p. 65-99.

83. Sanchez-Dalmau B, de Carvalho AM, Nieto C, Fontecilla C, Torres Torres R, Nogués S et al. Visual dysfunction induced by cobalt toxicity. Neuro-Ophthalmology, 2015. 39(sup1): p. S1-S87.

84. Sanz Pérez MI, Villoras AMR, Velasco AM, García SB, Loarte JC. Heart transplant secondary to cobalt toxicity after hip arthroplasty revision. HIP International, 2019. 29(4): p. NP1-NP5.

85. Shapiro JA, Eskildsen SM, Del Gaizo DJ. Systemic cobaltism manifesting as oral mucosal discoloration and metallic gustation after metal-on-metal hip resurfacing. Arthroplasty today, 2018. 4(4): p. 436-440.

86. Sotos JG and Tower SS. Systemic disease after hip replacement: aeromedical implications of arthroprosthetic cobaltism. Aviation, space, and environmental medicine, 2013. 84(3): p. 242245.

87. Tilney R, Burg MR, Sammut MA. Cobalt cardiomyopathy secondary to hip arthroplasty: an increasingly prevalent problem. Case reports in cardiology, 2017. 2017.

88. Tower SS. Arthroprosthetic cobaltism associated with metal on metal hip implants. Bmj, 2012. 344.

89. Tower SS. Arthroprosthetic cobaltism: neurological and cardiac manifestations in two patients with metal-on-metal arthroplasty: a case report. Jbjs, 2010. 92(17): p. 2847-2851.

90. Vasukutty NL andMinhas THA. Systemic effects of cobalt toxicity after revision hip replacement can manifest in intermediate to long term follow-up. Hip International, 2016. 26(4): p. e31-e34.

91. Woelber E, van Citters DW, Steck T, Glass GA, Tower S. Explant analysis from a patient exhibiting rapid acceleration of Parkinson disease symptoms and hypercobaltemia following metal-onmetal total hip arthroplasty: a case report. JBJS case connector, 2016. 6(2): p. e45. 
92. Wong CC and Nixon RL, Systemic allergic dermatitis caused by cobalt and cobalt toxicity from a metal on a metal hip replacement. Contact dermatitis, 2014. 71(2): p. 113-114.

93. Zeynalov E, Cutrufello N, Pierce A. Cobalt blues: A case report of cobalt intoxication associated obstrictive sleep apnea (OSA). Sleep, 2018. 41: p. A415.

94. Zywiel MG, Brandt JM, Overgaard CB, Cheung AC, Turgeon TR, Syed KA. Fatal cardiomyopathy after revision total hip replacement for fracture of a ceramic liner. The bone \& joint journal, 2013. 95(1): p. 31-37. 


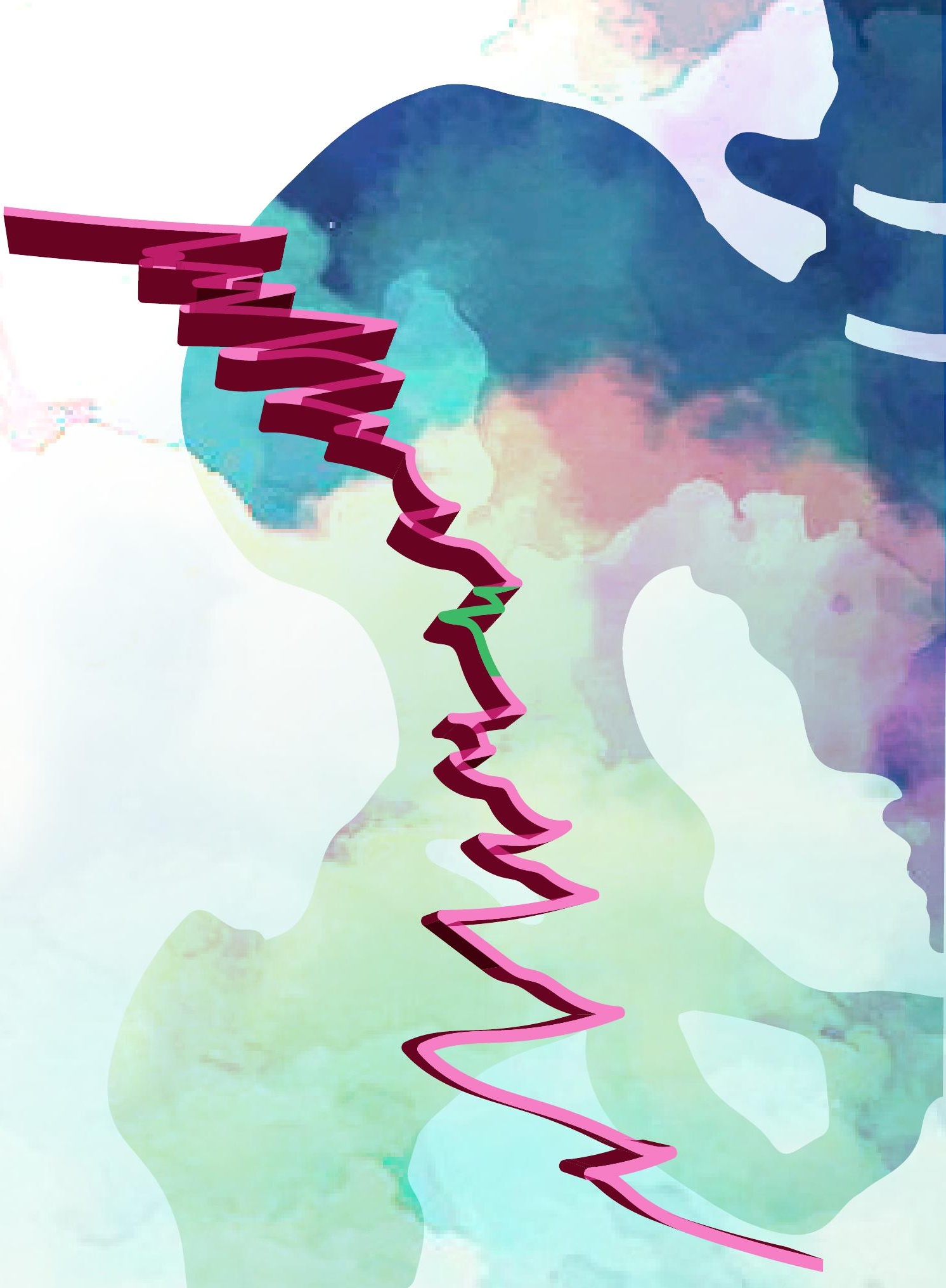




\section{Chapter VIII}

\section{Self-Reported Systemic}

Complaints in Patients with Metal-on-Metal Hip Arthroplasty

J Orthop. 2020 Jan 25;18:213-217

Jelsma J, Schotanus M, Kleinveld H, Grimm B, Heyligers I

What makes something special is not just what you have to gain, but what you feel there is to lose (Andre Agassi) 


\section{Abstract}

\section{Introduction}

An increase in blood serum metal ion levels is seen after implantation of all metalon-metal (MoM) hip prosthesis. Systemic complaints contributed to raised cobalt ion concentrations in patients with MoM arthroplasty may lead to a variety of symptoms. The aim of this study is to investigate self-reported systemic complaints in association with cobalt ion concentrations in patients with any type of MoM hip prosthesis.

\section{Methods}

A cohort study was conducted. Patients with both unilateral and bilateral, resurfacing and large head metal on metal total hip arthroplasties (LHMoM THA) were included. Cobalt ion concentrations were measured by inductively coupled plasma mass spectrometry. Based on the known cobalt toxicity symptoms of casereports and toxicology reports a new non-validated questionnaire was developed. Analysis was performed on two groups; a low cobalt ion concentration group and a high cobalt ion concentration group.

\section{Results}

A total of 62 patients were included with a mean age at surgery of $60.8 \pm 9.3$ years and a mean follow up of $6.3 \pm 1.4$ years. Mean cobalt ion concentrations were 104 $\pm 141 \mathrm{nmol} / \mathrm{L}$ (9-833). Based on the different thresholds (120-170 or $220 \mathrm{nmol} / \mathrm{L}$ ) the low cobalt ion concentration group consisted of 44 (71\%), 51 (82\%) or 55 (89\%) subjects respectively. In the $120 \mathrm{nmol} / \mathrm{L}$ and $170 \mathrm{nmol} / \mathrm{L}$ thresholds a significant difference in age was found. The composite score for OVS increased from $54 \%$ to $57 \%-68 \%$ with rising threshold value, a hint at the correlation between ion concentration and symptom prevalence

\section{Discussion}

Ocular-vestibular symptoms were more common in high cobalt ion concentration groups for the three threshold levels tested and with increasing prevalence for higher threshold values. With regards to proactively inquired, self-reported symptoms the threshold where effects may be present could be lower than values currently applied in clinical follow-up 


\section{Introduction}

An increase in blood serum metal ion levels is seen after implantation of all MoM hip prosthesis due to release from the metal surface directly, more so during articulation and corrosion of the bearing surfaces. Peak concentrations are reached at 9 to 12 months postoperative, hereafter an equilibrium is attained between metal ion release from the implant and metal ion discharge from the body (e.g. via urine)[1]. Design of the prosthesis, component positioning, contact patch to rim (CPR) distance, smaller joint sizes and renal impairment are factors which might influence metal ion concentrations after this period $[2,3]$. The continuous exposure to metal ions can result in soft tissue reactions and raised metal ion concentrations in blood, serum and urine $[4,5]$. The bearing surfaces in MoM prosthesis consist of cobalt, chromium and molybdenum. One of the most used hip resurfacing systems, Birmingham Hip Resurfacing (BHR), consists of $\pm 60 \%$ cobalt, $\pm 30 \%$ chromium, $\pm 5 \%$ molybdenum and $\pm 1 \%$ of nickel, manganese, carbon, silicon and iron [6]. The toxicity of the trivalent (III) form of chromium is low, as opposed to the hexavalent (VI) form [7]. The chromium ions released by MoM prosthesis are of the trivalent (III) form, and therefore non-hazardous [8]. This in contrast to released cobalt ions. Cobalt intoxication or cobaltism is mostly known from industrial exposure, medicinal use and beer additives [9]. This was further substantiated by a systematic review showing a correlation between symptom severity and cobalt ion concentrations but not with chromium ion concentrations [10]. Several case-reports of cobalt toxicity after hip arthroplasty have been published in the last decade, even fatal cases $[11,12]$. Systemic complaints in patients with MoM arthroplasty are also known as 'Prosthetic Hip-Associated Cobalt Toxicity' (PHACT) and may lead to a variety of symptoms: neuro-ocular toxicity (tinnitus, vertigo, deafness, blindness, convulsions, headaches and peripheral neuropathy), cardiotoxicity and thyroid toxicity. Nausea, anorexia and unexplained weight loss have been described [13-16]. It was shown that subjects with well functioning MoM hips have more structural and functional differences in organs (heart, liver, and spleen) and a changed structure of the visual pathways and the basal ganglia compared with a conventional total hip control group [17-19]. Thus, systemic effects from metal ions even with well functioning implants or with ion concentrations lower than those associated with known adverse effects may exist and warrant investigation. However, little is known in current literature about the clinical interpretation of raised metal ion concentrations and there potential systemic effects [15]. One can expect a relevant difference between complaints pro-actively self-reported or complaints specifically investigated. In the first case, patients may not report because these events are not so common, not so strong or not associated with the procedure to become reported, although they 
may exist and indicate an effect. The aim of this study is to investigate self-reported systemic complaints in association with cobalt ion concentrations in patients with any type of MoM hip prosthesis.

\section{Materials and Methods}

A cohort study was conducted between October 2012 and December 2016. The cohort was initially selected for another study; the methods are described in detail elsewere [20]. Patients with both unilateral and bilateral, resurfacing and large head metal on metal total hip arthroplasties (LHMoM THA) were included for the current study. Systemic symptoms were not a presenting complaint in any of these subjects.

Cobalt and chromium ion concentrations were measured by inductively coupled plasma mass spectrometry (ICP-MS) using the NexION ${ }^{\circledR} 300 \mathrm{X}$ ICP-MS (PerkingElmer, Waltham, Massachusetts, United States) at Ziekenhuis Groep Twente, The Netherlands. The first $5 \mathrm{~mL}$ of each vena punction was disposed, hereafter the blood was collected in a tube (BD Vacutainer ${ }^{\oplus}$ Trace Element, Franklin Lakes, New Jersey, United States) [21]. The blood was shipped within a week from collection and until then stored in a refrigerator at a temperature of $2^{\circ}-8^{\circ} \mathrm{C}$. Concentrations are described in $\mathrm{nmol} / \mathrm{L}$. Conversion from $\mathrm{nmol} / \mathrm{L}$ to $\mathrm{ug} / \mathrm{L}(\mathrm{ppm})$ is by multiplication with 0.052 for chromium and 0.059 for cobalt.

Based on the known cobalt toxicity symptoms of case-reports and toxicology reports a new non-validated questionnaire was developed. The subjects were asked to answer 17 questions on general health since placing of the MoM hip prosthesis. The questions were subdivided in general questions/symptoms, ocular-vestibular symptoms (OVS), neurological symptoms, emotional health and cardio- and thyroid toxicity symptoms. The answer options were yes and sometimes (score 1) and no (score 0). Combined scores were optained per group and a combined neuro-ocularvestibular composite score (NOVCS). The Hip disability and Osteoarthritis Outcome Score Physical function Shortform (HOOS-PS) was obtained and scored from no difficulty (0) to extreme difficulty (100) [22].

This study was performed in compliance with the 1975 Declaration of Helsinki, as revised in 2000, was studied and approved by the IRB (METC Zuyd, Heerlen, The Netherlands, IRB Nr. 10N72) and conducted in accordance with the guidelines for Good Clinical Practice (GCP). 


\section{Statistical Analysis}

Statistical analysis was performed using IBM SPSS Statistics 22 (International Business Machines Corporation, Armonk, New York, United States). Independent samples T test and Fisher's Exact Test were used. Analysis was performed on two groups; a low cobalt ion concentration group and a high cobalt ion concentration group. The upper limit of well functioning prosthesis was set at $170 \mathrm{nmol} / \mathrm{L}(10$ $\mu \mathrm{g} / \mathrm{L}$ ), as stated by the Dutch orthopaedic society (Nederlandse Orthopaedische Vereniging (NOV)) and described by Verhaar [23]. We also performed analysis with two arbitrarily chosen thresholds, a lower limit of $120 \mathrm{nmol} / \mathrm{L}$ and a higher one of $220 \mathrm{nmol} / \mathrm{L}$ to investigate whether for systemic effects another concentration level may be better suited than one which is established for known adverse effects. Results are shown as means \pm standard deviation and [range] or (percentage) with $\mathrm{p}<0.05$ as significance level.

\section{Results}

A total of 62 patients ( $58 \%$ men) with 71 prosthesis were included with a mean age at surgery of $60.8 \pm 9.3$ years $(41.6-78.1)$ and a mean follow up of $6.3 \pm 1.4$ years (3.7 - 9.6). There were 44 resurfacing and 27 LHMoM THA. The mean interval between the metal ion concentration measurement and fulfilling of the questionnaires was $1.4 \pm 0.8$ years $(0.2-2.5)$. Mean cobalt and chromium ion concentrations were $104 \pm$ $141 \mathrm{nmol} / \mathrm{L}(9-833)$ and $95 \pm 130 \mathrm{nmol} / \mathrm{L}(6-592)$, respectively (Table 1$)$.

Table 1. Baseline Characteristics

\begin{tabular}{lc}
\hline Gender & M 36 (58\%) / F26 (42\%) \\
Age at OR (years) & $60.8 \pm 9.3[41.6-78.1]$ \\
Follow-up (years) & $6.3 \pm 1.4[3.7-9.6]$ \\
Resurfacing (number of) & 44 \\
LHMoM (number of) & 27 \\
Unilateral (number of) & 53 \\
Bilateral (number of) & 9 \\
Interval (years)* & $1.4 \pm 0.8[0.2-2.5]$ \\
& $104 \pm 141[9-833]$ \\
Cobalt (nmol/L) & $95 \pm 130[6-592]$ \\
Chromium (nmol/L) & $18.9 \pm 17.9(0-67.9)$ \\
\hline
\end{tabular}

* Interval between measuring of metal ion concentrations and completing questionnaires 
Based on the different thresholds $(120$ - 170 or $220 \mathrm{nmol} / \mathrm{L})$ the low cobalt ion concentration group consisted of $44(71 \%), 51$ (82\%) or $55(89 \%)$ subjects respectively. In the $120 \mathrm{nmol} / \mathrm{L}$ and $170 \mathrm{nmol} / \mathrm{L}$ thresholds a significant difference in age was found. The composite score for OVS increased from $54 \%$ to $57 \%$ to $68 \%$ with rising threshold value, a hint at the correlation between ion concentration and symptom prevalence. Also, the NOVCS of the high cobalt ion concentration group in the $220 \mathrm{nmol} / \mathrm{L}$ threshold was significantly higher $(p=.047)$. A composite score for cardio- and thyroid toxicity showed no significant differences between the groups (Table 2).

\section{Discussion}

This study aimed to investigate if cobalt ion concentrations commonly observed with MoM hip arthroplasty may result in more frequent self-reported systemic complaints above various cobalt ion level thresholds. The main finding of this study was that OVS are more common in patients with high cobalt ion concentrations, independently of the thresholds investigated $(120-170$ or $220 \mathrm{nmol} / \mathrm{l})$. In accordance, the composite score of OVS was significantly higher in the high concentration group for all three threshold values tested and the score increased with raising the threshold value.

Subjects in the current study reported tinnitus (31\% overall) and hearing loss (40\% overall). This is in agreement with Leikin et al. who reported tinnitus and/ or hearing loss in 7 of their $26(27 \%)$ subjects with MoM arthroplasty with a mean age of 55.6 years and median cobalt ion concentration of $14.1 \mu \mathrm{g} / \mathrm{L}(239 \mathrm{nmol} / \mathrm{L})$. Patients were referred by self-referral, primary care physicians, orthopaedic physicians, poison centers and hip-arthroplasty manufacturers. Identification of symtoms was performed by the use of a clinic standard medical toxicology health history form [15]. Also Prentice et al. reported similar self-reported tinnitus (21-33\%) and hearing problems (33\%) in patients with MoM arthroplasty [24]. The average number of patients in the general population with tinnitus is far lower (14\%) [15]. Rizzeti et al. and Bradberry et al. described tinnitus and hearing loss as symptoms of cobalt toxicity $[12,13]$. This is further substantiated by the fact that the current study reports more subjects with tinnitus in the high cobalt ion concentration group at higher thresholds and with increasing threshold values. In contrast to these results, van Lingen et al. did not find a correlation between self-reported neurotoxic complaints and cobalt ion concentrations [25]. Only $10 \%$ of subjects were found to have cobalt ion concentrations $>170 \mathrm{nmol} / \mathrm{L}$, compared with $18 \%$ 
in the current study. This might have resulted in an underpowered study to detect neurotoxic effects. Also, van Lingen et al. used the NCS-60 questionnaire which is not designed and not validated for cobalt toxicity. The NCS-60 is a validated Dutch questionnaire mainly used to determine exposure to neurotoxic compounds in workers and in the evaluation of suspected neurotoxicity [26]. The current study used a questionnaire which has not been validated but was designed to specifically detect symptoms of cobalt toxicity, as opposed to the generic NCS-60. Prentice et al. could not associate slightly elevated cobalt ion concentrations $(<10 \mathrm{nmol} / \mathrm{L})$, with clinically demonstrable visual or auditory dysfunction [24]. The cobalt ion concentrationsin the cohort of Prentice et al. might be too low to generate visual or auditory dysfunction.

The clinically best-to-use cobalt ion concentration threshold is debatable, for well functioning hips, for the likely existence of pseudotumors and for possible cobalt toxicity. Tower advised neurological and cardiac assessment for patients with a cobalt concentration $\geq 7 \mu \mathrm{g} / \mathrm{L}(119 \mathrm{nmol} / \mathrm{L})$ [27]. In the 18 cobalt toxicity case reports reported by Bradberry et al. subjects showed a mean cobalt ion concentration of $398 \mu \mathrm{g} / \mathrm{L}(6754 \mathrm{nmol} / \mathrm{L})[13.6-6521 \mu \mathrm{g} / \mathrm{L}][13]$. Those patients with a failed ceramic prosthesis, revised with a metal-containing prosthesis, showed blood cobalt concentrations of $506 \mu \mathrm{g} / \mathrm{L}(8587 \mathrm{nmol} / \mathrm{L})[353-6521 \mu \mathrm{g} / \mathrm{L}]$. Patients with a primary MoM prosthesis, like all subjects in the current study, showed a blood cobalt concentration of $34.5 \mu \mathrm{g} / \mathrm{L}(586 \mathrm{nmol} / \mathrm{L})$ [13.6 - 398.6 $\mathrm{g} / \mathrm{L}]$. In constrast, a review of Paustenbach et al. concluded that significant systemic complaints of cobaltism will not occur when concentrations of cobalt ions stay below $300 \mu \mathrm{g} / \mathrm{L}(5091$ $\mathrm{nmol} / \mathrm{L}$ )[28]. Leikin et al. and Ho et al. could not correlate cobalt and chromium ion concentrations with the incidence of systemic symptoms $[15,16]$. The study by Ho et al. is a follow-up study of the aforementioned Leikin et al., a part retrospective and part prospective review of patients referred to toxicology clinics in London, UK and in the USA recorded in the Toxicology Investigators Consortium (ToxIC) Registry from June 2011 to June 2015.

Also the current study has some limitations. The study is uncontrolled to the extent, that there is no matched group with a non-MoM bearing or a matched group without a THA to serve as a comparator in a general or similar population. However, comparison is made between the high and low ion concentration groups for three threshold values. Patients were informed on the cobalt ion concentrations which could potentially affect the reported symptoms. A patient reported outcome measure (PROM) asking for complaints may bias patients towards reporting something for which they only generate awareness via the questionnaire but this new approach 


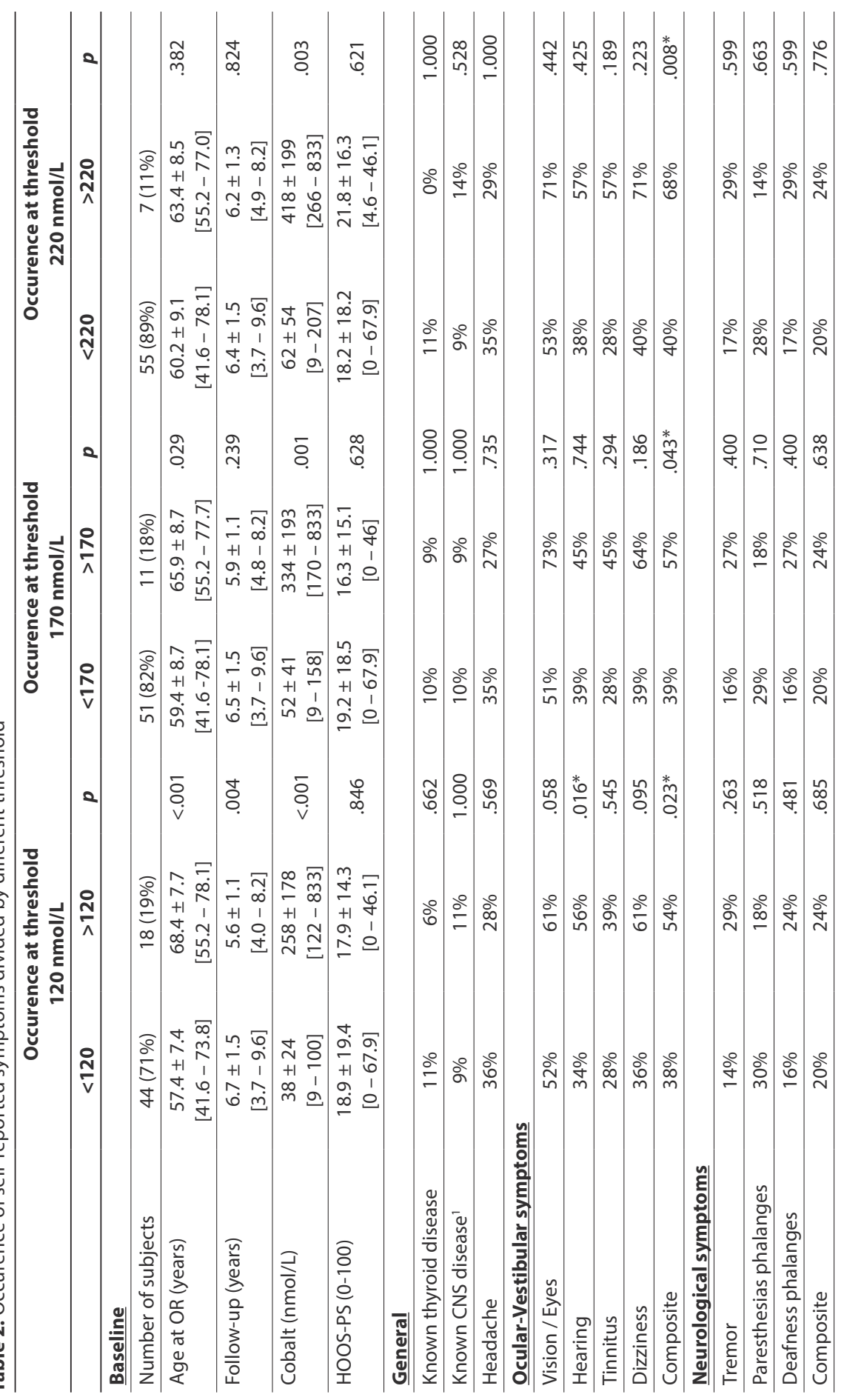




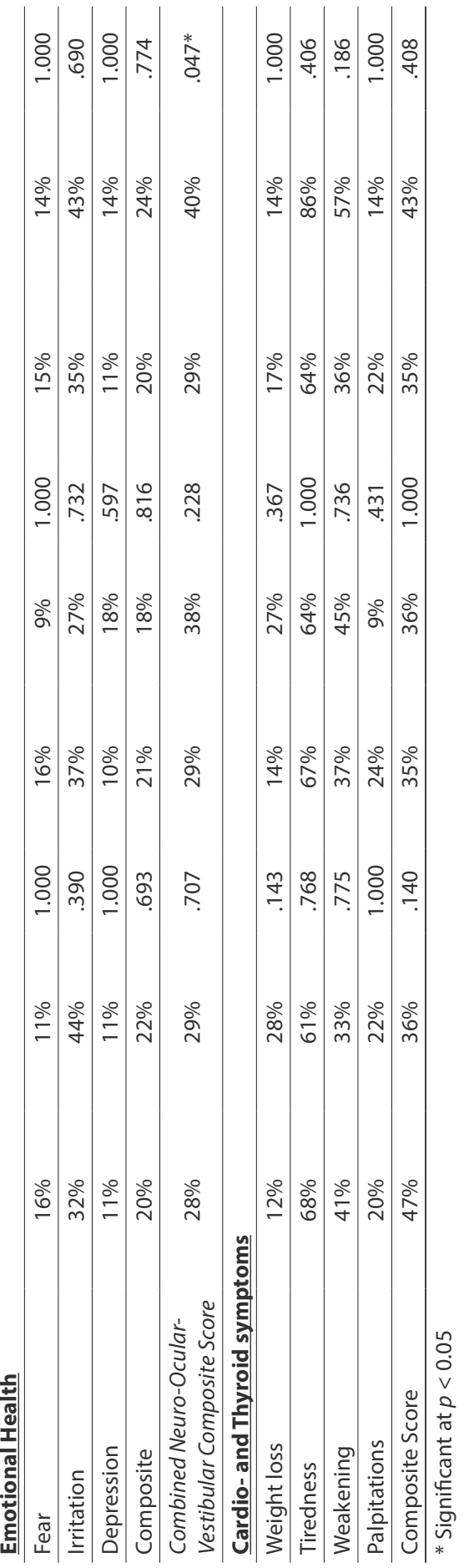


also differentiates this study from previous reports relying on generic PROM's or proactively reported complaints. The aim was to correlate symptoms with cobalt ion concentrations, presumably due to a MoM prosthesis, but it might be possible that other factors influenced cobalt ion concentrations or self-reported symptoms. Patient related factors such as allergies, diabetes, diet, medication and occupation, were not (fully) taken into account.Toxicity of cobalt is related to the unbound (free) form of cobalt $\left(\mathrm{Co}^{2+}\right)$, whereas most cobalt is bound to albumin. The refined biokinetic model of Unice et al. states that the concentration of unbound cobalt in the circulation raises and toxicity occurs at lower concentrations in susceptible subjects and in certain conditions such as kidney failure, iron deficiencies, sepsis, malnutrition and use of medication [29]. The used questionnaire was not formally validated but it was purely designed for the detection of symptoms of cobalt toxicity. It was not the intention of this study to create a new and validated questionnaire, but to study a possible effect yet unnoticed due to the lack of validated tools which are targeted and not generic. The interval between obtaining the questionnaire and the metal ion concentrations was rather large with $1.4 \pm 0.8$ years $(0.2-2.5)$. We aimed at measuring the steadystate concentrations so that the time difference between ion level assessment and PROM shall be less critical, than during the transient phase.The current study also did not measure renal functions, but severe renal insuffiencies can be ruled out and only milder forms which have produced no symptoms or have not yet been diagnosed may exist. Cobalt and chromium ions are rapidly excreted by the kidneys: $80-90 \%$ of cobalt ions within days and $60 \%$ of chromium ions within 8 hours $[3,5]$.

Although mild variations in metal ion concentrations might exist, the current study was designed to measure metal ion concentrations at a steady-state after the runningin period of 9-18 months [1]. Also, Lainala et al. showed no association between metal ion concentrations and mild or moderate renal insufficiency [30].

A significant difference in age between the groups was found for the $120 \mathrm{nmol} / \mathrm{L}$ and $170 \mathrm{nmol} / \mathrm{L}$ thresholds. This might have influenced the reported symptoms. Normal aging, with reduction in vision and hearing for example, might be confused with symptoms caused by increased cobalt ion concentrations and thus may have influenced the reported symptoms. The prevalence of hearing impairment for males in Dutch general practice is 3.9\% in agegroup 55-59 years, 6.3\% in agegroup 60-64 years, $9.7 \%$ for agegroup $65-69$ years and $13.4 \%$ for agegroup $70-74$. For females this is $3.6 \%, 5.1 \%, 6.9 \%$ and $9.0 \%$ respectively [31]. Hearing impairment is thus more frequent with increasing age, but does not fully explain the differences found in OVS in the current study, although these specific confounding factors (e.g. age) was not controlled for. 
Further research should focus on a larger cohort of MoM arthroplasties and investigate prevalence but also include symptom severity and frequency. The questionnaire used should be optimalized and focus on the main outcome of the current study. To optimize associations a shorter period of time between metal ion assessment and PROMs should be guaranteed. A long term follow-up like in this study must be considered as some systemic effect, e.g. depression, may need more time to manifest themselves.

This study aimed to detect a trend in self-reported systemic complaints in patients with metal-on-metal hip arthroplasty due to raised cobalt ion concentrations. Ocularvestibular symptoms were more common in high cobalt ion concentration groups for the three threshold levels tested and with increasing prevalence for higher threshold values. With regards to proactively inquired, self-reported symptoms the threshold where effects may be present could be lower than values currently applied in clinical follow-up. It is unknown how exposure to elevated metal ion concentrations for a longer period of time affects the health of aging subjects. Further research with a larger cohort and more standardized questionnaire is necessary to uncover previously undiscovered or under-reported effects warranting investigation. 


\section{References}

1. Daniel J, Ziaee H, Pradhan C, Pynsent PB, McMinn DJ. Blood and urine metal ion levels in young and active patients after Birmingham hip resurfacing arthroplasty: four-year results of a prospective longitudinal study. J Bone Joint Surg Br, 2007. 89(2): p. 169-73.

2. De Haan R, Pattyn C, Gill HS, Murray DW, Campbell PA, De Smet K. Correlation between inclination of the acetabular component and metal ion levels in metal-on-metal hip resurfacing replacement. J Bone Joint Surg Br, 2008. 90(10): p. 1291-7.

3. Keegan GM, Learmonth ID, Case CP. A systematic comparison of the actual, potential, and theoretical health effects of cobalt and chromium exposures from industry and surgical implants. Crit Rev Toxicol, 2008. 38(8): p. 645-74.

4. Brent J and Devlin JJ. Dilemmas about the toxicological consequences of metal-on-metal hip prostheses -- What we do and do not know, and what we should do? Clin Toxicol (Phila), 2013. 51(4): p. 195-8.

5. Newton AW, Ranganath L, Armstrong C, Peter V, Roberts NB. Differential distribution of cobalt, chromium, and nickel between whole blood, plasma and urine in patients after metal-onmetal (MoM) hip arthroplasty. J Orthop Res, 2012. 30(10): p. 1640-6.

6. Savarino L, Cadossi M, Chiarello E, Fotia C, Greco M, Baldini N et al. How do metal ion levels change over time in hip resurfacing patients? A cohort study. ScientificWorldJournal, 2014. 2014: p. 291925.

7. Afolaranmi GA, Tettey J, Meek RM, Grant MH. Release of chromium from orthopaedic arthroplasties. Open Orthop J, 2008. 2: p. 10-8.

8. Hart AJ, Quinn PD, Sampson B, Sandison A, Atkinson KD, Skinner JA et al. The chemical form of metallic debris in tissues surrounding metal-on-metal hips with unexplained failure. Acta Biomater, 2010. 6(11): p. 4439-46.

9. Tower S. Arthroprosthetic cobaltism: identification of the at-risk patient. Alaska Med, 2010. 52: p. 28-32.

10. Gessner BD, Steck T, Woelber E, Tower SS. A Systematic Review of Systemic Cobaltism After Wear or Corrosion of Chrome-Cobalt Hip Implants. J Patient Saf, 2015.

11. Zywiel MG, Brandt JM, Overgaard CB, Cheung AC, Turgeon TR, Syed KA. Fatal cardiomyopathy after revision total hip replacement for fracture of a ceramic liner. Bone Joint J, 2013. 95-B(1): p. 31-7.

12. Rizzetti MC, Liberini P, Zarattini G, Catalani S, Pazzaglia U, Apostoli P et al. Loss of sight and sound. Could it be the hip? Lancet, 2009. 373(9668): p. 1052.

13. Bradberry SM, Wilkinson JM, Ferner RE. Systemic toxicity related to metal hip prostheses. Clin Toxicol (Phila), 2014. 52(8): p. 837-47.

14. Devlin JJ, Pomerleau AC, Brent J, Morgan BW, Deitchman S, Schwartz M. Clinical features, testing, and management of patients with suspected prosthetic hip-associated cobalt toxicity: a systematic review of cases. J Med Toxicol, 2013. 9(4): p. 405-15.

15. Leikin JB, Karydes HC, Whiteley PM, Wills BK, Cumpston KL, Jacobs JJ. Outpatient toxicology clinic experience of patients with hip implants. Clin Toxicol (Phila), 2013. 51(4): p. 230-6.

16. Ho JH, Leikin JB, Dargan PI, Archer JRH, Wood DM, Brent J. Metal-on-Metal Hip Joint Prostheses: a Retrospective Case Series Investigating the Association of Systemic Toxicity with Serum Cobalt and Chromium Concentrations. J Med Toxicol, 2017. 13(4): p. 321-328.

17. Prentice JR, Clark MJ, Hoggard N, Morton AC, Tooth C, Paley MN. Metal-on-metal hip prostheses and systemic health: a cross-sectional association study 8 years after implantation. PLoS One, 2013. 8(6): p. e66186.

18. Clark MJ, Prentice JR, Hoggard N, Paley MN, Hadjivassiliou M, Wilkinson JM. Brain structure and function in patients after metal-on-metal hip resurfacing. AJNR Am J Neuroradiol, 2014. 35(9): p. 1753-8.

19. Juneau D, Grammatopoulos G, Alzahrani A, Thornhill R, Inacio JR, Dick A. Is end-organ surveillance necessary in patients with well-functioning metal-on-metal hip resurfacings? A cardiac MRI survey. Bone Joint J, 2019. 101-B(5): p. 540-546. 
20. Jelsma J, Schotanus MG, Senden R, Heyligers IC, Grimm B. Metal Ion Concentrations after Metal-on-Metal Hip Arthroplasty are Not Correlated with Habitual Physical Activity. Hip Int. 2019 Nov;29(6):638-646

21. De Pasquale D, Stea S, Squarzoni S, Bordini B, Amabile M, Catalani S. Metal-on-metal hip prostheses: correlation between debris in the synovial fluid and levels of cobalt and chromium ions in the bloodstream. Int Orthop, 2014. 38(3): p. 469-75.

22. De Groot IB, Reijman M, Terwee CB, Bierma-Zeinstra S, Favejee MM, Roos E. Validation of the Dutch version of the Hip disability and Osteoarthritis Outcome Score. Osteoarthritis Cartilage, 2009. 17(1): p. 132.

23. Verhaar JA. [The hard lesson of metal-on-metal hip implants]. Ned Tijdschr Geneeskd, 2012. 156(42): p. A5564.

24. Prentice JR, Blackwell CS, Raoof N, Bacon P, Ray J, Hickman SJ. Auditory and visual health after ten years of exposure to metal-on-metal hip prostheses: a cross-sectional study follow up. PLoS One, 2014. 9(3): p. e90838.

25. van Lingen CP, Ettema HB, Van Der Straeten C, Kollen BJ, Verheyen CC. Self-reported neurological clinical manifestations of metal toxicity in metal-on-metal hip arthroplasty. Hip Int, 2014. 24(6): p. 568-574.

26. Hooisma J, Emmen HH. [Research on limit values for the Neurotoxic Symptom Checklist 60 (NSC-60)]. [In Dutch]. Amsterdam: Stichting Arbouw, 1992

27. Tower SS. Arthroprosthetic cobaltism: neurological and cardiac manifestations in two patients with metal-on-metal arthroplasty: a case report. J Bone Joint Surg Am, 2010. 92(17): p. 2847-51.

28. Paustenbach DJ, Galbraith DA, Finley BL. Interpreting cobalt blood concentrations in hip implant patients. Clin Toxicol (Phila), 2014. 52(2): p. 98-112.

29. Unice KM, Kerger BD, Paustenbach DJ, Finley BL, Tvermoes BE. Refined biokinetic model for humans exposed to cobalt dietary supplements and other sources of systemic cobalt exposure. Chem Biol Interact, 2014. 216: p. 53-74.

30. Lainiala $\mathrm{O}$, Reito A, Jämsä P, Eskelinen A. Mild or moderate renal insufficiency does not increase circulating levels of cobalt and chromium in patients with metal-on-metal hip arthroplasty. Bone Joint J, 2017. 99-B(9): p. 1147-1152.

31. Volksgezondheidenzorg.info (2018a) Gehoorstoornissen [internet]. 2018. RIVM: Bilthoven, 12 oktober 2019. Available from: https://www.volksgezondheidenzorg.info/onderwerp/ gehoorstoornissen/cijfers-context/huidige-situatie\#node-prevalentie-slechthore 


\section{Chapter IX}

\section{General Discussion}

It is not the size of a man but the size of his heart that matters

(Evander Holyfield) 
Total hip arthroplasty (THA) is a successful procedure for patients suffering from pain, joint stiffness, functional disability and limitations in their activities, which are most often due to osteoarthritis of the hip. Each year, a million THA procedures are performed worldwide. THA is increasingly offered to younger osteoarthritis patients, and at any age patients tend to have high expectations of their operation and high demands regarding functional outcomes, which increases the need for durability of the different prostheses [1]. Survival in younger patients ( $<55$ years) is inferior to survival among older patients. Due to longer life expectancy, these younger patients will outlive their prosthesis [2].

The design of the prostheses has changed continuously, and materials have been developed to withstand the exposed stresses and to reduce the wear of bearing surfaces. The drive to improve the performance of THA resulted in the reintroduction of metal-on-metal (MoM) implants in the late 1990s and early 2000s [3]. It was shown that in-vivo wear rates of these 'second generation' MoM bearings were almost 100 times lower than those of metal-on-polyethylene (MoP) bearings and that the small particles were less likely to induce the macrophage-induced response observed in MoP bearings, which led to osteolysis ('polyethylene disease') $[4,5]$. In particular, hip resurfacing arthroplasty (HRA) was designed for highly active, young patients because of the various theoretical advantages over conventional stemmed MoP THA: low volumetric wear, femoral heads with a large physiological diameter offering stability, near-natural joint kinematics, an increased range of motion compared to THA with a small femoral head diameter, and preservation of the femoral bone, which would enable an easy revision if needed [6].

Since 2004, multiple cohort studies and national registry data of MoM hip implants have shown high failure rates, and the 10 -year survival rate threshold of $95 \%$ set by the National Institute for Health and Care Excellence (NICE) was not achieved [7, 8]. Many prostheses systems were recalled by their manufacturers. Currently, only a few MoM prostheses are still available [9]. In 2012, the NetherlandsOrthopaedicAssociation (NOV) advised against the use of MoM [10,11]. However, a large number of patients had already been treated with a MoM prostheses; estimates vary between 1 and 1.5 million patients worldwide $[12,13]$. In a report of the Network of Orthopaedic Registries of Europe (NORE) based on data of 11 national registries, the ten-year pooled revision rates were reported to be $12.1 \%$ for the HRAs and $15.5 \%$ for the stemmed large-head MoM (LHMoM) THA implants [9]. 


\section{Influence of physical activity}

In MoM hip arthroplasty, the metal surfaces are exposed to wear, which results in the release of metal ions. The concentration of metal ions in blood or serum is considered an indirect measure of such volumetric wear. Implant wear is a function of use and thus of a patient's physical activity (PA). This association between PA and implant wear was proven for THA with a polyethylene bearing, and in theory, it also applies to MoM hip arthroplasty [14]. To confirm or disprove this theory, we investigated the relation between objectively measured PA and blood metal ion concentrations in patients with a MoM hip arthroplasty (aim 1). For four consecutive days, PA in daily living was measured during waking hours using an accelerationbased activity monitor (AM). The analysis included data of 62 patients with any type of MoM hip implant (HRA and LHMoM THA), both uni- and bilateral, with a mean age at surgery of 61 years and a follow-up of 6 years. No correlations were found between serum cobalt ion concentrations and PA monitor parameters. The daily step count found in this study was comparable to that of healthy people of the same age, showing that this population with a MoM prosthesis was normally active [15]. At this point, the theory that implant wear is a function of use and thus of patient activity levels could not be confirmed for MoM hip arthroplasty. Since the heterogeneity in this study was a major concern, an attempt was made to solve this issue in the next study, which included a more homogenousgroup (16 subjects with unilateral HRA) with a long follow-up (10-years). During a short time span, metal ion concentrations were measured and PA was monitored, which revealed a statistically significant and clinically meaningful correlation between cobalt ionconcentrations and two distinct parameters of habitual PA: the number of sitstand-transfers, and high-intensity peaks. No statistically significant association with cobalt ion concentrations was found for the habitual level of time spent walking, the total number of steps, or the percentage of time spent on PA. The cause of increased metal ion concentrations after HRA seems multifactorial, and specific aspects of PA might constitute contributing factors. The qualitative aspects of PA seem more important than the conventionally measured quantitative parameters of PA. While the homogeneity of the study population was an advantage, the study had several limitations: the group size was rather small, metal ion concentrations were not normally distributed, and one subject showed abnormally high cobalt ion concentrations. When this specific subject was excluded from analysis, the correlations between PA and cobalt ion concentrations disappeared. However, also walking cadence, a proxy of walking speed was found to have a trend towards a significant correlation with cobalt ion concentrations. Further research should focus on patients with high metal ion concentrations and the correlation with PA, highintensity peaks in particular. 
The results of these studies suggest that patients with a MoM hip arthroplasty can walk as much as they desire without the risk of higher cobalt ion concentrations. However, if these patients walk too fast or too intensely (high impacts; qualitative aspects of PA) or execute a higher number of sit-standtransfers (behavior), they are more at risk for higher metal ion concentrations. It seems that general habitual PA such as normal walking does only slightly influence metal ionconcentrations. Only qualitative aspects of PA matter. For patients, it seems safe to engage in activities with low-intensity peaks, such as walking or cycling, without triggering critical wear, which means that they are able to maintain important general health benefits and quality of life. However, with the use of an HRA, it can be suggested by manufacturers and orthopaedic surgeons that patients can perform any type of movement ('sports-hip'), including large impact activities, although these activities have been shown to be especially precarious.

While in the present rehabilitation after THA the focus lies on the quantitative aspects of PA (walking), more attention should be paid to the training of qualitative aspects of PA. A more controlled movement (propriocepsis) could result in fewer high intensity events such as stumbles or falls and in a more controlled sit-stand transfer. This rehabilitation should preferably start prior to the hip replacement, because by improving preoperative functioning, one improves postoperative functioning ('better-in, better-out'), at least in theory. However, literature on this topic is unclear $[16,17]$. Further research on MoM hip arthroplasty should focus on a larger cohort of patients, especially those with high metal ion concentrations. The correlation with PA, in particular with its qualitative aspects, should be studied in-depth as an important contributor to the multifactorial aspect of chronically raised metal ion concentrations and their potential risk.

\section{Theoretical advantages}

Based on the theoretical advantages, such as the theoretically better implant design features of HRA that are claimed to support a more active lifestyle, the selection of patients for this particular implant (young and active), and the related patient expectations (high preoperative demands on postoperative activity), it can be expected that patients who received HRA would be more physically active after surgery than patients who received a conventional stemmed THA (aim 2). This was the reason for studying objectively measured PA in both groups of patients. The HRA group described earlier was compared with a non-MoM stemmed THA group matched for sex, age at surgery, followup since surgery, and BMI. There were no statistically significant differences between group characteristics at baseline. Contrary to expectations, it was 
shown that patients with an HRA were not physically more active; the groups showed similar PA monitor parameters.

It is common knowledge that PA provides health benefits, but not every individual participates in sports or is highly physically active. Anxiety and a lack of confidence were found to be the main barriers to participation of adults [18]. PA is influenced by social networks (e.g. the presence or absence of parental control, modelling), the physical environment (e.g. availability and accessibility, prices), the macro environment (e.g. media and advertising) and especially by individual factors (e.g. perceived enjoyment, self-discipline) [19]. The behavior of people, and thus also of patients, depends more on intrinsic factors than on extrinsic ones. While often pain is a reason for decreased PA, it seems that a pain-free hip and improved functional capacity is not necessarily associated with higher PA levels. Patients have their own level and style of PA, which is hardly adaptable.

The importance of PA and its influence on life should be trained and discussed at primary and high school. Sports should be available to everyone, and extra attention should be focused on negative experiences during PA classes at school, because these negative experiences are strong factors in discouraging participation, especially in young women [18]. By doing that, children and adolescents are made aware of the importance of PA and of the dangers of physical inactivity, which is considered a major risk factor for a number of adverse health outcomes. Reaching a daily step count of more than 8,000 steps has been associated with a lower risk of all-cause mortality [20]. However, only 6 out of 32 patients reached this threshold at 10 years after hip arthroplasty. In addition, almost half (13/32) would be considered to be leading sedentary lives with the associated risks of developing non-communicable diseases [15]. No differences were found between subjects with an HRA and those with a conventional stemmed THA with a MoP or CoP bearing. Both implant types enable the same level of PA, and activity levels depend more on individual lifestyle than on implant type. While short-term effects may exist, ageing and related behavioral adaptations or other effects seem to render the theoretical activity benefits of HRA irrelevant at longer follow-up. In addition, the development of ultra-high molecular weight polyethylene (UHMWPE) in to cross-linked UHMWPE (XLPE) led to a decrease in revision rates for THA at long-term follow-up (16 years) from 11.7\% for UHMWPE to 6.2\% for XLPE. In recent years, antioxidants such as Vitamin E were added to XLPE and showed promising early clinical results [21]. Based on the evolving development and current clinical performances of polyethylene, which does not have the risks known to MoM bearings, it is the golden standard in bearing choice for THA. There seems no role for MoM bearings in current orthopaedic practice. 
The theoretical advantages of HRA over stemmed THA should be explored in detail. The introduction of HRA shows how expectations may turn out to differ from reality and outcomes may develop differently than expected. The lack of adequate regulation lies at the base of this problem. While for pharmaceuticals, a phased evidence-based introduction is obligatory, this is not required per definition for orthopaedic implants due to the $510(\mathrm{k})$ pathways in the United States, for example. Unsafe orthopaedic implants can reach the market. In recent years, more attention has been gained for a phased evidence-based introduction of orthopaedic implants with a pre-market setting to detect early failure modes. One might think of biomechanical studies, radiostereophotometric analysis, implant retrieval and outcome assessment [22]. One of the early failure modes of HRA, which could have been detected in a pre-market setting, was the increased risk of a femoral neck fracture (within 3 months), with a reported prevalence of 1 to $2.5 \%$ [23]. Overweight, older female patients were at high risk, presumably due to osteoporosis of the femoral neck. Retrieved femoral heads showed avascular necrosis, while this had not been the indication for surgery [24]. Late failure modes, however, will also occur in the post-market phase. New implant designs, such as MoM, can introduce unexpected types of failure, e.g. pseudotumor formation and cobalt toxicity. Surgeons and national joint registries should be highly alert to these unexpected failures [25].

Worldwide, the expected theoretical advantages of HRA were only partially met, for example by some full distance triathletes, professional tennis player Andy Murray and National Hockey League player Ed Jovanovski [26]. These successful outcomes were especially used by the industries to show the possibilities of HRA and to convince future patients to choose HRA. On the other hand, it is unknown if athletes who were operated with conventional stemmed THA could return to their preoperative high level of sports activity after surgery. No high-quality comparative studies are available. However, most patients are less content due to complications such as femoral neck fractures, highly increased metal ion concentrations, adverse reactions to metal debris and a high change of revision within 10 years (12.1\%) [9].

Concerning the high number of problems, it is incredible that, while the NetherlandsOrthopaedicAssociation (NOV) advised against the use of MoM in 2012, it is still possible for patients in the Netherlands to cross national borders and receive MoM HRA abroad. Health insurers play a critical role; they control the funds and health care, while the scientific association (NOV) sets limits to their members concerning MoM hip replacements. In addition, direct to consumer advertising was a new way of promoting HRA, aiming to persuade the patient to choose this 
type of treatment. With the World Wide Web being the ideal medium to distribute information, large numbers of people can be reached. However, the quality of distributed information is variable [27]. HRA was advertised as the sporting hip, but in view of the results of this thesis and of the issues mentioned before, it would be more apt to speak of a political or financial hip. Choosing a technique for hip arthroplasty requires detailed information from surgeon to patient and clear insight into trade-offs between benefits and harms - in other words, it requires shared decision making. For orthopaedic surgeons, communication skills are at least as important as surgical skills. As my supervisor said: "a spoken word can be sharper than a knife" (Heyligers). The training of orthopaedic surgeons does not only involve learning to operate, but also setting indications for surgery and learning to be critical of new and existing procedures.

Current developments in prosthesis design are focussing on HRA with a cobaltchromium femoral component and a cementless acetabular cup with a XLPEacetabular liner, and on HRA with a ceramic-on-ceramic (CoC) bearing [28, 29]. It would be highly interesting to obtain objectively measured PA both pre- and postoperatively in patients with these types of HRA, and to compare these PA data to those of patients with conventional stemmed THA. It is, however, unsure if these new developments improve current results and solve current problems, or have benefits for multiple parties except for the patient itself. The development of new materials and techniques has to be a proven stepwise and well described process [25].

\section{Outcome assessment}

In orthopaedics, patient-reported outcome measures (PROMs) are designed to quantify changes in aspects that are important to patients, such as pain and physical function (PF) [30, 31]. While PROMs are commonly used, they can suffer from their subjective nature, recall bias, ceiling effects, low response and completion rates or transcription errors and the fact that PROMs are a time consuming method [32-35]. In addition, it is unknown if and how PROMs after THA reflect real levels or qualitative aspects of PA in daily life as captured with wearable AMs. Hence, we investigated to what extent objectively measured physical activity is associated with patient-reported physical activity (aim 3). PROMs of various dimensions, general health, disease specific outcome and in particular PF, joint awareness and selfperceived activity levels are correlated with objectively measured PA parameters derived from wearable AMs in subjects with a hip arthroplasty $(n=32)$. The Hip disability and Osteoarthritis Outcome Score Physical Function Short form (HOOSPS) and physical function subscale of the Short Form (36) (SF-36) were statistically significantly correlated with the daily time walking, the daily total time active and 
the number of daily steps. The Short QUestionnaire to ASsess Health-enhancing physical activity (SQUASH) only showed a statistically significant negative correlated with the age at surgery, but not with any of the objectively measured PA parameters. The correlations found were of moderate strength [36]. In order to reach sufficient content validity, van Poppel et al. recommended that at least duration and frequency should be determined by means of a questionnaire that assesses total PA and should also cover PA in all settings during daily life [37]. Surprisingly, the only questionnaire that meets these recommendations (SQUASH) was found not be correlated with objectively measured PA parameters.

The outcome of THA is influenced by an individual's interpretation and perception of joint functioning. PROMs remain inherently subjective; patients can have difficulties ignoring other negative conditions or illnesses that might have impaired their mobility, general fitness or quality of life [38]. The fact that subjectively reported PA levels and objectively measured PA levels do not correlate may indicate that it is inherently difficult to recall PA durations and frequencies in detail without bias, which challenges the use of PROMs for individual or group outcome studies and suggests that it might be limited to large population-based research, in which sensor-based assessment is not yet possible. For many PROMs, the main determinant of outcome seems to be pain, because patients have difficulties differentiating between pain and functional disability $[39,40]$. In addition, PROM data are highly influenced by a patient's postoperative pain relief, which may lead to an overestimation of the actual short-term and long-term changes in physical function [41-44].

A combination of PROMs and AM displays a patient's perception of physical functioning and the practitioner's or researcher's view of objectively determined PA of THA patients. For clinical practice, considering the value of PA for maintaining general health and the importance of restoring PA via surgery such as THA, sensorbased AMs seem to have a very high value in assessing the efficacy of treatments in this health-related dimension or as a tool for improving patient education, awareness and communication. Wearable PA monitoring gives useful information for the assessment of outcome of our treatments, such as THA, in particular in combination with PROMs. PA monitoring seems to deserve a place beside PROMs in the pre- and postoperative phase and follow-up of THA. PA monitoring provides reliable information to the patient and enables the surgeon to warn the patient if deviations from what was expected occur.

Future studies should focus on the changes in health status as measured by PROMs and their correlation with objectively measured PA, for example before 
and after total joint arthroplasty. For example, future PA research might focus on the differences in PA after THA with different surgical approaches (e.g., straight lateral, posterolateral, or direct anterior), different bearings and different prosthesis designs.

In current orthopaedic literature, the use of implant registers is increasing [45]. National joint replacement registries are multi-centre databases comprised of thousands of subjects and implants, which allow for objective outcome assessment and possibly for identifying variables of implant failure. Failed arthroplasties are often revised. One of the advantages of HRA was preservation of the femoral bone, which would result in an easy revision if needed. In general, revision procedures are technically challenging and expensive, and although these procedures provide clinical benefit and patient satisfaction, they tend to have a worse outcome than primary THA procedures $[46,47]$. The present research used the Dutch Arthroplasty Register (LROI) to determine the outcomes of revision surgery in failed MoM hip arthroplasties and to compare these outcomes to the outcomes of revision of non-MoM hip arthroplasties (aim 4). A total of 3,478 revised implant records were found, 873 of which (25.1\%) were MoM implants. Over the course of followup, the re-revision risk was $11.5 \%$ for MoM implants after slightly more than 5 years and $14.1 \%$ for non-MoM THA. The regression model showed that for MoM implants, significant risk factors for re-revision were a periprosthetic fracture as reason for index revision, a MoM articulation after the index revision, and femoralonly revisions. Large numbers of implant records can result in small $p$-values and narrow confidence intervals, but the statistically significant findings may not always be of clinical relevance, e.g., because functional outcomes are unknown. Joint registries are essential for detecting implant failures and for the phased evidencebased introduction of orthopaedic implants mentioned earlier. However, national arthroplasty registry studies are limited by the compliance of health institutions, completeness and revision surgery as the only outcome criterion [48].

\section{Cobalt toxicity}

An increase of metal ion levels in blood serum is seen after implantation of all types of MoM hip prostheses due to release of ions from the metal surface directly and more so during articulation and corrosion of the bearing surfaces [49]. This continuous exposure to metal ions can result in soft tissue reactions and raised metal ion concentrations in blood, serum and urine [50]. Initially, there were concerns that increased cobalt and chromium ion concentrations increased the risk for cancer, but this was proven otherwise in large comparative studies [51, 52]. However, little was known about the clinical interpretation of raised metal ion concentrations and their 
potential systemic effects [53]. An increasing number of case reports describing systemic reactions in relation to elevated serum cobalt, known as Prosthetic HipAssociated Cobalt Toxicity (PHACT), are available in literature $[50,54]$. The systemic complaints in patients with PHACT may lead to a variety of symptoms: neuro-ocular toxicity, cardiotoxicity and thyroid toxicity [55].

The present thesis includes two studies that aimed to determine whether chronically raised metal ion concentrations are associated with systemic complaints (aim 5). First, a systematic review of cobalt toxicity casereports was performed to determine the systematic symptoms described most often and to determine the toxicity threshold level of serum cobalt ion concentration. A total of 79 reported patients were found, with a mean age of $59.0 \pm 11.5$ years. A primary MoM bearing was used in 38 cases (48\%) and in 31 cases (39\%), a metal component was used in the revision of a fractured ceramic component. Most of the symptoms involved the sensory system (24\%), the most frequently described complaints being hearing and visual impairment or loss. Other frequently reported symptoms were neurological problems (19\%), such as cognitive, memory and concentration deficits and paraesthesia or anaesthesia, and cardiovascular complaints (22\%), such as dyspnoea, heart failure and cardiomyopathy. The cobalt threshold concentration differed greatly between all reports, which precluded the identification of a clear toxicity threshold.

For a subsequent study, we composed a new non-validated questionnaire based on the known cobalt toxicity symptoms of case-reports and toxicology reports. The questionnaire was answered by $62 \mathrm{MoM}$ hip arthroplasty patients with a mean age at surgery of 61 years and a mean follow-up of 6 years. The composite score for ocularvestibular symptoms increased from $54 \%$ to $57 \%-68 \%$ with rising threshold value (120-170 or $220 \mathrm{nmol} / \mathrm{L}$ ), which suggests a correlation between ion concentration and symptomprevalence. Subjects in the current study reported tinnitus and hearing loss far more often than patients in the general population [53, 56, 57]. Also, more subjects were found with tinnitus in the high cobalt ionconcentration group at higher thresholds and with increasing threshold values. A PROM asking for complaints may bias patients towards reporting something for which they only generate awareness via the questionnaire, but this new approach also differentiates this study from previous reports relying on generic PROMs or proactively reported complaints. Patients with a MoM hip arthroplasty, independent of the type, should be monitored systemically for the outcome of hip arthroplasty but also concerning systemic complaints, especially for ocular-vestibular symptoms in patients with chronically raised cobalt ion concentrations. It is unknown how exposure to 
elevated metal ion concentrations for a longer period of time affects the health of aging subjects. Further research with a large cohort and more standardized questionnaires is necessary to uncover previously undiscovered or under-reported effects warranting investigation.

\section{Conclusion}

This thesis showed the potential of monitoring physical activity with the use of wearable activity monitors during the pre- and postoperative follow-up of hip arthroplasty. The influence of physical activity on blood metal ion concentrations in patients with a metal-on-metal hip arthroplasty was demonstrated. It showed that physical activity is an important contributor, which was previously unknown. A statistically significant and clinically meaningful correlation was found between cobalt ion concentrations and distinct parameters of habitual physical activity. Chronically raised cobalt ion concentrations are a potential thread to general health in patients with a metal-on-metal hip arthroplasty. Ocular-vestibular symptoms were more common in high cobalt ion concentrations and with increasing prevalence for higher threshold values. Patients might experience symptoms with thresholds lower than values currently applied in clinical follow-up, only mentioned by patients because these were proactively inquired. In addition, if low-intensity physical activity does not result in excessive wear of the MoM bearing and thus in high metal ion concentrations as the indirect measure of this wear, systemic complaints as a result of chronically raised cobalt ion concentration might be prevented by informing patients about the type of PA that is most beneficial for their wellbeing. In comparison with patients with a conventional stemmed total hip arthroplasty, patients with a unilateral hip resurfacing were not physically more active at 10 year follow-up. Contrary to the expectations that were based on the theoretical advantages of hip resurfacing, both implant types enable the same level of physical activity. These activity levels depend on individual lifestyle choices rather than on implant type. Outcomes of revision procedures are not worse in patients with a metal-on-metal-hip arthroplasty: high revision and re-revision rates were found, but these rates are comparable and even lower than in patients with non-metal-onmetal arthroplasty. It was demonstrated that patient-reported outcome measures are of limited use for assessing physical activity levels. Patient-reported outcome measures hardly capture differences in activity that can be objectively measured with a wearable activity monitor. 


\section{References}

1. Schreurs BW and Hannink G, Total joint arthroplasty in younger patients: heading for trouble? Lancet, 2017;389(10077): p. 1374-1375.

2. Kuijpers MFL, Hannink G, Vehmeijer SBW, van Steenbergen LN, Schreurs BW. The risk of revision after total hip arthroplasty in young patients depends on surgical approach, femoral head size and bearing type; an analysis of 19,682 operations in the Dutch arthroplasty register. BMC Musculoskelet Disord, 2019;20(1): p. 385.

3. Amstutz HC and Le Duff MJ, Hip resurfacing: history, current status, and future. Hip Int,2015; 25(4): p. 330-8.

4. Anissian HL, Stark A, Gustafson A, Good V, Clarke IC. Metal-on-metal bearing in hip prosthesis generates 100-fold less wear debris than metal-on-polyethylene. Acta Orthop Scand, 1999; 70(6): p. 578-82.

5. Bitar D and Parvizi J, Biological response to prosthetic debris. World J Orthop, 2015;6(2): p. 172-89.

6. Corten K, Ganz R, Simon JP, Leunig M. Hip resurfacing arthroplasty: current status and future perspectives. Eur Cell Mater, 2011;21: p. 243-58.

7. Smith AJ, Dieppe P, Howard PW, Blom AW; National Joint Registry for England and Wales. Failure rates of metal-on-metal hip resurfacings: analysis of data from the National Joint Registry for England and Wales. Lancet, 2012;380(9855): p. 1759-66.

8. Smith AJ, Dieppe P, Vernon K, Porter M, Blom AW; National Joint Registry of England and Wales. Failure rates of stemmed metal-on-metal hip replacements: analysis of data from the National Joint Registry of England and Wales. Lancet, 2012. 379(9822): p. 1199-204.

9. Pijls BG, Meessen JMTA, Tucker K, Stea S, Steenbergen L, Fenstad AM et al. MoM total hip replacements in Europe: a NORE report. EFORT Open Rev, 2019. 4(6): p. 423-429.

10. Verhaar JA, [The hard lesson of metal-on-metal hip implants]. Ned Tijdschr Geneeskd, 2012. 156(42): p. A5564.

11. Van Steenbergen LN, Denissen GAW, Schreurs BW, Zijlstra WP, Koot HWJ, Nelissen RGHH. Dutch advice not to use large head metal-on-metal hip arthroplasties justifiable - results from the Dutch Arthroplasty Register. Nederlands Tijdschrift voor Orthopaedie, , 2020. 27(1).

12. Cohen D, How safe are metal-on-metal hip implants? BMJ, 2012. 344: p. e1410.

13. Matharu VK and Matharu GS, Metal-on-metal hip replacements: implications for general practice. Br J Gen Pract, 2017. 67(665): p. 544-545.

14. Schmalzried TP, Shepherd EF, Dorey FJ, Jackson WO, dela Rosa M, Fa'vae F et al. The John Charnley Award. Wear is a function of use, not time. Clin Orthop Relat Res, 2000(381): p. 36-46.

15. Tudor-Locke C, Craig CL, Aoyagi Y, Bell RC, Croteau KA, De Bourdeaudhuij I et al. How many steps/day are enough? For older adults and special populations. Int J Behav Nutr Phys Act, 2011. 8: p. 80.

16. Wang L, Lee M, Zhang Z, Moodie J, Cheng D, Martin J. Does preoperative rehabilitation for patients planning to undergo joint replacement surgery improve outcomes? A systematic review and meta-analysis of randomised controlled trials. BMJ Open, 2016. 6(2): p. e009857.

17. Moyer R, Ikert K, Long K, Marsh J. The Value of Preoperative Exercise and Education for Patients Undergoing Total Hip and Knee Arthroplasty: A Systematic Review and Meta-Analysis. JBJS Rev, 2017. 5(12): p. e2.

18. Allender S, Cowburn G, Foster C. Understanding participation in sport and physical activity among children and adults: a review of qualitative studies. Health Educ Res, 2006. 21(6): p. 826-35.

19. Deliens T, Deforche B, de Bourdeaudhuij I, Clarys P. Determinants of physical activity and sedentary behaviour in university students: a qualitative study using focus group discussions. BMC Public Health, 2015. 15: p. 201.

20. Saint-Maurice PF, Troiano RP, Bassett Jr DR, Graubard BI, Carlson SA, Shiroma EJ. Association of Daily Step Count and Step Intensity With Mortality Among US Adults. JAMA, 2020. 323(12): p. 1151-1160.

21. Zagra $L$ and Gallazzi E, Bearing surfaces in primary total hip arthroplasty. EFORT Open Rev, 2018. 3(5): p. 217-224. 
22. Hannan R, Arora V, Beaver R, Harvie P. How should new orthopaedic implants be introduced: an example and recommendations for best practice. ANZ J Surg, 2018. 88(4): p. 284-289.

23. Shimmin AJ and Back D, Femoral neck fractures following Birmingham hip resurfacing: a national review of 50 cases. J Bone Joint Surg Br, 2005. 87(4): p. 463-4.

24. Steffen RT, Foguet PR, Krikler SJ, Gundle R, Beard DJ, Murray DW. Femoral neck fractures after hip resurfacing. J Arthroplasty, 2009. 24(4): p. 614-9.

25. Pijls BG and Nelissen RG, The era of phased introduction of new implants. Bone Joint Res, 2016. 5(6): p. 215-7.

26. Girard J, Lons A, Pommepuy T, Isida R, Benad K, Putman S. High-impact sport after hip resurfacing: The Ironman triathlon. Orthop Traumatol Surg Res, 2017. 103(5): p. 675-678.

27. Ogunwale B, Clarke J, Young D, Mohammed A, Patil S, Meek RM. Direct to consumer advertising via the Internet, a study of hip resurfacing. Scott Med J, 2009. 54(1): p. 10-3.

28. Pritchett JW, Polyethylene for hip resurfacing-worth a second look. Annals of Joints, April 2020. Vol 5.

29. de Villiers D, Richards L, Tuke M, Collins S. Ceramic resurfacing: the future and challenges. Annals of Joint, 2020. Vol 5 (April 2020).

30. Fidai MS, Saltzman BM, Meta F, Lizzio VA, Stephens JP, Bozic KJ et al. Patient-Reported Outcomes Measurement Information System and Legacy Patient-Reported Outcome Measures in the Field of Orthopaedics: A Systematic Review. Arthroscopy, 2018. 34(2): p. 605-614.

31. Siljander MP, McQuivey KS, Fahs AM, Galasso LA, Serdahely KJ, Karadsheh MS. Current Trends in Patient-Reported Outcome Measures in Total Joint Arthroplasty: A Study of 4 Major Orthopaedic Journals. J Arthroplasty, 2018. 33(11): p. 3416-3421.

32. Pronk Y, Pilot P, Brinkman JM, van Heerwaarden RJ, van der Weegen W. Response rate and costs for automated patient-reported outcomes collection alone compared to combined automated and manual collection. J Patient Rep Outcomes, 2019. 3(1): p. 31.

33. Chughtai M, Khlopas A, Mistry JB, Gwam CU, Elmallah RK, Mont MA. Time Burden of Standardized Hip Questionnaires. Surg Technol Int, 2016. 28: p. 280-4.

34. Steinhoff AK and Bugbee WD, Knee Injury and Osteoarthritis Outcome Score has higher responsiveness and lower ceiling effect than Knee Society Function Score after total knee arthroplasty. Knee Surg Sports Traumatol Arthrosc, 2016. 24(8): p. 2627-33.

35. Weber BA, Yarandi H, Rowe MA, Weber JP. A comparison study: paper-based versus web-based data collection and management. Appl Nurs Res, 2005. 18(3): p. 182-5.

36. Evans J. Straightforward Statistics for the Behavioral Sciences. Brooks/Cole Publishing; Pacific Grove, Calif.: 1996, 1996.

37. van Poppel MN, Chinapaw MJ, Mokkink LB, van Mechelen W, Terwee CB. Physical activity questionnaires for adults: a systematic review of measurement properties. Sports Med, 2010. 40(7): p. 565-600.

38. Rolfson $\mathrm{O}$ and Malchau $\mathrm{H}$. The use of patient-reported outcomes after routine arthroplasty: beyond the whys and ifs. Bone Joint J, 2015. 97-B(5): p. 578-81.

39. Hossain FS, Patel S, Fernandez MA, Konan S, Haddad FS. A performance based patient outcome score for active patients following total knee arthroplasty. Osteoarthritis Cartilage, 2013. 21(1): p. 51-9.

40. Mizner RL, Petterson SC, Clements KE, Zeni JA Jr, Irrgang JJ, Snyder-Mackler L. Measuring functional improvement after total knee arthroplasty requires both performance-based and patient-report assessments: a longitudinal analysis of outcomes. J Arthroplasty, 2011. 26(5): p. 728-37.

41. Luna IE, Kehlet H, Peterson B, Wede HR, Hoevsgaard SJ, Aasvang EK. Early patient-reported outcomes versus objective function after total hip and knee arthroplasty: a prospective cohort study. Bone Joint J, 2017. 99-B(9): p. 1167-1175.

42. Mark-Christensen $\mathrm{T}$ and Kehlet $\mathrm{H}$, Assessment of functional recovery after total hip and knee arthroplasty: An observational study of 95 patients. Musculoskeletal Care, 2019.

43. Naili JE, Hedstrom M, Brostrom EW. Changes of and interrelationships between performancebased function and gait and patient-reported function 1 year after total hip arthroplasty. J Orthop Traumatol, 2019. 20(1): p. 14. 


\section{Chapter 9}

44. Jelsma J, Pijnenburg R, Boons HW, Eggen PJ, Kleijn LL, Lacroix $H$ et al. Limited benefits of the direct anterior approach in primary hip arthroplasty: A prospective single centre cohort study. J Orthop, 2017. 14(1): p. 53-58.

45. Delaunay C. Registries in orthopaedics. Orthop Traumatol Surg Res, 2015. 101(1 Suppl): p. S6975.

46. Lübbeke A, Roussos C, Barea C, Köhnlein W, Hoffmeyer P. Revision total hip arthroplasty in patients 80 years or older. J Arthroplasty, 2012. 27(6): p. 1041-6.

47. Ong KL, Lau E, Suggs J, Kurtz SM, Manley MT. Risk of subsequent revision after primary and revision total joint arthroplasty. Clin Orthop Relat Res, 2010. 468(11): p. 3070-6.

48. Gomes LSM, Roos MV, Takata ET, Schuroff AA, Alves SD, Camisa Júnior A, Advantages and limitations of national arthroplasty registries. The need for multicenter registries: the RemproSBQ. Rev Bras Ortop, 2017. 52(Suppl 1): p. 3-13.

49. Daniel J, Ziaee H, Pradhan C, Pynsent PB, McMinn DJ. Blood and urine metal ion levels in young and active patients after Birmingham hip resurfacing arthroplasty: four-year results of a prospective longitudinal study. J Bone Joint Surg Br, 2007. 89(2): p. 169-73.

50. Newton AW, Ranganath L, Armstrong C, Peter V, Roberts NB. Differential distribution of cobalt, chromium, and nickel between whole blood, plasma and urine in patients after metal-onmetal (MoM) hip arthroplasty. J Orthop Res, 2012. 30(10): p. 1640-6.

51. Haddad FS, Primary metal-on-metal hip arthroplasty was not associated with increased cancer risk. J Bone Joint Surg Am, 2013. 95(4): p. 364.

52. Kovochich M, Finley BL, Novick R, Monnot AD, Donovan E, Unice KM et al., Understanding outcomes and toxicological aspects of second generation metal-on-metal hip implants: a state-of-the-art review. Crit Rev Toxicol, 2018. 48(10): p. 853-901.

53. Leikin JB, Karydes HC, Whiteley PM, Wills BK, Cumpston KL, Jacobs JJ. Outpatient toxicology clinic experience of patients with hip implants. Clin Toxicol (Phila), 2013. 51(4): p. 230-6.

54. Brent $\mathrm{J}$ and Devlin JJ, Dilemmas about the toxicological consequences of metal-on-metal hip prostheses -- What we do and do not know, and what we should do? Clin Toxicol (Phila), 2013. 51(4): p. 195-8.

55. Leyssens L, Vinck B, van Der Straeten C, Wuyts F, Maes L. Cobalt toxicity in humans-A review of the potential sources and systemic health effects.Toxicology, 2017. 387: p. 43-56.

56. Volksgezondheidenzorg.info, Prevalentie slechthorendheid in huisartsenpraktijk. 2019.

57. Volksgezondheidenzorg.info, Gehoorstoornissen [internet]. .RIVM: Bilthoven, 12 oktober 2019, 2018. 


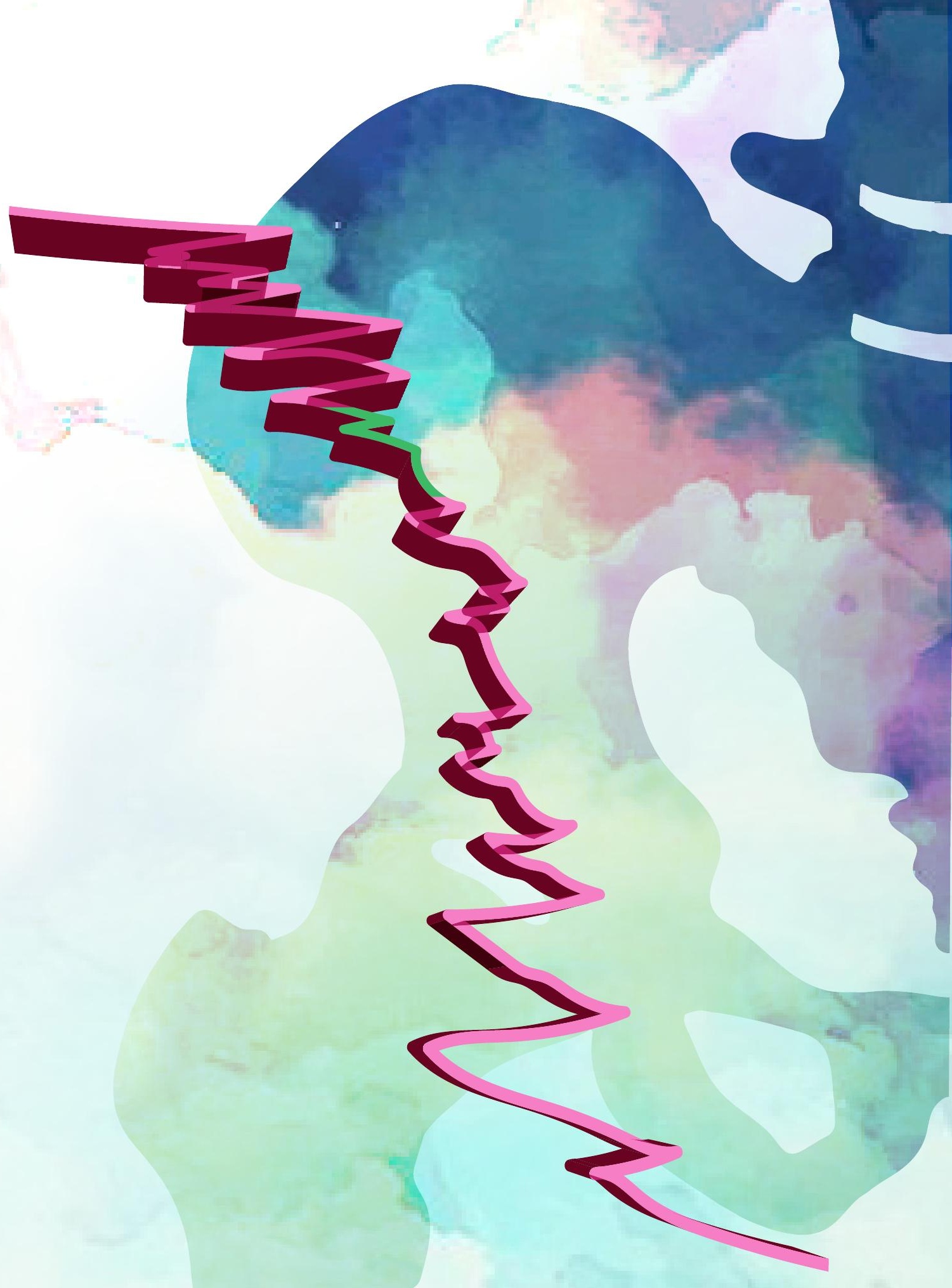




\section{Chapter X}

\section{Valorisation}

Persistence can change failure into extraordinary

achievement

(Marv Levy) 
This paragraph describes how the knowledge acquired in the reserach for this thesis can be made available for economic and social utilization.

The litature concerning results of metal-on-metal (MoM) hip arthroplasty, both large head metal-on-metal (LHMoM) total hip arthroplasty (THA) and hip resurfacing arthroplasty (HRA), showed how expectations turn out to be different. A discrepancy between the expected advantages and the long-term patient related outcomes in clinical practice is observed. The theoretical advantages were presented as the new 'big thing' in hip arthroplasty. Money-driven strategies with patient-attraction magnets ('sportship') were only beneficial for investors and developers of HRA. Unfortunately, the sales talk and news spread faster than the acquisiton of postoperative results, the disadvantages of HRA only became clear after hundreds of thousands of patients had already been operated. The influence of industries, e.g. by direct mailing to patients to make a connection to the 'consumers', and of health care insurance companies should not be underestimated. In 2012, the NetherlandsOrthopaedicAssociation (NOV) advised against the use of any MoM hip arthroplasty [1]. Hereafter, the use of hip arthroplasties with a MoM articulation decreased. The Dutch Arthroplasty Register (LROI) data showed that MoM was used in 5.2\% of THA cases in 2010, 1.51\% in 2012 and $0.02 \%$ to $0.12 \%$ between2014 and 2019 [2]. Interestingly and in contrast to the advice of the NOV, health care insurances provided patients with opportunities to travel abroad for HRA procedures. The financial incentive seemed more important than protecting and informing patients.

Orthopaedic surgeons are obligated to inform patients about both conservative and operative therapies according to the Hippocratic Oath [3]. A decision for treatment is ideally based on a shared-decision process. For surgeons, it is easier to perform a hip arthroplasty than to convince and support patients to lose weight and increase their physical activity. Currently, there is too little attention for preventive medicine. Prevention of overweight, smoking and inactivity is not stimulated enough and should start as early as possible, preferably in primary school. In the current situation, opting for a surgical intervention is easier for both the patient and the surgeon. In the training of orthopaedic residents, this temptation should be addressed with more urgency. Communication skills and recognizing the right indication for surgery are equally important as surgical skills. As residents have numerous 'general tasks' and their training is divided into stages (e.g. hip, knee, spine, trauma), it can be difficult to follow a patient over time. However, it is highly important for a resident to follow a patient during the postoperative phase after indicating the patients for surgery, so that postoperative results can be used as feedback. Of course, this 
also applies to conservative treatment. In addition, conducting scientific research leads to developing a critical view and, among other things, improves planning and organizational skills.

The introduction of new orthopaedic implants should be phased and evidencebased, none of which was the case in the introduction of MoM hip arthroplasty. A decent pre-market setting to detect early failure modes would have shown the increased risk of femoral neck fractures. Also, with careful thinking in combination with in-vitro testing, wear of the articulating surfaces and release of metal ions could have been predicted. New designs of HRA are developed and implanted in the context of clinical research, e.g. HRA with a cobalt-chromium femoral component and cementless acetabular cups with a cross-linked ultra-high molecular weight polyethyelene (XLPE)-acetabular liner and with a ceramic-on-ceramic (CoC) bearing $[4,5]$.

A phased and evidence-based introduction should not only consider subjective outcomes, such as clinically administered tools and patient-reported outcome measures (PROMs); as the present research has demonstrated, it is highly valuable to include objective measures, such as wearable activity monitors, to obtain objective data on physical activity in daily living. The new designs of HRA described above should be subject to meticulous clinical research. Physical activity should be measured objectively both pre- and postoperatively in these patients and should be compared with physical activity measurements of patients who received conventional stemmed THA. In this way, the theoretical advantages of HRA could be evaluated on objective grounds. Before new materials and techniques are investigated, there must first be a clear understanding of the problem of the existing technique that needs to be solved.

Physical activity monitoring, with the use of wearable monitors, could be used in a wide spectrum, both in clinical settings and in research. This thesis showed that PROMs hardly capture the intensity levels and behavioral differences that can be objectively measured by monitoring physical activities of daily living. PROMs are increasingly used to assess pain and physical function and to serve as indicators of outcome quality in national joint registries, but the true functional recovery after joint arthroplasty can be better determined with objective outcome assessment, such as wearable activity monitoring. There is ample evidence of the importance of physical inactivity as a major risk factor for a number of adverse health outcomes. Wearable activity monitors may be used in cardiovascular, neurodegenerative and orthopaedic patient populations. Also, the geriatric patient population might 
benefit from activity monitoring as a wearable fall detection system in daily living. Often, falls and related injuries mark the onset of deterioration of health [6].

The long-term follow-up of patients after hip arthroplasty is questionable. In prostheses with known excellent long-term clinical results, especially those validated by joint registry studies, follow-up could be modified. Routine follow-up of asymptomatic patients after hip arthroplasty may be highly costly and perhaps unnecessary. Other, less intensive review methods might be more appropriate, such as objective physical activity monitoring with wearables. With the recent improvements of the capabilities of smartphones and smartwatches, these appliances could be useful in the follow-up of patients after total joint arthroplasty. Applications can support and guide patients and can deliver data and patient reported feedback to facilitate improved care, outcomes and satisfaction. Physical activity tracking is available, but it is not yet as complete as the wearable activity monitoring used in the present thesis. However, a smartphone is a more accesible platform with $93 \%$ of the Dutch population owning a smarthphone. Various patientproof applications are already widely available. Apps were developed to inform the patients about their pre-, peri- and postoperative phase and to obtain information regarding their activites. The use of smartphone applications is highly interesting for patient monitoring at a distance and for putting the patient in control of their own rehabilitation, for instance after a hip arthroplasty. Issues may arise about data ownership, since this information may offer a source of profit both for industries and health insurances. Current laws lack specific regulation. Another option might be the use of smart hip implants, which have been available since 1966 and have been used to measure pressure, forces, strain, displacement, temperature and physical paramaters from inside the body. However, smart implants have only been used in research and have not yet become a part of daily clinical practice. With the rapid advance of technology, it seems that the widespread implementation of smart implants is near and will potentially affect clinical care and enable personalized medicine [7]. It is, however, questionable if that makes sense for smart implants in or with THA; they are probably mainly usefull in clinical research.

After MoM hip arthroplasty, patients should be routinely monitored. Those with a painful hip will find their way to the outpatient clinic. In all other cases, monitoring should focus on the general symptoms of chronically raised metal ion concentrations as described in this thesis. At this moment, it is still unclear what the effects of chronically elevated metal ion concentrations are (unexpected failures at the post-market phase). Ideally, these effects should be investigated with a validated questionnaire, followed by referral to a specialist (ophthalmologist, ENT 
doctor, neurologist, cardiologist, internal physician, toxicologist), determination of blood metal ion concentrations and, if necessary, explantation or revision of the MoM hip. Orthopaedic surgeons all around the world decided to implant this type of hip arthroplasty without knowing the potential side effects. It is our responsibility, in cooperation with the implant industry, to support these patients where possible.

This thesis underscores the importance of training medical specialists in independent thinking, of doing the appropriate research before introducing new techniques and materials, and of carefully examining the clinical processes and not taking for granted what is suggested by others.

\section{References}

1. Verhaar JAN, [The hard lesson of metal-on-metal hip implants]. Ned Tijdschr Geneeskd, 2012;156(42): A5564.

2. Online LROI annual report 2019, Dutch Arthroplasty Register (LROI), www.Iroi-rapportage.nl

3. Yip L, McCoy KL, Carty SE, Remembering the Hippocratic Oath in Surgical Training. JAMA Surg, 2019;154(10): p.958-959.

4. Pritchett JW, Polyethylene for hip resurfacing-worth a second look. Ann Joint 2020;5:10

5. de Villiers D, Richards L, Tuke M, Collins S, Ceramic resurfacing: the future and challenges. Ann Joint 2020;5:12

6. Pannurat N, Thiemjarus S, Nantajeewarawat E, Automatic fall monitoring: a review. Sensors (Basel), 2014;14(7): p.12900-36.

7. Ledet EH, Liddle B, Kradinova K, Harper S. Smart implants in orthopedic surgery, improving patient outcomes: a review. Innov Entrep Health, 2018;5: p.41-51. 


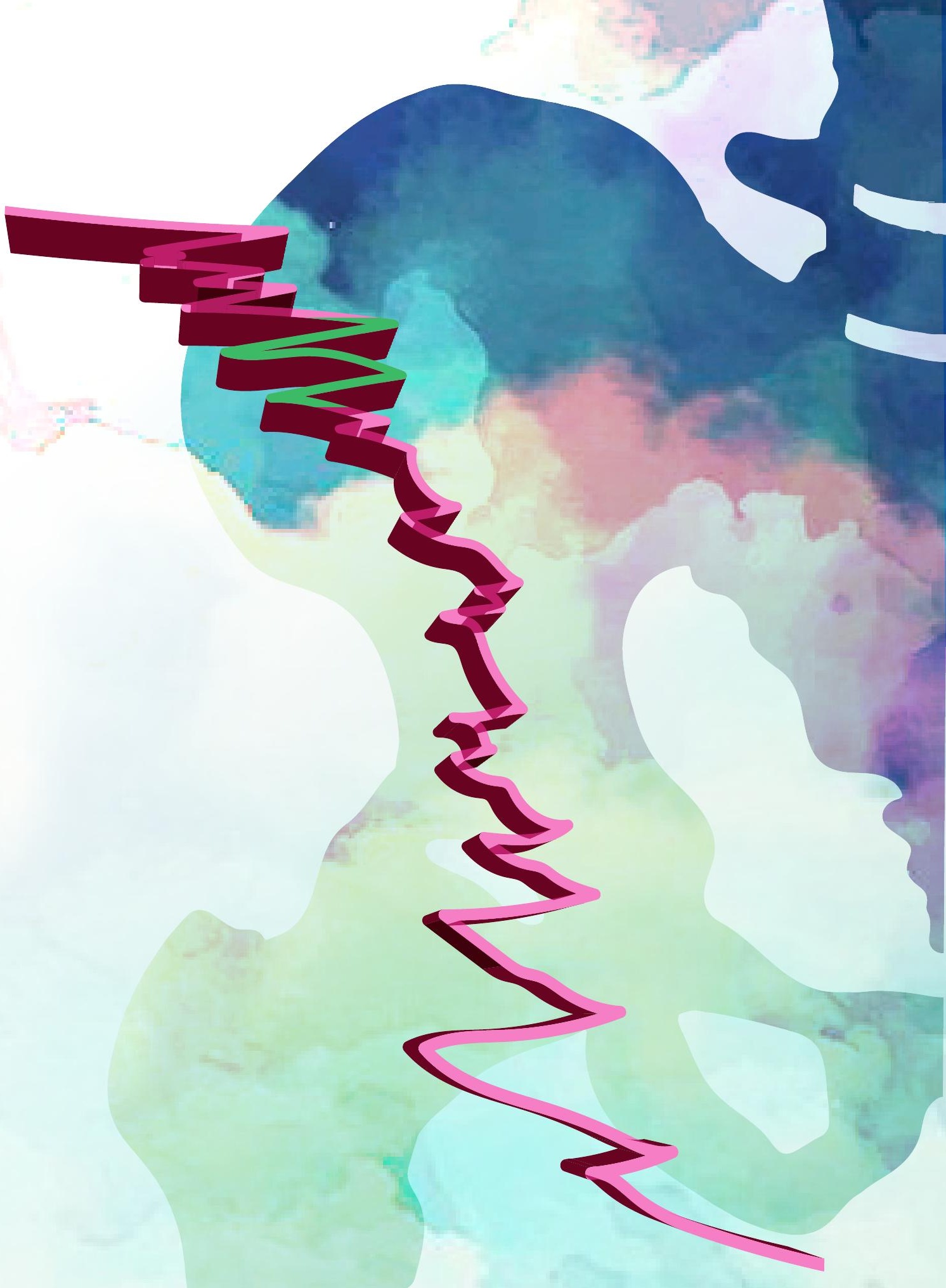




\section{Chapter XI}

\section{Summary}

Good is not good when better is expected

(Vin Scully) 
Worldwide, hip arthroplasty is increasingly performed as treatment for end-stage osteoarthritis. The operation is one of the most successful procedures in the history of healthcare. Improvement of outcomes after these surgeries is not solely based on the theoretical advantages of this surgical procedure itself. Since the start of hip arthroplasty (1821) all modifications on the design of the prosthesis, including the development of new materials, the surgical approach, fixation techniques and bearing surfaces, were implemented because of their theoretical advantages. In the early 2000s, the worldwide popularity of metal-on-metal (MoM) total hip arthroplasty (THA), both large-head THA (LHMoM) and hip resurfacing (HRA) was at its peak. HRA had, at least in theory, various advantages compared to conventional stemmed THA with a metal-on-polyethylene (MoP) bearing, such as low volumetric wear, femoral heads with a large physiological diameter offering stability, nearnatural joint kinematics, a greater range of motion than THA with a small femoral head diameter, and preservation of the femoral bone, which would permit an easy revision if needed. The introduction of this thesis describes the history and development of hip arthroplasty from 1821 up to the early 2000s. Concerns about MoM hip arthroplasty have been raised since 2004 due to the reported high failure rates and the discovery that all patients with a MoM hip prosthesis have raised blood/serum metal ion concentrations of cobalt and chromium after implantation. These concentrations are used as a surrogate marker of in-vivo wear and are influenced by a variety of parameters, both patient-, implant- and surgery-related factors. The influence of physical activity (PA) is unknown, while in theory, the daily habitual PA of patients with a MoM hip arthroplasty could be associated with metal ion concentrations in blood. MoM hip arthroplasty was mainly offered to younger patients, who tend to have higher demands on functional outcomes. Outcome measures after THA can be assessed in multiple ways and by different judgements, i.e., by the clinician and by the patient, but disagreement between them was shown. Patient-reported outcome measures (PROMs) relate to the patients' beliefs and experiences regarding their functional ability, while objective PA monitoring with the use of a wearable activity monitor (AM) proves what a patient actually does in activities of daily life. The introduction outlines the aims of this thesis and the research questions:

- What is the relation between objectively measured physical activity and blood metal ion concentrations in patients with a metal-on-metal hip arthroplasty?

- Are patients with an HRA physically more active than patients with a conventional stemmed THA?

- Is objectively measured physical activity associated with patient-reported physical activity? 
- Is the outcome of revision surgery after failed MoM hip arthroplasties worse than the outcome of revision after failed non-MoM hip arthroplasties?

- Are chronically raised metal ion concentrations in blood associated with systemic complaints?

In this thesis, PA in daily life was measured during the waking hours of four consecutive days using a commercially available AM with a 3-axis accelerometer, gyroscope and magnetometer, attached to the leg. The relation between objectively measured PA and blood metal ion concentrations was described in chapter II. In a cohort-study $(n=62)$, metal ion concentrations were determined using inductively coupled plasma mass spectrometry (ICP-MS), and habitual PA of subjects was measured in daily living with an AM. Subgroups with low cobalt ion concentrations ( $<40 \mathrm{nmol} / \mathrm{L})$ and high cobalt ion concentrations ( $>40 \mathrm{nmol} / \mathrm{L}$ ) were compared. The results showed that cobalt ion concentrations were highly elevated overall at follow-up after more than 6 years. None of the PA parameters showed any correlation with cobalt ion concentrations, and in addition, the subgroup analysis showed no significant differences in terms of PA. The daily step count in this study was comparable to that of healthy people of the same age, showing that this population with a MoM prosthesis is normally active and that MoM hip arthroplasty does not limit patients with regard to habitual walking activities.

A major concern in the first study was the heterogeneity of prostheses included and the follow-up since surgery. An attempt was made to solve this issue in the next study, which is described in chapter III. In a more homogenous cohort $(n=16)$ of patients with a unilateral HRA, PA and blood metal ion concentrations were determined at 10-year follow-up. The study aimed to uncover an important contributor that might previously have been overlooked. The cohort showed a wide range in cobalt ion concentrations. A significant and clinically meaningful correlation was found between higher cobalt ion concentrations and two distinct parameters of habitual PA: a higher number of sit-standtransfers (SST) and high-intensity peaks. No significant association was found between cobalt ion concentrations and the habitual level of time spent walking, the total number of steps, or the percentage of time being active. It seems that metal ion concentrations are not or only slightly influenced by general habitual PA, such as normal walking. The only aspects of PA that matter are behavioral (many STT) and qualitative (high intensity, fast walking). For patients, it seems safe to engage in activities with low-intensity peaks, such as walking or cycling without triggering critical wear or metal ion release, which enables them to achieve important general health benefits and quality of life. 
It can be expected that patients who received an HRA would be more physically active after surgery than patients who received a stemmed THA with a smalldiameter metal-on-polyethyelene (MoP) or ceramic-on-polyethylene (CoP) bearing. This expectation is based on multiple reasons: the theoretically better implant design features, which claim to support a more active lifestyle, the selection of patients for this particular implant (young and active), and the related patient expectations (high preoperative demands on postoperative activity). To objectify if patients with an HRA are more physically active, a study was performed as described in chapter IV: objective PA at long term follow-up (10-years) was determined in a cohort of 16 HRA and 16 stemmed THA subjects matched for sex, age at surgery, follow-up since surgery, and BMI. Group characteristics did not differ statistically at baseline. Contrary to expectations, results showed that patients with a unilateral HRA were not more physically active. In the stemmed THA group, two factors established to be related with a less active lifestyle were higher: the median age (difference: \pm 4 years) and BMI (difference: $\pm 3 \mathrm{~kg} / \mathrm{m}^{2}$ ), but these differences were not statistically significant. HRA patients do not seem to be more physically active; both implant types enable the same level of PA, and activity levels depend on individual lifestyle rather than on implant type, at least at 10-year follow-up. Even well-reasoned theoretical advantages concerning functionality of any implant design require clinical validation and should not be assumed as an indication, especially at the risk of a potential disadvantage.

The reliability of PROMs can be hampered by their subjective nature, recall bias, ceiling effects, low response andcompletion rates or transcription errors, and by the fact that it is a time-consuming method. There is no hard evidence in current literature how objectively measured PA is related to patient-reported PA. Chapter $V$ describes a study on the correlation of PROMs of general health (SF-36), diseasespecific outcome and physical function (HOOS-PS), joint-awareness (FJS-12) and selfperceived activity levels (SQUASH) with objectively measured PA parameters. This study included the same cohort $(n=32)$ that was also used in the study described in the previous chapter (IV). The main finding was that objectively measured PA levels (time walking, total time active, number of steps) did not show a correlation with the FJS-12 and SQUASH, but did show a significant correlation with the HOOS-PS and the physical functioning subscale of the SF-36. The correlations found were of moderate strength (Pearson's $r$ 0.40-0.59).The association between objectively measured PA and PROMs is limited: this study shows that PROMs are hardly affected by or do hardly capture levels and differences in objectively measured PA, which is a supposedly patient-centred outcome and a goal of THA. Objectively measured PA, assessed with a wearable AM, and PROMs should be considered complementary, and both should be used in clinical practice. 
Some literature suggested that the outcome of revision surgery in failed MoM hip arthoplasties is moderate, especially when revision was performed due to an adverse reaction to metal debris (ARMD). To determine whether this suggestion is valid, the preferred type of research is a large database study. National joint replacement registries are multi-centre databases comprising data on thousands of subjects and implants, which allows for identifying variables predictive of implant failure. The Dutch Arthroplasty Register (LROI) has a coverage of $100 \%$ and a completeness $>95 \%$. LROI data was used to determine the outcome of revision of a failed MoM hip arthroplasty and to compare this outcome to the outcome of revised failed non-MoM hip arthroplasties. Results are reported in Chapter VI. Records were excluded if the reason for index revision was infection. A total of 3.478 records of revised implants were included, 873 of which were MoM-implants (25.1\%). Over the course of follow-up, $12 \%$ of MoM implants were re-revised, at a median follow-up of 5 years. The re-revision rate of non-MoM THA was $14 \%$ at 5-year follow-up. Statistically significant risk factors for re-revision of failed MoM implants were a periprosthetic fracture as reason for index revision (HR 1.98), a MoM articulation after the index revision (HR 2.48), and femoral-only revisions (HR 3.20). A symptomatic MoM bearing as reason for index revision (HR 0.53) was found to be a statistically significant factor for reducing the probability of re-revision. This success may have been helped by patient characteristics such as minimal bone loss and a good bone stock. Revision surgery in failed MoM hip arthroplasties has a high risk of re-revision, but this risk is comparable to and even lower than the risk of re-revision in non-MoM hip arthroplasties. Femoral-only revisions and MoM articulations post-revision should not be used in revision of a failed MoM hip arthroplasty. The outcomes of this study can behelpful in managing the expectations of patients and orthopaedic surgeons regarding the outcomes of re-revisions.

After the implantation of a MoM hip arthroplasty, an increase is seen in metal ion levels in blood serum, which is due to the release of ions from the metal surface, directly and even more so during articulation, and to corrosion of the bearing surfaces. Patients should be identified prior to experiencing systemic symptoms, although it is unknown whether chronically raised metal ion concentrations are associated with systemic complaints. An increasingly described complication with severe systemic symptoms and sometimes even leading to mortality is cobalt intoxication. A chronically raised cobalt ion concentration may result in a variety of symptoms and lead to toxicity, which is known as 'Prosthetic Hip-Associated Cobalt Toxicity (PHACT)'. The next study of this thesis aimed to elucidate whether symptoms are associated with cobalt ion concentrations in blood. Chapter VII described the outcomes of a systematic review of cobalt toxicity case reports to 
identify the systematic symptoms described most frequently and to determine the toxicity threshold level of serum cobalt ion concentration. Of a total of 7645 identified references, 67 relevant reports were included describing 79 patients. Risk of bias was classified as low (Newcastle-Ottawa Scale; $98.5 \%, \mathrm{~N}=66$ ), and methodological quality was rated as good (Murad et al.; $76.1 \%, N=51$ ). A primary MoM bearing was used in 38 cases (48\%) and in 31 cases (39\%), a metal component was used in the revision of a fractured ceramic component. Of all the described symptoms, most were seen in the sensory system (24\%), followed by the cardiovascular system (22\%) and the neurological system (19\%). The calculated individual serum cobalt ion threshold for MoM was 123.7 ( \pm 96.8) ppb and 1078.2 ( \pm 1267.5) ppb for CoC bearings. Since many MoM bearings are still in situ, more PHACT cases can be expected. Unfortunately, the cobalt ion concentration varied widely between all reports, hence no clear toxicity threshold could be extracted from these case studies.

Chapter VIII describes a cohort study $(n=62)$ investigating the self-reported systemic complaints of patients with a MoM hip arthroplasty at different cobalt ion concentration thresholds (120, 170 or $220 \mathrm{nmol} / \mathrm{L})$. The results demonstrated that ocular-vestibular symptoms were more common in high cobalt ion concentration groups for the three threshold levels tested and that the prevalence increased at higher threshold values. This finding suggests a correlation between cobalt ion concentration and symptom prevalence. With regard to proactively requested, self-reported symptoms, the threshold at which effects may be present could be lower than the cobalt ion concentration values that are currently applied in clinical follow-up.

Chapter IX (general discussion) discussed the main findings of this PhD-thesis in a broader perspective. Clinical implications and suggestions for further research are described. Chapter $X$ on valorisation describes how the knowledge acquired in the research for this thesis can be made available for economic and social utilization.

\section{Final remarks}

This thesis showed the possibilities of using wearable physical activity monitors in the daily practice of patients with a hip arthroplasty. The use of wearable activity monitors in the present research demonstrated that moderate habitual physical activity, such as normal walking, only slightly influences serum metal ion concentrations (as an indirect measure of wear). On the other hand, higher serum metal ion concentrations were associated with a higher number of sit-stand transfers (SST) and high-intensity peaks in patients with a metal-on-metal hip arthroplasty. Despite the subjective nature of patient-reported outcomes, their 
potential value in current practice is shown, for example in determining systemic complaints due to chronically raised cobalt ion concentrations. Theoretically better implant design features are not necessarily also superior in practice. For all new types of implants, a phased evidence-based introduction is highly mandatory. This advice also applies to new designs of HRA: thorough clinical research should be performed, especially concerning objectively measured physical activity, both preand postoperatively, in patients with these new designs of HRA in comparison with conventional stemmed THA. In this way, the theoretical advantages of HRA could be determined on objective grounds. 


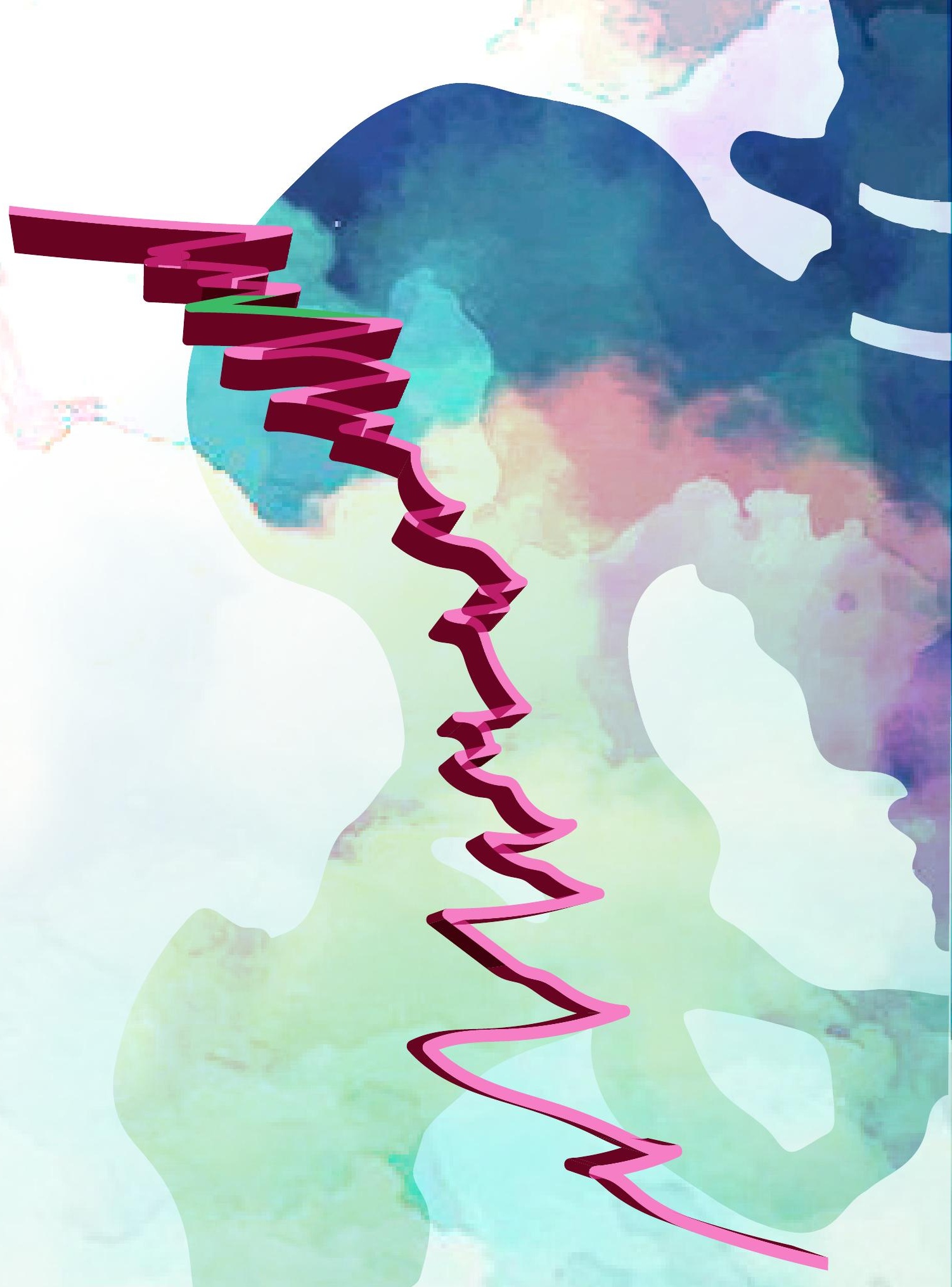




\section{Chapter XII}

\section{Samenvatting}

If you fail to prepare, you're prepared to fail (Matt Biondi) 
Een totale heup prothese (THP) wordt wereldwijd in toenemende mate geplaatst, voornamelijk als behandeling voor het eindstadium van artrose. De operatie wordt beschouwd als één van de meest succesvolle in de historie van de gezondheidszorg. Sinds het begin van chirurgische ingrepen aan het heupgewricht (1821) zijn er vele modificaties gedaan aan de procedure: de ontwikkeling van nieuwe materialen, de chirurgische benadering, de fixatie technieken en de articulerende contact oppervlakten. De populariteit van metaal-op-metaal (MoM) heupprothesen was op zijn top begin 2000, zowel voor de grote-kop MoM THP, Large Head Metal on Metal (LHMoM), als voor de heup resurfacing artroplastiek (HRA). De HRA had vergeleken met de conventionele gesteelde THP met een metaal-op-polyethyleen (MoP) articulerend contact oppervlak verschillende theoretische voordelen: minder slijtage, meer stabiliteit, een natuurlijkere gewrichtskinematica en een groter bewegingsbereik vergeleken met een THP met een kleine heupkop. Indien nodig zou een revisie gemakkelijker zijn en de resultaten beter omdat het proximale femur grotendeels behouden blijft bij een resurfacing heup artroplastiek.

De introductie van dit proefschrift beschrijft de historische ontwikkelingen van het kunstheupgewricht sinds 1821 tot het begin van de jaren 2000. In 2004 ontstond bezorgdheid over de MoM prothesen vanwege het hoge faal percentage. Daarnaast vond men dat patiënten met een MoM prothese verhoogde metaalconcentraties in het bloed hadden. Deze bloedwaarden kunnen gebruikt worden om de mate van slijtage van de metaal oppervlakten aan te tonen. Zij worden beïnvloed door verschillende factoren: de patiënt, het implantaat en de operatietechniek. In theorie bestaat er een directe relatie tussen de dagelijkse fysieke activiteiten van patiënten met een MoM heupprothese en de hoogte van de metaalconcentraties in het bloed. Deze theorie is tot op heden echter niet bevestigd. Vooral bij jongere patiënten werd een MoM heupprothese aangeboden, die op hun beurt hoge verwachtingen hadden op het gebied van functionele uitkomsten. Deze uitkomsten na een THP kunnen zowel door de dokter als door de patiënt worden beoordeeld. Zij verschillen echter vaak in hun beoordelingen van elkaar. Hierbij kan gebruik worden gemaakt van vragenlijsten en van meetinstrumenten die activiteiten registreren. Patiënt gerapporteerde uitkomstmaten met vragenlijsten (Patient Reported Outcome Measures, PROMs) hebben betrekking op de ervaring van de patiënt en zijn of haar functionele mogelijkheden. De monitoring van de fysieke activiteit (FA) van een patiënt door gebruik van een (draagbare) activiteitenmonitor (AM) registreert wat een patiënt daadwerkelijk doet qua activiteiten in het dagelijks leven. In Hoofdstuk I worden de doelstellingen en de onderzoeksvragen van dit proefschrift besproken: 
- Wat is de relatie tussen objectief gemeten fysieke activiteit en metaal concentraties in het bloed, bij patiënten met een metaal-op-metaal heupprothese?

- Zijn patiënten met een resurfacing heup artroplastiek fysiek actiever in vergelijking met patiënten met een conventionele totale heup prothese?

- Is objectief gemeten fysieke activiteit van patiënten met een heupprothese in overeenstemming met de uitkomsten van patiënt gerapporteerde fysieke activiteit?

- Is de uitkomst van revisie chirurgie bij patiënten met een gefaalde MoM heupprothese slechter in vergelijking met revisie chirurgie bij een gefaalde nietMoM heupprothese?

- Zijn chronisch verhoogde metaal concentraties in het bloed als gevolg van een MoM heupprothese geassocieerd met systemische klachten?

Voor dit proefschrift werd gebruik gemaakt van een commercieel verkrijgbare activiteitenmonitor met een versnellingsmeter, gyroscoop en magnetometer in drie richtingen (X-, Y- en Z-as). De AM werd op het been geplakt om de FA gedurende vier dagen te meten. De relatie tussen objectief gemeten fysieke activiteit en de metaalconcentraties in het bloed bij patiënten met een MoM heupprothese zijn beschreven in hoofdstuk II. In een cohort studie $(n=62)$ werden de metaalconcentraties in het bloed bepaald middels 'inductively coupled plasma mass spectrometry (ICP-MS)'en de dagelijkse fysieke activiteit met behulp van de activiteitenmonitor. De resultaten toonden aan dat de gemiddelde kobalt concentraties fors verhoogd waren, ook na meer dan 6 jaar postoperatief. Een subgroep analyse werd verricht tussen een groep met lage kobalt concentraties in het bloed $(<40 \mathrm{nmol} / \mathrm{L})$ en een groep met hoge kobalt concentraties ( $>40 \mathrm{nmol} / \mathrm{l})$. Geen enkele van de fysieke activiteiten parameters toonde een correlatie met de kobaltconcentraties. Ook de subgroep analyse toonde geen significante verschillen tussen de groepen aan. Het gemiddeld aantal stappen per dag van de patiënten in deze studie was vergelijkbaar met gezonde proefpersonen van dezelfde leeftijd. Dit duidt op een normaal activiteitniveau van de patiënten populatie in deze studie. Tevens voelen patiënten met een MoM heupprothese zich niet beperkt in dagelijkse fysieke activiteiten. Een belangrijke beperking van deze studie was dat deze werd uitgevoerd met een heterogene patiënten populatie. Patiënten met zowel een unilaterale en/of bilaterale prothese maar ook met beide typen MoM heupprothesen (HRA en/of LHMoM) werden geïncludeerd. 
In een volgende studie werd getracht om deze heterogeniteit er uit te filteren, de resultaten worden beschreven in Hoofdstuk III. Een meer homogeen cohort $(n=16)$ van patiënten met een unilaterale HRA 10 jaar postoperatief werd samengesteld. De fysieke activiteit werd gemeten en de kobalt concentratie in het bloed werd bepaald op de eerste dag. Het doel van deze studie was om fysieke activiteit als een belangrijke verklaring te vinden voor verhoogde kobalt concentraties. Er was sprake van een grote spreiding in de kobalt concentraties van de patiënten. Er werd een significante correlatie gevonden tussen de kobalt concentraties en verschillende parameters van dagelijkse fysieke activiteit (aantal zit-sta-transfers en hogeintensiteit pieken). Er werden geen statistisch significante verbanden gevonden tussen kobalt concentraties en de dagelijkse tijd besteed aan wandelen, het totaal aantal stappen en het totaal percentage van de tijd dat men fysiek actief was. Het lijkt erop dat de kwantitatieve algemene dagelijkse activiteiten, zoals normaal wandelen, de kobalt concentraties niet of slechts in geringe mate beïnvloeden. Vooral kwalitatieve aspecten van de activiteiten (hoge intensiteit, snel wandelen, veel zit-sta transfers) lijken invloed te hebben op de kobalt concentraties. Het lijkt veilig voor patiënten met een MoM heupprothese om te participeren in activiteiten met een lage intensiteit, zoals wandelen en fietsen. Hierdoor ontstaat geen ernstige slijtage van de articulerende contact oppervlakten en worden er geen hoge metaalconcentraties veroorzaakt.

Om meerdere redenen is het logisch om te veronderstellen dat patiënten met een HRA meer fysieke activiteit vertonen dan patiënten met een conventioneel gesteelde THP met een metaal-op-polyethyleen (MoP) of keramisch-op-polyethyleen (CoP) articulerende contact oppervlakten: op basis van het theoretische veronderstelde betere design van de HRA werd de mogelijkheid van een actievere levensstijl gepromoot. Hierdoor was de selectie van patiënten voor dit type implantaat (jong en actief) en van hun verwachtingen (hoge preoperatieve verwachtingen van de postoperatieve activiteit) anders dan bij een conventionele gesteelde THP. Of patiënten met een HRA daadwerkelijk fysiek actiever waren werd onderzocht. Deze studie wordt beschreven in hoofdstuk IV van dit proefschrift: de objectieve fysieke activiteit na een lange termijn follow-up (10 jaar) werd bepaald voor een geslacht-, leeftijd bij operatie-, follow-up sinds operatie-, en BMI- vergelijkbaar cohort van HRA patiënten en van patiënten met een conventionele gesteelde THP. De groepen waren homogeen, er waren geen statistisch significante verschillen tussen de groepen bij aanvang van de studie. In tegenstelling tot de verwachtingen bleken de patiënten met een HRA niet fysiek actiever te zijn. Patiënten vertonen vergelijkbare fysieke activiteiten onafhankelijk van het type implantaat. De mate van fysieke activiteit lijkt meer afhankelijk te zijn van de individuele levensstijl dan van het 
type prothese, tenminste 10-jaar na de operatie. Dit laat nog eens zien dat zelfs goed onderbouwde theoretische voordelen van een implantaat klinische validatie vereisen en niet zondermeer als voordeel mogen worden beschouwd.

De validiteit van PROMs is beperkt door het subjectieve karakter, verstoring van de resultaten omdat patiënten zich bepaalde zaken anders herinneren dan de manier waarop ze in werkelijkheid gebeurt zijn, plafondeffecten, de tijdrovende methodologie, het lage respons- en voltooiing percentage en/ of transcriptiefouten. Tot op heden was er geen literatuur beschikbaar die objectief gemeten fysieke activiteit relateert aan patiënt gerapporteerde fysieke activiteit. In Hoofdstuk V wordt een studie beschreven waarin PROMs ten aanzien van de algemene gezondheid (SF-36), de ziektespecifieke uitkomsten en het fysiek functioneren (HOOS-PS), het gewrichtsbewustzijn (FJS-12) en het zelfwaargenomen activiteitenniveau (SQUASH) worden gecorreleerd aan objectief gemeten activiteiten. Dit patiëntencohort $(n=32)$ werd ook gebruikt in het vorige hoofdstuk (IV). De belangrijkste bevinding van deze studie was dat verschillende objectief gemeten fysieke activiteit parameters (wandeltijd, totale actieve tijd en het aantal stappen per dag) geen correlatie toonden met de FJS-12 en de SQUASH. Er werd wel een statistisch significante correlatie gevonden met de HOOS-PS en de subschaal 'fysiek functioneren' van de SF-36. De gevonden correlaties waren van matige sterkte (Pearson's r 0.40-0.59). Deze studie liet zien dat PROMs nauwelijks overeenkomen met de objectief gemeten fysieke activiteit. De objectief gemeten fysieke activiteit, bijvoorbeeld door middel van een draagbare activiteitenmonitor, en PROMs moeten als complementair worden beschouwd en kunnen beide een rol spelen in de klinische praktijk.

In de literatuur wordt gesuggereerd dat de uitkomsten van revisie chirurgie van een gefaalde MoM heupprothese matig is, in het bijzonder wanneer de revisie is uitgevoerd in verband met locale reacties op metaalpartikels, 'adverse reactions to metal debris' (ARMD). Door middel van grote database studies kunnen deze suggesties onderzocht worden. Nationale registers voor gewrichtsvervanging zijn multicenter databases met gegevens van duizenden patiënten. Dit maakt het mogelijk om variabelen te identificeren die een voorspellende waarde kunnen hebben voor het falen van een implantaat. De Nederlandse Landelijke Registratie Orthopedische Implantaten (LROI) van de Nederlandse Orthopedische Vereniging (NOV) heeft een dekking van $100 \%$ en een volledigheid van $>95 \%$. LROI-gegevens werden gebruikt om de resultaten van revisies van MoM heupprothesen te vergelijken met revisies van niet-MoM heupprothesen. De resultaten van deze studie worden gerapporteerd in hoofdstuk VI. Alle eerste revisie ingrepen die 
werden uitgevoerd in verband met een infectie, werden geëxcludeerd voor dit onderzoek. In totaal werden 3.478 gereviseerde heupimplantaten onderzocht, waarvan 873 (25.1\%) MoM-implantaten. Gedurende de follow-up onderging 12\% van de primaire MoM-implantaten een re-revisie, dit bleek $14 \%$ te zijn voor de nietMoM prothesen, bij een mediane follow-up duur van 5 jaar. Het regressiemodel liet zien dat voor MoM-implantaten een periprothetische fractuur als reden voor de eerste revisie (hazard ratio (HR)1.98), een MoM-articulatie na de eerste revisie (HR 2.48) en een partiële revisie van de steel (HR 3.20) statistisch significante risicofactoren waren voor een re-revisie. Een symptomatische MoM heupprothese, zonder aanwijzingen voor een fractuur of loslating, als reden voor de eerste revisie (HR 0.53) bleek een statistisch significante verkleinende factor voor de kans op rerevisie. De uitkomsten wijzen op een degelijke chirurgische ervaring in Nederland voor dit soort revisies, mogelijk bijgedragen door patiëntkenmerken zoals minimaal botverlies en een goede botvoorraad. Revisiechirurgie bij gefaalde MoM heupprothesen heeft een hoog risico op re-revisies, maar dit is vergelijkbaar met de uitkomst van revisies bij niet-MoM heupprothesen. Een partiële revisie van de steel en een MoM-articulatie na de eerste revisie laten slechte resultaten zien in de chirurgische behandeling van een gefaalde MoM heupprothese. De resultaten van deze studie kunnen bruikbaar zijn bij het managen van de verwachtingen van patiënten en orthopedisch chirurgen.

Na de implantatie van een MoM heupprothese wordt bij patiënten een stijging gezien in metaal concentraties in het bloed en serum door directe afgifte van het metalen oppervlak. Kobalt intoxicatie is een steeds vaker beschreven complicatie met potentieel ernstige symptomen, mogelijk met de dood tot gevolg. Idealiter zouden patiënten voordat een intoxicatie ontstaat al geïdentificeerd zijn. Het is echter onduidelijk of en hoe chronisch verhoogde metaal concentraties geassocieerd zijn met systemische afwijkingen en symptomen. Deze symptomatologie kan leiden tot een beeld dat bekend is als 'Prosthetic HipAssociated Cobalt Toxicity (PHACT)'. Welke symptomen geassocieerd zijn met kobalt concentraties in het bloed, werd onderzocht in Hoofdstuk VII. Dit hoofdstuk beschrijft een systematische review van case reports betreffende kobalt intoxicaties om te bepalen welke systemische klachten het meest voorkomen. Aanvullend doel was om een kobalt drempelwaarde te bepalen waarboven klachten ontstaan. In totaal werden 7.645 referenties gevonden waarvan er 67 overbleven na exclusie. Deze artikelen beschreven gezamenlijk 79 patiënten. Het risico op een systematische fout in onder meer de analyse, de resultaten of de conclusies van een onderzoek werd in deze analyse als laag geclassificeerd (Newcastle-Ottawa Scale; $98.5 \%, N=66$ ), bij een goede methodologische kwaliteit (Murad et al.; $76.1 \%, N=$ 
51). Een primaire MoM articulatie werd in 38 (48\%) patiënten gebruikt, bij 31 (39\%) patiënten werd een metalen component gebruikt bij de revisie van een gebroken keramische component. De oorsprong van de meeste symptomen lag in het sensorische systeem ( $n=77,24 \%)$, gevolgd door het cardiovasculaire $(n=71,22 \%)$ en neurologische systeem ( $n=62,19 \%)$. De berekende individuele drempelwaarde voor MoM prothesen was 123.7 ( \pm 96.8) parts per billion (ppb) en 1078.2 ( \pm 1267.5) ppb voor CoC-contact oppervlakten. Omdat er nog vele patiënten met een MoM heupprothese zijn, kunnen er in de toekomst meer patiënten met kobalt gerelateerde systemische klachten verwacht worden. De drempelwaarde van kobalt, waarbij klachten zich gaan manifesteren, kon niet worden bepaald door de sterke spreiding van de beschreven concentraties.

Aanvullend op de systematische review wordt in hoofdstuk VIII een cohort studie $(n=62)$ beschreven naar de zelfgerapporteerde systemische klachten bij patiënten met een MoM heupprothese. Het optreden van deze symptomen werd bepaald bij verschillende drempelwaarden van kobalt in het bloed (120, 170 of $220 \mathrm{nmol} / \mathrm{L})$. De resultaten toonden aan dat oculo-vestibulaire symptomen vaker voorkwamen in de groepen met een hoge kobalt concentratie en met toenemende prevalentie voor hogere drempelwaarden. Dit is een aanwijzing voor de correlatie tussen kobalt concentratie en symptoomprevalentie. Met betrekking tot proactief onderzochte, zelfgerapporteerde symptomen zou de drempelwaarde waarbij klachten aanwezig zijn, lager kunnen zijn dan de waarden die momenteel worden gehanteerd tijdens de klinische follow-up.

In Hoofdstuk IX (general discussion) worden de belangrijkste bevindingen van dit proefschrift in een breder perspectief besproken. Klinische implicaties en suggesties voor verder onderzoek komen hier aan bod. Hoofdstuk X (valorisation) beschrijft hoe de kennis opgedaan in dit proefschrift toegepast kan worden in de maatschappij.

Dit proefschrift beschrijft een mogelijkheid voor het gebruik van draagbare fysieke activiteitenmonitoren in de dagelijkse praktijk. Algemene dagelijkse activiteit, zoals lopen, heeft slechts een geringe invloed op metaal concentraties in het bloed bij patiënten met een metaal-op-metaal heupprothese. Anderzijds zijn kwalitatieve aspecten van fysieke activiteit wel van belang bij deze patiënten. De subjectieve aard van patiënt gerapporteerde uitkomsten wordt geschetst, maar hun waarde wordt ook getoond in de huidige praktijk, bijvoorbeeld bij het vaststellen van systemische klachten als gevolg van chronisch verhoogde kobalt concentraties. Een theoretisch onderbouwt beter ontwerp van een implantaat is niet per definitie beter in de 


\section{Chapter 12}

praktijk. Een gefaseerde, op bewijs gebaseerde introductie is van groot belang voor alle nieuwe implantaten. Dit geldt ook voor nieuwe ontwerpen van de resurfacing artroplastiek. Ethisch en methodologisch onderbouwd klinisch onderzoek moet worden uitgevoerd bij patiënten met deze nieuwe implantaten. Met betrekking tot objectief gemeten fysieke activiteit zou het de voorkeur hebben om patiënten met nieuw ontwikkelde gewrichtsprothesen zowel pre- en postoperatief te monitoren. Op deze manier kunnen de theoretische voordelen objectieve gronden worden bepaald. 


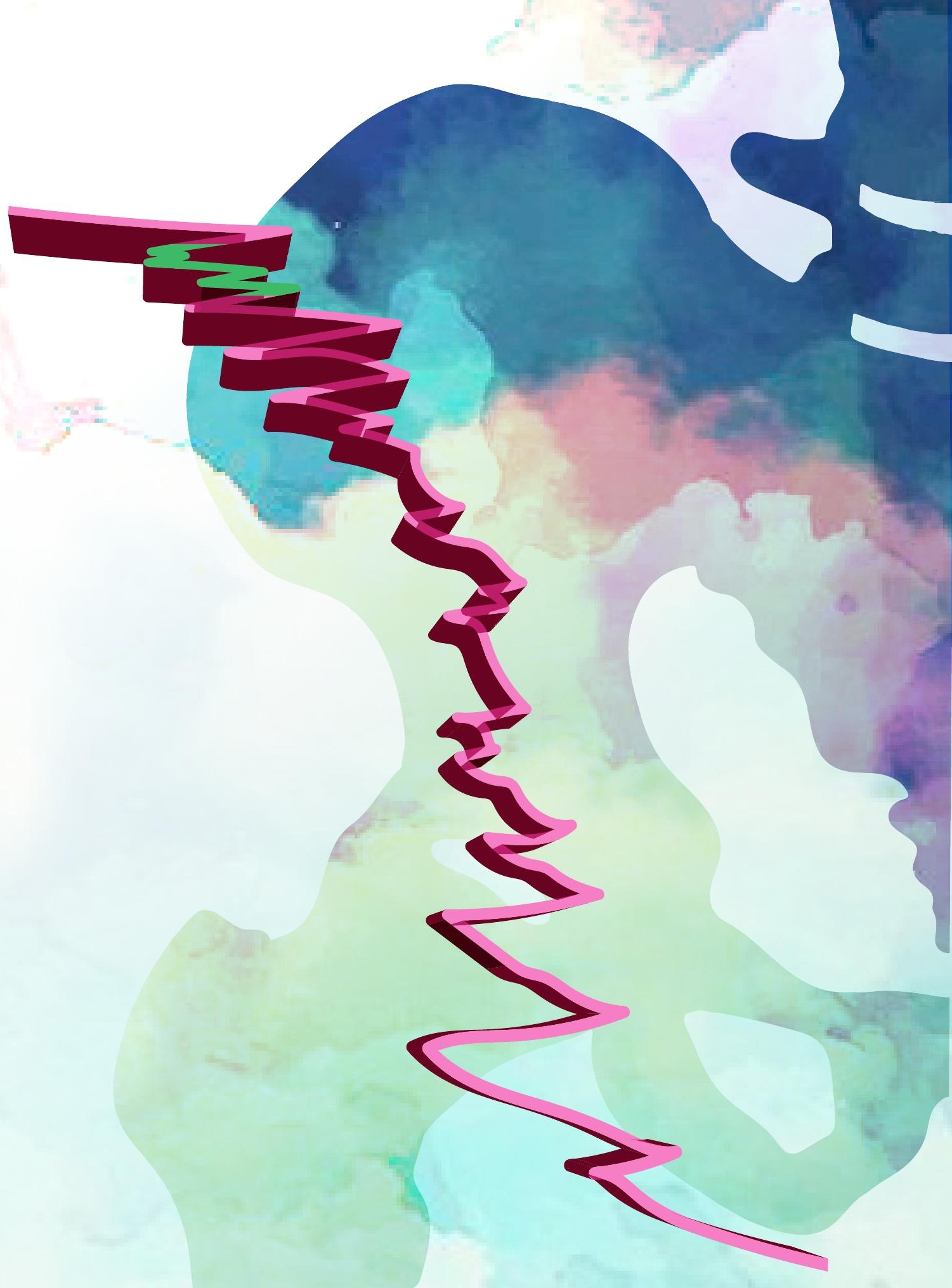




\section{List of Publications}

Always make a total effort, even when the odds are against you

(Arnold Palmer) 


\section{This thesis}

Metal ion concentrations after metal-on-metal hip arthroplasty are not correlated with habitual physical activity

Jelsma J, Schotanus M, Senden R, Heyligers IC, Grimm B

Hip Int. 2019 Nov;29(6):638-646.

Quality, but not quantity of physical activity is associated with metal ion concentrations in unilateral hip resurfacing

Jelsma J, Schotanus MGM, van Kuijk SMJ, Buil I, Heyligers IC, Grimm B.

J Orthop Res. 2020 Feb 22.

Patients with hip resurfacing arthroplasty are not physically more active than those with a stemmed total hip

Jelsma J, Schotanus MGM, Buil ITAF, van Kuijk SMJ, Heyligers IC, Grimm B.

Acta Orthop . 2020 Jun 4;1-5

Only limited correlations between patient-reported outcomes and objectively monitored physical activity 10-years after THA

Jelsma J, van Kuik S, Buil I, Heyligers I, Grimm B, Schotanus M

Accepted in: Acta Orthop Belg on 06.06.2021

Outcome of Revised Metal-on-Metal Hip Arthroplasties: a Dutch Arthroplasty Register Study

Jelsma J, van Kuijk S, Spekenbrink-Spooren A, Grimm B, Heyligers I, Schotanus M Accepted in: Arch Orthop Trauma Surg on 12.11.2021

Prosthetic hip associated cobalt toxicity: a systematic review of case series and case reports

Crutsen JRWA, Koper MCA, Jelsma J, Heymans M, Heyligers IC, Grimm G, Mathijssen NMC, Schotanus MGM

Revision submitted to: EFORT Open Reviews on 12.12.2021

Self-reported systemic complaints in patients with metal-on-metal hip arthroplasty Jelsma J, Schotanus M, Kleinveld H, Grimm B, Heyligers IC.

J Orthop. 2020 Jan 25;18:213-217 


\section{Other publications}

- Zwelling van het bovenbeen na een scooterongeval

Krist GTA, Jelsma J, van Buul GM

Ned Tijdschr Geneeskd. 2021;165:D5758

- Neurology in metal-on-metal hip arthroplasty - a case of suspected PHACT Jelsma J, Kleinveld HA, Rozemuller JM, Heyligers IC Acta Orthop. Belg., 2020, 86 e-supplement 1, 67-70

- Spinal surgeons' opinions on pre- and postoperative rehabilitation in patients undergoing lumbar spinal fusion surgery: a survey-based study in the Netherlands and Sweden.

van Erp RM, Jelsma J, Huijnen IP, Lundberg M, Willems PC, Smeets RJ. Spine (Phila Pa 1976). 2017 Sep 6.

- Limited benefits of the direct anterior approach in primary hip arthroplasty: a prospective single centre cohort study Jelsma J, Pijnenburg R, Boons HW, Eggen PJ, Kleijn LL, Lacroix H, Noten HJ. J Orthop. 2016 Oct 26;14(1):53-58

- B-cell lymphoma of the tibia mimicking chronic osteomyelitis - a case report and literature study

Eggen T, Jelsma J, Janssen M, Schreuder B.

Ned. Tijd. Orthopedie. 2016 Dec;23;4;136-141

- Monthly swelling of the knee - case report and review of the literature Jelsma J, Mayne A, Steffanie B Knee. 2016 Jun;23(3):559-60

- Simultaneous bilateral distal tibia and fibula stress fractures - case report and review of literature Jelsma J, de Nijs R, Boons H. Ned. Tijd. Orthopedie. 2015 Dec;22;4:91-96

- A painful hip after revision [Dutch] Jelsma J, Dinjens R, Adriaensen M, Heyligers IC. Medisch Contact. 2014 Nov;69;46:2267

- A blood donor with MoM hip prothesis [Dutch] Jelsma J, Kleinveld H, Heyligers IC.

Ned. Tijdschr. Klin. Chem. Labgeneesk. 2014 Jan;39:28-30 


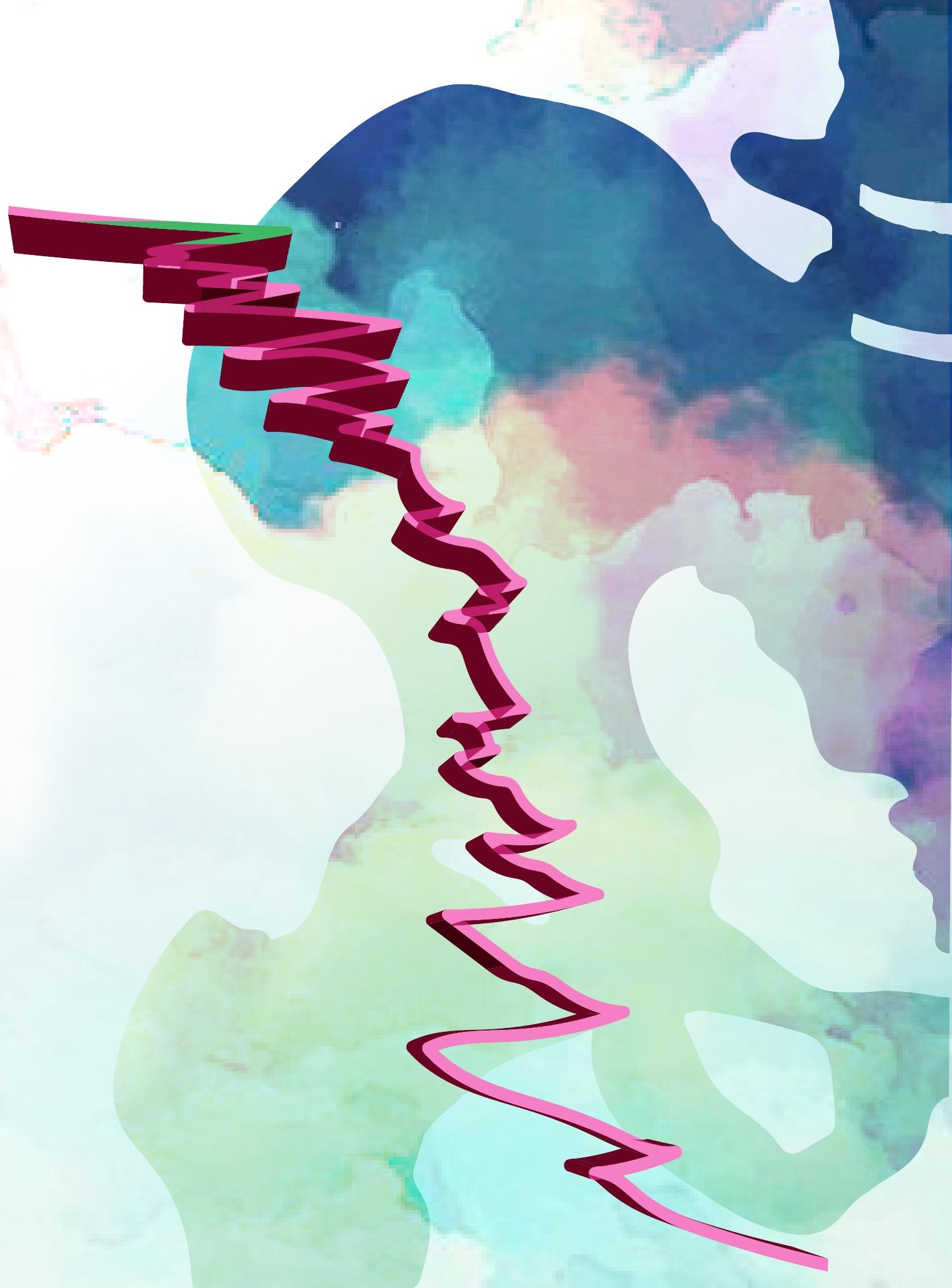




\section{Dankwoord}


Het verrichten van wetenschappelijk onderzoek, de totstandkoming van dit proefschrift en de ontwikkeling van mij als mens en dokter is te danken aan velen. ledereen individueel benoemen is welhaast onmogelijk, maar heeft $u$ op welke wijze dan ook hieraan een bijdrage geleverd dan dank ik $u$. Desalniettemin wil ik enkele personen uitlichten:

Geachte prof. dr. Heyligers, beste Ide. Als promotor en als initiële opleider heb ik veel aan je te danken. Vanaf onze eerst ontmoeting heb je ten alle tijden het beste met mij voor gehad. Jij zag iets waarin je uitdaging zocht om dit te polijsten en te perfectioneren. Ik hoop dat dit naar jouw tevredenheid is verlopen. Je oneliners zoals het 'verbaal opereren', 'het niet hoger springen door de lat laag te leggen' en 'het behandelen van de mens en niet de foto', zijn aan de orde van de dag. Hoewel e-mailcontact niet je favoriet is, heb ik je altijd kunnen bereiken als het nodig was. Verheugd ben ik met het feit dat je mij nu als doctor moet aanspreken in plaats van doctorandus. Mijn dank is groot en ik houd het contact in de toekomst graag.

Geachte dr. ir. Grimm, beste Bernd. Jouw enthousiasme voor wetenschap is besmettelijk. Met jou aan boord in het team steeg het niveau van mijn onderzoek en publicaties aanzienlijk. Je kennis van wetenschappelijk onderzoek en je innovatieve wijze van denken maakte elke discussie tot een bijzondere ervaring. Veelal leverde discussie over een vraagstuk nieuwe vraagstukken op. Na een dergelijke discussie was ik altijd vol energie om direct weer aan de slag te gaan. Onderzoek bracht ons naar Venetië, New Orleans, Montreal en Bristol. Onze diners aldaar zijn voor mij momenten om nooit te vergeten. Het doorzettingsvermogen wat je hebt getoond is ongeëvenaard. Met veel trots zeg ik je te kennen!

Geachte dr. ir. Schotanus, beste Martijn. Jouw rechttoe, rechtaan manier van werken spreekt mij buitengewoon aan. Je hebt een waardevolle bijdrage gehad in de totstandkoming van dit proefschrift, met name voor de praktische handvatten was je onmisbaar. Minstens zo belangrijk is het feit dat ik altijd in 'jouw hoekje' terecht kon, om te lachen, maar zeker om te klagen. Ik kijk uit naar de toekomst als je, hopelijk net als ik, in Maastricht woont en we het leven kunnen bespreken onder het genot van een borrel. Want wat is er nu mooier dan twee noordelingen die een beerenburg bestellen in de meest zuidelijke stad van het land?

Dank aan de beoordelingscommissie en oppositieleden bestaande uit prof. $\mathrm{dr}$. van Rhijn, prof. dr. Poeze, prof. dr. Schreurs, dr. Ten Broeke, dr. van Haaren en dr. Boymans voor de tijd en moeite die zij hebben gestoken in de beoordeling van mijn proefschrift en het voeren van oppositie. 
Naast het promotie-team heb ik prettig mogen samenwerken met Ivo Buil, dr. Rachel Senden, dr. Henne Kleinveld en dr. Sander van Kuijk. Ook dank aan coauteurs Anneke Spekenbrink-Spooren, Janneke Crutsen, Maarten Koper, Marion Heymans en Nina Mathijssen.

Zij die mij de mogelijkheid gaven tot mijn eerste baan als arts binnen de revalidatiegeneeskunde in het MUMC+ te Maastricht (prof. dr. Rob Smeets) en mijn eerste baan binnen de orthopedie (Harm Boons, Peter Eggen, Lucas Kleijn, Herman Lacroix en Hub Noten) in het Elkerliek Ziekenhuis te Helmond. Zonder een begin, is er geen vervolg.

Orthopeden, (trauma)chirurgen, arts-assistenten, collega's van de operatiekamers, gipskamers, verpleegafdelingen, spoedeisende hulpen, poliklinieken en secretariaten van het Elkerliek Ziekenhuis, Maastricht Universitair Medisch Centrum, Maxima Medisch Centrum/Catharina Ziekenhuis en Zuyderland Medisch Centrum

Geachte paranimfen, dr. Hermans en dr. Sigterman, beste Tom en Tim. Jullie gaven mij de afgelopen jaren reeds het goede voorbeeld ten aanzien van promoveren en het hebben van een prachtige dag hierbij. Samen met Ruud Verhees vormen we een mooi kwartet van vrienden die elkaar door dik en dun steunen.

Tom, één van de stellingen van dit proefschrift luidt: pedaleren doet filosoferen. Mijns inziens hebben wij dat op ongekende wijze samen kunnen doen. In jouw dankwoord beschreef je enkele memorabele ervaringen, waaronder berggeiten op Mallorca, blaffende honden en wilde zwijnen in Portugal en ratatouille met champagne in Frankrijk. In mijn speech voor jou vulde ik deze aan met onder andere een braadworst op de Stelvio, Leonie Meijer, Jeroen van der Boom en Robbie de roker. Het leek mij dan ook volledig passend je als paranimf te vragen terwijl wij beide diep in de kramp een berg opfietsten in de Ardennen tijdens de Velomediane Criquelion.

Tim, naast paranimf en voormalig directe collega bovenal vriend. Het startte bij de chirurgie als coassistenten, maar later kruisten onze paden met veel genoegen nog tweemaal op verschillende momenten in onze carrière. Je keuze voor de traumachirurgie had ik na je onderzoeksperiode en proefschrift niet zien aankomen, maar stemt mij bijzonder gelukkig. Wie weet kruisen onze paden nog wel een keer, voor definitief? Zo niet, dan zijn we in ieder geval vrienden voor het leven. 
Ik had geen anderen aan mijn zijde kunnen wensen op deze heugelijke dag. Ik hoop dat we ondanks reisafstand, gezinssituaties en werkzaamheden fantastisch mooie dagen en avonden blijven beleven die in ons geheugen worden gegriefd.

Anna Maria, David Luca, Tim Levi en Lana Linn. Schoonzus, neefjes en nichtje. Tot mijn spijt is de afstand tussen ons dermate groot dat het moeilijk is om veelvuldig over de vloer te komen in jullie warme thuis waar ik altijd volledig verzorgd wordt. Als ik er ben, dan met onnoemelijk veel plezier om met David en Tim te stoeien en te voetballen en met Lana om te knuffelen! Dat houd ik graag vol tot in de eeuwigheid.

Het veilige thuisfront. Lieve papa en mama, we zijn als kinderen nooit wat tekort geschoten. We konden vrij zijn en ons ontwikkelen zoals we wilden. Nu kijkend heb ik een beroep gekozen wat een combinatie is van jullie voormalige werkzaamheden: papa die zich ingenieur mag noemen en werkzaam was in de bouw en mama als fysiotherapeut betrokken bij het bewegingsapparaat en de patiëntenzorg. De stap naar Maastricht destijds, was groot en spannend, maar heeft mij op alle vlakken veel gebracht. Mijn voorliefde voor sport is genetisch en met gemak kan het ons als familie een hele dag plezieren. Dank voor alles.

Wiemer en Gerben. Als de jongste van drie met ook nog wat leeftijdsverschil was het altijd opkijken naar en opboksen tegen mijn grote broers. Wie weet heeft mij dat gebracht tot waar ik nu ben. We hebben gedurende onze jeugd niks te klagen gehad. Ik denk vooral aan voetballen op straat (met af en toe een bal op auto door een chocolade-been), basketballen in de achtertuin op veel te weinig $\mathrm{m}^{2}$ en op vakantie eindeloos bezig zijn met beachtennis. We hebben allen onze eigen weg gekozen en zijn goed terecht gekomen. Het dagelijkse contact heeft wellicht niet altijd evenveel omhanden, maar zou ik niet willen missen. Laten we onze belofte om leuke dingen te blijven doen nakomen!

Lieve Laura, jij bent mijn stabiele basis, mijn andere helft. Vele avonden zat ik met mijn neus in de laptop aan de keukentafel te werken aan dit proefschrift terwijl jij op de bank op mij zat te wachten. Jij geeft mij de ruimte om te doen wat ik leuk vind, zorgt voor afleiding wanneer dat nodig is en tovert een lach op mijn gezicht. Samen zijn we op de ontdekkingsreis van het leven, waar wat mij betreft nooit een einde aan hoeft te komen. 


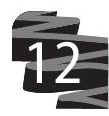




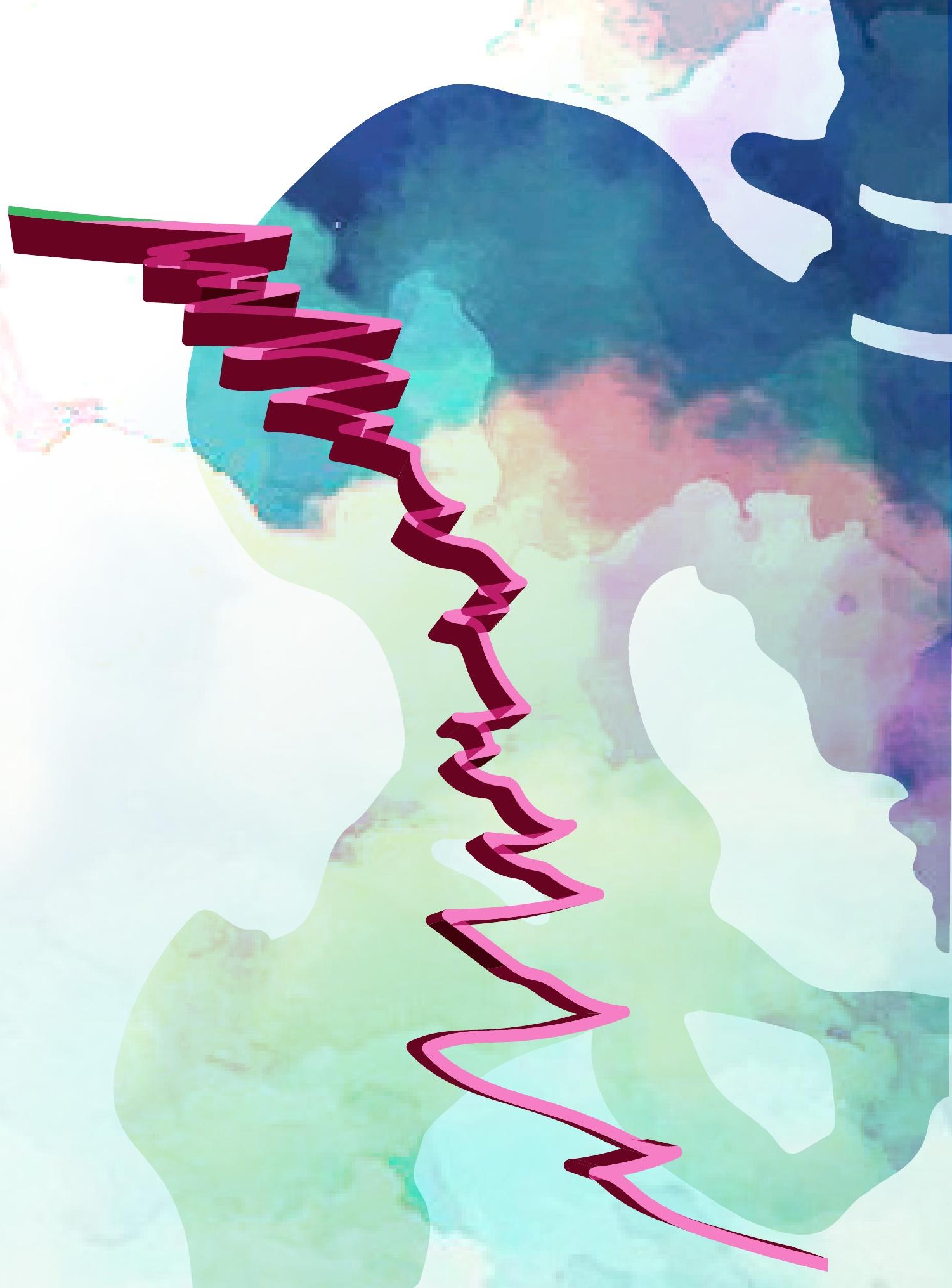




\section{Curriculum Vitae Auctoris}


The author of this thesis, Jetse Jelsma, was born on the $12^{\text {th }}$ of March 1989 in Leeuwarden, the Netherlands. He grew up with his parents and two older brothers. After graduation from preuniversity education (VWO), OSG Piter Jelles Aldlân, Leeuwarden in 2007, he started studying medicine at Maastricht University the same year.

During his study his interest in the musculoskeletal system increased which led an internship at the Orthopaedic and Traumatology Department of Orbis Medical Centre - SittardGeleen, the Netherlands (dr. N.P. Kort, 2010). The

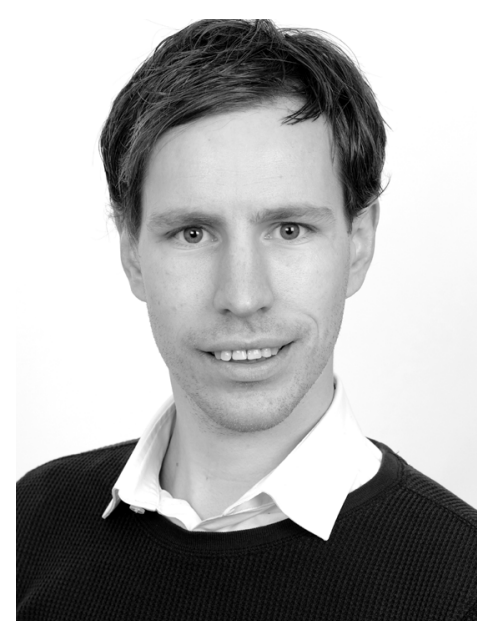
foundation for this thesis and his career was laid in his final year of study at the Department of Orthopaedics and Traumatology at Atrium Medical Centre - Heerlen, the Netherlands (prof. dr. I.C. Heyligers, 2012-2013).

After his graduation as Master of Medicine in 2013 he worked briefly as a resident in Rehabilitation Medicine at Maastricht University Medical Centre, the Netherlands (prof. dr. R.J. Smeets 2013-2014). He moved away from Maastricht and continued his career as Orthopaedic resident at the Elkerliek Hospital - Helmond, the Netherlands (drs. H. Lacroix, 2014-2015).

In 2016, he moved back to Maastricht and was able to start his training in general surgery at the Zuyderland Medical Centre - Heerlen/Sittard-Geleen (dr. M. Sosef, 2016-2017). His Orthopaedic training was performed at Zuyderland Medical Centre - Heerlen/Sittard-Geleen (prof. dr. I.C. Heyligers, 2017), Maastricht University Medical Centre (dr. H.M. Staal, 2018), Máxima Medical Centre - Veldhoven (dr. R.P.A. Janssen, 2019), Zuyderland Medical Centre - Heerlen/Sittard-Geleen (dr. E.J.P. Jansen, 20202021) and finished with an in-depth internship with dr. R.H.M. ten Broeke and dr. J.A.P. Geurts at Maastricht University Medical Centre (2021) focussing on pelvic-, acetabular- and hip surgery. During his training he continued working on this thesis.

From the $1^{\text {st }}$ of February 2022 he will start as clinical fellow in advanced hip surgery at Southmead Hospital, Bristol, United Kingdom (prof. dr. A.W. Blom). In his spare time he loves watching and participating in sports (cycling). He currently lives in the city centre of Maastricht with his beloved partner, Laura. 


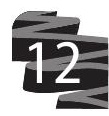




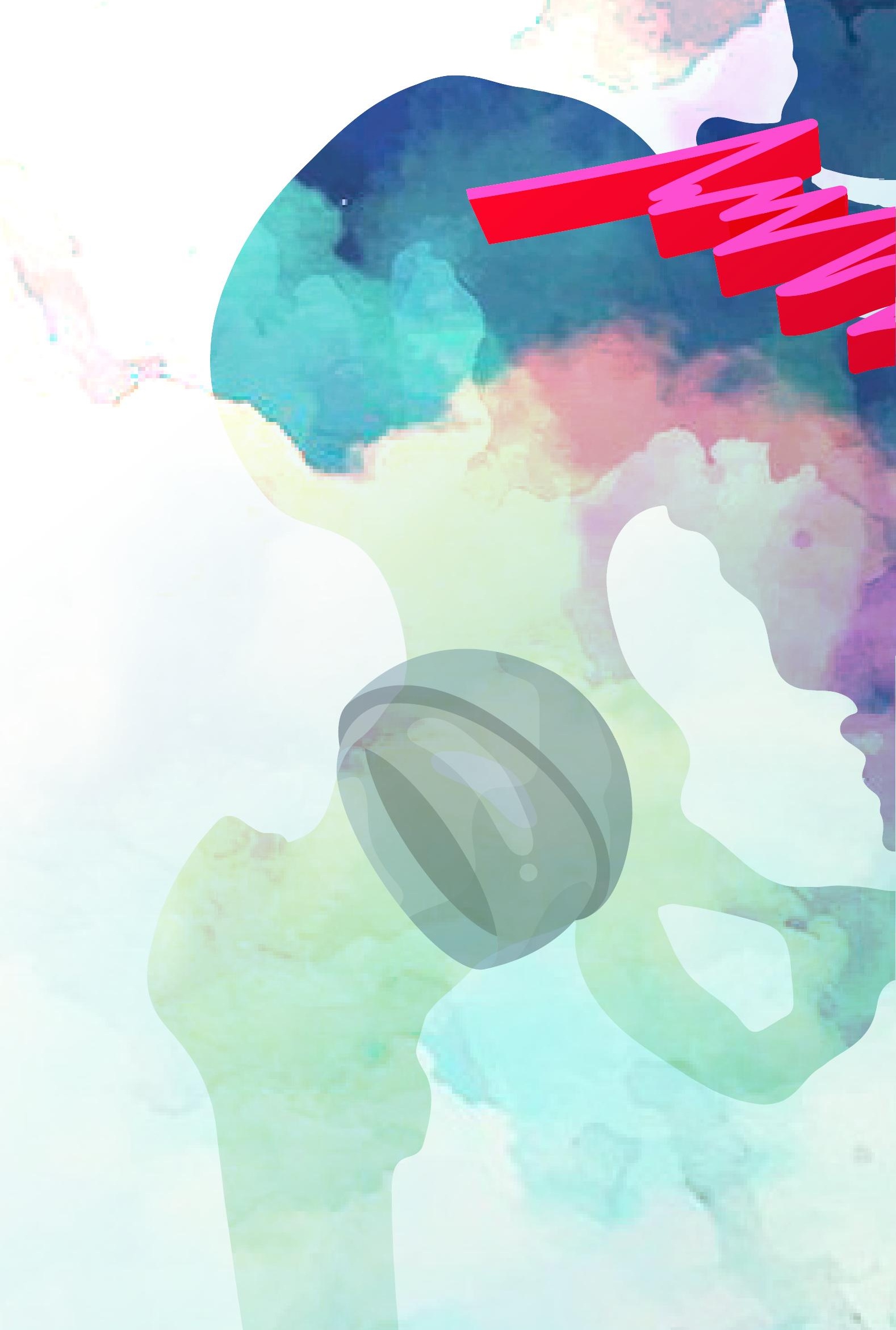

